\title{
VISITOR SATISFACTION WITH SERVICES FOR ENVIRONMENTAL INTERPRETATION IN CAT TIEN NATIONAL PARK, VIETNAM
}

\author{
By
}

\section{Thi Thuy Linh Phan}

\author{
A thesis \\ submitted to the Victoria University of Wellington \\ in partial fulfilment of the requirements for the degree of \\ Master of Tourism Management
}

Victoria University of Wellington 


\begin{abstract}
The increase in visitor demand creates more and more pressures on visitor management, especially in protected areas like national parks. Environmental interpretation is regarded as an effective soft management strategy that aims to educate visitors in national parks. However, no study about visitor satisfaction with environmental interpretation using Importance-Performance analysis has been undertaken in national parks in general and national parks of Vietnam in particular. This study attempts to fill in the research gaps in the literature by examining visitor satisfaction with services for environmental interpretation in Cat Tien National Park of Vietnam using Importance-Performance Analysis. The research aims are: (1) To identify current interpretive services in Cat Tien National Park; (2) To explore visitor use of these services for environmental interpretation; (3) To investigate visitor satisfaction with these services using Importance-Performance Analysis and (4) To analyze similarities and differences in visitor satisfaction with services according to motivation-based segments and marketbased segments.
\end{abstract}

Secondary research, a site visit and three semi-structured interviews were first implemented to provide information background for the study. Next, the main survey for both international and domestic visitors was conducted at the entry point of Cat Tien National Park. Data from 237 pre-visit and post-visit questionnaires collected in four weeks was then analyzed with relevant statistical analyses. Marketbased segmentation and motivation-based segmentation were also implemented to analyze the data.

The findings show that site interpreters were the most important service provider for environmental interpretation in Cat Tien National Park. Site interpreters, interpretive signs and staff at the museum are very important and very satisfying services for environmental interpretation. Displays at the museum need to be redesigned to meet visitor satisfaction. Moreover, videos at the rescue centre need to improve the performance to ensure domestic visitor satisfaction. With regard to twelve roles of site interpreters, the role for a comfortable pace of the trip, the role for a good group organisation, the communicative roles and the roles of an environmental interpreter are important and satisfying roles according to visitors. The performance of the instrumental role for visitor safety and the social role for a positive group environment need to be enhanced to meet visitor satisfaction. Also, two roles of a motivator of responsible behaviour need to be enhanced to meet the satisfaction of "Passive visitors" and "Active learners", as well as international visitors.

The study highlights the need for continuing research on visitor satisfaction with environmental interpretation using importance performance analysis and visitor segmentation. Some management 
implications were given for future development of services for environmental interpretation in Cat Tien National Park.

Key words: visitor satisfaction, national parks, motivation, importance-performance analysis, segmentation. 


\section{ACKNOWLEDGEMENTS}

First and foremost, I would like to say thank you to NZAID for giving me a chance to study my Master's degree at Victoria University of Wellington. Being here in New Zealand is a great opportunity for me not only to study but also to explore Kiwi's nature and culture. Thank you for letting me to meet such kind people in my life.

My academic journey would not have been successful without the support and guidance of my lecturers. I would like to express my sincere gratitude to my supervisor, Dr Christian Schott. Christian, I really appreciate your expert guidance and the way you encourage me to make decisions for my thesis as an independent researcher. Thank you for all of your written feedback you gave for every piece of work I did. I take all the research skills you provided me as a foundation for my future career.

All the other Tourism lecturers (Assoc. Prof. Ian Yeoman, Prof. Karen Smith, Dr Adam Weaver, and Dr Mondher Sahli), to whom I would like to express my gratitude for your sharing, advice and support during my two years at Victoria University.

I also wish to express my gratitude to all staff members in Centre of Environmental Education and Services in Cat Tien National Park who assisted me during my fieldwork. I also wish to acknowledge the participation of the visitors in Cat Tien National Park, who has been patient to fill in my questionnaires.

I would like to thank Dr Lisa Woods, Victoria's Statistician Consultant, for your advice regarding my statistical analysis. You are amazing. Many thanks to Susan for her patience in proof reading this thesis.

This journey would not have been interesting without the love and support of my Masters colleagues: Arya, Bernadeth and Margaret. Thank you for sharing with me the joy and pain of being a Master's student.

My family has always encouraged me during my two years here in New Zealand. Thank you Mom, Dad and my sister for your unconditional love.

Finally, I would like to send my special thanks to my love for giving me inspiration, faith and strength to complete this thesis.

To all of people above, thank you! 


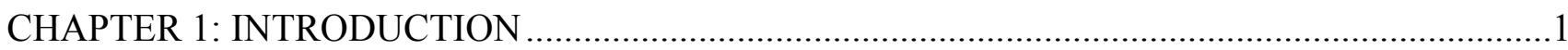

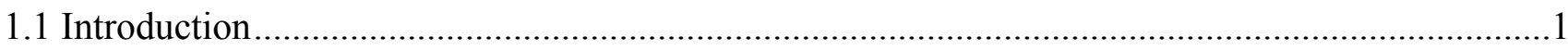

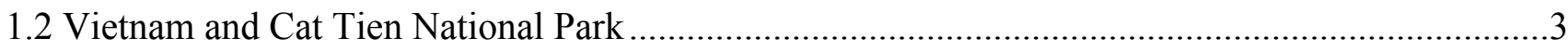

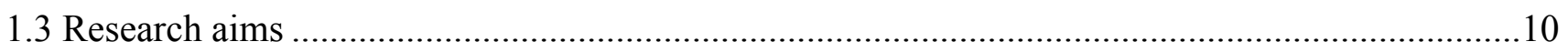

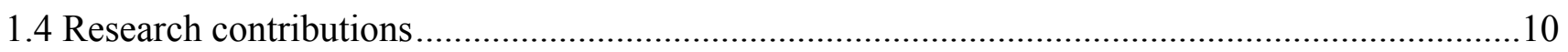

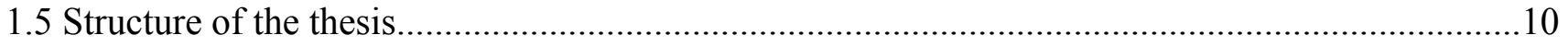

CHAPTER 2: LITERATURE REVIEW …………………………………………………......12

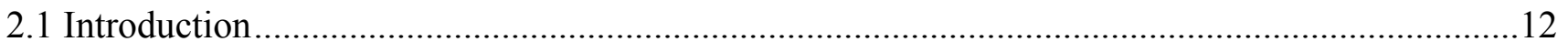

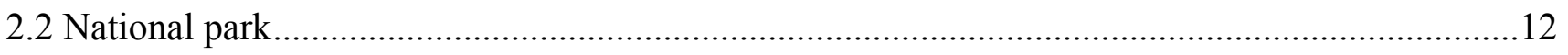

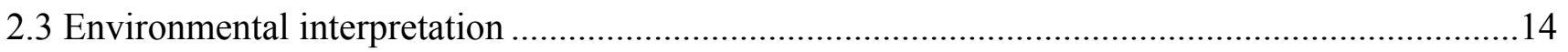

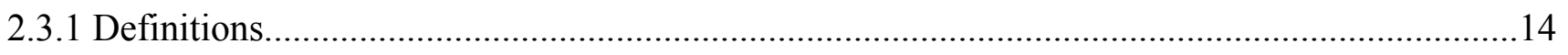

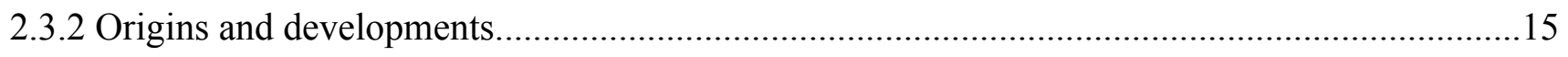

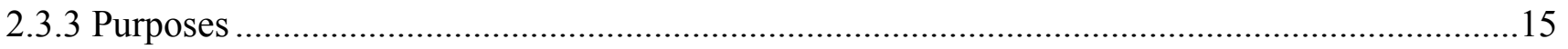

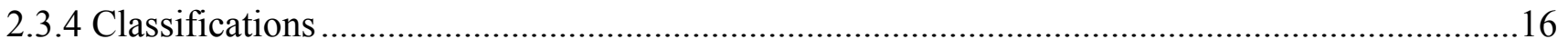

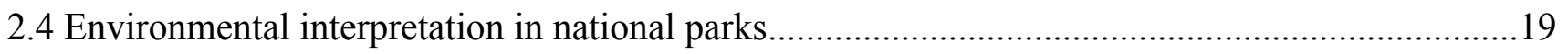

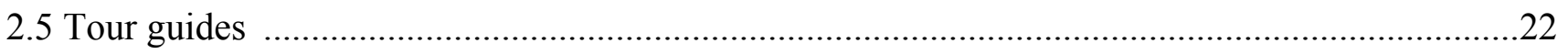

2.6 Measurement of visitor satisfaction in national parks ...........................................................24

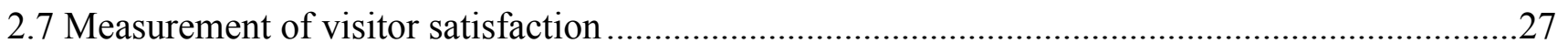

2.8 Comparative studies using Importance-Performance Analysis ....................................................29

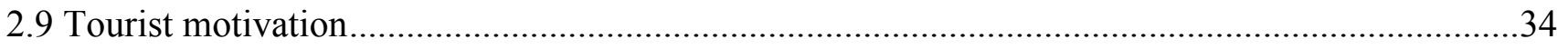



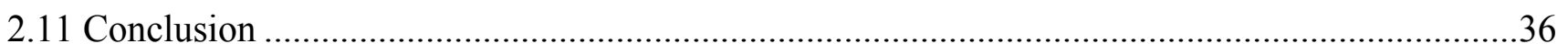

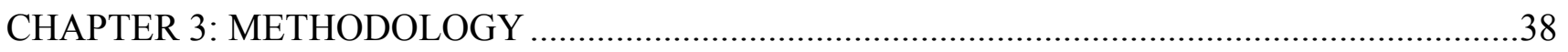

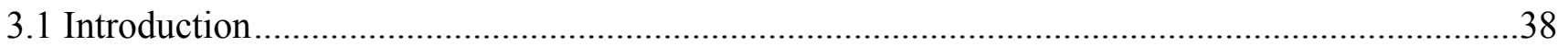




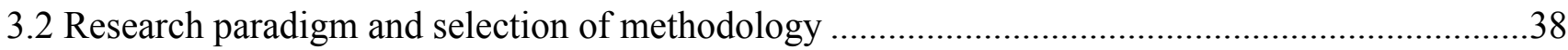

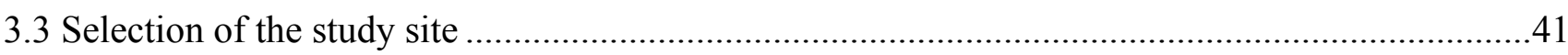

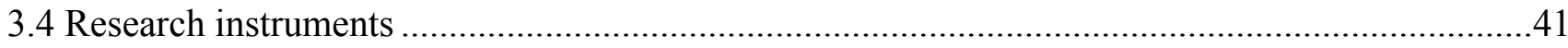

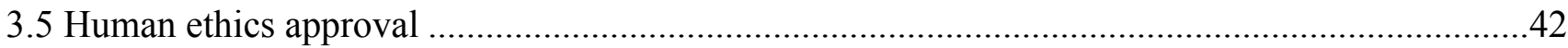

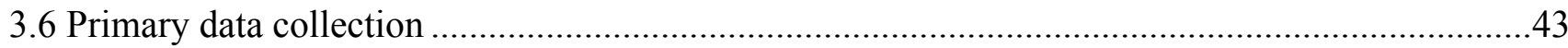

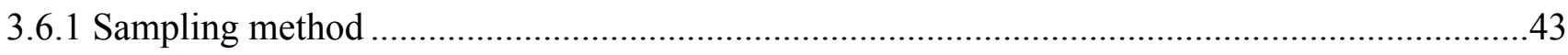

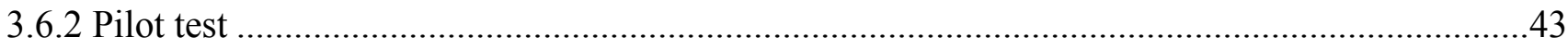

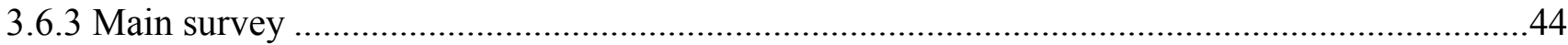

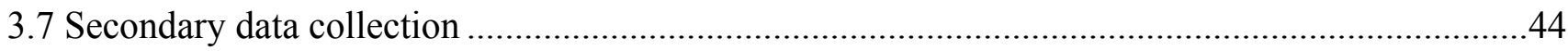

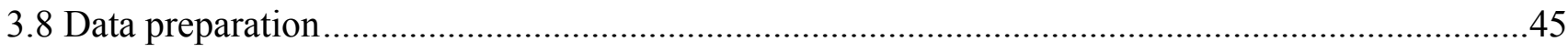

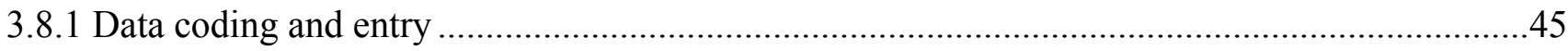

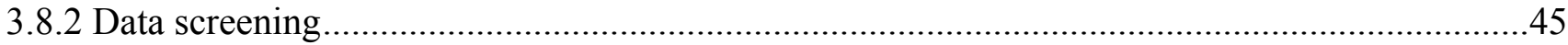

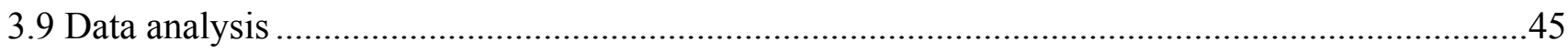

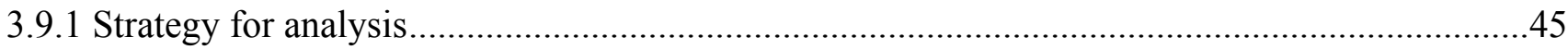

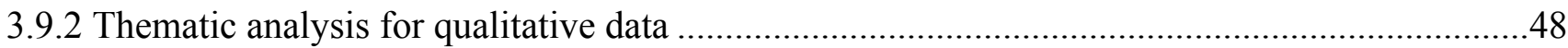

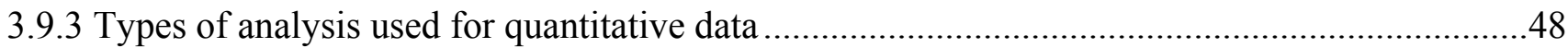

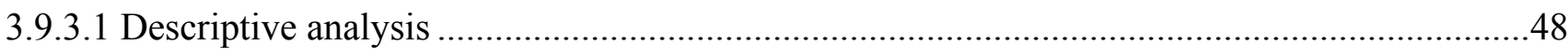

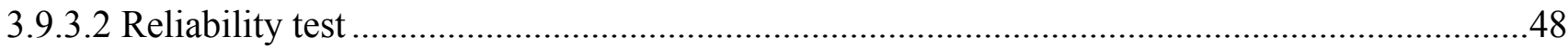

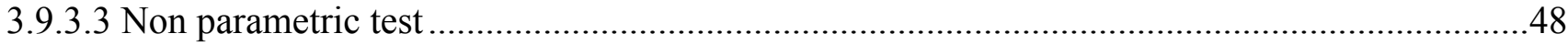

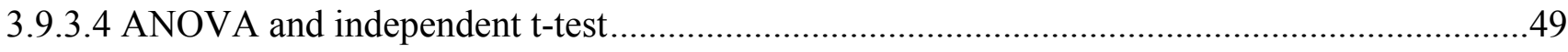

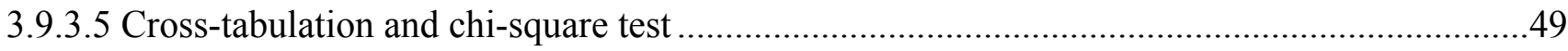

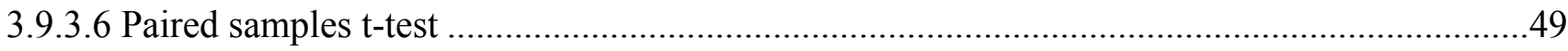

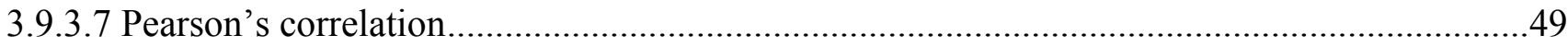

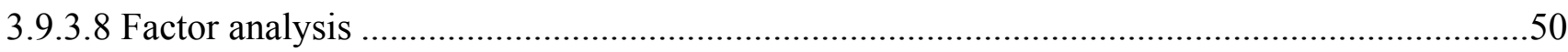

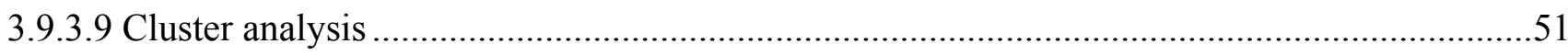

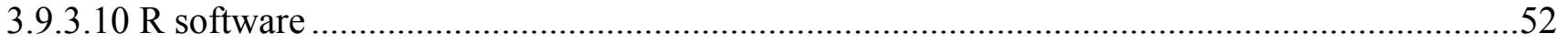


3.11 Conclusion .53

CHAPTER 4: MANAGEMENT OF ENVIRONMENTAL INTERPRETATION AND VISITOR USE OF INTERPRETIVE SERVICES

4.1 Introduction. .54

4.2 Management of services for environmental interpretation in Cat Tien National Park .54

4.2.1 Interviewees’ profile. .54

4.2.2 Responsibilities of the interviewees .55

4.2.3 Knowledge and understanding of the interviewees about interpretation .55

4.2.4 Services for environmental interpretation in Cat Tien National Park .56

4.2.5 Management of services for environmental interpretation in Cat Tien National Park

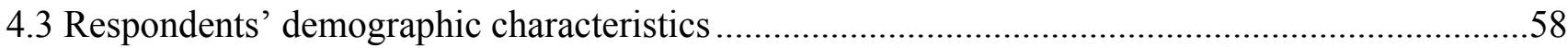

4.4 Respondents' trip related characteristics ............................................................................60

4.5 Visitor use of services for environmental interpretation in Cat Tien National Park ...................62

4.5.1 Services used frequently by visitors .62

4.5.2 Reasons why visitors did not use a specific interpretive service .62

4.5.3 Messages that visitors received from each service 63

4.6 Conclusion .64

CHAPTER 5: VISITOR SATISFACTION WITH SERVICES FOR ENVIRONMENTAL INTERPRETATION IN CAT TIEN NATIONAL PARK .......................................................66

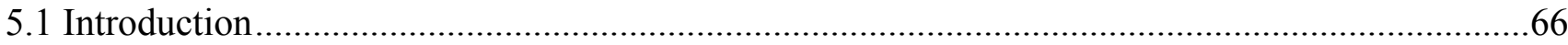

5.2 Visitor satisfaction with services for environmental interpretation in Cat Tien National Park......66

5.2.1 The importance of services for environmental interpretation in Cat Tien National Park to visitor satisfaction 66

5.2.2 The performance of services for environmental interpretation in Cat Tien National Park to visitor satisfaction 
5.2.3 Differences between the importance and performance means of services for environmental

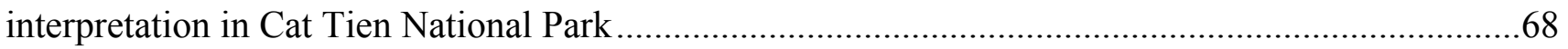

5.2.4 The importance-performance grid of services for environmental interpretation......................69

5.3 Visitor satisfaction with roles of site interpreters in Cat Tien National Park .............................71

5.3.1 The importance of roles of site interpreters in Cat Tien National Park to visitor satisfaction ....72

5.3.2 The performance of roles of site interpreters in Cat Tien National Park to visitor satisfaction ..74

5.3.3 Differences between the importance and performance means of roles of site interpreters in Cat

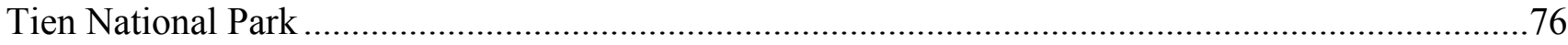

5.3.4 The importance-performance grid of roles of site interpreters in Cat Tien National Park ..........77

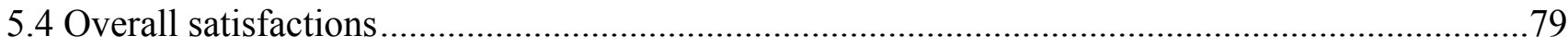

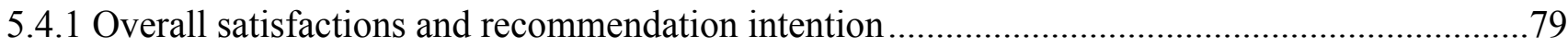

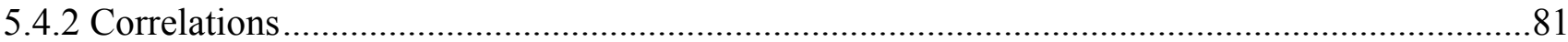

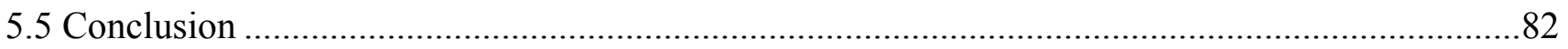

CHAPTER 6: VISITOR SATISFACTION WITH SERVICES FOR ENVIRONMENTAL INTERPRETATION ACCORDING TO MOTIVATION AND MARKET SEGMENTS ................84

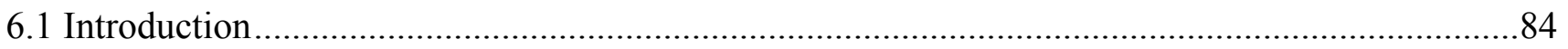

6.2 Visitor satisfaction with services for environmental interpretation according to motivation segments .84

6.2.1 Visitor motivation to visit Cat Tien National Park .................................................................84

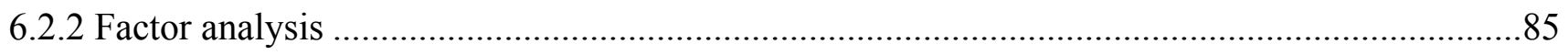

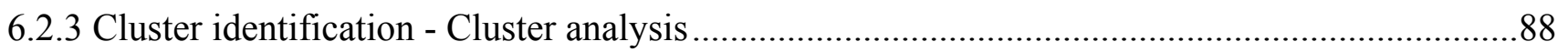

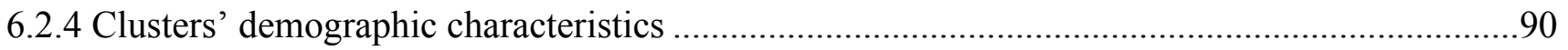

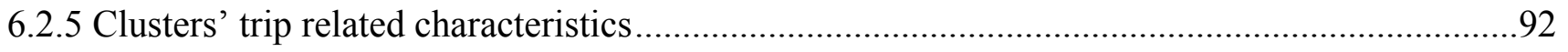

6.2.6 Visitor satisfaction with services for environmental interpretation according to motivation

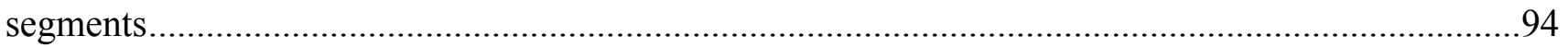

6.2.6.1 The importance of services for environmental interpretation by clusters............................95

6.2.6.2 The performance of services for environmental interpretation by clusters .........................97 
6.2.6.3 The importance-performance grid of services for environmental interpretation for each cluster

6.2.7 Visitor satisfaction with roles of site interpreters according to motivation segments

101

6.2.7.1 The importance of roles of site interpreters by clusters .101

6.2.7.2 The performance of roles of site interpreters by clusters. 104

6.2.7.3 The importance-performance grid of roles of site interpreters for each cluster 106

6.3 Visitor satisfaction with services for environmental interpretation according to market segments 109

6.3.1 Visitor satisfaction with services for environmental interpretation according to market segments 109

6.3.1.1 The importance of services for environmental interpretation by nationalities .110

6.3.1.2 The performance of services for environmental interpretation by nationalities

6.3.1.3 The importance-performance grid of services for environmental interpretation for each market segment

6.3.2 Visitor satisfaction with roles of site interpreters according to market segments 115

6.3.2.1 The importance of roles of site interpreters by nationalities.

6.3.2.2 The performance of roles of site interpreters by nationalities .116

6.3.2.3 The importance-performance grid of roles of site interpreters for each market segment.......118

6.4 Conclusion

CHAPTER 7: DISCUSSIONS, IMPLICATIONS AND CONCLUSIONS 122

7.1 Introduction. 122

7.2 Services for environmental interpretation and visitor use of services for environmental interpretation in Cat Tien National Park 124

7.3 Visitor satisfaction with services for environmental interpretation in Cat Tien National Park....124

7.4 Similarities and differences in visitor satisfaction with services for environmental interpretation according to motivation-based and market-based segments. 128

7.5 Importance-Performance Analysis and its implications 


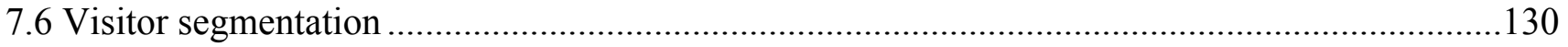

7.7 Implications and recommendations for tourism practitioners ……….....................................131

7.7.1 Implications and recommendations for Vietnam's national tourism organisations....................132

7.7.2 Implications and recommendations for the management of Cat Tien National Park and other

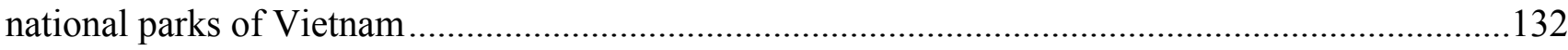



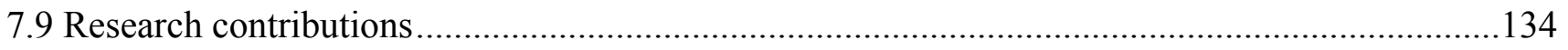

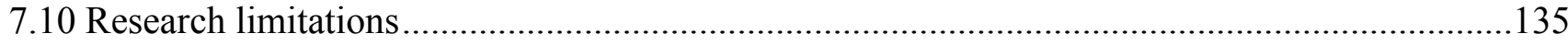

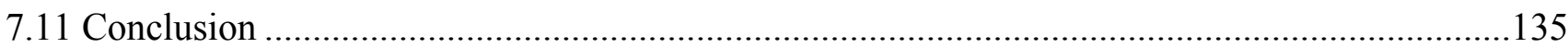

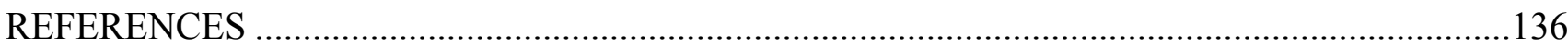

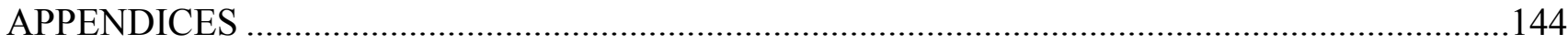




\section{LIST OF TABLES}

Table 1.1. Tourism statistics of Cat Tien National Park from 2010 to 2015.......................................9

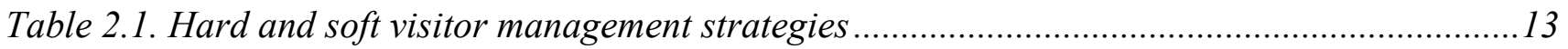

Table 2.2. Types of interpretive services provided in Hong Kong Wetland Park .............................17

Table 2.3. Summary of research topics on environmental interpretation in national parks

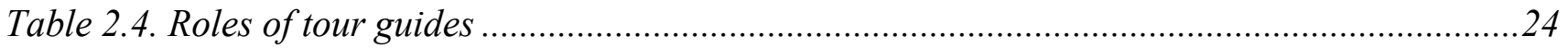

Table 2.5. Summary of research topics on visitor satisfaction in national parks..............................25

Table 2.6. Summary of comparative studies using IPA and segmentation .....................................31

Table 2.7. Summary of common motivations in wildlife tourism and tourism in national parks .........35

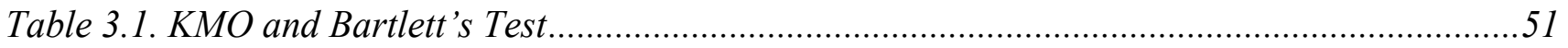

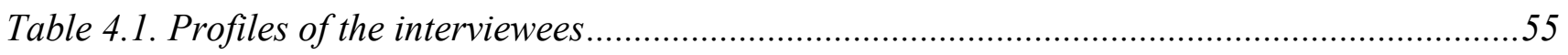

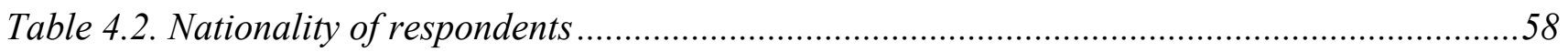

Table 4.3. Age, gender and educational level of respondents ......................................................59

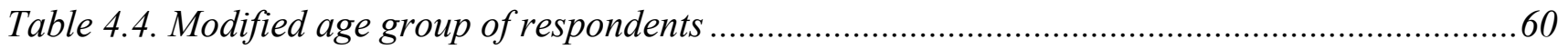

Table 4.5. Modified educational level of respondents ..............................................................60

Table 4.6. Trip related characteristics of respondents ..............................................................61

Table 4.7. Modified times visited national parks of respondents .................................................61

Table 4.8. The use of services for environmental interpretation ................................................62

Table 5.1. The importance means of services for environmental interpretation ..............................67

Table 5.2. The performance means of services for environmental interpretation.............................68

Table 5.3. Paired samples $t$ test for the importance and performance means of services for

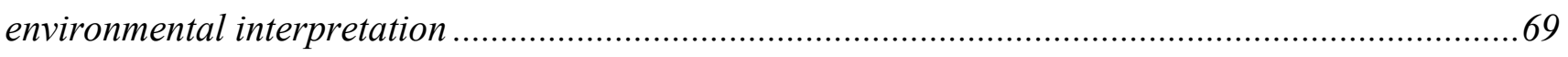

Table 5.4. The importance means of roles of site interpreters .....................................................73

Table 5.5. The performance means of roles of site interpreters .................................................... 75 
Table 5.6. Paired samples $t$-test for the importance and performance means of roles of site interpreters 77

Table 5.7. Overall satisfaction with services for environmental interpretation ................................80

Table 5.8. Overall satisfaction with the visit to Cat Tien National Park.............................................80

Table 5.9. Pearson's correlation test for the performance of 8 interpretive services and post visit

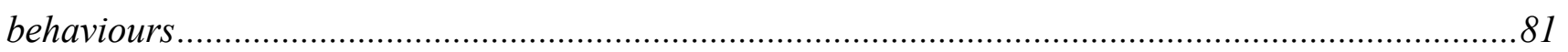

Table 6.1. Comparison of motivation variables........................................................................85

Table 6.2. Factor analysis for visitor motivations to visit Cat Tien National Park .........................87

Table 6.3. Mean comparison of motivation factors by clusters..................................................8

Table 6.4. Distances between final clusters centres .................................................................90

Table 6.5. Summary of Chi square test for clusters' social demographic profiles.............................91

Table 6.6. Social demographic profiles by clusters ..............................................................92

Table 6.7. Summary of Chi square test for clusters' trip related characteristics..............................93

Table 6.8. Trip related characteristics by clusters ......................................................................94

Table 6.9. The importance of services for environmental interpretation by clusters ........................95

Table 6.10. ANOVA testing for the importance ratings of services across clusters..........................96

Table 6.11. The performance of services for environmental interpretation by clusters.....................97

Table 6.12. ANOVA testing for the performance ratings of services across clusters.........................98

Table 6.13. The importance of roles of site interpreters by clusters ...........................................102

Table 6.14. ANOVA testing for the importance ratings of roles across clusters............................103

Table 6.15. The performance of roles of site interpreters by clusters .......................................... 105

Table 6.16. ANOVA testing for the performance ratings of roles across clusters.............................106

Table 6.17. The importance of services for environmental interpretation by nationalities ..............110

Table 6.18. Independent t-test for the importance ratings of services across nationalities

Table 6.19. The performance of services for environmental interpretation by nationalities ............112

Table 6.20. Independent t-test for the performance ratings of services across nationalities.............113 
Table 6.21. The importance of roles of site interpreters by nationalities 115

Table 6.22. Independent t-test for the importance ratings of roles across nationalities ...................116

Table 6.23. The performance of roles of site interpreters by nationalities ..................................117

Table 6.24. Independent t-test for the performance ratings of roles across nationalities.................118

Table 7.1. Summary of the research aims and results ...............................................................123 


\section{LIST OF FIGURES}

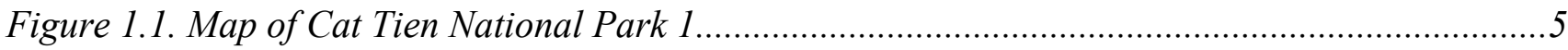

Figure 1.2. Map of Cat Tien National Park 2.........................................................................

Figure 1.3. Map of Cat Tien National Park 3............................................................................

Figure 1.4. Administrational map of Cat Tien National Park ...........................................................8

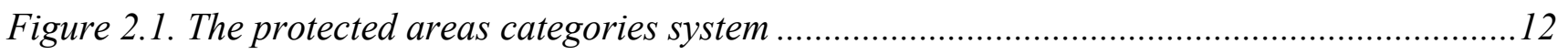

Figure 2.2. Conceptualization of purposes of environmental interpretation ..................................16

Figure 2.3. Services for environmental interpretation in protected areas .....................................18

Figure 2.4. Conceptualization of classifications of environmental interpretive services....................19

Figure 2.5. The links between eco tour guides, environmental interpreters and environmental educators .23

Figure 2.6. Conceptual framework of visitor satisfaction and national park visitor management......36

Figure 3.1. Multi-stage research process for examining visitor satisfaction with interpretive services

Figure 3.2. Analytical framework for data analysis and presentation ........................................4 47

Figure 4.1. Reasons why visitors did not use a specific interpretive service .................................63

Figure 4.2. Messages that visitors received from each service .................................................64

Figure 5.1. Importance - performance grid of services for environmental interpretation .................70

Figure 5.2. Importance - performance grid of services for environmental interpretation with iso rating

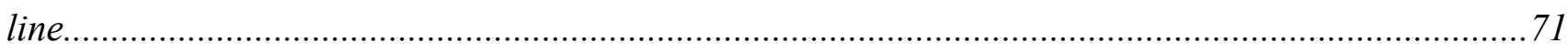

Figure 5.3. Importance - performance grid of roles of site interpreters .......................................78

Figure 5.4. Importance - performance grid of roles of site interpreters with iso rating line......

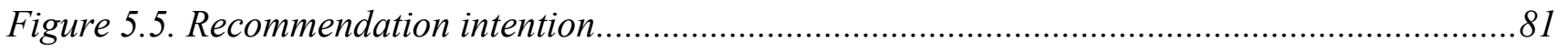

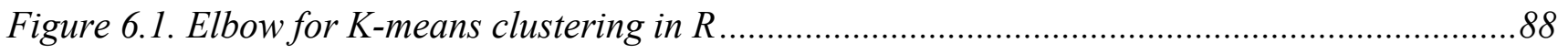

Figure 6.2. The grid of services for Area enthusiasts .............................................................99 
Figure 6.3. The grid of services for Passive visitors .......................................................................99

Figure 6.4. The grid of services for Active learners ................................................................. 100

Figure 6.5. The grid of services for Novelty seekers ................................................................ 100

Figure 6.6. The grid of roles for Area enthusiasts..................................................................... 107

Figure 6.7. The grid of roles for Passive visitors ........................................................................ 108

Figure 6.8. The grid of roles for Active learners .................................................................... 108

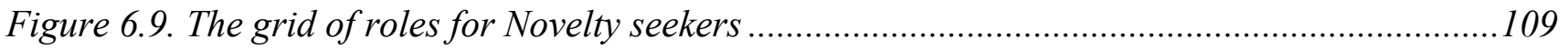

Figure 6.10. The grid of services for domestic visitors ......................................................... 114

Figure 6.11. The grid of roles for international visitors ........................................................114

Figure 6.12. The grid of roles for domestic visitors ............................................................ 119

Figure 6.13. The grid of roles for international visitors .......................................................119 


\section{CHAPTER 1}

\section{INTRODUCTION}

\subsection{Introduction}

One of the rationales for the setting up of protected areas is to mitigate adverse impacts from tourism and other human activities (Mason, 2005). Although national parks and some important areas are protected, they cannot be prevented from the degradation caused by tourist visitation (Tubb, 2003). The visitation of tourists to national parks can create many impacts on different scales, from each individual to accommodation development within their boundaries (Wearing and Whenman, 2009). The increase in visitor demand in national parks requires more suitable and effective visitor management (Eagles and McCool, 2002; Sowman and Pearce, 2000; Tubb, 2003).

Visitor management can support tourism impact management. Effective visitor management can keep the balance between tourism development in sites and the use of resources for sustainable development (Kuo, 2002). Visitor management not only comprises establishing and applying rules and regulations as the instructions for visitors to minimize visitor impacts, but also bringing about the enjoyment for visitor experiences. There are two types of visitor management including hard and soft management strategies that were often discussed by current scholars (Kuo, 2002; Mason, 2005). Environmental interpretation is a soft management strategy alongside targeted marketing and landscaping and planting. Soft visitor management strategies were used to support hard strategies to create long term effects (Kuo, 2002).

Environmental interpretation is regarded as a major intermediary channel between managers and visitors together with physical settings and legal punishment (Munro, Morrison-Saunders and Hughes, 2008). Moreover, environmental interpretation enhances visitor experience at the site and monitors visitor impacts (Komatsu and Liu, 2007; Moscardo, 2003). Moscardo (2003) discussed the roles of interpretation in sustainable tourism including enhancing visitor experience (providing information on alternatives and options, providing information for safety and comfort, creating the actual experience) and managing visitors and their impacts (influencing where visitors go, providing an alternative experience, informing visitors about proper behaviours and developing visitor concern).

Mason (2005) indicated that for sustainable development of national parks, it is essential to implement research into both hard and soft visitor management strategies. Interpretation is regarded as an indirect and effective tool to manage visitor impacts (Kuo, 2002; Mason, 2005; Orams, 1996). According to Kuo (2002), environmental interpretation can stimulate visitors to behave properly for sustainable 
tourism development without influencing visitor experience. Munro et al. (2008) suggested that establishing some kind of interpretation assessment is necessary to improve current practice and invest effectively in these services in future. Moscardo (2014) also asserted that practical research on a particular site supports the managers to enhance the effectiveness of interpretation.

Various aspects of environmental interpretation in national parks have been studied including interpretation and marketing in national parks (Archer and Wearing, 2002), effectiveness of a specific interpretive service (Tubb, 2003; Wearing and Whenman, 2009), effectiveness of interpretive services using qualitative approach (Xu, Cui, Ballantyne and Packer, 2013), effectiveness of interpretive services using quantitative approach (Tsang, Cheung and Yeung, 2011), local culture in interpretive content (Carr, 2004), relationship among ecotourism perception, level of satisfaction and interpretation needs (Wei-ching, 2015), relationship among tourist participation, interpretation service quality and place attachment (Hwang, Lee, and Chen, 2005) and the influence of interpretation on knowledge, attitudes and behaviours of tourists (Powell and Ham, 2008) (discussed later in Chapter 2). The research has found that there is a gap between research on visitor satisfaction using Importance-Performance Analysis and environmental interpretation. Importance-Performance Analysis is a framework developed by Martila and James in 1977 to measure visitor satisfaction (discussed later in Chapter 2). This research is important because some studies indicated that not all services have the same importance to environmental interpretation. Some services may perform well and satisfy visitors but are not so important. Some services may have low performance but they have low importance, too. Accordingly, these services should not be in the priority list for future investment. Attention should only be given to services having their performance lower than their importance.

This study has been developed based on the gaps in the current literature about environmental interpretation in national parks. These gaps will be closed by taking the following steps: firstly, the study will not focus on any specific service, the use and the satisfaction with all interpretive services will be investigated; secondly, Importance-Performance Analysis will be adopted to measure visitor satisfaction with interpretive services to know the importance and performance levels of each service for environmental interpretation; thirdly, site interpreters (tour guides) were assessed separately in this study to examine the idea supported by many current studies that tour guides are an important and necessary tool for environmental interpretation; finally, this study will break the sample into visitor segments (market segments and motivation segments) to provide managers with more accurate information rather than information from aggregated sample as in previous research. The aims of this study are discussed in full in Section 1.4 below. 
This chapter sets the context for this study. The selection of Cat Tien National Park will be explained, before the main aims are introduced. The contribution of this research will be then presented. This chapter also presents the structure of the thesis with the most important contents of each part. The next section provides basic information about Vietnamese tourism and Cat Tien National Park and the reasons why Cat Tien National Park was chosen as the study site for this study.

\subsection{Vietnam and Cat Tien National Park}

According to Stolton, Nguyen and Dudley (2004), Vietnam is a country with outstanding high levels of biodiversity with many rare and endemic species such as the saola (of the bovine genus), the largeantlered muntjac, the near-endemic red-shanked douc, tigers and Asian elephants, etc. Understanding the significance of nature conservation, the Vietnamese government has launched many regulations on nature and environmental conservation in the past 30 years, including the Strategy on Forest Protection in 1972, Strategy on Nature Conservation in 1985, the National Plan on Environment and Sustainable Development 1991-2000 in 1991, the Law on Forest Protection and Development in 1991, the Law on Environmental Development in 1994 and the Action Plan on Biodiversity Conservation (Hoang, Le, Nguyen, Nguyen and Vu, 2001). Since 1962, the Vietnamese government has established 11 National Parks, 52 Nature Reserves, 16 Wildlife Protected Areas, and 22 Cultural, Historical and Environmental sites (Hoang et al., 2001).

Vietnam is a developing destination that attracts millions of international tourists each year. According to the statistics of the Vietnam National Administration of Tourism, Vietnam welcomed about 7.9 million international tourists in 2015. This has created increasing pressure on the natural environment. According to Lipscombe and Thwaites (2003), to face with the rapid development of the tourism industry, the Vietnamese government has elaborated many tourism policies since 1999 such as Ordinance on Tourism and the Tourism Master Plan for Sustainable Tourism Development in Vietnam. Ecotourism and cultural tourism are the two top priorities whereas the protected area system of Vietnam is one of the important destinations (Lipscombe and Thwaites, 2003).

Although there have been some studies about national parks in Vietnam (e.g. Rugendyke and Nguyen, 2005; Polet and Ling, 2004), until now no study about environmental interpretation of national parks in Vietnam has been undertaken. Thus, the author decided to conduct a study in a national park of Vietnam to examine visitor use of and visitor satisfaction with services for environmental interpretation in this national park. The author chose Cat Tien National Park to implement the study for several reasons. Firstly, Cat Tien National Park is one of the largest and most important national parks of Vietnam. Moreover, although site interpretation of Cat Tien has been designed for using and guides have been 
trained to deliver site interpretive tours, no measurement of their effectiveness has been undertaken. According to interviewee 1 (personal communication, 2016), services for interpretation in Cat Tien National Park were designed by experts from an international organization (WWF) who have little knowledge about the national park; therefore, they may be unsuitable to the site. This was also pointed out by Moscardo (2014) that the issues relating to interpretation (e.g. the decisions for what is heritage, the contents for interpretation, and the design of interpretation, etc.) which should be developed by local community and visitors are often decided by experts from other destinations, who have different expertise and are supported by governments at higher levels. Therefore, it is necessary to conduct a study to examine tourist satisfaction with services for interpretation in Cat Tien National Park to meet visitors' wants and needs in future.

According to Hoang et al. (2001), Cat Tien National Park has changed names several times since its first recognition in 1978:

$7^{\text {th }}$ July, 1978: Nam Cat Tien Restricted Forest with 35,000 ha (Dong Nai Province).

1992: upgraded to Nam Cat Tien National Park (Dong Nai Province).

1998: Cat Tien National Park (Cat Loc rhino protected area and Nam Cat Tien National Park)

Located in South Vietnam, Cat Tien National Park covers an area of 71,920 ha including the South of Cat Tien (Dong Nai province) 39,627 ha; Cat Loc (Lam Dong province) 27,850 ha; the West of Cat Tien (Binh Phuoc province) 4,4431 ha (UNESCO, n.d.) (Figure 1.1). 


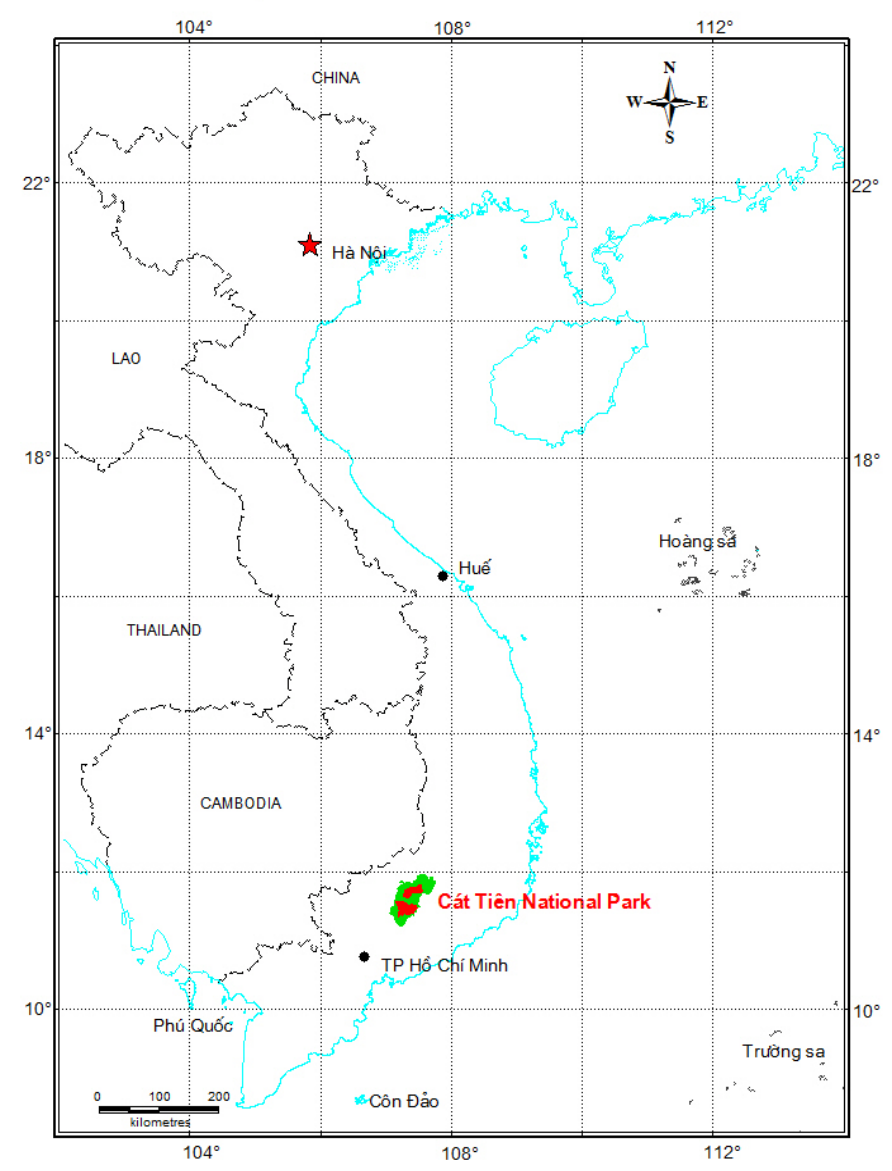

Figure 1.1. Map of Cat Tien National Park 1

(Source: Centre of Environmental Education and Services, Cat Tien National Park, 2016)

Cat Tien is approximately 150 kilometres from from Ho Chi Minh City. It is located in National Road 20 from Ho Chi Minh City to Da Lat (Hoang et al., 2001) (Figure 1.2). The wet season in Cat Tien National Park is from May to October and the dry season is from November to April. The Dong Nai River covers $90 \mathrm{~km}$ boundaries of the north, west and east of Cat Tien National Park (Hoang et al., 2001). 


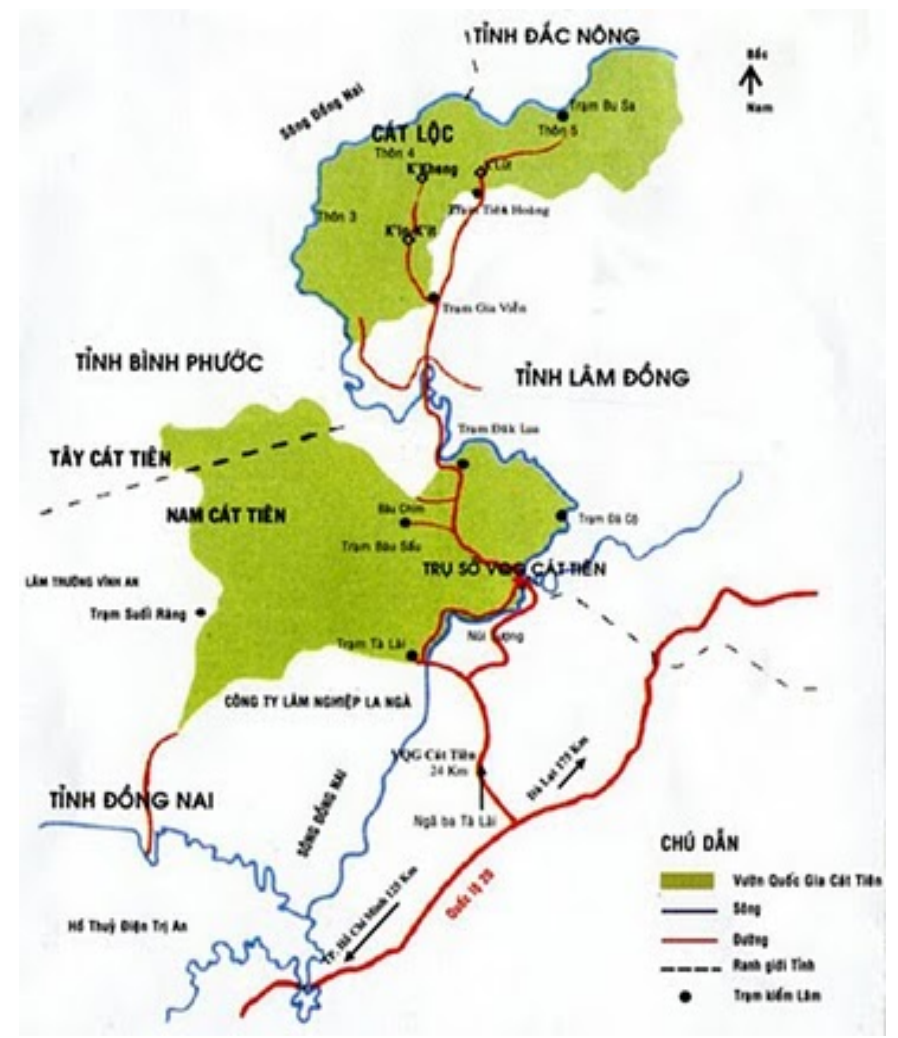

Figure 1.2. Map of Cat Tien National Park 2

(Source: Centre of Environmental Education and Services, Cat Tien National Park, 2016)

Cat Tien National Park is a typical area of lowland tropical rainforest in Vietnam (Lonely Planet, n.d.). Cat Tien has high biodiversity with rare and endemic genes of flora and fauna (mammals, birds, reptiles, and amphibians and fish). Many of species are listed in the Red Data Book of Vietnam and the world (Hoang et al., 2001) (Figure 1.3). According to the Centre of Environmental Education and Services of Cat Tien National Park (2016), there are around 1610 species of flora, 105 species of mammals, 351 species of birds, 159 species of fish, 80 species of reptiles, 41 species of amphibians and 457 species of butterflies. Cat Tien National Park has been recognized by UNESCO in 2001 as the 411th biosphere Reserve Zone in the world (UNESCO, n.d.). 


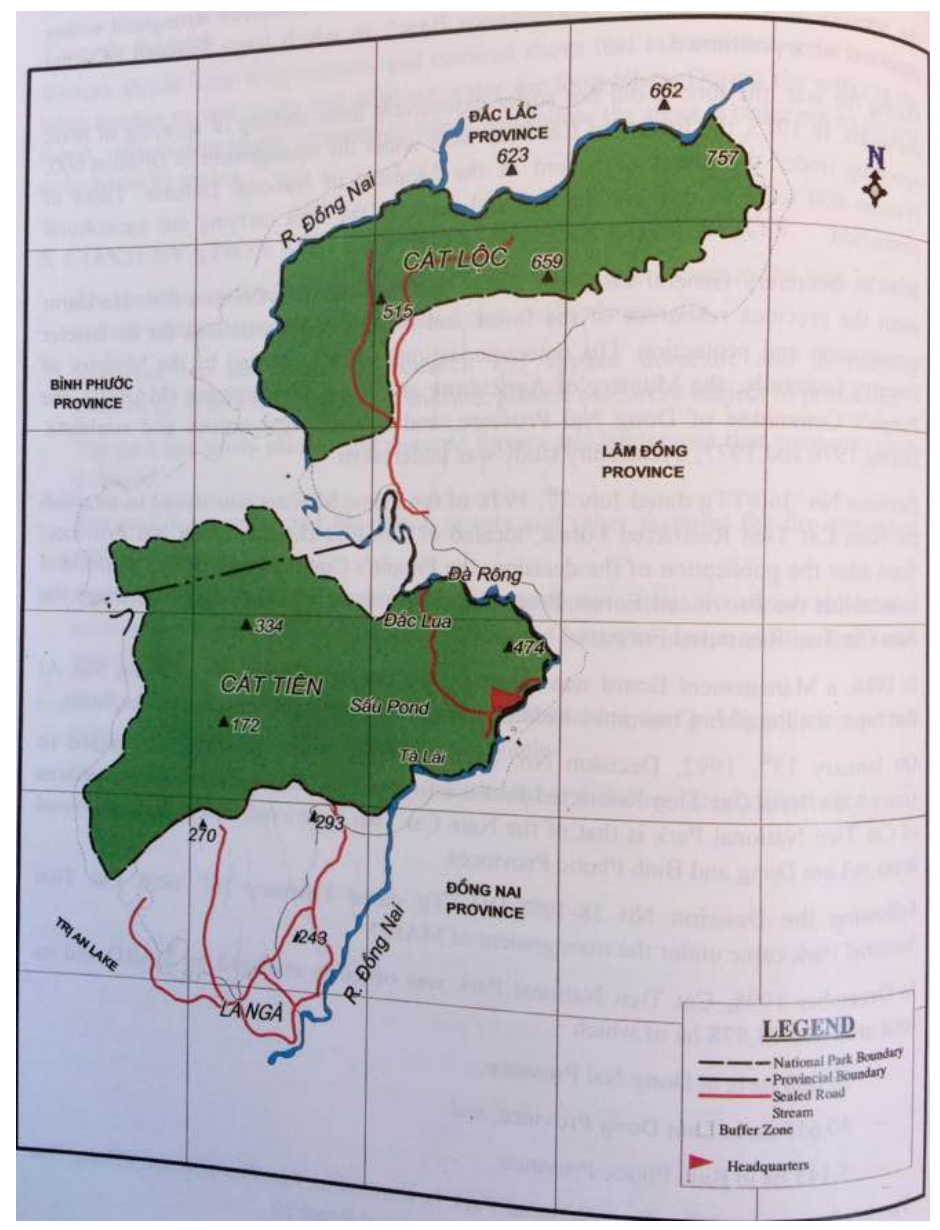

Figure 1.3. Map of Cat Tien National Park 3

(Source: Hoang et al., 2001)

The national park has six divisions comprising Financial Planning, International Relations and Science, Administration, Centre of Environmental Education and Services, Rescue Centres and Forest Protection (Centre of Environmental Education and Services, Cat Tien National Park, 2016). The positions of the headquarter, Forest Protection Division, Centre of Environmental Education and Services, two rescue centres, the museum, camping area and two restaurants are depicted in Figure 1.4. Two rescue centres were established in Cat Tien National Park by national and international organizations. The Bear Rescue Centre was established in 2005 with financial and technical assistance from a non-profit organization based in Ho Chi Minh City, Wildlife At Risk (WAR) and an organization from Australia, Free The Bear (FTB). The Primate Rescue Centre was established on the $12^{\text {th }}$ of July, 2008 and is 3 ha in area. It was funded and assisted by Monkey World of United Kingdom, Endangered Asian Species Trust (EAST), Pingtung Rescue Centre for Endangered Wild Animals of Taiwan (PTRC) (Centre of Environmental Education and Services, Cat Tien National Park, 2016). Other facilities and infrastructures in the national park include a museum (orange square), camping areas (red square), restaurants (red circles) and guesthouses (the rest of house symbols) (Figure 1.4). 

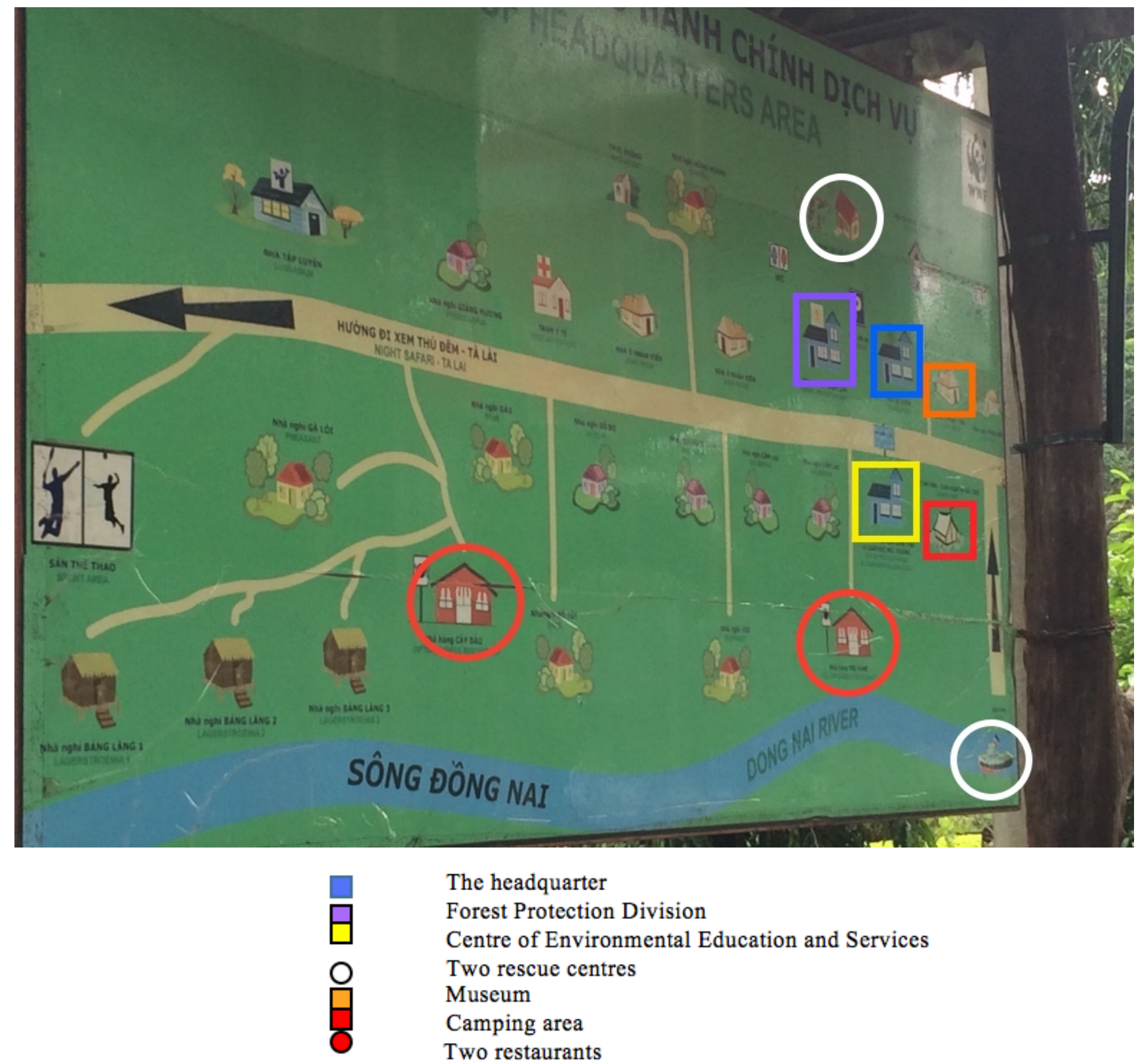

Figure 1.4. Administrational map of Cat Tien National Park

\section{(Source: photo taken by the author)}

Table 1.1 shows the number of visitors in Cat Tien National Park between 2010 and 2015. In general, the number of visitors in Cat Tien National Park increased gradually from 2010 to 2015 (from 17,634 in 2010 to 26,664 in 2015) although there were some fluctuations in the number of visitors in 2012 and 2013 due to the decline in the number of domestic tourists. As can be seen in Table 1.1, the number of domestic visitors far outweighed the number of international visitors. Domestic visitors accounted for $75-84 \%$ of the total visitors in the given period. The number of international visitors in 2015 was more than double the number of international visitors in 2010 (2,890 in 2010 to 6,535 in 2015). 
Table 1.1. Tourism statistics of Cat Tien National Park from 2010 to 2015

\begin{tabular}{|c|c|c|c|c|c|c|c|c|c|c|c|c|c|c|c|c|c|c|c|}
\hline \multirow{4}{*}{ Year } & \multirow{4}{*}{$\begin{array}{l}\text { Tourist } \\
\text { volume }\end{array}$} & \multicolumn{18}{|c|}{ TOURIST VOLUME } \\
\hline & & \multicolumn{2}{|c|}{ Domestic tourists } & \multicolumn{16}{|c|}{ International tourists } \\
\hline & & \multirow{2}{*}{$\begin{array}{l}\text { Tourist } \\
\text { volume }\end{array}$} & \multirow{2}{*}{$\begin{array}{l}\text { Percentage } \\
(\%)\end{array}$} & \multirow{2}{*}{$\begin{array}{l}\text { Tourist } \\
\text { volume }\end{array}$} & \multicolumn{15}{|c|}{ Percentage of international tourists according to nationality (\%) } \\
\hline & & & & & German & British & French & Dutch & Belgian & Danish & Swiss & Russian & Japanese & Korean & Australian & ASEAN & American & African & Others \\
\hline 2010 & 17,634 & 14,744 & 84 & 2,890 & 8 & 9 & 7 & 9 & 5 & 11 & 8 & 6 & 5 & 2 & & 8 & 6 & 4 & 6 \\
\hline 2011 & 19,492 & 15,985 & 82 & 3,507 & 12 & 8 & 9 & 7 & 7 & 10 & 7 & 5 & 7 & 3 & 5 & 10 & 4 & 2 & 4 \\
\hline 2012 & 18,355 & 14,760 & 80 & 3,595 & 8 & 10 & 11 & 6 & 6 & 8 & 8 & 7 & 8 & 5 & 6 & 9 & 3 & 3 & 2 \\
\hline 2013 & 18,348 & 13,902 & 76 & 4,446 & 9 & 8 & 7 & 5 & 7 & 7 & 7 & 7 & 6 & 6 & 8 & 11 & 5 & 3 & 4 \\
\hline 2014 & 23,217 & 17,514 & 75 & 5,703 & 13 & 11 & 8 & 7 & 5 & 4 & 6 & 7 & 6 & 6 & 6 & 12 & 4 & 2 & 3 \\
\hline 2015 & 26,664 & 20,139 & 76 & 6,525 & 16 & 13 & 11 & 9 & 7 & 7 & 6 & 5 & 3 & 3 & 2 & 7 & 4 & 3 & 4 \\
\hline
\end{tabular}

(Source: Centre of Environmental Education and Services, Cat Tien National Park, 2016) 


\subsection{Research aims}

As mentioned earlier, there is a lack of research about visitor satisfaction with all services for environmental interpretation in national parks using Importance-Performance Analysis in the literature. Furthermore, until now no study about environmental interpretation was undertaken in national parks of Vietnam in general and in Cat Tien National Park in particular. Hence, this research attempts to fill in the research gaps by examining visitor satisfaction with services for environmental interpretation in Cat Tien National Park using Importance-Performance Analysis and visitor segmentation. The main aims are to:

1. Identify current interpretive services in Cat Tien National Park.

2. Explore the use of services for environmental interpretation in Cat Tien National Park by visitors.

3. Investigate visitor satisfaction with services for environmental interpretation in Cat Tien National Park using Importance-Performance Analysis.

4. Analyse similarities and differences in visitor satisfaction with services for environmental interpretation according to motivation segments and market segments.

\subsection{Research contributions}

This research aims to make a significant contribution to both the tourism literature and directly to Vietnamese tourism. Firstly, this research contributes to the literature on environmental interpretation in national parks by investigating visitor satisfaction with all services for environmental interpretation using Importance-Performance Analysis. Secondly, this research will incorporate market segmentation and motivation segmentation into Importance-Performance Analysis. Segmentation can give managers better information about the wants and needs of different kinds of visitors when visiting a national park in order to provide a better response (Eagles et al., 2002). Thirdly, this research contributes to the literature on visitor satisfaction using ImportancePerformance approach when separating pre-visit testing and post-visit testing for the importance and performance of services and roles of site interpreters and collecting the pre-visit and post-visit data from the same participants. Fourthly, this study about environmental interpretation has not been done before in any national park of Vietnam. Hence, it is hoped that this study will contribute to the development of interpretive services in national parks of Vietnam in general and in Cat Tien National Park in particular.

\subsection{Structure of the thesis}

This thesis includes seven chapters. This Introduction chapter has presented the research topic and the research gaps in the literature about environmental interpretation. This chapter also provided an 
overview of Vietnamese tourism and Cat Tien National Park. The research aims and the research contributions were also highlighted in this chapter.

Chapter 2, Literature Review sets up a theoretical background for this study. It discusses the literature related to the research topic and the research aims. This literature will be linked together to identify the research gaps. Also, this literature provides a solid background knowledge for the researcher to develop the research methodology of the next chapter.

The process of developing of research methodology is described in Chapter 3, Methodology. The selections of research paradigm, research methods and the study site will be justified. Details of how data was collected and entered will also be included together with an explanation of how data will be analysed. Finally, limitations of this research are acknowledged at the end of this chapter.

The results of this research will be presented in three chapters. Chapter 4 starts the findings by providing some information about the management of services for environmental interpretation in Cat Tien National Park. Visitors' profile with demographic and trip-related characteristics is presented in this chapter to provide an overview of the study sample. This is followed by visitor use of services for environmental interpretation. Main findings about visitor satisfaction will then be presented in Chapter 5 and 6.

Chapter 5 addresses the third aim of this research, to investigate visitor satisfaction with services for environmental interpretation. The importance and performance means of services for environmental interpretation and roles of site interpreters are presented in this chapter. This chapter also demonstrates the relationship between these importance and performance ratings via the results from a paired samples t-test and importance-performance grid. Lastly, overall satisfactions and recommendation intentions are presented together with their relationship with performance ratings.

Chapter 6 helps to answer the fourth aim, which is to analyse the similarities and differences in visitor satisfaction with services for environmental interpretation according to market and motivation segments. Particularly, factor analysis is conducted to determine motivation factors before cluster analysis is adopted to identify visitor segments. Clusters will be identified with their demographic and trip related characteristics. Similarities and differences among clusters in their satisfaction will be analysed. Likewise, similarities and differences between international and domestic markets in their satisfaction will also be included in this chapter.

Chapter 7, Discussions, Implications and Conclusions, summarizes and discusses the findings in relation to previous studies. The entire research is reviewed and the aims are revisited. Implications generated from the findings are put forward, and recommendations for tourism practitioners and future research are presented at the end of this chapter. 


\section{CHAPTER 2}

\section{LITERATURE REVIEW}

\subsection{Introduction}

The previous chapter described the main aims of this study. In order to achieve these aims, it is critical to review the relevant literature for this research. Specifically, this study focuses on environmental interpretation in national parks; hence, a general understanding of national parks, environmental interpretation, environmental interpretation in national parks and tour guides is very important. Moreover, literature on the measurement of visitor satisfaction in general, and in national parks specifically, will provide the information about relevant methods to investigate visitor satisfaction. Comparative studies using Importance Performance Analysis will be reviewed to identify the most suitable kind of segmentation for this study and to provide information about relevant analytical approaches and statistical tests. Literature on visitor motivations will also be reviewed to find out common motivations of visitors to national parks.

\subsection{National park}

The World Conservation Union, IUCN (1994) defined a protected area as "an area of land and/or sea especially dedicated to the protection and maintenance of biological diversity, and of natural and associated cultural resources, and managed through legal or other effective means" (cited in Phillips, 2004, p.10). A national park is regarded as a protected area that falls into Group A managed by CNPPA, the Commission on National Parks and Protected Areas of IUCN (Figure 2.1).

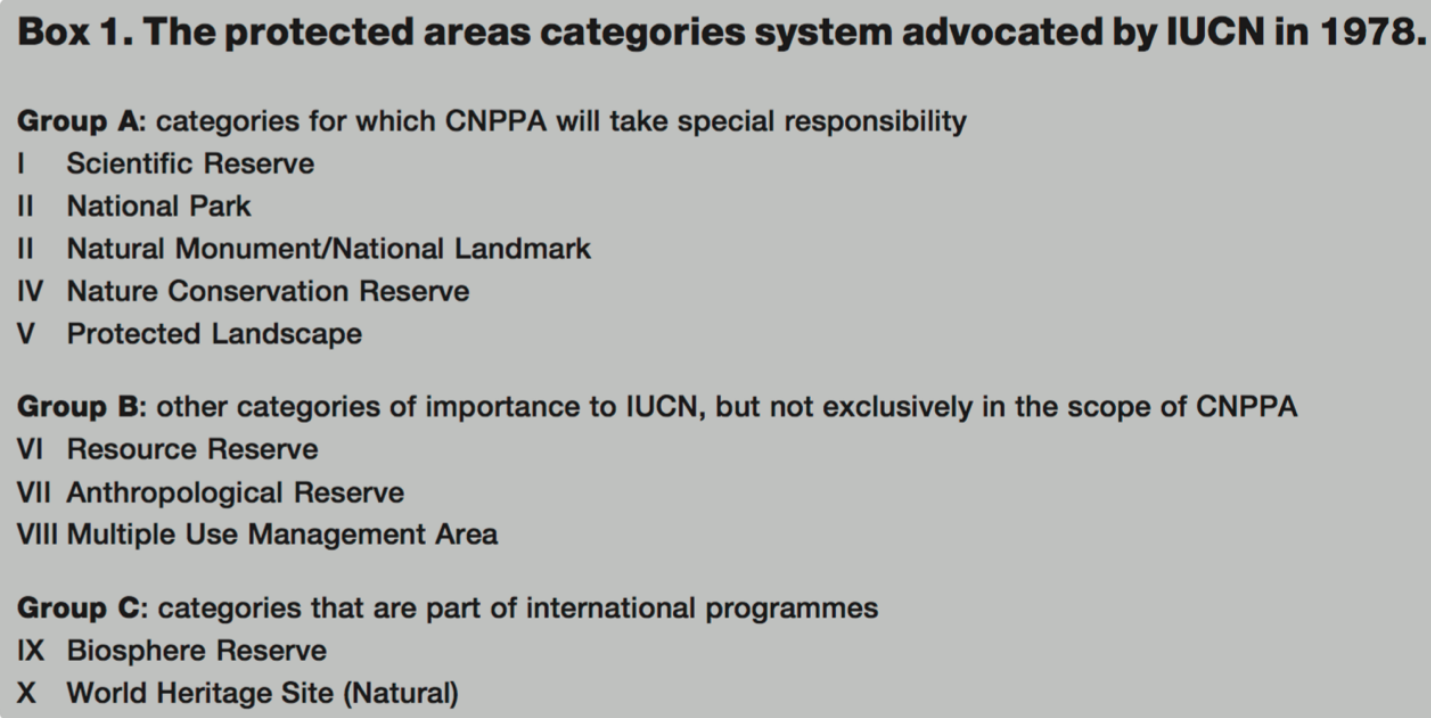

Figure 2.1. The protected areas categories system

(Source: Phillips, 2004, p.8) 
A Vietnamese national meeting was held in November, 1997 by the Forest Protection Department (FPD), the body within Ministry of Agriculture and Rural Development (MARD) with responsibility for protected areas in Vietnam. The meeting concluded that the current network of protected areas classified according to IUCN was unsuitable to the condition of Vietnam for several reasons: a lack of some important habitats, the adverse intrusion on some protected areas, the status change in some forests and the objectives and strategies for management became inappropriate (Anon, 1999, cited by Stolton et al., 2004).

Because of the above irrelevances when applying the classification system of IUCN in the context of Vietnam, a new special-use forest system was established with four categories: National Park, Nature Reserve, Species/Habitat Management Protected Areas and Protected Landscape or Seascape (Hoang et al., 2001). In this new classification system, National Parks in Vietnam were defined as "terrestrial and marine areas that have not experienced significant human impact and consist of many rare and endemic species and beautiful landscapes and seascapes that are nationally and internationally renowned" (Hoang et al., 2001, p.18). The objectives of a National Park were also indicated. Those are "to protect nationally and internationally rare and important flora and fauna, to serve scientific research, and to develop ecotourism" (Hoang et al., 2001, p.18).

The increase in visitor demand in national parks requires more and more suitable and effective visitor management. Eagles and McCool (2002) indicated that two challenges of visitor management in national parks are increasing visitor experience and minimizing visitor impact on national parks. Hard and soft visitor management strategies were often mentioned as two types of visitor management (e.g. Kuo, 2002; Mason, 2005). Hard visitor management strategies are used to monitor visitor activities. Whereas, soft visitor management strategies utilize information and interpretation to educate visitors (Kuo, 2002). Table 2.1 describes a number of hard and soft visitor management strategies in the literature.

\section{Table 2.1. Hard and soft visitor management strategies}

\begin{tabular}{ll}
\hline $\begin{array}{l}\text { Hard visitor management strategies: aimed at } \\
\text { regulating visitor activities }\end{array}$ & $\begin{array}{l}\text { Soft visitor management strategies: aimed at } \\
\text { educating visitors }\end{array}$ \\
\hline $\begin{array}{l}\text { Restrictions on access and certain activities } \\
\begin{array}{l}\text { Implem site personnel/rangers/police } \\
\text { Implementation of rules and regulations }\end{array}\end{array}$ & $\begin{array}{l}\text { Provision of visitor information and environmental } \\
\text { interpretation } \\
\text { Marketing for targeted visitor groups } \\
\text { Zoning }\end{array}$ \\
$\begin{array}{l}\text { Resource hardening such as construction of } \\
\text { boardwalks, reconstruction and repair of heritage } \\
\text { buildings and monuments }\end{array}$ \\
\hline
\end{tabular}

(Source: Kuo, 2002, p.89) 
According to Eagles and McCool (2002), there are two reasons for using information and interpretation to manage visitors in national parks. Firstly, visitors who live in cities may not know well how to behave in national parks and protected areas in comparison to local residents, so they should be informed beforehand. Secondly, information and interpretation are regarded as appropriate management tools which do not affect much visitor experience in national parks as much as other direct tools. Moreover, according to park managers in Australia, informing and educating visitors about the characteristics of the park as well as increasing visitor satisfaction through interpretative programs are the values of national parks (Archer and Wearing, 2002). The next sections review literature on environmental interpretation in general and environmental interpretation in national parks in particular.

\subsection{Environmental interpretation}

Daniels and Marion (2005) stressed that environmental education is one of the rare programs containing ethical and emotional elements that can raise environmental awareness and stimulate positive changes in human behaviour. Catibog-Sinha and Wen (2008) stated that the quality of interpretation programs is very important to education in tourism. Komatsu and Liu (2007) suggested that interpretive services should be designed to meet both recreational and learning purposes which stimulate visitors' informal learning. As indicated by Diamond (1999) (cited in Komatsu and Liu, 2007), informal learning can encourage life-long learning for participants.

\subsubsection{Definitions}

Interpretation has been defined in many different ways by tourism scholars. Moscardo (2003) defined interpretation as "a special kind of communication" (p.113) "providing information to visitors about the places they are in and encouraging them to appreciate and care for these places" (p.112). Similarly, Archer and Wearing (2002) defined interpretation in national parks as "a means for communicating information, stories, values, and ideas to assist people in understanding their relationship with environment" (p.32).

Meanwhile, according to Fernandez and Ramos (2015), interpretation is a way of guiding tourists. It is a learning process that can foster the awareness of environment and promote local identity. Likewise, Eagles and McCool (2002) understood interpretation as "explaining natural and cultural phenomena in such a way that the visitor begins to understand the subject yet is stimulated to learn more" (p.134). In brief, interpretation is a communication channel that provides visitors with information about the site (e.g. nature and culture, etc.) through interesting stories, raises visitors' awareness and further encourages visitors to care more about environment. 


\subsubsection{Origins and developments}

Xu et al. (2013) in their article indicated that in western countries in the 1970s, interpretation had an influence on tourists in changing their attitudes towards environmental respect and reverence and promoting pro-environmental behaviour. This approach included four components: information, understanding, appreciation and persuasion. In other words, interpretation was used as a tool to educate tourists in aspects of tourism. Eagles and McCool (2002) regarded interpretation as " $a$ technique closely related to information and education" (p.134).

The study of Archer and Wearing (2002) also pointed out that there is another progress in the development of interpretation in tourism. Interpretation not only focuses on on site visitors (regular park users) through traditional programs but also aims to off site visitors (irregular and non park users) through tourism centres, media and publications, Internet, school educational programs, and other community activities.

\subsubsection{Purposes}

According to Munro et al. (2008), environmental interpretation is regarded as a major intermediary channel between the managers and visitors, together with physical settings and legal punishment. One of the main purposes of interpretation in national parks and protected areas is enhancing visitor experience (e.g. Komatsu and Liu, 2007; Moscardo, 2003). Moscardo (2003) mentioned that enhancing visitor experience is one of the roles of interpretation in sustainable tourism. Interpretation can enhance visitor experience through providing information on choices, providing information for safety and comfort and generating the actual experience. Moreover, according to Moscardo (2003), interpretation is used to create "visitor enjoyment" and "exciting curiosity" (p.113). Komatsu and Liu (2007) also indicated that in natural settings, visitor experience can be increased with interesting stories about the site through interpretation. However, Moscardo (2014) stated that although current research has demonstrated the positive influence of interpretation on tourists' experience, there was no evidence suggesting that interpretation makes the site more attractive or makes tourists stay longer or spend more.

In addition, interpretation can help the national parks to manage visitors and their impacts (e.g. Archer and Wearing, 2002; Komatsu and Liu, 2007; Moscardo, 2003; Moscardo, 2014). Munro et al. (2008) stated that environmental interpretation is considered an important tool in impacting visitor knowledge, attitudes and behaviour. Moscardo (2014) contended that changing visitor behaviour is the second important role of interpretation, "visitor impact management" (p.467). She also indicated that current research supports the idea that interpretation can assist the management of negative visitor behaviours. Firstly, interpretation can help to manage visitors and their impacts through affecting where visitors go and providing an alternative experience (Moscardo, 2003). Secondly, interpretation can assist the management of visitor impacts through raising visitor 
awareness about the site. According to Archer and Wearing (2002), the main purpose of on-site interpretive programs in national parks in Australia is raising visitor "awareness, appreciation, and understanding of the range of natural and cultural values inherent in national parks" (p.32). Also, Archer and Wearing (2002) stated that interpretation can raise visitor awareness about their possible impacts when they visit national parks. Catibog-Sinha and Wen (2008) suggested that interpretation programs should convey rich information about the site and the important role of tourism in the conservation of local environment and culture. Thirdly, interpretation can monitor visitor impacts by informing and encouraging visitors to adopt proper behaviours (Archer and Wearing, 2002; Komatsu and Liu, 2007; Moscardo, 2003).

Finally, interpretation can be used to create tourism itineraries whether the trips relate to environmental issues or not (Fernandez and Ramos, 2015). According to Moscardo (2003), interpretation can be actual experiences (e.g. guided walks and tours). These purposes of environmental interpretation are presented in Figure 2.2.

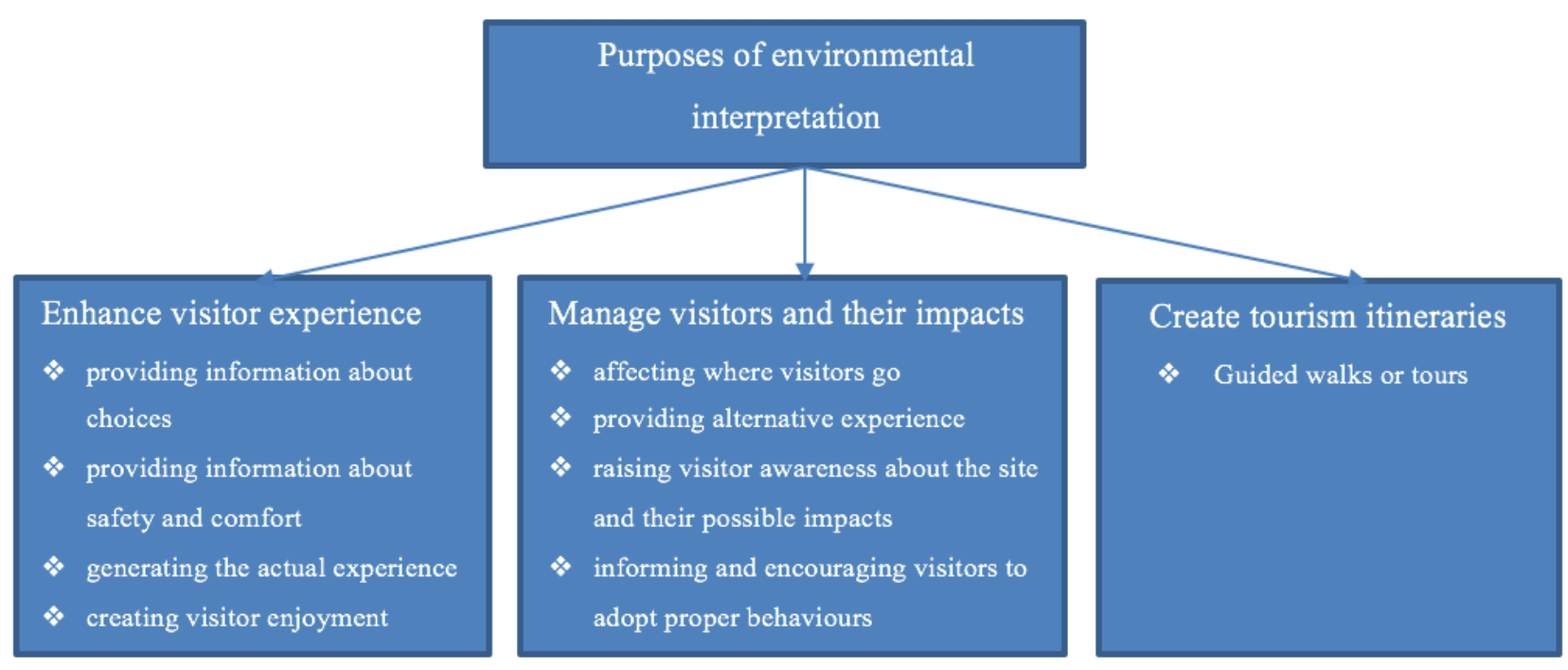

Figure 2.2. Conceptualization of purposes of environmental interpretation (Source: Archer and Wearing, 2002; Fernandez and Ramos, 2015; Komatsu and Liu, 2007; Moscardo, 2003)

\subsubsection{Classifications}

Munro et al. (2008) pointed out that for interpretation, managers in natural areas use a variety of interpretive tools. Archer and Wearing (2002) stated that interpretive programs were firstly just based on basic signs and later on included other media based services such as visitor centres, exhibits, interpretive trails, publications, school educational initiatives and rangers guided programs. Interpretation tools at the Hanauma Bay Education Program in the study of Komatsu and Liu (2007) in Hawaii were interpretive talks, educational kiosks, interactive computer exhibits, displays, signs and an orientation film about conservation and safety information. Interpretive services in the study 
of Stein, Denny and Pennisi (2003) included interpretive signs, a visitor centre, a museum, wildlife classes, outdoor kiosks, nature hikes, exhibits, children's programs, cultural events, evening interpretation programs and day camps.

$\mathrm{Xu}$ et al. (2013) in their paper mentioned that there are two types of interpretation including selfguided (via interpretive signage, directional signage, an information centre, guidebooks, maps and a geological museum using scientific information: formation of Danxia landscape) and guided (communication between tour guides and tourists using stories and poems).

Munro et al. (2008) divided interpretation into interpersonal interpretation and non-personal interpretation. They regarded interpersonal interpretation as the two-way communication between staff and visitors (e.g. site staff, guided tours, information desk personnel, formal presentations and organized entertainment activities, etc.), not only interpretation by tour guides. Whereas, nonpersonal interpretation is the one-way communication, where visitors should take the messages from non-personal media in their own ways (e.g. signs, brochures, computers, touch tables, art, etc.).

Likewise, Skanavis and Giannoulis (2010) indicated that interpretation services can be personal (e.g. talks, interpreter-led hikes, campground programs, etc.) or non-personal (e.g. exhibits, waysides, films, and publications). Tsang et al. (2011) also classified interpretive services of Hong Kong Wetland Park into two types including personal interpretive services (guided interpretive walks and informational services) and non-personal interpretive services (brochures, exhibits, a resource centre, interpretive signs, multi-media programs and experiential displays) (Table 2.2). The study indicated that experiential facilities, interpretive signs and exhibition materials were used commonly by most respondents.

Table 2.2. Types of Interpretive services provided in Hong Kong Wetland Park

Table 1 Types of Interpretive Service Provided in HKWP

\begin{tabular}{ll}
\hline Types of Interpretive Service & \multicolumn{1}{c}{ Interpretive Services Items } \\
\hline Personal interpretive services & $1 . \begin{array}{l}\text { Guided interpretive walks } \\
\text { (Presentational services) }\end{array}$ \\
Non-personal interpretive services & 2. Enquiry centre \\
& (Informational services) \\
& 1. Brochures \\
& 2. Exhibits \\
\hline
\end{tabular}

(Source: Tsang et al., 2011, p.126)

Tan and Law (2016) classified environmental interpretive services in protected areas into three types: static/ physical displays, tours/interpretive guides and ICT and mobile driven applications 
(Figure 2.3). Tan and Law (2016) stressed that technological development and mobile innovation provide advantages to adopt mobile-driven applications into interpretive programs.

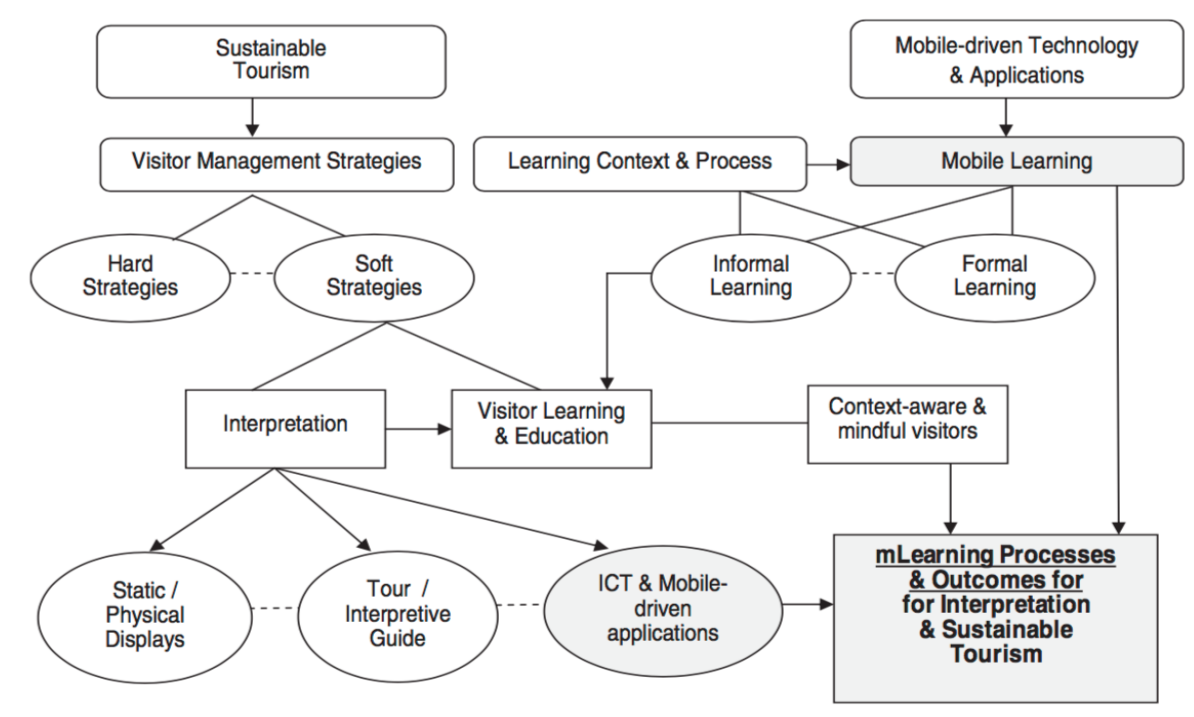

Figure 1. Concept map of mLearning for interpretation and sustainable tourism.

Figure 2.3. Services for environmental interpretation in protected areas

(Source: Tan and Law, 2016, p. 140)

Regarding the effectiveness of services for environmental interpretation, Munro et al. (2008) stated that interpersonal interpretation (or personal interpretation) was often described as a more effective way than non-personal interpretation. However, interpersonal interpretation (or personal interpretation) involves higher costs in training and staff payment. The study of Tsang et al. (2011) indicated that most respondents showed high satisfaction with the performance of guided interpretive tours in delivering educational messages, although many visitors did not know about this service. Xu et al. (2013) also showed that self-guided interpretation with signage, information centres and a geological museum was ineffective whereas guided tours using stories, art and poetry seemed to be more suitable and effective in China. Moreover, they pointed out that adjectival words, figurative or metaphorical landscape descriptions and exaggeration should be adopted by guides in China. In terms of non-personal services, the findings of Stein et al. (2003) showed that among nonpersonal services, visitor centres and museums were rated highly by visitors in water-based recreation areas in terms of providing learning opportunities. These were followed by interpretive signs and outdoor kiosks. 


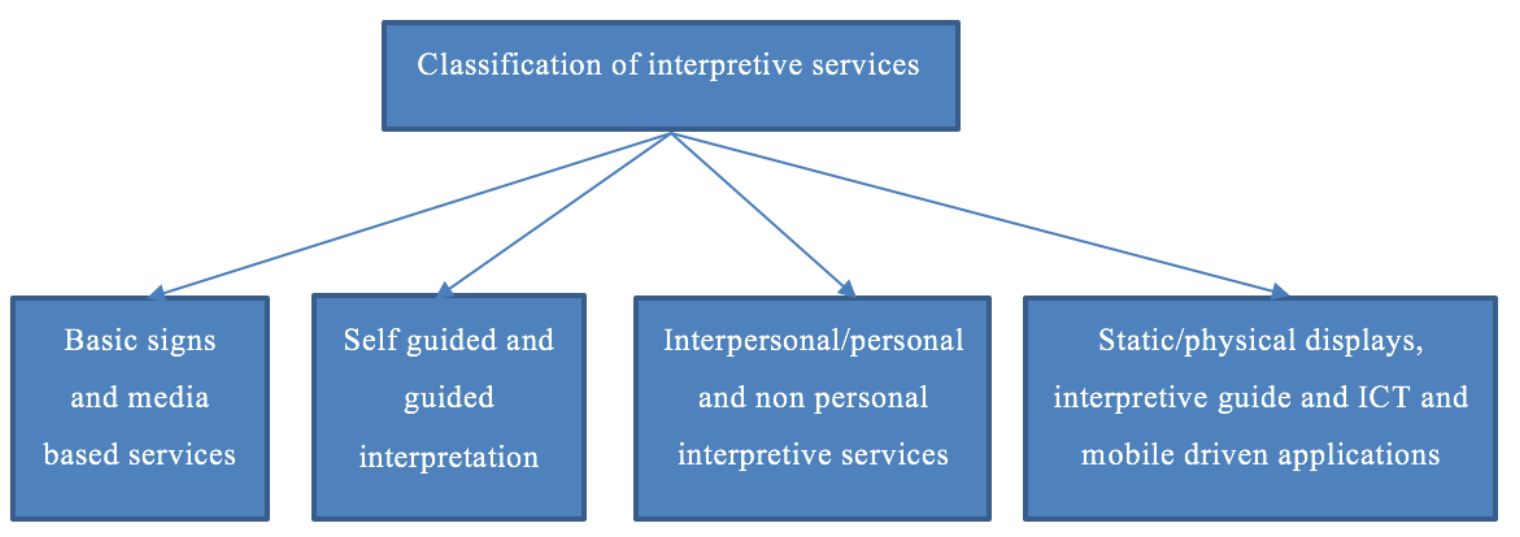

Figure 2.4. Conceptualization of classifications of environmental interpretive services (Source: Archer and Wearing, 2002; Munro, Morrison-Saunders and Hughes, 2008; Skanavis and Giannoulis, 2010; Tan and Law, 2016; Tsang, Cheung and Yeung, 2011; Xu, Cui, Ballantyne and Packer, 2013)

In short, interpretive services were classified into different categories by current scholars: Basic signs and media based services; Self-guided and guided interpretation; Interpersonal/personal and non personal interpretive services; Static/physical displays, interpretive guides and ICT and mobiledriven applications (Figure 2.4). This study adopts the third classification shown in Figure 2.4 (Munro et al., 2008; Skanavis and Giannoulis, 2010; Tsang et al., 2011). The next section presents the literature review on environmental interpretation in national parks to know which aspect of environmental interpretation has been examined in national parks.

\subsection{Environmental interpretation in national parks}

Many aspects of environmental interpretation in national parks have been investigated by tourism scholars including the influence of interpretation on knowledge, attitudes and behaviours of tourists (Powell and Ham, 2008); local culture in interpretive content (Carr, 2004); effectiveness of a specific interpretive service (Tubb, 2003; Wearing and Whenman, 2009); visitor use and satisfaction with services for environmental interpretation (Tsang et al., 2011); the relationship among ecotourism perception, level of satisfaction and interpretation needs (Wei-ching, 2015); the relationship among tourist participation, interpretation service quality and place attachment (Hwang et al., 2005); the effectiveness of interpretive services using a qualitative approach (Xu et al., 2013); interpretation and marketing in national parks (Archer and Wearing, 2002) and an experiment of new interpretive service (Nielsen and Liburd, 2008) (Table 2.3). 
Table 2.3. Summary of research topics on environmental interpretation in national parks

\section{Topies}

Authors

Methodology

\begin{tabular}{|c|c|c|}
\hline $\begin{array}{l}\text { Influence of a well-conceived } \\
\text { interpretation/ecotourism product on } \\
\text { the knowledge, attitudes and behaviors } \\
\text { of visitors }\end{array}$ & Powell and Ham (2008) & $\begin{array}{l}\text { Quantitative approach } \\
\text { Same visitors } \\
59 \text { Pre-visit questionnaires } \\
57 \text { Post-visit questionnaires }\end{array}$ \\
\hline $\begin{array}{l}\text { Incorporation of local culture into } \\
\text { interpretation }\end{array}$ & Carr (2004) & $\begin{array}{l}\text { Mix methods: } \\
\text { Observations and interviews } \\
\text { Questionnaire survey } \\
250 \text { questionnaires for visitors } \\
\text { "Next to pass" selection method }\end{array}$ \\
\hline $\begin{array}{l}\text { Effectiveness of interpretation of } \\
\text { Visitor Centre }\end{array}$ & Tubb (2003) & $\begin{array}{l}\text { Mix methods: } \\
\text { Participant observation } \\
\text { Questionnaire survey } \\
2 \text { different visitor samples: } \\
112 \text { pre-visit questionnaires } \\
76 \text { post-visit questionnaires }\end{array}$ \\
\hline $\begin{array}{l}\text { Effectiveness of guidebooks as an } \\
\text { effective interpretive tool }\end{array}$ & Wearing and Whenman (2009) & $\begin{array}{l}\text { Qualitative approach } \\
29 \text { interviews with trekkers }\end{array}$ \\
\hline $\begin{array}{l}\text { Visitor use and satisfaction with } \\
\text { services for environmental } \\
\text { interpretation }\end{array}$ & Tsang et al. (2011) & $\begin{array}{l}\text { Quantitative approach } \\
206 \text { questionnaires for visitors } \\
\text { Convenience sampling }\end{array}$ \\
\hline $\begin{array}{l}\text { Relationship among tourist } \\
\text { participation, interpretation service } \\
\text { quality and place attachment }\end{array}$ & Hwang et al. (2005) & $\begin{array}{l}\text { Quantitative approach } \\
2547 \text { questionnaires for visitors } \\
\text { Stratified probability sampling } \\
\text { Structural equation model }\end{array}$ \\
\hline $\begin{array}{l}\text { Relationship among ecotourism } \\
\text { perception, level of satisfaction and } \\
\text { interpretation needs of visitors }\end{array}$ & Wei-ching (2015) & $\begin{array}{l}\text { Quantitative approach } \\
356 \text { questionnaires for visitors } \\
\text { Convenience sampling }\end{array}$ \\
\hline $\begin{array}{l}\text { Interpretive needs of Chinese tourists } \\
\text { towards western scientific interpretive } \\
\text { services }\end{array}$ & Xu et al. (2013) & $\begin{array}{l}\text { Qualitative approach } \\
\text { Observation with } 3 \text { tour groups } \\
\text { Formal interviews with } 3 \text { managers } \\
\text { and } 3 \text { guides } \\
\text { Informal interviews with } 11 \\
\text { visitors }\end{array}$ \\
\hline $\begin{array}{l}\text { Conflicts in using interpretation and } \\
\text { marketing tools }\end{array}$ & Archer and Wearing (2002) & Literature review \\
\hline $\begin{array}{l}\text { Potential of using geographic data in } \\
\text { tourist communication }\end{array}$ & Nielsen and Liburd (2008) & Scenario planning \\
\hline
\end{tabular}

Powell and Ham (2008) examined the influence of a well-conceived interpretation on the knowledge, attitudes and behaviours of visitors in Galapagos National Park, Ecuador towards environmental conservation. The study indicated that there was a significant effect on tourist knowledge, attitudes and intentional behaviours resulting from the interpretation strategy. This finding demonstrated that interpretation is an important research area for the environmental protection of national parks. 
Carr (2004) also investigated on-site interpretation of Aoraki/Mount Cook National Park, New Zealand. The findings showed that only $15.1 \%$ of visitors were satisfied and $3.3 \%$ of them extremely satisfied with on-site interpretation. This finding showed that not all on-site interpretations in national parks perform well, and that there is always a need to conduct research about visitor satisfaction with on site interpretive services in a national park.

The effectiveness of a particular interpretive service was examined by several scholars. Tubb (2003) assessed the effectiveness of interpretation services at High Moorland Visitor Centre in Dartmoor National Park, UK. The results indicated that a visitor centre is an important tool in educating visitors in national parks, and that conducting research about environmental interpretation is necessary. Wearing and Whenman (2009) examined the effectiveness of guidebooks in Overland Track, Tasmania, Australia. The results revealed that guidebooks have little impact on changing visitor behaviours towards environmental protection. The results from these two studies pointed out that not all interpretive services have the same influence in educating visitors. These two studies show that there is a gap in research about visitor satisfaction with all environmental interpretive services in national parks to assess visitor satisfaction levels with these services (e.g. what is the importance levels, what is the performance levels) in order to improve them in future.

Tsang et al. (2011) examined visitor satisfaction with the current interpretive services in Hong Kong Wetland Park in order to enhance tourist satisfaction in the future. However, they did not indicate which service was of high importance or performance in delivering environmental messages for better investment in the future. This pointed out that there is a lack of research about visitor satisfaction with all interpretive services in a national park using an Importance-Performance analysis.

Hwang et al. (2005) conducted a survey with visitors at five National Parks in Taiwan to test the relationship between tourist participation, interpretation service quality and place attachment. The results from their structural equation model indicated that tourist participation positively affected tourists' perceptions of interpretation service quality and place attachment. Hwang et al. (2005) defined tourist participation as a hypothetical construct that "refers to a psychological state of interest, motivation, or arousal in national parks" (p.148). This means that visitor motivation has an influence on visitor interpretation satisfaction. This finding supports the use of motivation segmentation in research on visitor satisfaction with environmental interpretation in national parks.

Some other researchers explored visitor needs of on site interpretation using different approaches. Wei-ching (2015) studied the relationship among ecotourism perception, level of satisfaction and interpretation needs of visitors in Taijiang National Park, Taiwan, using a quantitative approach. The findings indicated that interpretation by tour guides was perceived necessary by most of the respondents. $\mathrm{Xu}$ et al. (2013) tested whether interpretive services designed by a western scientific 
approach can meet the interpretive needs of Chinese tourists in Danxia Shan National Natural Reserve and Geo-Park. The results showed that western scientific interpretation is ineffective in comparison with guided tours. These two studies indicated that interpretation delivered by tour guides was perceived more effective and necessary by visitors. Thus, visitor satisfaction with tour guides needs to be analyzed in depth. The study of Xu et al. (2013) also showed that guided tours using stories, art and poetry seemed to be more suitable and effective for Chinese tourists rather than self-guided interpretation with signage, information centres and a geological museum. This finding pointed out the need to examine whether there are differences in interpretation preference between different visitor groups (Eastern and Western groups) in national parks. Vietnam is also a country in Asia and hence, this examination is relevant and necessary to the context of national parks of Vietnam. Costs for establishing facilities (services) for interpretation in national parks are often very high. Knowing visitor preference between different visitor groups can help national parks invest effectively in these facilities (services).

Archer and Wearing (2002) explored interpretation and marketing tools in Australian national parks. They discussed the origins, aims and characteristics of both management tools. It is suggested that interpretation and marketing programs should be developed and support each other to create advantages for the parks and involve both on site and off site visitors. This is an interesting finding for the future development of interpretive programs of national parks.

Nielsen and Liburd (2008) tested geographic data in tourist communication in Salt River Bay National Park, USA. They argued that internet-based neo-geography has high potential for specific tourist groups. Yet, the authors also suggested that careful considerations about communication with historical maps and population data should be taken and quality content should be developed. The study demonstrated that careful research is always needed when applying any new service for interpretation.

In short, the above studies pointed out that there is a lack of research on visitor satisfaction with all services for environmental interpretation in a national park. Moreover, the literature suggested that visitor motivations need to be considered when examining visitor satisfaction with environmental interpretation. Also, the examination of visitor satisfaction with environmental interpretation among different market segments (e.g. Eastern and Western) is needed in the context of national parks of Vietnam. Furthermore, the literature suggested that visitor satisfaction with tour guides needs to be analyzed in depth. The next section will present the literature on visitor satisfaction with tour guides/site interpreters.

\section{$2.5 \quad$ Tour guides}

The terms 'environmental educator', 'environmental interpreter' and 'eco-tour guide' often refer to the same kind of job (Skanavis and Giannoulis, 2010). According to Skanavis and Giannoulis 
(2010), an eco tour guide is regarded as a person who leads a group of visitors and explains about the cultures and environment (Environmental educator). Environmental interpreter is also an important role of tour guide. Figure 2.5 shows the relationship between environmental interpreters, eco tour guides and environmental educators. Current studies about environmental interpretation have shown the importance and effectiveness of tour guides in conveying environmental messages to tourists (e.g. Tsang et al., 2011; Wei-ching, 2015; Xu et al., 2013). Kuo, Chang, Cheng and Lin (2016) indicated that providing information about the local environment is one of the main tasks of a tour guide. Moreover, tour guides can educate visitors about proper behaviours to support visitor impact management in natural areas (Randall and Rollins, 2009).

\section{Figure 1. The link between ecotour guides environmental interpreters and environmental educators}

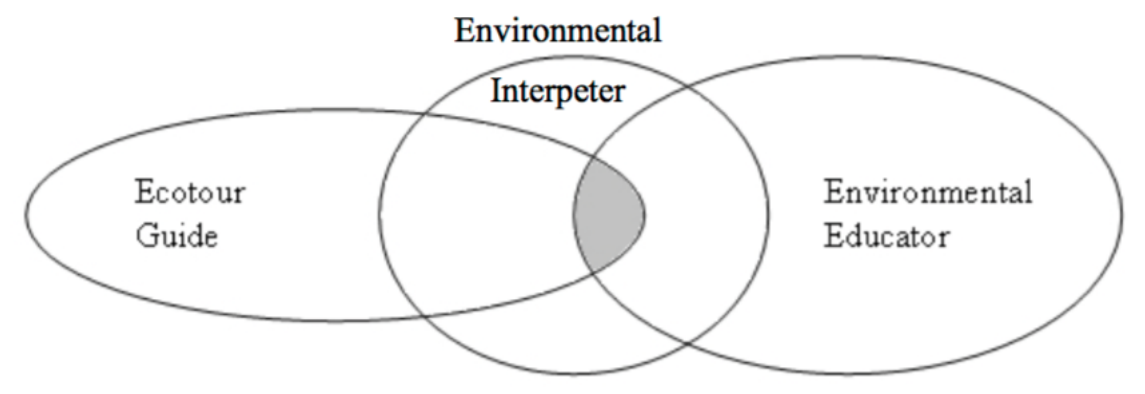

Figure 2.5. The links between ecotour guides, environmental interpreters

and environmental educators

(Source: Skanavis and Giannoulis, 2010, p.57)

The review of the literature on visitor satisfaction in protected areas showed that little research has focused on visitor satisfaction with tour guides as well as service quality of tour guides (e.g. Hwang et al., 2005; Randall and Rollins, 2009). Hwang et al. (2005) examined the causal relationships among tourists' involvement, interpretation service quality and place attachment in five National Parks in Taiwan. To evaluate tourist satisfaction levels with the service quality of interpreters, Hwang et al. (2005) used the five dimensions of the Parasuraman et al. (1988): service quality scale: reliability, responsiveness, assurance, empathy and tangibility.

Randall and Rollins (2009) adopted the approach of Weiler and Davis (1993) investigating the roles of tour guides. Weiler and Davis (1993) added two roles related to resource management (Motivator and Environmental Interpreter) to four roles of tour guides developed by Cohen (1985) (Table 2.4). This study adopted the work of Randall and Rollins (2009) in assessing the importance and performance of these roles of tour guides because this approach had a focus on monitoring visitor impacts that are relevant to the aims of this study. The results of Randall and Rollins (2009) indicated 
that only communicative roles of tour guides were not perceived as important. Two roles of a motivator of responsible behaviour had the performance lower than their importance.

Table 2.4. Roles of tour guides

\begin{tabular}{|c|c|}
\hline Roles of tour guides & Content \\
\hline $\begin{array}{l}4 \text { roles developed by Cohen (1985): } \\
\text { - The Instrumental Role } \\
\text { - The Interactional Role } \\
\text { - The Social Role } \\
\text { - The Communicative Role }\end{array}$ & $\begin{array}{l}\text { - focusing on direction-giving, navigation, access to } \\
\text { the territory and safety. } \\
\text { focusing on representation of the area to the } \\
\text { followers in a non-threatening manner and } \\
\text { organization. } \\
\text { - focusing on tension management, social } \\
\text { integration and cohesion and using humor and } \\
\text { entertainment to maintain and build group morale. } \\
\text { focusing on selecting points of interest for the } \\
\text { group, dissemination of correct information and } \\
\text { the translation of the unfamiliar } \\
\text { (cited in Randall and Rollins, 2009, p.359). }\end{array}$ \\
\hline $\begin{array}{l}2 \text { new roles added by Weiler and Davis (1993): } \\
\text { - The Motivator } \\
\text { - The Environmental interpreter }\end{array}$ & $\begin{array}{l}\text { - the modification of tourist behaviour and impacts } \\
\text { on site; } \\
\text { the understanding and appreciation of } \\
\text { environmental issues to facilitate responsible } \\
\text { tourist behaviours in the long term } \\
\text { (cited in Randall and Rollins, 2009, p.359). }\end{array}$ \\
\hline
\end{tabular}

\subsection{Measurement of visitor satisfaction in national parks}

This section discusses the literature on visitor satisfaction in national parks to identify the methods which previous research has used to measure visitor satisfaction. The literature review shows that many studies have been done to assess visitor satisfaction in national parks. Most of the research (e.g. Akama and Kieti, 2003; Tonge, Moore, and Taplin, 2011, etc.) focused on evaluating visitor satisfaction with services provided in national parks. Some of them used Importance-Performance Analysis to measure visitor satisfaction (e.g. Crilley, Weber and Taplin, 2012; Tonge et al., 2011, etc.). Little research has been done on visitor satisfaction with environmental interpretation in national parks (Table 2.5). 
Table 2.5. Summary of research topics on visitor satisfaction in national parks

\begin{tabular}{|l|l|l|}
\hline \multicolumn{2}{|c|}{ Topics } & \multicolumn{1}{c|}{ Authors } \\
\hline Visitor satisfaction with services & Akama and Kieti (2003) & $\begin{array}{l}\text { Quantitative approach } \\
\text { SERVQUAL model }\end{array}$ \\
\hline Visitor satisfaction with services & Tonge et al. (2011) & $\begin{array}{l}\text { Mix methods: } \\
\text { Questionnaire survey } \\
\text { Importance-Performance Analysis } \\
\text { Focus group }\end{array}$ \\
\hline $\begin{array}{l}\text { Visitor satisfaction with services } \\
\text { satisfaction }\end{array}$ & Crilley et al. (2012) & $\begin{array}{l}\text { Quantitative approach } \\
\text { Importance-Performance Analysis }\end{array}$ \\
\hline $\begin{array}{l}\text { Visitor } \\
\text { transportation modes }\end{array}$ & White, Aquino, Budruk and & $\begin{array}{l}\text { Quantitative approach } \\
\text { Random sampling }\end{array}$ \\
\hline $\begin{array}{l}\text { Visitor use and satisfaction with } \\
\text { services for environmental } \\
\text { interpretation }\end{array}$ & Tsang et al. (2011) & $\begin{array}{l}\text { Quantitative approach } \\
\text { Convenience sampling }\end{array}$ \\
\hline $\begin{array}{l}\text { Relationship among } \\
\text { participation, interpretation service } \\
\text { quality and place attachment }\end{array}$ & Hwang et al. (2005) & $\begin{array}{l}\text { Quantitative approach } \\
\text { Stratified probability sampling } \\
\text { Structural equation model }\end{array}$ \\
\hline $\begin{array}{l}\text { Relationship among ecotourism } \\
\text { perception, level of satisfaction and } \\
\text { interpretation needs of visitors }\end{array}$ & Wei-ching (2015) & $\begin{array}{l}\text { Quantitative approach } \\
\text { Convenience sampling }\end{array}$ \\
\hline
\end{tabular}

Visitor satisfaction with services has been a common topic of research on national parks. Akama and Kieti (2003) measured visitor satisfaction with services provided Tsavo West National Park, Kenya using SERVQUAL attributes. Two hundred international visitors were involved in this research. More than $70 \%$ of the respondents showed satisfaction with their experiences in the park. Tonge et al. (2011) studied visitor satisfaction with services of Yanchep National Park, Australia using the Importance-Performance framework. Four hundred and eighty questionnaires asking about 21 attributes related to information, accessibility, cleanliness, personal interactions, activities, water, etc. were distributed to tourists in the park. This was followed by a focus group with staff members of the Western Australia Department of Environment and Conservation. The findings suggested that good water condition, useful directional road signs and clean, well-presented toilets were the areas should be concentrated on by the managers of the park. Crilley et al. (2012) evaluated visitor satisfaction with services in Kakadu National Park, Australia using Importance-Performance approach. They collected 299 self-administered questionnaires asking visitors about 22 attributes related to facilities, service and information. The findings pointed out that attributes related to facilities and services including useful visitor guides and maps, quality directional signage on roads and walking trails, park infrastructure, a broad range of experiences available, clean and wellpresented toilet facilities and access to toilet facilities were perceived as important by the respondents. The performance of each of these services was assessed fairly highly by tourists. 
Regarding studies about visitor satisfaction with a specific service, White et al. (2011) explored visitor perception of the importance and performance of transportation modes in Yosemite National Park, USA. They distributed 533 self-administered questionnaires on-site using random sampling. The findings showed that there was a dependence on private automobiles as the main means to travel to and from the park. Visitors perceived alternative transportation inside the park as important. Moreover, they showed their satisfaction with the convenience of alternative transportation means. In general, visitors were satisfied with the convenience of private vehicles. The results showed that there were some statistically significant differences in their assessments of private vehicles and park shuttle busses regarding the sense of stress and conflict, freedom and access, and nature experience. Little research has been found on visitor satisfaction with environmental education and interpretation in national parks (e.g. Hwang et al., 2005; Wei-Ching, 2015). Wei-ching (2015) studied the relationship among ecotourism perception, level of satisfaction and interpretation needs of visitors in Taijiang National Park of Taiwan. The study distributed 356 questionnaires to visitors in the national park using convenience sampling. The findings indicated that interpretation by tour guides was perceived as necessary by most respondents. In particular, those who have a deep understanding of ecotourism showed a greater interest in interpretation. Hwang et al. (2005) conducted a survey with 2,547 respondents of five National Parks in Taiwan. A structural equation model was used to test the relationship among visitor participation, interpretation service quality and place attachment. The results indicated that visitor participation positively affected visitors' perceptions of interpretation service quality and place attachment. Moreover, it was found that place attachment can positively and indirectly affect interpretation satisfaction. Tsang et al. (2011) examined visitor satisfaction with the current interpretive services in Hong Kong Wetland Park. The findings indicated that experiential facilities, interpretive signs and exhibition materials were three services used commonly by these respondents. Moreover, guided interpretive tours were perceived as most effective service for environmental interpretation.

In brief, the review of the literature pointed out that there is a lack of research on visitor satisfaction with services for environmental interpretation in national parks. Moreover, Importance-Performance approach and Performance-Only approach were the two approaches used commonly in most of the research about visitor satisfaction in national parks. In addition, to identify the list of attributes, most of the above researchers reviewed related literature and consulted the opinions of the managers and specialists. Hence, in this research, a combination of secondary research, a site visit and interviews with the managers of Cat Tien National Park will be undertaken to identify the list of current services for environmental interpretation in the national park. 


\subsection{Measurement of visitor satisfaction}

This section discusses popular theories used to evaluate visitor satisfaction and implications for using them. Three major theories (expectancy-disconfirmation theory, performance-only theory and importance-performance theory) were often used by tourism scholars when studying visitor satisfaction.

First of all is expectancy-disconfirmation theory. The expectations, performance and disconfirmation build up visitor satisfaction (Martín, Collado and del Bosque, 2009). Martín et al. (2009) indicated that when assessing service performance, consumers often make a comparison with their expectations or comparison standards. Disconfirmation of their expectations is referred to consumers' assessment of service performance after making a comparison. In other words, it shows the performance of a service that was better or worse than their expectations. The expectancydisconfirmation theory was used in many studies on visitor satisfaction with destination (e.g. Jin, Uysal and Williams, 2003; Naidoo, Ramseook-Munhurrun and Ladsawut, 2010; Pizam and Milman, 1993, etc.). These scholars emphasized the usefulness of the theory for marketers and managers in helping them to understand visitor satisfaction through the relationship between their expectations and their experiences with the performance of tourism attributes.

However, according to Martín et al. (2009), there is no consistency in the kind of visitor expectations and comparison standards. Their comparison standards can be generated from their predictive or ideal expectations or their previous experiences. Martín et al. (2009) pointed out that predictive expectation about future performance is regarded as the most popular standard in previous research. Other types of expectations or standards are the comparison standard based on their experiences with similar brand or their ideal expectations about the best performance of service. Because of this inconsistency, it is difficult to gain exact results from a customer survey if we do not provide a clear explanation about the standard for comparison. Therefore, it is necessary to have a clear explanation about the degree of expectation mentioned in each study to have consistency in visitor evaluation. Furthermore, this paradigm does not provide the level of importance of each tourism attribute. Visitors can have high expectations with all tourism attributes. Therefore, it is hard for managers to invest money effectively into tourism products to meet all of the visitor expectations.

There are also many studies on visitor satisfaction using the performance-only theory (Adina Cosma, 2012; Li and Carr, 2004; McDowall and Ma, 2010, etc.). Li and Carr (2004) stressed that this approach was a "simple, easy and reliable tool" to measure visitor satisfaction (p.45). However, Wade and Eagles (2003) indicated that the performance-only approach can result in incorrect assumptions and wrong investment because the importance of attributes is not mentioned. Jurdana and Frleta (2012) also agreed with this viewpoint. Despite its ease, other approaches such as 
expectancy-performance theory and importance-performance theory should be used to provide a clear guideline for management activities.

Another way for measuring visitor satisfaction is Importance-Performance theory. ImportancePerformance analysis was first introduced by Martilla and James in 1977 when they measured the performance of marketing programs. The variables were disseminated into four quadrants: Concentrate here, Keep up with the good work, Low priority and Possibly overkill. 'Concentrate here' is the quadrant showing that consumers evaluated the attributes falling here as very important but their performances led to low satisfaction. 'Keep up with the good work' is the quadrant containing the attributes that were evaluated very importantly and also performed very well. 'Low priority' is the quadrant comprising attributes that received very low evaluation regarding both their importance and performance. 'Possibly overkill' is the quadrant containing the attributes that are not perceived very importantly and also did not perform well in the customers' view. Cross-hairs are placed into the importance-performance grid to create four quadrants. There are several ways to place the cross-hairs. Firstly, they can be placed at the midpoint of the scale (e.g. 3 on the 5 point Likert scale) (e.g. Martilla and James, 1977; Oh, 2001). Otherwise, they can be put at the grand means for importance and performance means, or at a point on the higher end of the scale if the managers want to reach a higher standard (e.g. Bruyere, Rodriguez and Vaske, 2002; Martillas and James, 1977; Okata, Inui, Lankford \& Scholl, 2007; Wade and Eagles, 2003).

The same set of methods applied in most of the studies using Importance-Performance Analysis (e.g., Okata et al., 2007; Wade \& Eagles, 2003) includes conducting focus groups with tourism experts to identify distinct tourism attributes, developing questionnaires with these attributes using Likert scales for both importance and performance statements, and using an importanceperformance grid to explain the data. All of these scholars have confirmed the usefulness of Importance-Performance analysis in evaluating visitor satisfaction and giving practical management implications. Martilla and James (1977) stated that Importance-Performance analysis was a lowcost and helpful tool for assessing the performance of marketing programs in terms of customer satisfaction. Moreover, in the tourism field, De Nisco, Riviezzo and Napolitano (2015) also stressed that this tool can help policy makers and practitioners to more deeply understand visitor perceptions of the major strengths and weaknesses of the destination for the destination management process. Wade and Eagles (2003) emphasized that Importance-Performance Analysis can give a simple and visual support for management activities with relevant resources and expertise.

Nevertheless, according to Oh (2001), it is necessary to carefully consider on the reliability and validity of this measurement tool. Issues encountered in Importance-Performance Analysis studies include an unclear definition of the concept of importance, unclear standard variables for the Importance-Performance analysis, a misunderstanding of importance and expectation and a lack of 
research on absolute versus relative importance. Some other noticeable issues include relationships between importance and performance, no instructions for elaborating a set of attributes, the length of the variable list, misinterpretation by using actual means versus scale means in drawing the importance-performance grid and difficulties in classifying the attributes in the grid. Therefore, to optimize the effectiveness of this framework, these issues should be addressed.

This study chose the Importance-Performance approach to assess visitor satisfaction with current interpretive services because this approach can demonstrate visitor perceptions of the importance of these services for environmental interpretation and provide a very clear analytical framework, helpful when identifying the strengths and weaknesses of the environmental interpretation system in Cat Tien National Park. To overcome the problems of using Importance-Performance Analysis as encountered in previous research, some solutions have been put forward. Firstly, the author asked visitors to rate the importance and performance of interpretive services with respect to their satisfaction, to assess the importance and performance related statements consistently. Secondly, high evaluations of the importance of interpretive services do not exist because all interpretive services were included in the variable list. Thirdly, the researcher chose the scale from 1 (not at all important) to 5 (extremely important) instead of the scale from 1 (very unimportant) to 5 (very important) because "the concept of importance reflects the level or strength rather than evaluations of goodness or badness" and "the unidirectional scale seems to make sense more than the bidirectional ones" (Oh, 2001, p.623). Fourthly, to minimize the causal relationship between importance and performance ratings, the questions for the importance of services were separated with the questions for their performance by using pre-visit and post-visit questionnaires. Finally, cross hairs were drawn by grand means (actual means) rather than by scale means for a proper dissemination of services in the Importance-Performance grid.

\subsection{Comparative studies using Importance-Performance Analysis}

This section discusses comparative studies using Importance-Performance Analysis with visitor segmentation. The types of segmentations, methodology, analytical approach and statistical tests of each study will be presented in this section.

Many studies have demonstrated the usefulness of using Importance-Performance Analysis with visitor segmentation in measuring visitor satisfaction. Caber, Albayrak and Matzler (2012) suggested that Importance-Performance Analysis should be presented according to market segments rather than an aggregated form. Farnum and Hall (2007) suggested that segmenting customers via visitors' characteristics can create more meaningful importance-performance grids. Hendricks, Schneider and Budruk (2004) explained that differences among clusters should be taken into consideration, because the decisions made for a homogenous group may be unsuitable and the differences among clusters may affect visitor satisfaction, their recommendations and intentions of 
returning. Bruyere et al. (2002) pointed out that the incorporation of segmentation into ImportancePerformance analysis helps to determine the differences between visitor groups for more precise management decisions. Importance-Performance analysis and segmentation can provide managers with information about management strategies which can satisfy many user groups especially within the conditions of limited resources (Bruyere et al., 2002). Also, segmentation can help managers to implement targeted marketing (Hendricks et al., 2004).

Many kinds of visitor segmentations have been incorporated in studies using ImportancePerformance Analysis, including visitor segmentation according to nationality (e.g. Kuo, 2009; Lee and Lee, 2009), residency (e.g. Bruyere et al., 2002), demographic and socio-economic variables (e.g. Wade and Eagles, 2003), benefits sought (e.g. Hendricks et al., 2004; Williams and Dossa, 2003), benefits achieved (e.g. Crilley et al., 2012), loyalty levels (e.g. Farnum and Hall, 2007), support levels of facility development (e.g. Vaske, Kiriakos, Cottrell and Khuong, 2009), etc. These are described in Table 2.6. 
Table 2.6. Summary of comparative studies using IPA and segmentation

\begin{tabular}{|c|c|c|c|}
\hline Comparative studies & Authors & Methodology & Statistic tests \\
\hline According to nationality & Kuo (2009) & $\begin{array}{l}\text { Mix methods: } \\
\text { In depth interviews } \\
\text { Questionnaire survey }\end{array}$ & $\begin{array}{l}\text { - One-way ANOVA } \\
\text { - } t \text { test. }\end{array}$ \\
\hline According to nationality & Lee and Lee (2009) & Quantitative approach & $\begin{array}{l}\text { - Independent } t \text { test } \\
\text { - Chi square test. }\end{array}$ \\
\hline According to nationality & $\begin{array}{l}\text { Rood and } \\
\text { Dziadkowiec } \\
(2010)\end{array}$ & $\begin{array}{l}\text { Mix methods: } \\
\text { Focus group } \\
\text { Pre-visit and post-visit } \\
\text { questionnaires }\end{array}$ & - Reliability test. \\
\hline According to residency & $\begin{array}{l}\text { Bruyere et al. } \\
(2002)\end{array}$ & Quantitative methods & \\
\hline $\begin{array}{l}\text { According to benefits } \\
\text { sought }\end{array}$ & $\begin{array}{l}\text { Hendricks et al. } \\
(2004)\end{array}$ & Quantitative approach & $\begin{array}{l}\text { - Reliability test } \\
\text { - Principal components } \\
\text { analysis } \\
\text { - Cluster analysis } \\
\text { - ANOVA } \\
\text { - MANOVA } \\
\text { - Crosstab } \\
\text { - Chi-square test. }\end{array}$ \\
\hline $\begin{array}{l}\text { According to benefits } \\
\text { sought }\end{array}$ & $\begin{array}{l}\text { Williams } \\
\text { Dossa (2003) }\end{array}$ & Quantitative approach & $\begin{array}{l}\text { - Cluster analysis } \\
\text { - Chi-square test } \\
\text { - Independent t test. }\end{array}$ \\
\hline $\begin{array}{l}\text { According to benefits } \\
\text { achieved }\end{array}$ & Crilley et al. (2012) & Quantitative approach & $\begin{array}{l}\text { - Cluster analysis } \\
\text { - Paired t test } \\
\text { - Pearson's correlations. }\end{array}$ \\
\hline $\begin{array}{l}\text { According to } \\
\text { demographic and socio- } \\
\text { economic characteristics }\end{array}$ & $\begin{array}{l}\text { Wade and Eagles } \\
(2003)\end{array}$ & $\begin{array}{l}\text { Mix methods: } \\
\text { Focus groups } \\
\text { Questionnaire survey }\end{array}$ & - One way ANOVA. \\
\hline $\begin{array}{l}\text { According to level of } \\
\text { loyalty }\end{array}$ & $\begin{array}{l}\text { Farnum and Hall } \\
(2007)\end{array}$ & $\begin{array}{l}\text { Mix methods: } \\
\text { Focus groups } \\
\text { Pre-visit and post-visit } \\
\text { questionnaires }\end{array}$ & - $\mathrm{t}$ test. \\
\hline $\begin{array}{l}\text { According to facility } \\
\text { development support }\end{array}$ & Vaske et al. (2009) & Quantitative approach & $\begin{array}{l}\text { - Reliability analyses } \\
\text { - Cluster analysis } \\
\text { - Confirmatory factor } \\
\text { analyses } \\
\text { - Independent t tests. }\end{array}$ \\
\hline
\end{tabular}

Market segmentation is a common segmentation used in the tourism field. Many studies of different tourism aspects (service attitudes of hotel employees, destination image, destination selection, etc.) added market segmentation into Importance-Performance Analysis and proved the usefulness of this combination for more accurate management and decision - making. 
Kuo (2009) examined customer satisfaction with service attitudes of employees in international hotels in Taiwan across three market segments (Taiwanese, Japanese and American). Regarding the analytical approach, a comparison of demographic features was made according to each nationality. Because there were many attributes, only the top and bottom three importance and performance means of service attitude attributes were compared according to each nationality. Also, a comparison of quadrants was undertaken according to each nationality. This comparison did not provide positions of each attribute in the importance-performance grid.

Lee and Lee (2009) tested how images of Guam were perceived by the two most important markets (Japanese and Korean tourists). A comparison of demographic features according to each segment were presented in this study. This was followed by a comparison of importance and performance means according to each market segment. Importance-performance grids were then presented for each segment. Finally, the authors compared main trip characteristics and post-trip behaviours according to each segment.

Rood and Dziadkowiec (2010) assessed service qualities of restaurants in two different countries (the United States and Poland). Regarding the analytical approach, a comparison of importance and performance means according to each segment was implemented. Next, an importance-performance grid for each segment was presented. This was followed by a comparison of top 10 importance means according to each segment as there were many attributes.

Bruyere et al. (2002) examined the effectiveness of the combination of Importance-Performance Analysis and market segmentation. Year-round residents, seasonal residents, and tourists of Estes Park, Colorado, USA were three segments used in this study. Regarding the analytical approach, an importance-performance grid for the three segments was presented with both traditional and adjusted crosshairs. An importance-performance grid was also analyzed for aggregated sample.

Another common approach for segmentation in the literature of Importance-Performance Analysis is benefit based segmentation. This approach has been used more popularly than traditional approaches such as demographic or geographic based segmentation (Frochot and Morrison, 2000). Hendricks et al. (2004) indicated that the incorporation of benefit-based segmentation into Importance-Performance Analysis helps to provide managers with more information for decisionmaking. According to Frochot and Morrison (2000), benefit-based segmentation was firstly mentioned by Russell Haley in 1968. Benefit-based segmentation was regarded as a superior approach because it can help profile and classify visitors. Benefit-based segmentation can help researchers to differentiate clearly among the individuals and to predict visitor behaviours, while demographic-based segmentation cannot. In travel and tourism, benefit-based segmentation was often based on attributes-based or psychologically-based benefits (visitor motivations) (Frochot and Morrison, 2000). 
Hendricks et al. (2004) assessed the satisfaction of campers at Timothy Lake in Oregon, USA with site conditions and facilities. This type of study with benefit-based segmentation can help managers in improving site design, planning and visitor information. In order to build up benefit-based groups, principal components analysis and cluster analysis were applied. Regarding the analytical approach, a comparison of demographic features was made according to each cluster. Secondly, a comparison of the importance means of attributes according to each cluster was implemented. This was followed by a comparison of the performance means of attributes according to each cluster. Finally, the data was analyzed with an importance-performance grid for the whole sample and then for each different cluster. The research followed the analytical approach from this study.

Likewise, Williams and Dossa (2003) aimed to clarify visitor motivations and dominant characteristics of tourists coming to British Columbia, Canada. Two clusters, Immersionists and Generalists, were identified by motivation-based hierarchical cluster analysis. In terms of analytical approach, a comparison of importance and performance means were presented according to each cluster. Importance-performance grids were also used to illustrate destination selection factors according to each cluster.

Crilley et al. (2012) also used benefit-based segmentation in their study about service quality in Kakadu National Park, Australia. The two clusters identified from cluster analysis were Naturebased and Relaxation. In terms of the analytical approach, a comparison of importance and performance means for the whole sample were presented. Pearson's correlations were conducted between performance items and visitor recommendation and overall satisfaction.

Other segmentations can be based on visitor characteristics, loyalty levels and facility development support. Wade and Eagles (2003) examined visitor satisfaction with tourism attributes in national parks of Tanzania. A variety of segmentation scenarios from demographic and socio-economic variables were analyzed to assess which type of segmentation was useful for the study. The behavioural segments proved to be the most useful segmentation. Regarding the analytical approach, a comparison of the importance and performance means were presented according to each national park. Each segmentation scenario was constructed such as accommodation segments or visited park position segments, etc.

Furthermore, loyalty levels of customers were also regarded as a way of segmentation. Farnum and Hall (2007) evaluated tourist satisfaction with whitewater rafting services in Colorado and Idaho, USA. The two market segments examined were high-loyalty and low-loyalty customers. Regarding the analytical approach, the importance and performance means of service attributes were presented with variations according to confidence interval. Next, a comparison of importance and performance means was presented according to low- and high-loyalty customers. Data was then presented in an importance-performance grid according to low- and high-loyalty customers. 
Vaske et al. (2009) also used segmentation in their study about tourism attributes in Can Gio Mangrove Biosphere Reserve, Vietnam. The two visitor segments were supportive and non supportive groups for facility development. Regarding the analytical approach, a comparison of the importance and performance means across facility development segments was conducted. It was followed by an importance-performance grid for both facility development segments.

To recapitulate, this study will incorporate market-based and motivation-based or benefit-based segmentation into Importance-Performance Analysis to measure visitor satisfaction with services for environmental interpretation in Cat Tien National Park. Xu et al. (2013) pointed out that Eastern and Western groups may have different interpretation preference in national parks. Also, motivation segmentation has been considered as a useful tool in designing services as well as in evaluating service quality (Frochot and Morrison, 2000). Hence, these two kinds of segmentations seem to be the most relevant for the aims of this study. Regarding methodology, these comparative studies elaborated research tools (research attributes) through reviewing relevant literature and consulting with management personnel/experts or focus groups or interviews (Bruyere et al., 2002; Crilley et al., 2012; Farnum and Hall, 2007; Kuo, 2009; Lee and Lee, 2009; Rood and Dziadkowiec, 2010; Wade and Eagles, 2003). These studies also used pre-tests and pilot tests to ensure the accuracy of the questionnaire before distribution (Crilley et al., 2012; Kuo, 2009; Lee and Lee, 2009; Rood and Dziadkowiec, 2010). In this study, secondary research, interviews with staff of Cat Tien National Park and pilot tests with visitors will be used to identify the list of services for environmental interpretation. To identify visitor motivations used for segmentation, related literature will be reviewed in the next section. Pilot tests will also be used in this study to refine the list of motivations. However, Hendricks et al. (2004) emphasized that meaningful differences among segments must be evaluated with statistical analysis. Therefore, a range of data analysis techniques will be conducted in this study including descriptive analysis, paired samples $t$ test, principal component analysis, cluster analysis, crosstabs, Chi-square test, ANOVA, reliability test and Pearson's correlations.

In terms of analytical approach, many aspects were adopted from the literature review including the comparison of demographic and trip-related features according to each segment, the comparison of importance means according to each segment, the comparison of performance means according to each segment, gaps between importance and performance means for the whole sample, an importance-performance grid for each segment with both traditional and adjusted crosshairs, an importance-performance grid for an aggregated sample and Pearson's correlations between performance items and visitor recommendation and overall satisfactions.

\subsection{Tourist motivation}

This section presents common motivations of tourists to visit protected areas in previous research to develop the list of motivations for this study. The list of relevant motivations will also be used later 
for motivation-based segmentation. There have been many studies on tourist motivation (e.g. Curtin, 2010; Beh and Bruyere, 2007; Slabbert and Laurens, 2011; Slabbert and Du Plessis, 2011, etc.). Table 2.7 shows some common tourist motivations in wildlife tourism and tourism in national parks. For this study, most of the motivations in Table 2.7 were selected except for "To know about site elements" and "To seek for personal development" as they seemed to be irrelevant to the study site, Cat Tien National Park.

Table 2.7. Summary of common motivations in wildlife tourism and tourism in national parks

\begin{tabular}{|c|c|}
\hline Motivations & Authors \\
\hline To relax, to be outside & $\begin{array}{l}\text { Beh and Bruyere (2007); Crilley et al. (2012); Curtin (2010); } \\
\text { Driver (1983); Mehmetoglu and Normann (2013); Muso, } \\
\text { Hall and Higham (2004); Pan and Ryan (2007); Slabbert and } \\
\text { Du Plessis (2011); Slabbert and Laurens (2011) }\end{array}$ \\
\hline To learn about nature & $\begin{array}{l}\text { Beh and Bruyere (2007); Crilley et al. (2012); Curtin (2010); } \\
\text { Driver (1983); Pan and Ryan (2007); Slabbert and Du Plessis } \\
\text { (2011); Slabbert and Laurens (2011) }\end{array}$ \\
\hline To talk with others & $\begin{array}{l}\text { Beh and Bruyere (2007); Driver (1983); Muso et al. (2004); } \\
\text { Pan and Ryan (2007); Slabbert and Du Plessis (2011); } \\
\text { Slabbert and Laurens (2011) }\end{array}$ \\
\hline To seek new experience & $\begin{array}{l}\text { Beh and Bruyere (2007); Slabbert and Laurens (2011); } \\
\text { Slabbert and Du Plessis (2011); Mehmetoglu and Normann } \\
\text { (2013); Muso et al. (2004); Pan and Ryan (2007) }\end{array}$ \\
\hline To see spectacular landscapes & $\begin{array}{l}\text { Beh and Bruyere (2007); Driver (1983); Crilley et al. (2012); } \\
\text { Curtin (2010); Muso et al. (2004) }\end{array}$ \\
\hline To know about site elements & $\begin{array}{l}\text { Mehmetoglu and Normann (2013); Slabbert and Du Plessis } \\
\text { (2011); Slabbert and Laurens (2011) }\end{array}$ \\
\hline To escape from the daily life routine & Beh and Bruyere (2007); Crilley et al. (2012) \\
\hline To travel with friends and my family & Crilley et al. (2012) \\
\hline To take photographs & Driver (1983); Muso et al. (2004) \\
\hline To seek for personal development & Beh and Bruyere (2007) \\
\hline To know more about local culture & Beh and Bruyere (2007) \\
\hline To view mega fauna & Beh and Bruyere (2007) \\
\hline To learn about mega fauna & Beh and Bruyere (2007) \\
\hline To learn about the history of national park & Beh and Bruyere (2007) \\
\hline
\end{tabular}

\subsection{Conceptual framework}

After reviewing the literature, it is important to summarize what will be examined in this study. The conceptual framework can depict "the relationships between the concepts or variables that have been selected to represent the phenomena being researched" (Pearce, 2012, p.29). Figure 2.6 shows the relationship between supply side (visitor management of national parks) and demand side (visitor satisfaction). Two types of visitor management strategies in national parks are hard and soft visitor management strategies. Environmental interpretation is one of the soft visitor management strategies 
that aims to educate visitors in national parks. Three major approaches for measuring visitor satisfaction are The Expectancy-Disconfirmation Theory, The Performance-Only Theory and The Importance-Performance Theory. This study focuses on measuring visitor satisfaction with services for environmental interpretation in a national park using Importance-Performance Analysis and visitor segmentation.

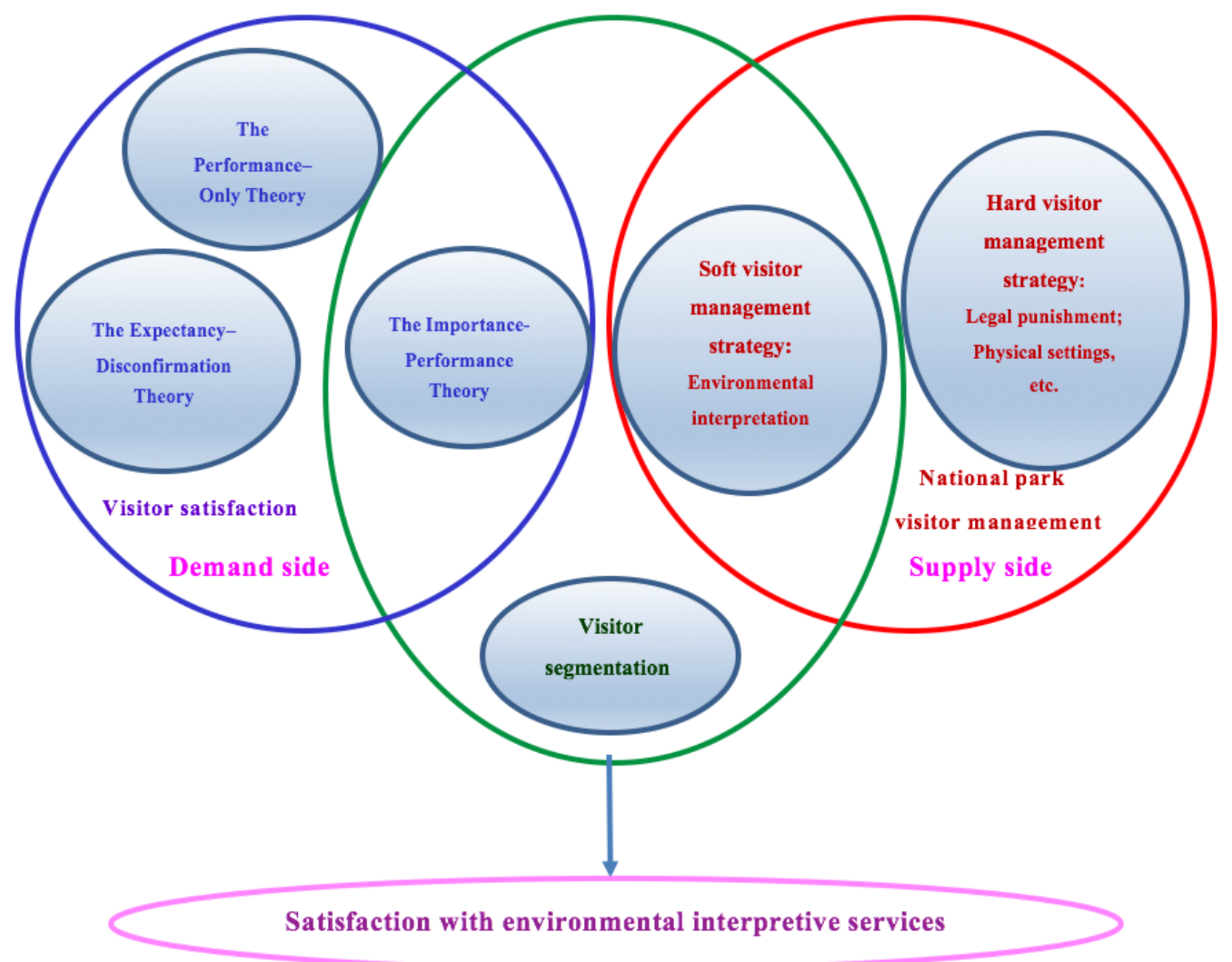

Figure 2.6. Conceptual framework of visitor satisfaction and national park visitor management

\subsection{Conclusion}

In conclusion, this chapter has reviewed the literature related to the research topic, "Visitor satisfaction with services for environmental interpretation in Cat Tien National Park, Vietnam”. This chapter introduced the definition of national parks and issues surrounding visitor management in national parks before discussing the literature on environmental interpretation in general and in national parks, as well as tour guides. The literature on measuring visitor satisfaction, visitor satisfaction in national parks and comparative studies using Importance-Performance Analysis was also reviewed to explore a suitable methodology for this research. After reviewing studies related to 
the research topic and research aims, the research gaps were identified and some major issues were pointed out.

Firstly, there is a lack of research on visitor satisfaction with all services for environmental interpretation in a national park using Importance Performance Analysis. Some studies have been done on visitor satisfaction with services for environmental interpretation in national parks. However, only one study of (Tsang et al., 2011) investigated visitor satisfaction with all services. The importance levels of each service were not mentioned in this study. The literature also indicated that not all services have the same importance to environmental interpretation; hence, this research should be undertaken. Some issues surrounding using Importance-Performance Analysis were pointed out in previous studies, and are considered in this research.

Secondly, the literature review pointed out that market segmentation and motivation-based (benefitbased) segmentation should be incorporated in Importance-Performance Analysis to examine visitor satisfaction. Market-based and motivation-based segmentation are considered as the two most common and useful types of segmentations in the literature.

Thirdly, the literature suggested that visitor satisfaction with tour guides needs to be analyzed indepth. The findings of previous studies showed that interpretation by tour guides was more important than interpretation by other services. There was one study in the literature evaluating visitor satisfaction with roles of tour guides (Randall and Rollins, 2009). However, the importance and performance ratings were collected from two different samples. This study will contribute to the literature on visitor satisfaction with tour guides by collecting importance and performance ratings from the same participants.

This study attempts to fill in the research gaps in the literature by examining visitor satisfaction with services for environmental interpretation in Cat Tien National Park, Vietnam using ImportancePerformance Analysis and visitor segmentation (market- and motivation-based segmentation) (Figure 2.6). Based on the theoretical background provided in this chapter, a research methodology is developed and presented in the next chapter. 


\section{CHAPTER 3}

\section{METHODOLOGY}

\subsection{Introduction}

The previous chapter set out the theoretical background for this study. The gaps from the literature were the foundation to develop the methodology. This chapter will firstly present the research paradigm and methodology chosen to explore visitor satisfaction with services for environmental interpretation in Cat Tien National Park. The research instruments used to collect data will then be described. Next, the steps for primary data collection involving pilot tests and sampling method will be outlined. The analytical framework and enlisted statistical tests will then be presented, followed by the limitations and strengths of this research at the end of this chapter.

\subsection{Research paradigm and selection of methodology}

Post-positivism was chosen as the research paradigm for this study. The post-positivist paradigm guides the beliefs of the researcher to address the research aims, as well as setting up the position of the researcher in this study. Firstly, post-positivists perceive that the epistemological positions of the researcher and the participants are "objective" (Teddlie and Tashakkori, 2009, p.90; Creswell, 2014). However, post-positivists acknowledge the influence of values of the researcher on the research (value-ladenness of inquiry) (Plano Clark and Creswell, 2008; Teddlie and Tashakkori, 2009); therefore, they put efforts into choosing suitable methods in order to control the influence of personal values (Teddlie and Tashakkori, 2009). In this research, the researcher tried not to influence the viewpoints of the interviewees by not giving any hints in the interview questions. Moreover, different methods were combined to make sure the objectiveness of this research.

Secondly, post-positivists believe in the truth, the real reality; still, the real reality can be "imperfect and fallible" (Creswell, 2014, p.7; Teddlie and Tashakkori, 2009). They perceive that "data, evidence and rationale considerations shape knowledge" (Creswell, 2014, p.7). Post-positivists use mainly survey research to evaluate and explain the connections among variables (Teddlie and Tashakkori, 2009). A post-positivist approach allows researchers to use mixed methods (Henderson, 2011) in order to avoid bias (from an interpretivist approach) and improve accuracy (from a positivist approach). Hence, post-positivist paradigm is the most appropriate paradigm for this research. This research used mixed methods and questionnaire survey was a major method to collect data.

As indicated by Balnaves and Caputi (2001), all quantitative research methods tend to include bias and error. Hence, a combination of methods was used to optimize the validity of the research. According to Denscombe (2007), qualitative methods (e.g. interviews or focus groups) can be conducted initially to provide the input for the questionnaire survey (e.g. establishing relevant 
questions and checking their wording) to enhance the validity of the questionnaire survey. While qualitative methods are used to reveal attitudes and points of view of individuals, quantitative methods collect information about attitudes and points of view of the whole sample (Veal, 2006). This research paradigm and the research aims shape the way in which the research methods were chosen. Figure 3.1 describes the stages in which the research was undertaken.

This study used both quantitative and qualitative approaches to achieve a better understanding of environmental interpretation in Cat Tien National Park, Vietnam. Firstly, to identify the current interpretive services in Cat Tien National Park, a secondary research, a site visit and three semistructured interviews with staff members in the Centre of Environmental Education and Services were conducted. The interviews were conducted to confirm the results from secondary research and further to get information about the management of current environmental interpretive services in the park. This is also the common method to identify research tools in previous research on visitor satisfaction (e.g. Bruyere et al., 2002; Crilley et al., 2012; Farnum and Hall, 2007). Semi-structured interviews were chosen because semi-structured interviews can handle more specific issues and the results are more easily understood (Zikmund, Babin, Carr and Griffin, 2013).

Secondly, a questionnaire survey for visitors was conducted in Cat Tien National Park to explore visitor satisfaction with services for environmental interpretation. A questionnaire survey collects information from individuals in the form of questionnaire (Veal, 2006). In this research, pre- and post-visit questionnaires were disseminated to both domestic and international visitors. Importance rating and performance rating for environmental interpretive services were collected in two different times. Pre-visit questionnaires with questions about the importance were distributed to the visitors when they got in the entry point of the national park and post-visit questionnaires with questions about the performance were distributed to the same visitors when they got out the national park. Munro et al. (2008) suggest that pre and post experience testing can give more exact results because comparison can be undertaken and the result of pre-experience testing cannot influence the result of post-experience testing and vice versa. Some studies used pre-visit and post-visit questionnaires to examine the importance and performance (e.g. Farnum and Hall, 2007; Randall and Rollins, 2009; Rood and Dziadkowiec, 2010). However, Randall and Rollins (2009) collected importance and performance ratings from two different samples. The researcher believed that importance and performance ratings for services should be derived from the same participants for more accurate results. Farnum and Hall (2007) and Rood and Dziadkowiec (2010) in their papers collected importance and performance ratings from the same participants. However, the performance ratings were collected after two months and visitors need to recall their experience. This may create incorrect evaluations in some attributes. Rood and Dziadkowiec (2010) collected the importance ratings from testing groups two months before they experienced mystery shopping. This can not be applied in the case of Cat Tien National Park as real visitors were investigated. This study distributed the pre-visit and post-visit questionnaires right after visitors got in and got out the national park. 


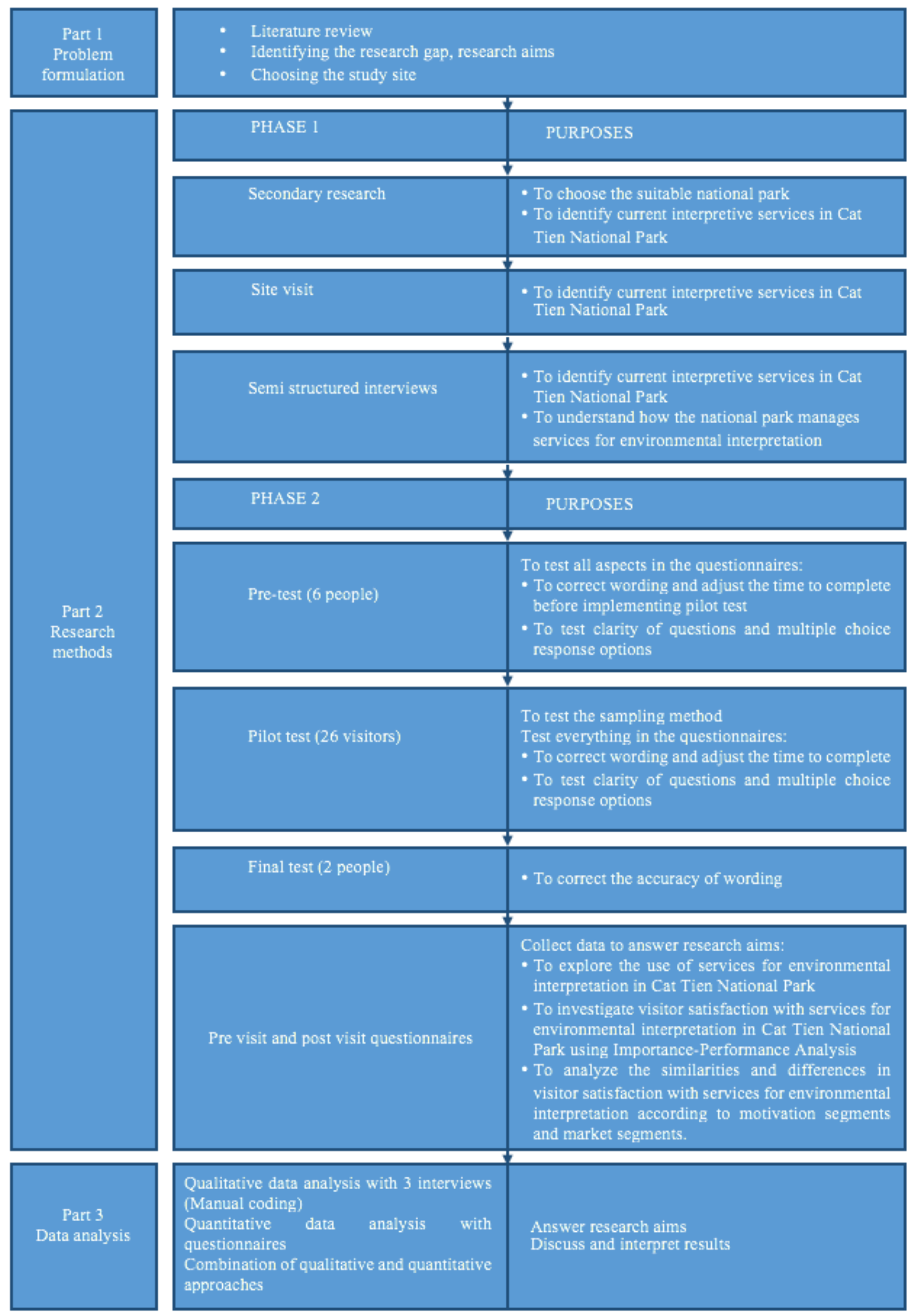

Figure 3.1. Multi-stage research process for examining visitor satisfaction with interpretive services 


\subsection{Selection of the study site}

One of the major decisions to be made was the choice of a study site. This study investigates environmental interpretation in national parks; therefore, a national park should be chosen as the study site. As mentioned in the Introduction chapter, Cat Tien is one of the largest and most important national parks in Vietnam, with high biodiversity. This national park also attracts a large number of visitors every year. The increase in the number of visitors creates an increasing pressure on visitor management of the national park. Hence, research on environmental interpretation is essential in this park. Moreover, services for environmental interpretation in Cat Tien are relatively adequate in comparison with other national parks of Vietnam that focus mainly on interpretation by site interpreters. This is a good condition to conduct a questionnaire survey about visitor satisfaction with services for environmental interpretation.

In addition, because Cat Tien National Park is surrounded by Dong Nai river, the entry and exit of this national park are the same point, which is suitable for collecting pre-visit and post-visit questionnaires from the same people. The coffee shops near the entry of the national park provide shade and a resting place for visitors to answer the questionnaires when they are waiting for the boat. These factors allowed the researcher to approach visitors and receive more questionnaires.

\subsection{Research instruments}

An interview agenda was used as the research instrument for three semi-structured interviews with staff members of Centre of Environmental Education and Services in Cat Tien National Park. The questions in the interview agenda were developed based on the researcher's understanding of the literature and issues related to the research topic (Appendix 2).

Questionnaires were used as the research instruments for the survey with both domestic and international visitors in Cat Tien National Park. The questionnaires for survey were based mainly on the classification of Tsang et al. (2011), which divided interpretation into personal and non personal services. After implementing a site visit, documentary review and interviews with staff members in Centre of Environmental Education and Services of Cat Tien National Park, the list of eight interpretive services was identified and used in the questionnaires. Twelve roles of site interpreters used in the questionnaires were adopted from the study of Randall and Rollins (2009). Importance-Performance approach was chosen to assess visitor satisfaction with interpretive services in Cat Tien National Park as discussed in Chapter 2. This approach has guided the design of the questionnaires. Questions about the importance of services for environmental interpretation and roles of site interpreters were included in the pre-visit questionnaire. The questions about the performance of services for environmental interpretation and roles of site interpreters were included in the post-visit questionnaire (Appendix 4). 
The pre-visit questionnaire consisted of three parts. The first part included the questions about trip characteristics (mode of travel, length of stay, accommodation and motivations to visit). These characteristics help the researcher to understand more about the sample investigated. The importance levels of services towards visitor satisfaction with environmental interpretation were then asked in the second part. Also, importance levels of roles of site interpreters (tour guides) towards visitor satisfaction were also included in this part. This part is important in the pre-visit questionnaire because the importance ratings were used to assess visitor satisfaction. The third part included questions about personal information of visitors (nationality, gender, age, times visited national parks in the past, etc.). Categories for these questions were derived from national surveys, tourism statistics of Vietnam and from the study of Stein et al. (2003). This part provided an overview of visitor demographic characteristics.

The post-visit questionnaire comprised four parts. Firstly, visitors were asked about their use of services for interpretation in this national park. The reasons for not using any service were then asked. This part helps to identify services that were not used frequently by visitors. Some specific reasons for not using any service were also pointed out in this part. The second part of this questionnaire included questions about performance levels of services towards visitor satisfaction with environmental interpretation. Visitors were also asked about the performance of site interpreters in Cat Tien National Park towards their satisfaction. This part is the most important part of the post-visit questionnaire because the performance ratings were used to evaluate visitor satisfaction. The third part of this questionnaire included questions about the messages that visitors received from each service (the messages were adopted from Tsang et al., 2011 and Komatsu and Liu, 2007). This part helps to reveal which environmental messages from the national park were delivered to visitors through interpretive services. The final part included questions about overall visitor satisfactions and future behaviours. This part was included because it provides information about the general satisfaction level of visitors with interpretive services and with their trip to Cat Tien.

\subsection{Human ethics approval}

Victoria University of Wellington requires that research involving human subjects has to pass the human ethics approval process. This policy aims to protect the rights, privacy and safety of individuals, groups or communities as well as the safety of the researcher and the reputation of the University (Victoria University of Wellington, 2016, Human Ethics Policy).

This research received Human Ethics approval on June $22^{\text {nd }}, 2016$, before data collection began. Human ethics approval was obtained on the 22th of June 2016. This research also received the permission from the manager of Cat Tien National Park on July $11^{\text {th }}, 2016$ to conduct interviews 
with staff of Centre of Environmental Education and Services and disseminate the questionnaires at the entry point of the national park.

\subsection{Primary data collection}

\subsubsection{Sampling method}

Self-administered questionnaires were disseminated to both international and domestic visitors at the gate of Cat Tien National Park using a type of non-probability sampling known as convenience sampling. Convenience sampling was described by Zikmund et al. (2013) as the process of recruiting "those people or units that are most conveniently available" (p.392). Convenience sampling was chosen in this study because the questionnaires were distributed in the low season of Cat Tien National Park when there were not many visitors. This sampling method helped the researcher to distribute a large number of questionnaires quickly and economically. Pre-visit questionnaires were distributed from $10 \mathrm{am}$ to $1 \mathrm{pm}$ and the post-visit questionnaires were distributed from $3 \mathrm{pm}$ to $5 \mathrm{pm}$ because these time frames are the peak times visitors enter and exit the national park.

To make sure that the pre-visit questionnaires and post-visit questionnaires were distributed to the same group of visitors, playing cards were used to track respondents. The playing card was a suitable tool for tracking because it is small and waterproof so would not be affected by rain during rainy season. Moreover, playing cards are cheap and available in the local area. After visitors came to the entry and sat down at a coffee shop to wait for the boat, the researcher approached them and gave them the information sheet to invite them to participate in the survey (Appendix 3). When the visitors agreed to participate, the researcher gave them the pre-visit questionnaire as well as the card with number. The number was also written down on the questionnaire. After the visitors completed the pre-visit questionnaire, the researcher asked visitors to keep the card with number and also to take a picture of the questionnaire if they can. When visitors came back the entry after their visits, the researcher asked them about their number and gave them the post-visit questionnaires. Only questionnaires collected as a complete set (pre-visit and post-visit) were used for analysis.

\subsubsection{Pilot test}

Three tests were conducted to test all aspects of the questionnaires (e.g. the wording, the clarity of questions and multiple choice response options, approximate time to complete, etc.).

The pre-test was undertaken with six people who are friends and colleagues of the researcher. The researcher sent the questionnaires to them via email on July $15^{\text {th }}, 2016$ and received their feedbacks within three days. The participants were asked whether the questionnaires were easy to complete and easy to understand and how long it took to complete them. The approximate time to complete was then included in the information sheet. Also, the sequence of questions was arranged in a more appropriate order. 
After receiving Human Ethics approval from Victoria University of Wellington and permission from Cat Tien National Park, the questionnaires were tested on visitors at the entry of Cat Tien National Park on the $2^{\text {nd }}$ and $3^{\text {rd }}$ of August, 2016. This pilot test was used to test the sampling method. A total of 26 pre-visit questionnaires (17 domestic; 9 international visitors) and 18 post-visit questionnaires (11 domestic; 7 international visitors) were collected. Some changes were made from the contribution of this pilot test. Firstly, domestic visitors made some comments about the wording of the questionnaires. Secondly, one interpretive service (meeting room) was removed from the list and another interpretive service (videos at rescue centre) was added.

After making changes to the questionnaires, two friends of the researcher who have an academic background were asked to check again the accuracy of the wording (in both English and Vietnamese) on the $4^{\text {th }}$ and the $5^{\text {th }}$ of August, 2016. During this final test, the questionnaires worked well and were understood. The refined questionnaires were then printed and distributed to visitors from the $6^{\text {th }}$ of August to the $2^{\text {nd }}$ of September 2016.

\subsubsection{Main survey}

The questionnaires were distributed over four weeks from the $6^{\text {th }}$ of August to the $2^{\text {nd }}$ of September, 2016. Three hundred sixteen visitors agreed to participate in the survey, while 335 visitors did not want to participate. The first round response rate was $48.54 \%$. From the 316 visitors who agreed, 304 usable pre-visit questionnaires were collected. However, only 237 usable post-visit questionnaires were collected, resulting in the second round response rate of 77.96\% (Appendix 5).

\subsection{Secondary data collection}

Secondary data was synthesized from journals, books, documents and statistic figures of local governments, national parks of Vietnam, and the internet. Firstly, information from journals, books and the internet helped the researcher to choose a suitable national park. Journals and books provided information about previous research in national parks of Vietnam, tourism activities, maps and distinctive characteristics of national parks in Vietnam. Some websites such as TripAdvisor and LonelyPlanet helped the researcher to identify current interpretive services in Cat Tien National Park, and provided information about visitor satisfaction with services for environmental interpretation in Cat Tien National Park. Statistic figures from the Vietnam National Administration of Tourism and Cat Tien National Park were also searched, providing a useful comparison for the respondents' profiles. As mentioned by Finn et al. (2000) and Zikmund et al. (2013), secondary data can be used to make comparison with information from other methods. 


\subsection{Data preparation}

\subsubsection{Data coding and entry}

Firstly, a coding manual with Name and Values was developed based on pre- and post-visit questionnaires. The coding manual was used to assist the development of the database and data entry process. All closed questions in the questionnaires were pre-coded. The code for each question was decided based on the order of the question in the questionnaires. Data from the questionnaires was then entered into the computer by the researcher. For open-ended questions, every word written by the respondents was noted. Common answers were then identified and grouped together.

\subsubsection{Data screening}

After the data from the set of 237 questionnaires (pre-visit and post-visit) was entered, it was checked again to prepare for the next stage of data analysis. Data from the computer was compared again with the original questionnaire to minimize errors during the entry stage. Using the descriptive function of SPSS helped the researcher to correct any values entered incorrectly.

Data analysis is a critical part in the procedure that explains how research questions can be answered or the research aims can be achieved (Blaikie, 2003). The testing of theoretical hypotheses is sometimes an intermediary step but normally, the research questions or research aims are answered or achieved directly via a specific method of analysis (Blaikie, 2003). All of the statistical tests in this study were significant at 0.05 level. During analysis for clusters, the number of respondents were 234 instead of 237 due to some missing values of motivation variables.

\subsection{Data analysis}

\subsubsection{Strategy for analysis}

The analysis followed the four research aims of this study which were presented in Chapter 1 . The research aims were divided into smaller research objectives. Each objective contains several variables (expected outcomes) which were used to collect data as presented in Figure 3.2. The analytical approach and statistical tests for data analysis were adopted from the literature on comparative studies using Importance-Performance Analysis discussed in Chapter 2.

For the first research aim, thematic analysis was used to analyse qualitative data from three semistructured interviews. For the second aim, frequency and percentage were used to describe visitors' profiles and further to quantify the most commonly used services, common reasons for not using a specific service, etc.

To achieve the third aim, mean and standard deviation were used to describe visitor ratings for the importance and performance of services for environmental interpretation and roles of site interpreters. Next, a paired samples t-test was used to test the significant difference between the 
importance and performance ratings of eight services as well as twelve roles of site interpreters. An importance-performance grid was then performed to illustrate the relationship between importance and performance means. Finally, Pearson's correlation was applied to examine whether the performances of these services influence overall visitor satisfactions and recommendation intention or not. This test was adopted from the study of Crilley et al. (2012).

To achieve the fourth aim, visitor segmentation according to motivations was undertaken. The steps for visitor segmentation were learnt from the study of Hendricks et al. (2004) and the literature review of Frochot and Morrison (2000). Factor analysis was firstly adopted to find out the main factors of visitor motivations which served as dimensions for cluster analysis. A reliability test was used to test the internal consistence of the variables in each factor. K-means was run in R to identify the optimal clusters (recommended by Frochot and Morrison, 2000). Cluster analysis was then applied with the dimensions from factor analysis and optimal number of clusters from $\mathrm{R}$. The importance and performance of services across clusters were described by mean and standard deviation. Chi-square and crosstabs were used to examine the relationship among variables (e.g. nationality and motivation segments) (recommended by Frochot and Morrison, 2000). Lastly, ANOVA was performed to test the significant difference among clusters in their importance and performance ratings (recommended by Frochot and Morrison, 2000). To find out the similarities and differences between market segments, the importance and performance of 8 services and 12 roles were also analysed by means and standard deviations. Independent t-test was performed to test the significant difference between market segments in their importance and performance ratings (adopted from Farnum and Hall, 2007; Williams and Dossa, 2003). The analytical framework presented in Figure 3.2 indicates the order that quantitative data was analysed. 

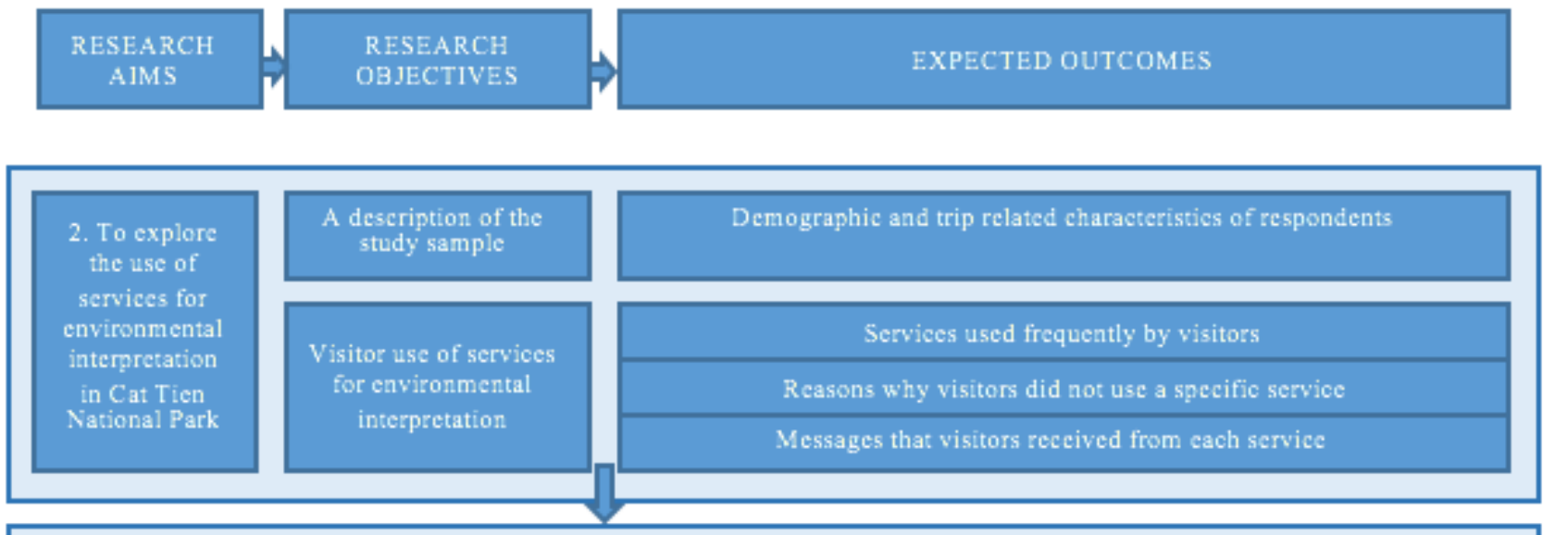

\begin{tabular}{|c|c|c|}
\hline \multirow{9}{*}{$\begin{array}{c}\text { 3. To } \\
\text { investigate } \\
\text { visitor } \\
\text { satisfaction } \\
\text { with services } \\
\text { for } \\
\text { interpretation } \\
\text { in Cat Tien } \\
\text { National Park }\end{array}$} & \multirow{4}{*}{$\begin{array}{l}\text { Visitor satisfaction } \\
\text { with } 8 \text { services for } \\
\text { environmental } \\
\text { interpretation }\end{array}$} & The importance of services for environmental interpretation \\
\hline & & The performance of services for environmental interpretation \\
\hline & & Paired t test for the importance and performance means of services \\
\hline & & The importance and performance grid of services \\
\hline & \multirow{4}{*}{$\begin{array}{l}\text { Visitor satisfaction } \\
\text { with } 12 \text { roles of site } \\
\text { interpreters }\end{array}$} & The importance of roles of site interpecters \\
\hline & & The performance of roles of site interpreters \\
\hline & & Paired t test for the importance and performance means of roles \\
\hline & & The importance and performance grid of roles \\
\hline & $\begin{array}{l}\text { Overall satisfactions } \\
\text { and recommendation }\end{array}$ & $\begin{array}{l}\text { Overall satisfactions and recommendation intention } \\
\text { Correlations between performance ratings and post visit behaviours }\end{array}$ \\
\hline \multirow{9}{*}{$\begin{array}{l}\text { 4. To analyze } \\
\text { the similarities } \\
\text { and differences } \\
\text { in visitor } \\
\text { satisfaction } \\
\text { with services } \\
\text { for } \\
\text { environmental } \\
\text { interpretation } \\
\text { according to } \\
\text { market }\end{array}$} & \multirow{2}{*}{$\begin{array}{l}\text { Visitor segmentation } \\
\text { according to } \\
\text { motivation }\end{array}$} & Cluster identification \\
\hline & & Clusters' profile \\
\hline & \multirow{3}{*}{$\begin{array}{l}\text { Visitor satisfaction } \\
\text { with } 8 \text { services } \\
\text { according to } \\
\text { motivation segments }\end{array}$} & The importance of services for environmental interpretation by clusters \\
\hline & & The performance of services for environmental interpretation by clusters \\
\hline & & The importance and performanee grid of services for each cluster \\
\hline & \multirow{3}{*}{$\begin{array}{l}\text { Visitor satisfaction } \\
\text { with } 12 \text { roles } \\
\text { according to } \\
\text { motivation segments }\end{array}$} & The importance of roles of site interpreters by clusters \\
\hline & & The performance of roles of site interpreters by clusters \\
\hline & & The importanee and performance grid of roles for each cluster \\
\hline & \multirow{4}{*}{$\begin{array}{l}\text { Visitor satisfaction } \\
\text { with } 8 \text { services } \\
\text { according to market } \\
\text { segments }\end{array}$} & The importance of services for environmental internnetation by nationality \\
\hline \multirow{6}{*}{$\begin{array}{l}\text { segments and } \\
\text { motivation } \\
\text { segments }\end{array}$} & & \\
\hline & & The performance of services for environmental interpretation by nationality \\
\hline & & The importance and performanee grid of services for each nationality \\
\hline & \multirow{3}{*}{$\begin{array}{l}\text { Visitor satisfaction } \\
\text { with } 12 \text { roles } \\
\text { according to market } \\
\text { segments }\end{array}$} & The importance of roles of site interpreters by nationality \\
\hline & & The performanee of roles of site interpreters by nationality \\
\hline & & The importanee and performance grid of roles for each nationality \\
\hline
\end{tabular}

Figure 3.2. Analytical framework for data analysis and presentation 


\subsubsection{Thematic analysis for qualitative data}

Saldaña (2013) defines a theme as "an extended phrase or sentence that identifies what a unit of data is about and/or what it means" (p.175), and states that a theme results from coding, classifications and analytic process. At its manifest level (an integrated theme), a theme can summarise and describe a group of the same ideas expressed by participants during interviews. At its latent level, themes express phenomenon (nature or meaning of everyday experiences).

\subsubsection{Types of analysis used for quantitative data}

\subsubsection{Descriptive analysis}

Data was first summarized by the descriptive functions of SPSS. According to Blaikie (2003), descriptive analysis can be univariate or bivariate. Univariate descriptive analysis depicts the features of some social phenomenon by counting the frequency and calculating measures of central tendency (mean, mode and median). Mean is calculated by dividing the total values of the data set by the number of values. Mode is the most frequent value appeared in the data set. Median is the value in the middle of the data set (Finn, Elliot-White and Walton, 2000). Moreover, the use of percentages helps in comparing two or more variables (Finn et al., 2000). The standard deviation was also used in this study to assess the variance of mean scores. If the standard deviation is small, the data is more focused around the mean and vice versa (Field, 2009; Finn et al., 2000).

Bivariate descriptive analysis includes setting up similarities and differences between the features of categories of people or objects and illustrating patterns or relations between these features (Blaikie, 2003). Specific bivariate descriptive analyses in this study were comparing means to explore the differences between the importance and performance means of services for environmental interpretation and describing the strength of the relationship between performance means and overall satisfaction scores.

\subsubsection{Reliability test}

Cronbach's alpha is the most popular test for scale reliability (Blaikie, 2003; Hair, Black, Babin, and Anderson, 2010). The alpha coefficient falls between 0 and 1 . The higher the coefficient is, the higher the consistence among the items (Blaikie, 2003). 0.7 is regarded as the acceptable value for Cronbach's alpha coefficient (Hair et al., 2010).

\subsubsection{Non parametric test}

Non-parametric tests are used when the distribution on a variable in a population is not a normal distribution. Non-parametric tests are also used in some instances when comparing samples from different populations where the variances (the square of standard deviations) of the variables are not the same in these populations (Blaikie, 2003). Kruskal Wallis test is a non parametric test. 


\subsubsection{ANOVA and independent t-test}

ANOVA (Analysis of Variance) is a parametric test that examines whether there are significant differences among samples or groups. To conduct this test, the dependent variables need to be in interval or ratio level and independent variables need to be categorical. If the p-value is less than 0.05, we can conclude that there is a significant difference among the groups (Finn et al., 2000). The Levene's test of homogeneity is used to examine whether the samples or groups had equal variances (or equal standard deviations) or not. If the p-value is less than 0.05 , the samples or groups do not have equal variances (or equal standard deviations). Normality of the data was sometimes in doubt, in these instances ANOVA was supplemented by a rank-based method, the Kruskal-Wallis test (Field, 2009). After an ANOVA, post-hoc tests need to be conducted to identify which groups differ. Tukey is often used when the sample sizes are equal and group variances are similar. Games-Howell is used to supplement the results from Tukey procedure when the assumption of group variances is in doubt (Field, 2009).

Likewise, an independent t-test is used to examine whether there is a significant difference between two means from two different samples or groups. If the p-value is less than 0.05 , we can conclude that there is a significant difference between 2 samples or groups (Field, 2009). To minimize type I error (rejecting null hypotheses when they are true), the significant values need to be less than 0.05 divided by the number of tests (Field, 2009). This is referred as the Bonferroni correction (an adjustment for multiple comparisons) (Perrett and Mundfrom, 2010).

\subsubsection{Cross-tabulation and chi-square test}

Cross-tabulation shows a combination of the frequency distribution of observations on two or more variables. A chi-square test is used to examine the statistical significance of relationships between two variables. The independent and dependent variables for this test need to be categorical (nominal or ordinal). Moreover, the expected count need to be greater than five (Veal, 2006).

\subsubsection{Paired samples t-test}

A paired samples t-test is a type of dependent t-test. It compares two means which derive from the same participants. If the p-value is less than 0.05 , we can conclude that there is a significant difference between two means (Field, 2009). For example, the test may look at the difference between two time points, for example, and if the p-value is less than 0.05 , we conclude that there is a difference.

\subsubsection{Pearson's correlation}

Pearson's correlation is often used to measure the connection between two variables with interval and ratio level (Blaikie, 2003; Veal, 2006; Zikmund et al., 2013). It is used in bivariate descriptive analysis (Blaikie, 2003). The correlation between two variables can be positive or negative. The correlation coefficient falls between -1.0 and +1.0 . The correlation coefficient $(r)$ is zero if there is 
no relationship between two variables (Field, 2009; Veal, 2006; Zikmund et al., 2013). The coefficients of \pm 0.1 are small, the coefficients of \pm 0.3 are medium and the coefficients of \pm 0.5 are large (Field, 2009). Pearson's correlation was supplemented by Spearman's correlation when the data can not meet parametric assumptions (Field, 2009).

\subsubsection{Factor analysis}

Factor analysis helps researchers to explore the main connections in a large number of variables and to reduce these variables into a smaller set of factors that can best explain these variables (Blaikie, 2003; Hair et al., 2010; Manly, 1994).

Before conducting factor analysis, it is critical to assess the suitability of the data set for factor analysis. The sample size of this study (237) is more than 18 times as many as the number of variables (13). This exceeds the minimum requirement that the number of observations should be at least five times as many as the number of variables (Hair et al., 2010).

To test the inter-correlations among variables, the correlation matrix was examined and run on 13 motivation variables with 237 responses. The correlation matrix showed that there were linear dependencies among the motivation variables. Some variables were measuring the same thing including motivation 1 and $9(\mathrm{r}=0.985)$; motivation 3 and $5(\mathrm{r}=0.990)$ and motivation 4 and 6 $(\mathrm{r}=1.000)$. Blaikie (2003) stated that items with very high correlation coefficients $(0.9$ or above) with any other item should be excluded. Hence, one variable from each pair (motivation 1: To enjoy scenic beauty; motivation 3: To view mammals, and motivation 4: To learn mammals) was removed before conducting factor analysis again. Motivation 1 was removed because motivation 9 (To relax and rest) is a common motivation of visitors in protected areas and has a broader meaning than motivation 1 (To enjoy scenic beauty). Motivation 3 and 4 were removed because most of the visitors expressed that they visited the national park for viewing reptiles (motivation 5) and learning reptiles (motivation 6).

After conducting factor analysis again with remaining 10 variables, inspection of the correlation matrix showed that all variables had at least one correlation coefficient greater than 0.3 . The KaiserMeyer-Olkin measure (KMO) was used to test sampling adequacy of the items (Blaikie, 2003). The overall Kaiser-Meyer-Olkin values equal to 0.6 or above are suggested as a requirement for sampling adequacy (Hair et al., 2010). The KMO value for this sample size was 0.757 , which is considered high according to Blaikie (2003). Therefore, the sample size was adequate for factor analysis. The anti-image correlation matrix includes the KMO measures for individual variables. All KMO measures were greater than or equal to 0.680 , greater than 0.5 , the acceptable value according to Hair et al. (2010). This also confirmed the adequacy of sampling. The Bartlett's Test of Sphericity was significant at $p$-value $=0.000$. These tests showed that factor analysis could be applied. 
Table 3.1. KMO and Bartlett's Test

\begin{tabular}{|c|c|c|}
\hline $\begin{array}{l}\text { Kaiser-Meyer-Ol } \\
\text { Adequacy. } \\
\text { Bartlett's Test of } \\
\text { Sphericity }\end{array}$ & $\begin{array}{l}\text { asure of Sampling } \\
\text { Approx. Chi-Square } \\
\text { df } \\
\text { Sig. }\end{array}$ & $\begin{array}{r}.757 \\
1243.798 \\
45 \\
.000\end{array}$ \\
\hline
\end{tabular}

The Principal Component Analysis with Varimax orthogonal rotation was employed as the factor extraction method. The orthogonal rotation helps to make sure that the factors independent when they are rotated (Blaikie, 2003). Varimax rotation is regarded as a successful analytic approach that provides a clearer differentiation of the factors (Hair et al., 2010).

\subsubsection{Cluster analysis}

Cluster analysis is used to categorize a set of individuals or objects into a smaller number of groups or clusters. This classification makes sure there is homogeneity within clusters and the heterogeneity between clusters (Blaikie, 2003; Hair et al., 2010; Manly, 1994).

Although cluster analysis and factor analysis are similar in their objective of evaluating the data structure, cluster analysis is different from factor analysis. Cluster analysis helps researchers to group individuals or objects according to some criterion while factor analysis is used to gather variables into factors (Blaikie, 2003; Hair et al., 2010; Veal, 2006). Moreover, cluster analysis groups individuals or objects based on distance (proximity) while factor analysis groups variables based on tendencies of variation (correlation) in the data (Hair et al., 2010).

Cluster analysis includes at least three steps: identifying how many groups or clusters exist in the sample, distributing individuals or objects into groups or clusters (actual clustering process) and making cluster profiles (Hair et al., 2010).

Two common clustering procedures are hierarchical and non hierarchical methods (Hair et al., 2010). The hierarchical method has been used widely not only because it was the first clustering method developed, but also because it helps researchers to investigate alternative clustering solutions. However, using the hierarchical method can create incorrect clusters because early combinations existing in the analysis can result in false results (Hair et al., 2010).

Meanwhile, the non-hierarchical method has been increasingly achieved the acceptances and applications. A commonly used non-hierarchical method is K-means. The results from this method are less sensitive to outliers in the data. Moreover, it can be applied for a large sample size (Hair et al., 2010). However, the number of clusters need to be known in advance. This study used K-means clustering as the method for classifying clusters. K-means was firstly run in $\mathrm{R}$ and the elbow approach applied in order to identify the number of clusters. 


\subsubsection{R software}

According to Frochot and Morrison (2000), the main problem of cluster analysis is to find out the optimal number of clusters. Frochot and Morrison (2000) indicated that the elbow approach is one of the available techniques to identify the number of clusters. $\mathrm{R}$ is a statistical computing system used to analyse data and produce graphics. The K-means function in $\mathrm{R}$ helps to identify a distribution of the observations into a specific number of clusters by reducing the within cluster variation (Hothorn and Everitt, 2009). The total within-group sum of squares from the K-means output specifying 1 to $\mathrm{X}$ clusters are drawn in a scatter plot. The total sum of squares is "the sum of the squared deviations of all the observations from their mean" (Everitt, 2002, p.375). The optimal number clusters can be identified thanks to the 'elbow' which appears in the curve (Hothorn and Everitt, 2009).

\subsection{Research limitations}

Although the research was designed carefully, there were still some limitations. The sample may not be representative due to the use of convenience sampling. Further research should adopt other sampling methods (e.g. probability sampling) in other conditions (e.g. dry season) to confirm the results from this study. Frochot and Morrison (2000) also suggested that studies with benefit segmentation should be applied in different seasons in every two or three years because benefit segments may not be the same over time due to internal and external factors. Also, the sample size was not large because of several reasons. Firstly, the questionnaires were distributed in the low season of Cat Tien National Park. Secondly, many visitors did not want to participate because there were two questionnaires to be completed. Thirdly, the researcher did not receive 67 post-visit questionnaires. Reasons for this include: some visitors followed the tours after their visits; some returned in the morning because of a lack of interesting activities when the researcher was not there yet or was distributing pre-visit questionnaires; and some of them lost the playing card. Future research should collect more questionnaires to give a stronger conclusion. In addition, the researcher should give each visitor a separate order number rather than repeat the order after two days. This caused some confusions when matching the questionnaires. Moreover, this study was relied mainly on quantitative methods that aimed to clarify the importance and performance levels of services for environmental interpretation from a significant response. This approach has limitation in that it lacks in-depth information. Further research should conduct qualitative interviews with visitors in Cat Tien National Park to have a deeper understanding of their needs and get more feedback and suggestions from them.

Apart from these limitations, this study developed a suitable methodology to examine visitor satisfaction with services for environmental interpretation in Cat Tien National Park. Firstly, the combination of qualitative and quantitative methods enhanced the accuracy and validity of the 
research. The qualitative methods provided necessary information about current services for environmental interpretation in Cat Tien National Park to develop the questionnaires for the survey. The use of a quantitative approach helped the researcher to quantify visitor satisfaction with services for environmental interpretation. Secondly, the importance-performance approach helped the researcher to capture visitor perception of the importance of services for environmental interpretation while other approaches cannot. Thirdly, using pre-and post-visit questionnaires to collect the data made advantages for comparing importance and performance ratings and gave more accurate results because the importance ratings cannot influence the performance ratings and vice versa. Fourthly, convenience sampling is a suitable sampling method because there were not enough visitors during the time of data collection to implement probability sampling. Fifthly, the sample size $(n=237)$ is adequate for deep analyses such as factor analysis and cluster analysis. Finally, the appropriate statistical tests supported the researcher to gain an in-depth understanding about visitor satisfaction with services for environmental interpretation in Cat Tien National Park. The strengths of this research methodology help to create more reliable and accurate findings.

\subsection{Conclusion}

This chapter has presented the methodology applied for this research. A mixed-methods were chosen after reviewing related literature and considering the research aims. Cat Tien National Park appeared to be a suitable place to conduct a quantitative research about services for environmental interpretation, and was practical for distributing pre- and post-visit questionnaires. The questionnaire survey method was suitable because it helped the researcher to obtain a large sample of visitors. A large sample can provide more exact results about the importance and performance of services for environmental interpretation for better investments in the future. The questionnaire design contained all of the variables needed to achieve the research aims such as visitor use of services for environmental interpretation, the importance of services for environmental interpretation, the importance of roles of site interpreters, the performance of services for environmental interpretation, the performance of roles of site interpreters, visitor motivations, personal and trip characteristics, etc. A detailed analytical framework was developed based on the research aims. In conclusion, despite some limitations, this study developed an appropriate methodology to conduct an in-depth investigation of visitor satisfaction with services for environmental interpretation in Cat Tien National Park.

The next three chapters will present the findings of this study. Chapter 4 will give some information about services for environmental interpretation in Cat Tien National Park and their management. It also presents visitor use of services for environmental interpretation in Cat Tien National Park. Chapter 5 will show visitor satisfaction with services for environmental interpretation. Visitor satisfaction with services for environmental interpretation according to motivation segments and market segments will then be presented in Chapter 6 . 


\section{CHAPTER 4}

\section{MANAGEMENT OF ENVIRONMENTAL INTERPRETATION}

AND VISITOR USE OF INTERPRETIVE SERVICES

\subsection{Introduction}

This chapter describes the first part of the research findings, and attempts to answer the first two research aims. Firstly, this chapter presents information about the management of services for environmental interpretation, which resulted from semi-structured interviews with three staff members of Centre of Environmental Education and Services. Secondly, a respondents' profile will be provided to give readers an overview of the research participants (who they are, where they are from and how they organise their trip). Finally, visitor use of services for environmental interpretation, reasons for not using any service and messages received from each service will be presented.

\subsection{Management of services for environmental interpretation in Cat Tien National Park}

\subsubsection{Interviewees' profile}

The three interviewees were the staff members of the Centre of Environmental Education and Services in Cat Tien National Park, who are responsible for environmental education and interpretation. As can be seen in Table 4.1, one interviewee is a manager and two are assistant managers. In terms of working experience, interviewees 1 and 3 have been working in Cat Tien National Park for a long time (17 and 21 years). Interviewee 2 had much less working experience in Cat Tien National Park and in his position (3 years). Regarding their previous jobs, interviewee 1 worked for community development in the national park. Interviewee 3 has worked as a chief accountant in projects of the national park, and interviewee 2 was a staff member of a local authority before working in the national park (Table 4.1). 
Table 4.1. Profile of the interviewees

\begin{tabular}{|l|c|}
\hline \multicolumn{2}{|c|}{ Interviewees' } \\
\hline Position & Nuformation \\
\hline Manager & 2 \\
\hline Assistant manager & Number of years \\
\hline Years in this position & 15 \\
\hline Interviewee 1 & 3 \\
\hline Interviewee 2 & 8 \\
\hline Interviewee 3 & Number of years \\
\hline Years working in Cat Tien & 17 \\
National Park & 3 \\
\hline Interviewee 1 & 21 \\
\hline Interviewee 2 & Positions \\
\hline Interviewee 3 & Community development staff member \\
\hline Previous job & Staff member of local authority \\
\hline Interviewee 1 & Chief accountant of projects \\
\hline Interviewee 2 &
\end{tabular}

\subsubsection{Responsibilities of the interviewees}

The three staff members of the Centre of Environmental Education and Services have different duties. The main responsibilities of interviewee 1 are operating ecotourism activities and implementing environmental educational activities for visitors and the local community. Interviewee 2 is responsible for the housekeeping group (guesthouses within the national park), technical group (e.g. boatmen, drivers, repairers for electricity and water related issues, etc.) and restaurants. Interviewee 3 manages ecotourism activities and environmental education activities, and makes decisions in dealing with environmental violations. Regarding interpretation issues, interviewees 1 and 3 are responsible for solving interpretation issues in the national park.

\subsubsection{Knowledge and understanding of the interviewees about interpretation}

The results from the interviews show that all of the interviewees understood interpretation to mean interpretation by a site interpreter. According to the interviewees, interpretation is an explanation by a site interpreter of a certain tourist site. Site interpreters are the people who had deep knowledge about natural resources, biodiversity and ecosystems about the site. Interviewee 1 (personal communication, 2016) defined interpretation as:

"a communication way to convey information to visitors according to different purposes. Methods, time and location for interpretation will be adjusted according to different kinds of audiences."

Regarding the importance of interpretation to visitor experience, the three interviewees agreed that interpretation is of high importance in conveying information about the site. According to 
interviewee 1, interpretation helps to increase visitor knowledge but more importantly, enhances visitor experience through interesting stories about the site. Interviewee 3 stated that if the interpretation was done well, visitors would explore more in the national park.

\subsubsection{Services for environmental interpretation in Cat Tien National Park}

The results from the interviews indicate that services for environmental interpretation in Cat Tien National Park include interpretive signs, directional signs, brochures, site interpreters, a meeting room and a museum. These services are used for guiding, ensuring safety and providing information about the site for visitors. Moreover, these services are also a channel for delivering environmental messages to visitors (Interviewee 1 and 3). To the national park, these services had the same importance because each service is relevant to a specific kind of visitors (Interviewee 1).

The three interviewees emphasized the importance and the effectiveness of site interpreters towards environmental interpretation. According to them, there were four site interpreters in Cat Tien National Park (3 males, 1 female). Still, only 2 male site interpreters can communicate with visitors in English. According to interviewee 3, the museum was established by funding from Vietnamese Central Government for Conservation education. Staff members in the Department of Science and International Relations provide information in the museum. Directional signs and interpretive signs in the national park were set up by Danish International Development Agency (DANIDA), WWF Denmark from 2009-2012 (Interviewee 1 and 3). Directional and interpretive signs in rescue centres were funded by international organisations (e.g. MonkeyWorld). However, interviewee 2 (personal communication, 2016) revealed that signs are not always effective for all visitors. He said:

"Interpretive signs and directional signs are only suitable for international visitors. Domestic visitors are not interested in reading interpretive signs with many words inside”.

Regarding educational messages from these services, the three interviewees revealed that the national park wants visitors to understand and appreciate more the values of Cat Tien National Park. Interviewee 1 (personal communication, 2016) stated:

"Visitors can appreciate more the pure atmosphere and understand more the values of natural resources and biodiversity of Cat Tien National Park. Moreover, they can understand more about the life of people working in Cat Tien National Park".

Visitors are also encouraged to take care of the environment through information such as "No littering" in interpretive signs (Interviewee 2 and 3) and the slogan "Take nothing but pictures. Leave nothing but footprints" (Interviewee 2).

\subsubsection{Management of services for environmental interpretation in Cat Tien National Park}

To manage services for environmental interpretation, interviewee 3 stated that the centre measures the quality of each service via visitor satisfaction feedback. From the demand side, visitors can 
comment about the service quality in the national park via a paper sheet in each room (Interviewee 2 and 3). Visitors can also make a call to the hotline of the national park (Interviewee 3) or comment in the website of the national park (Interviewee 2) or send an email to the national park (Interviewee 1). The customer care team will deal with this feedback from visitors. If visitors come to talk directly to the staff of the national park, the customer care team can deal with visitors directly (Interviewee 1 and 3). Regarding the kinds of feedbacks, the three interviewees indicated that most of the feedbacks about interpretation were for site interpreters. For example, visitors felt that the English level of site interpreters was poor, or site interpreters were not enthusiastic.

In addition, they revealed that some surveys about visitor satisfaction have been conducted by some organisations (e.g. DANIDA, University of Forestry, etc.). The results from these surveys show that about $60-80 \%$ of the visitors were satisfied with the interpretation by site interpreters in Cat Tien National Park.

From the supply side, according to the three interviewees, the national park has changed the wage policy for site interpreters to stimulate them to learn more and enhance their enthusiasm and responsibility. Site interpreters do not receive the same salary for each month but receive a salary according to the amount of work they do (how many tours per month). Good site interpreters will receive more tours and accordingly, they have higher salary (Interviewee 3).

In terms of training for personnel, interviewee 1 and 3 said that training courses about ecotourism and skills (communication and English) were conducted every year for site interpreters and receptionists because most of them are locals who have deep knowledge about the area but little skills. Some training organised by international organisations lasted for one month. They focused on practical skills. Some organisations (e.g. JICA) provided trainees with certificates. Central Government funded some short courses that lasts for 1-3 days. Trainers were university lecturers and specialists in the fields of culture and tourism. The three interviewees indicated that English is the issue that needs to be learnt more by the staff of Cat Tien National Park.

In short, interpretation is understood by these interviewees as the explanation of site interpreters about the site. Other services for environmental interpretation were set up by international organisations and Central Government (e.g. signs, museum, etc.). The national park has no fund for setting up services for environmental interpretation. These services are still inadequate and ineffective to many visitors. In terms of management, the national park has developed some channels to receive feedback from visitors (e.g. telephone, email, mailbox, etc.). Moreover, wage policy has been changed recently to enhance the service quality of site interpreters. However, surveys and training courses were conducted mainly by outside agencies (international organisations and Central Government). 
According to the interviewees, current services for environmental interpretation include interpretive signs, directional signs, brochures, site interpreters, a meeting room and a museum. Staff at the ticket office was added in the list by the researcher from the site visit. Museum was separated into 2 different services (staff at the museum and displays at the museum). The meeting room was removed and videos at the rescue centre were added in the list as the results from the pilot test with visitors. The list of services for environmental interpretation was then finalized and used in the questionnaires. The next sections present the results from the questionnaire survey for visitors.

\subsection{Respondents' demographic characteristics}

The profile of respondents is an important part of quantitative research because it provides information about the nature of the sample used. The profile includes the information about respondents' nationality, gender, age and educational level.

As mentioned in Chapter 3, the study involved 237 respondents. In terms of nationality, the sample was dominated by domestic visitors who made up 74.3\% (176 respondents) of the total sample. International visitors accounted for $25.7 \%$ (61 respondents). This finding was consistent with the tourism statistics from the Centre of Environmental Education and Services from 2010 to 2015 (Table 4.2).

Table 4.2. Nationality of respondents

\begin{tabular}{|l|c|c|c|c|}
\hline \multirow{2}{*}{ Category } & \multicolumn{2}{|c|}{ The study sample } & \multicolumn{2}{c|}{$\begin{array}{c}\text { National Park statistics } \\
\text { in 2015 }\end{array}$} \\
\cline { 2 - 5 } & $\begin{array}{c}\text { Number of } \\
\text { respondents }\end{array}$ & $\begin{array}{c}\text { Percentage } \\
\text { (\%) }\end{array}$ & $\begin{array}{c}\text { Number of } \\
\text { visitors }\end{array}$ & $\begin{array}{c}\text { Percentage } \\
\text { (\%) }\end{array}$ \\
\hline Total & $\mathbf{2 3 7}$ & $\mathbf{1 0 0}$ & $\mathbf{2 6 ~ 6 6 4}$ & $\mathbf{1 0 0}$ \\
\hline Vietnamese visitors & 176 & 74.3 & 20139 & 75.5 \\
\hline International visitors & 61 & 25.7 & 6525 & 24.5 \\
\hline American & 10 & 4.2 & 261 & 1.0 \\
\hline Australian & 7 & 3.0 & 130 & 0.5 \\
\hline Japanese & 5 & 2.1 & 196 & 0.7 \\
\hline Singaporean & 5 & 2.1 & NA & NA \\
\hline Thai & 5 & 2.1 & NA & NA \\
\hline Chinese & 4 & 1.7 & NA & NA \\
\hline Korean & 4 & 1.7 & 196 & 0.7 \\
\hline British & 4 & 1.7 & 848 & 3.2 \\
\hline Dutch & 4 & 1.7 & 587 & 2.2 \\
\hline Belgian & 4 & 1.7 & 457 & 1.7 \\
\hline Taiwanese & 2 & 0.8 & NA & NA \\
\hline Cambodian & 2 & 0.8 & NA & NA \\
\hline Austrian & 1 & 0.4 & NA & NA \\
\hline Canadian & 1 & 0.4 & NA & NA \\
\hline Other & 3 & 1.3 & 3850 & 14.4 \\
\hline
\end{tabular}


Regarding gender, there was a relative balance between the number of males and females. There were more female respondents (53.6\%) in the sample than male (46.4\%) (Table 4.3). This study's sample appears to be dominated by young visitors. A majority of respondents were between 15 to 34 years old (43.5\%). The next largest group was 45 and above (30.8\%). The remainder (25.7\%) were between 35-44 years old (Table 4.3). This finding is consistent with the finding of Tsang et al. (2011). The finding is different from the finding of Stein et al. (2003) which indicated that most of the visitors (about 90\%) who came to Ocala National Forest in Florida, USA were in the age range of 36 and above. This may be a cultural difference between Eastern and Western visitors.

Regarding educational level, visitors to Cat Tien National Park seem to be well educated. $80.1 \%$ of respondents were university graduates or post graduates (Table 4.3). Particularly, 69.6\% of respondents hold College or University degrees. The percentage of respondents who achieved post graduate degrees was $10.5 \%$. In addition, the number of respondents who graduated from vocational school constituted $17.7 \%$ of the total sample. Small proportions of visitors had only graduated from secondary school and high school $(0.8 \%$ and $1.3 \%$ respectively). This finding is in line with the finding of Carr (2004), Stein et al. (2003) and Tsang et al. (2011). Visitors who go to protected areas tend to be well educated.

Table 4.3. Age, gender and educational level of respondents

\begin{tabular}{|l|c|c|}
\hline \multicolumn{1}{|c|}{ Demographic characteristics } & Number of respondents & Percentage (\%) \\
\hline Gender & $\mathbf{2 3 7}$ & $\mathbf{1 0 0}$ \\
\hline Female & 127 & 53.6 \\
\hline Male & 110 & 46.4 \\
\hline Age & $\mathbf{2 3 7}$ & $\mathbf{1 0 0}$ \\
\hline $25-34$ & 93 & 39.2 \\
\hline $45-54$ & 64 & 27.0 \\
\hline $35-44$ & 61 & 25.7 \\
\hline $15-24$ & 10 & 4.20 \\
\hline $55-64$ & 9 & 3.80 \\
\hline Highest educational level achieved & $\mathbf{2 3 7}$ & $\mathbf{1 0 0}$ \\
\hline College/University Graduate & 165 & 69.6 \\
\hline Vocational school & 42 & 17.7 \\
\hline Postgraduate & 25 & 10.5 \\
\hline High school & 3 & 1.3 \\
\hline Secondary school & 2 & 0.8 \\
\hline
\end{tabular}

In order to meet the requirements of the Chi-squared test (see section 3.9.3.5) presented in the next chapter, some categories of age group and educational level have been modified. Specifically regarding the age, the age group of 15-24 was merged into the age group of 25-34 to become the group of 15-34. The group of 55-64 was combined with the group of 45-54 to become the group of 45 and above (Table 4.4). 
Table 4.4. Modified age group of respondents

\begin{tabular}{|l|c|c|}
\hline \multicolumn{1}{|c|}{ Age } & Number of respondents & Percentage (\%) \\
\hline $15-34$ & 103 & 43.5 \\
\hline $35-44$ & 61 & 25.7 \\
\hline 45 and above & 73 & 30.8 \\
\hline Total & 237 & 100 \\
\hline
\end{tabular}

Some categories of educational level of the respondents were also modified to meet the requirements of the Chi-squared test. Categories of secondary school, high school and vocational school were combined to become the category of secondary education and vocational school (Table 4.5).

Table 4.5. Modified educational level of respondents

\begin{tabular}{|l|c|c|}
\hline \multicolumn{1}{|c|}{ Educational level } & Number of respondents & Percentage (\%) \\
\hline $\begin{array}{l}\text { Secondary education and } \\
\text { vocational school }\end{array}$ & 47 & 19.8 \\
\hline College/University Graduate & 165 & 69.6 \\
\hline Postgraduate & 25 & 10.5 \\
\hline Total & 237 & 100 \\
\hline
\end{tabular}

\subsection{Respondents' trip related characteristics}

This section explains how the respondents organized their trip. Travel behaviours of respondents including mode of their travel, their intended length of stay, accommodation, their past experience of visiting national parks and Cat Tien National Park are described.

Table 4.6 shows that most of the respondents were free independent travellers (64.6\%). Only 35.4\% of the respondents followed a tour to visit Cat Tien National Park. It is evident from Table 4.6 that most of the respondents (67.1\%) intended to stay two days and one night in Cat Tien National Park with $67.1 \%$. The remaining respondents $(32.9 \%)$ wanted to stay only a day.

In terms of accommodation, $40.9 \%$ of the respondents chose to stay in a guesthouse in Cat Tien National Park. Following was the respondents who intend to stay in camps with $17.7 \%$. Backpacker hostel was the option of $8.9 \%$ of the total sample. Other kinds of accommodation were home of friend/family member and homestay with low rates of $0.8 \%$ and $0.4 \%$ respectively. Besides, $32.5 \%$ of respondents did not intend to stay and use any kind of accommodation (Table 4.6). 
Table 4.6. Trip related characteristics of respondents

\begin{tabular}{|l|c|c|}
\hline \multicolumn{1}{|c|}{ Trip related characteristics } & Number of respondents & Percentage (\%) \\
\hline Mode of travel & $\mathbf{2 3 7}$ & $\mathbf{1 0 0}$ \\
\hline Free independent traveller & 153 & 64.6 \\
\hline Packaged tour & 84 & 35.4 \\
\hline Length of stay & $\mathbf{2 3 7}$ & $\mathbf{1 0 0}$ \\
\hline 2 days and 1 night & 159 & 67.1 \\
\hline 1 day & 78 & 32.9 \\
\hline Accommodation & & \\
\hline Guesthouse & 97 & 40.9 \\
\hline Camps & 42 & 17.7 \\
\hline Backpacker hostel & 21 & 8.9 \\
\hline Home of friend/family member & 2 & 0.8 \\
\hline Homestay & 1 & 0.4 \\
\hline Others & 77 & 32.5 \\
\hline $\begin{array}{l}\text { Times visited national parks in } \\
\text { the last 3 years }\end{array}$ & $\mathbf{2 3 7}$ & $\mathbf{1 0 0}$ \\
\hline 0 times & 126 & 53.2 \\
\hline 1-3 times & 105 & 44.3 \\
\hline 4-6 times & 6 & 2.5 \\
\hline $\begin{array}{l}\text { Times visited Cat Tien National } \\
\text { Park in the last 3 years }\end{array}$ & $\mathbf{2 3 7}$ & $\mathbf{1 0 0}$ \\
\hline 0 times & 214 & 90.3 \\
\hline Once & 23 & 9.7 \\
\hline
\end{tabular}

Table 4.6 shows that the respondents in this sample had rarely visited national parks in the past. Specifically, $53.2 \%$ of the respondents had never visited national parks in the last three years. Those who visited national parks between one to three times accounted for $44.3 \%$ of the total sample. Only $2.5 \%$ of respondents had visited national parks between four and six times in the last three years.

In terms of the number of times respondents had visited Cat Tien National Park, $90.3 \%$ of the respondents indicated that they had not visited Cat Tien National Park in the last three years. Only $9.7 \%$ of the respondents were visiting Cat Tien National Park for the second time (Table 4.6).

In order to meet the requirement for the Chi-squared test (see section 3.9.3.5), the categories of times visited national parks in the last three years (1-3 times and 4-6 times) were combined to become the category of one and more times (Table 4.7).

Table 4.7. Modified times visited national park of respondents

\begin{tabular}{|l|c|c|}
\hline \multicolumn{1}{|c|}{ Times visited national parks } & Number of respondents & Percentage (\%) \\
\hline 0 times & 126 & 53.2 \\
\hline One and more times & 111 & 46.8 \\
\hline Total & 237 & 100 \\
\hline
\end{tabular}

In brief, the findings show that the majority of respondents were domestic visitors. The visitors included both males and females but there were slightly more female visitors than male visitors. 
They seemed to be young and well educated. Most of them were free independent travellers and intended to stay in Cat Tien National Park for two days and one night. The respondents tended to choose guesthouses and camps to stay in Cat Tien National Park. Regarding their past experience, most of the visitors had rarely visited national parks in the past and had not been to Cat Tien National Park before.

Although this profile was limited due to the sample size, it contributed basic information about who the visitors are, where they are from and how they organised their trip. Knowing these characteristics of visitors will contribute to the understanding of visitor use of services for environmental interpretive services in Cat Tien National Park that will be presented in section 4.5.

\subsection{Visitor use of services for environmental interpretation in Cat Tien National Park}

This section will provide basic information about which services for environmental interpretation were used commonly and which services were not used by the respondents. Reasons why visitors did not use a specific service follow. Messages that the respondents received from each service will then be presented.

\subsubsection{Services used frequently by visitors}

Table 4.8 describes the frequency in using services for environmental interpretation. The findings showed that among services for environmental interpretation in Cat Tien National Park, interpretive signs, directional signs, brochures at the ticket office and staff at the ticket office were the most popular services used by the respondents with very high proportions of $100 \%, 99.6 \%, 98.7 \%$ and $98.3 \%$ respectively. These were followed by use of a site interpreter by $89.9 \%$ of the respondents. Staff and displays at the museum were ranked at the sixth position with $84.8 \%$. Lastly, videos at the rescue centre was the least common service with the use rate of $81.4 \%$.

Table 4.8. The use of services for environmental interpretation

\begin{tabular}{|l|c|c|c|c|}
\hline \multicolumn{1}{|c|}{$\begin{array}{c}\text { Services for environmental } \\
\text { interpretation }\end{array}$} & $\begin{array}{c}\text { Number of } \\
\text { respondents } \\
\text { used }\end{array}$ & $\begin{array}{c}\text { Percentage } \\
\mathbf{( \% )}\end{array}$ & $\begin{array}{c}\text { Number of } \\
\text { respondents } \\
\text { did not use }\end{array}$ & $\begin{array}{c}\text { Percentage } \\
\text { (\%) }\end{array}$ \\
\hline Interpretive signs about the site & 237 & 100 & 0 & 0 \\
\hline Directional signs & 236 & 99.6 & 1 & 0.4 \\
\hline Brochure at ticket office & 234 & 98.7 & 3 & 1.3 \\
\hline Staff at ticket office & 233 & 98.3 & 4 & 1.7 \\
\hline Site interpreter/ local tour guide & 213 & 89.9 & 24 & 10.1 \\
\hline Staff at museum & 201 & 84.8 & 36 & 15.2 \\
\hline Displays at museum & 201 & 84.8 & 36 & 15.2 \\
\hline Videos at rescue centre & 193 & 81.4 & 44 & 18.6 \\
\hline
\end{tabular}

\subsubsection{Reasons why visitors did not use a specific interpretive service}

Figure 4.1 explains the reasons why some visitors did not use a specific service in Cat Tien National Park. In general, "not enough time" and "no need to use" were the two most common reasons 
visitors gave for not using services for environmental interpretation. "Not enough time" and "no need to use" were the two common reasons for not using staff and displays at museum while "not aware of service" was indicated as the reason for not using brochure at ticket office. Reasons for not using staff at the ticket office were "no need to use" and "others". The reasons for not using site interpreters were "no need to use", "not enough time" and "not aware of service". 43 visitors explained that they did not use videos at rescue centre because they did not have enough time. Some of them also explained that videos were in English so they could not understand. Other reasons for not using videos were "not aware of service" and "no need to use" (see more in Appendix 6).

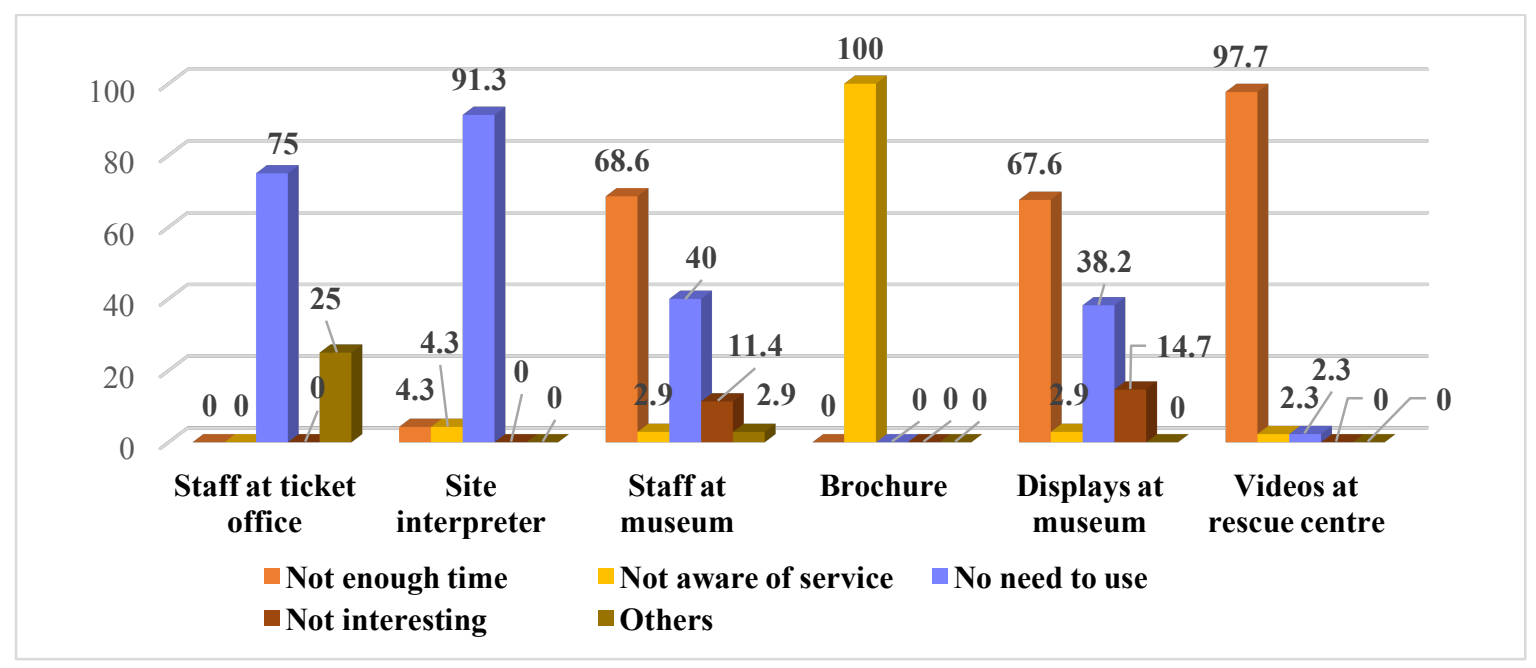

Figure 4.1. Reasons why visitors did not use a specific interpretive service

\subsubsection{Messages that visitors received from each service}

Previous sections described which services were used frequently by the respondents and reasons why some specific services were not used. This section presents the messages that these respondents received from each service during their visit in Cat Tien National Park. Knowing which messages are delivered by each service will help the managers of Cat Tien National Park adjust their interpretation strategy in the future.

Figure 4.2 describes the messages received by visitors. All of the respondents expressed that these services enhanced their experience in general. Overall, the messages received by visitors from interpretive services mostly were information about the site (staff at the ticket office, site interpreters, staff and displays at the museum, interpretive signs, brochures and videos at the rescue centre) and safety information (staff at the ticket office, site interpreters and directional signs). Only some services delivered information about potential impacts of visitors on environment (site interpreters, staff at the museum and videos at the rescue centre) and educated visitors with proper behaviours (interpretive signs and site interpreters). This finding for videos at the rescue centre was in line with the finding of Komatsu and Liu (2007). The results from this study indicated that educational movies raised visitors' environmental awareness. However, videos at the rescue centre 
did not deliver educational content of proper behaviours like educational movies in the study of Komatsu and Liu (2007).

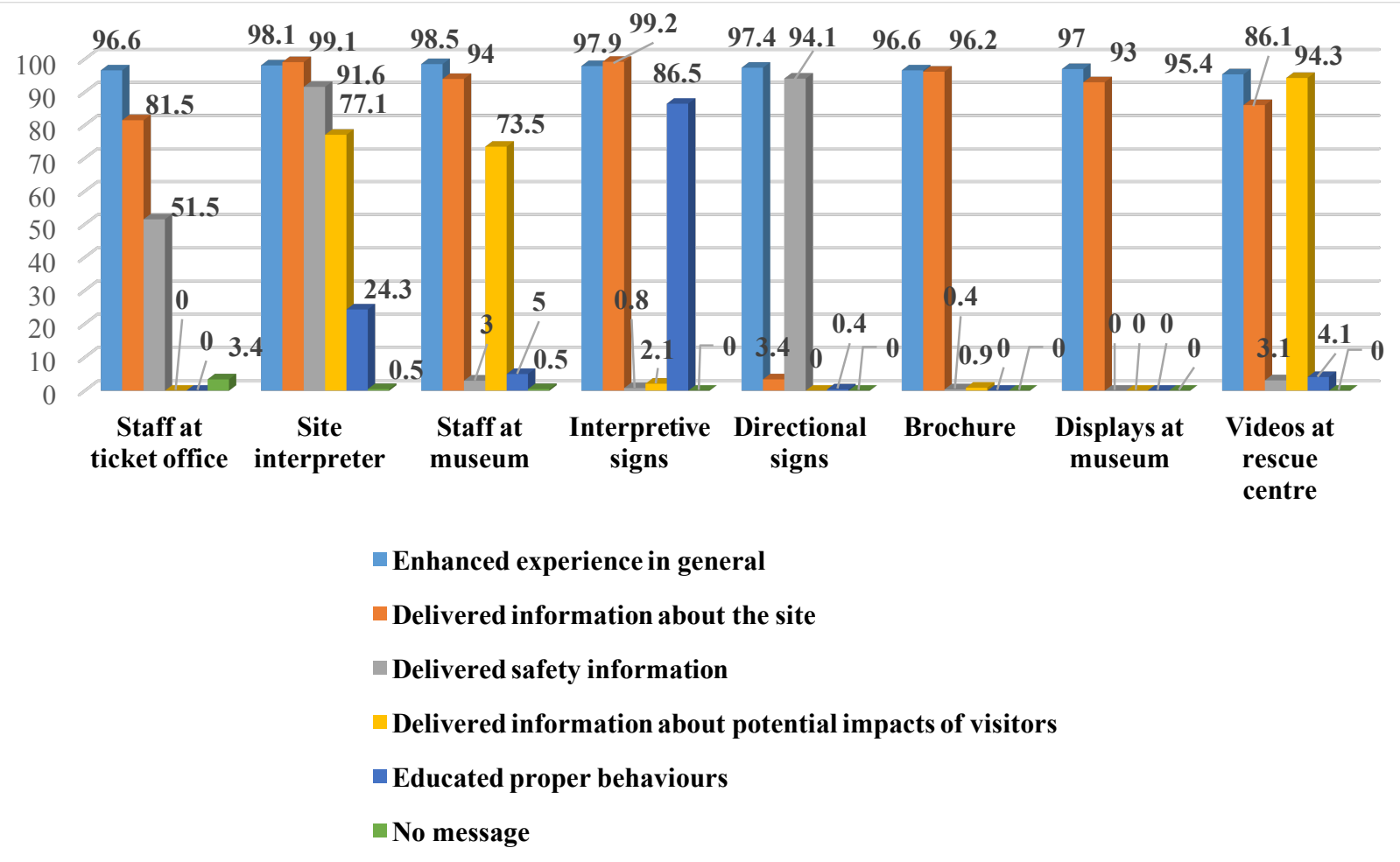

Figure 4.2. Messages that visitors received from each service

It is obvious from Figure 4.2 that all interpretive services in Cat Tien National Park enhanced visitor experience in general, with each being rated over 95\%. Information about potential impacts of visitors on environment was delivered through videos at rescue centre (94.3\%), site interpreters (77.1\%) and staff at the museum (73.5\%). Some services comprising interpretive signs, site interpreter and staff at the museum were evaluated that they had an effect on educating visitors with proper behaviours (e.g. do not litter, do not take anything from the park) with the percentages of $86.5 \%, 24.3 \%$ and 5\% respectively (see more in Appendix 7).

\subsection{Conclusion}

In conclusion, this chapter provided general information about management of services for environmental interpretation in Cat Tien National Park and visitor use of these services. Regarding the management, services for environmental interpretation have not received high attention from the managers of the national park. The national park has little fund for maintaining services for environmental interpretation. Most of these services were invested by international organizations. The national park has developed some channels to receive feedback from visitors (e.g. telephone, email, mailbox, etc.) and changed wage policy to improve the service quality of site interpreters. In terms of visitor use of these services, interpretive signs, directional signs, brochures at the ticket office and staff at the ticket office were the most common services used by the respondents while videos at the rescue centre, staff and displays at the museum were the least common. The popular 
reasons for not using a specific service were "not enough time" and "no need to use". Common messages delivered by these services were information about the site and safety information. The next chapter will present visitor satisfaction with services for environmental interpretation in Cat Tien National Park. 


\section{CHAPTER 5}

\section{VISITOR SATISFACTION WITH SERVICES FOR ENVIRONMENTAL INTERPRETATION IN CAT TIEN NATIONAL PARK}

\subsection{Introduction}

This chapter attempts to answer the third research aim: to investigate visitor satisfaction with services for environmental interpretation in Cat Tien National Park. Specifically, visitor satisfaction with services for environmental interpretation will be analysed with the importance and performance ratings, paired samples t-test and the importance-performance grid. Visitor satisfaction with roles of site interpreters will then be analysed separately. Finally, this chapter will present findings on overall visitor satisfactions with interpretive services and with their visit to Cat Tien National Park, as well as the likelihood of recommending the park to others.

\subsection{Visitor satisfaction with services for environmental interpretation in Cat Tien National Park}

This section explores visitor satisfaction with each service in-depth for environmental interpretation through importance - performance ratings. A paired samples t-test is used to examine the significant differences between importance and performance means. Also, an importance-performance grid is presented to illustrate how well these services for environmental interpretation performed in relation to their importance.

\subsubsection{The importance of services for environmental interpretation in Cat Tien National Park to visitor satisfaction}

Table 5.1 shows the importance means of eight services for environmental interpretation in Cat Tien National Park. The five services for environmental interpretation with the highest importance means were site interpreters (4.82), interpretive signs about the site (4.67), videos at the rescue centre (4.64), staff at the museum (4.58) and displays at the museum (4.44) (Table 5.1). Site interpreters were perceived the most important service for environmental interpretation. Domestic visitors often use site interpreters to lead the tour and ensure their safety because many dangerous animals may appear in national parks. All of the standard deviations were less than 1.0. This means that there was a consistency in visitors' evaluations about the importance of these five services. 
Table 5.1. The importance means of services for environmental interpretation

\begin{tabular}{|l|c|c|}
\hline $\begin{array}{c}\text { Services for environmental } \\
\text { interpretation }\end{array}$ & $\begin{array}{c}\text { Importance } \\
\text { mean }\end{array}$ & SD \\
\hline Site interpreter/ local tour guide & $4.82(\# 1)$ & 0.39 \\
\hline Interpretive signs about the site & $4.67(\# 2)$ & 0.53 \\
\hline Videos at rescue centre & $4.64(\# 3)$ & 0.52 \\
\hline Staff at museum & $4.58(\# 4)$ & 0.64 \\
\hline Displays at museum & $4.44(\# 5)$ & 0.70 \\
\hline Brochure at ticket office & $3.51(\# 6)$ & 0.64 \\
\hline Directional signs & $2.18(\# 7)$ & 0.75 \\
\hline Staff at ticket office & $2.03(\# 8)$ & 0.71 \\
\hline
\end{tabular}

$S D=$ Standard deviation; $n=237$ in all cases

Table 5.1 also presents the bottom three services with the lowest importance means. As can be seen from Table 5.1, services perceived the least important by the respondents included directional signs (2.18) and staff at the ticket office (2.03), as these two services had little potential to delivered environmental messages. All of the standard deviations were less than 1.0. This means that there was a consensus among the respondents in evaluating the importance of these three services.

\subsubsection{The performance of services for environmental interpretation in Cat Tien National Park}

\section{to visitor satisfaction}

Table 5.2 shows the performance means of eight services for environmental interpretation in Cat Tien National Park. As shown in Table 5.2, there were four services with high performance means in visitors' perceptions (above 3.9). They were interpretive signs about the site (4.45), site interpreters (4.03), staff at the museum (4.00) and brochures at the ticket office (3.94). All of the standard deviations were less than 1.0, which means that there was consistency in visitor assessment about the performance of these four services. 
Table 5.2. The performance means of services for environmental interpretation

\begin{tabular}{|l|c|c|}
\hline \multicolumn{1}{|c|}{$\begin{array}{c}\text { Services for environmental } \\
\text { interpretation }\end{array}$} & $\begin{array}{c}\text { Performance } \\
\text { mean }\end{array}$ & SD \\
\hline Interpretive signs about the site & $4.45(\# 1)$ & 0.59 \\
\hline Site interpreter/ local tour guide & $4.03(\# 2)$ & 0.34 \\
\hline Staff at museum & $4.00(\# 3)$ & 0.49 \\
\hline Brochure at ticket office & $3.94(\# 4)$ & 0.43 \\
\hline Directional signs & $3.42(\# 5)$ & 0.52 \\
\hline Staff at ticket office & $3.34(\# 6)$ & 0.50 \\
\hline Displays at museum & $3.28(\# 7)$ & 0.71 \\
\hline Videos at rescue centre & $3.26(\# 8)$ & 0.53 \\
\hline
\end{tabular}

$S D=$ Standard deviation; $n=237$ in all cases

Table 5.2 also presents the bottom four services for environmental interpretation with the worst performance (below 3.5). These were directional signs (3.42), staff at the ticket office (3.34), displays at the museum (3.28) and videos at the rescue centre (3.26). This finding is in line with visitors' comments about these services. Regarding directional signs, some visitors commented that some safety signs were faded, unclear anymore and need to be replaced. In terms of displays at the museum, many visitors said that the exhibits and displays in the museum were not attractive. They suggested that some visual interpretation (e.g. images and videos, etc.) could be more effective. Regarding the performance of videos in the rescue centre, some visitors commented that the quality and the content of of the videos were quite poor. The sound of the the videos was not loud enough. Moreover, the videos were only available in English, which is not suitable for domestic visitors and visitors who do not know English. In addition, some international visitors expressed their disappointment that there was no video in the Bear Rescue Centre. Still, some of international visitors expressed that the content of the videos was interesting. All of the standard deviations were less than 1.0, indicating that there was a high consensus in visitors' evaluations about the performance of these four services.

\subsubsection{Differences between the importance and performance means of services for environmental interpretation in Cat Tien National Park}

The means of services for environmental interpretation were tested in pairs (paired samples t-test) to examine whether there was a significant difference between the importance means and performance means. Statistical significance is important as it helps to confirm that the difference is real and does not happen by chance. Accordingly, we can state confidently that there was a significant difference between the importance and performance means. The difference between the importance means and performance means is statistically significant when the p-value is less than or equal to 0.05 (two-tailed) and not statistically significant when the p-value is greater than 0.05 
(two-tailed). The p-values (two-tailed) and t-values of services for environmental interpretation are presented in Table 5.3.

The paired $t$-test showed that all of the importance means were statistically different from their corresponding performance means. This means that the importance ratings of visitors did not significantly influence their performance ratings. Regarding personal services, site interpreters $(t(212)=-23.276, \mathrm{p}<0.05)$ and staff at the museum $(t(201)=-12.087, \mathrm{p}<0.05)$ had higher importance means than their performance means. Meanwhile, the importance mean of staff at the ticket office was lower than its performance mean $(t(232)=25.310, \mathrm{p}<0.05)$.

In terms of non-personal services, the importance means of interpretive signs $(t(235)=-5.711$, $\mathrm{p}<0.05)$, displays at the museum $(t(201)=-16.115, \mathrm{p}<0.05)$ and videos at the rescue centre $(t(193)$ $=-25.991, \mathrm{p}<0.05)$ were significantly higher than the corresponding performance means. On the contrary, the importance means of directional signs $(t(235)=20.925, \mathrm{p}<0.05)$ and brochures at the ticket office $(t(233)=8.562, \mathrm{p}<0.05)$ were significantly lower than their performance means. Future investment should focus on site interpreters, interpretive signs, staff and displays at the museum and videos at the rescue centre, as these services had performance means lower than the importance means.

Table 5.3. Paired samples t test for the importance and performance means of services for environmental interpretation

\begin{tabular}{|l|c|c|c|c|c|}
\hline $\begin{array}{c}\text { Services for environmental } \\
\text { interpretation }\end{array}$ & $\begin{array}{c}\text { Importance } \\
\text { mean }\end{array}$ & $\begin{array}{c}\text { Performance } \\
\text { mean }\end{array}$ & $\begin{array}{c}\text { Gap } \\
\text { (P-I) }\end{array}$ & t & $\begin{array}{c}\text { Sig. } \\
\text { (2-tailed) }\end{array}$ \\
\hline Site interpreter/ local tour guide & 4.82 & 4.03 & -0.79 & -23.276 & $\mathrm{p}<0.0005$ \\
\hline Staff at ticket office & 2.03 & 3.34 & 1.31 & 25.310 & $\mathrm{p}<0.0005$ \\
\hline Staff at museum & 4.58 & 4.00 & -0.58 & -12.087 & $\mathrm{p}<0.0005$ \\
\hline Interpretive signs about the site & 4.67 & 4.45 & -0.22 & -5.711 & $\mathrm{p}<0.0005$ \\
\hline Directional signs & 2.18 & 3.42 & 1.24 & 20.925 & $\mathrm{p}<0.0005$ \\
\hline Brochure at ticket office & 3.51 & 3.94 & 0.43 & 8.562 & $\mathrm{p}<0.0005$ \\
\hline Displays at museum & 4.44 & 3.28 & -1.16 & -16.115 & $\mathrm{p}<0.0005$ \\
\hline Videos at rescue centre & 4.64 & 3.26 & -1.38 & -25.991 & $\mathrm{p}<0.0005$ \\
\hline
\end{tabular}

$t=(t$-values); Sig (2-tailed $)=p$-value; degree of freedom is 237 in all cases.

\subsubsection{The importance-performance grid of services for environmental interpretation}

The importance-performance grid illustrates the relationship between the importance means and performance means. The importance and performance means of different attributes were plotted on a scatter chart: importance on the $\mathrm{y}$-axis and performance on the $\mathrm{x}$-axis (Figure 5.1).

The green intersection lines were created by middle means of two scales, as in the traditional approach of Martilla and James in 1977 to produce the four quadrants of the importanceperformance grid. With these intersection lines, six of the services including site interpreters, staff 
at the museum, interpretive signs, brochures, displays at the museum and videos at the rescue centre fell into the "Keep up the good work" quadrant. Only two services (staff at the ticket office and directional signs) were in the "Possibly Overkill" quadrant. This indicates that there is no need to improve any service for environmental interpretation and the importance-performance grid did not provide any managerial message.

However, the orange intersection lines created by the grand means of these services $(3.87 ; 3.72)$ depicted a different distribution of these services. Site interpreters, staff at the museum and interpretive signs were disseminated in the "Keep up the good work" quadrant. Brochures were in the "Possibly Overkill" quadrant. Staff at the ticket office and directional signs fell into the "Low priority" quadrant. The "Concentrate here" quadrant contained displays at the museum and videos at the rescue centre. This shows that displays at the museum and videos at the rescue centre were two important services for environmental interpretation but their performances were not so high in visitor perceptions. According to this grid, they need more attention from the managers of Cat Tien National Park to improve their performances to meet visitor satisfaction. The results from this grid show that an order for future investments can be videos at the rescue centre, displays at the museum, site interpreters, staff at the museum, interpretive signs, brochures, directional signs and staff at the ticket office.



Figure 5.1. Importance - performance grid of services for environmental interpretation 
This study also adopted the iso-rating or iso-priority line (where importance mean equals performance mean) that was used in the study of Dwyer, Cvelbar, Edwards and Mihalic (2012) to identify the gap between importance and performance. A $45^{\circ}$ upward sloping line was combined with the Importance-Performance grid. As can be seen clearly from the Figure 5.2, the importance of five services (site interpreters, interpretive signs, staff at the museum, displays at the museum and videos at the rescue centre) were higher than their performance. Hence, these services need more attention from the managers of Cat Tien National Park to improve their performance. This finding was consistent with the findings from the paired samples t-tests. By contrast, the performances of brochures, directional signs and staff at the ticket office were higher than their importance. The performances of these services need to be maintained to satisfy the visitors.

The relative distance between the current position of a certain service and the iso-rating line shows how far it is to meet visitor satisfaction. As a consequence, the priority should be given to services with greater gaps. An order of the priority should be videos at the rescue centre, displays at the museum, site interpreters and staff at the museum.

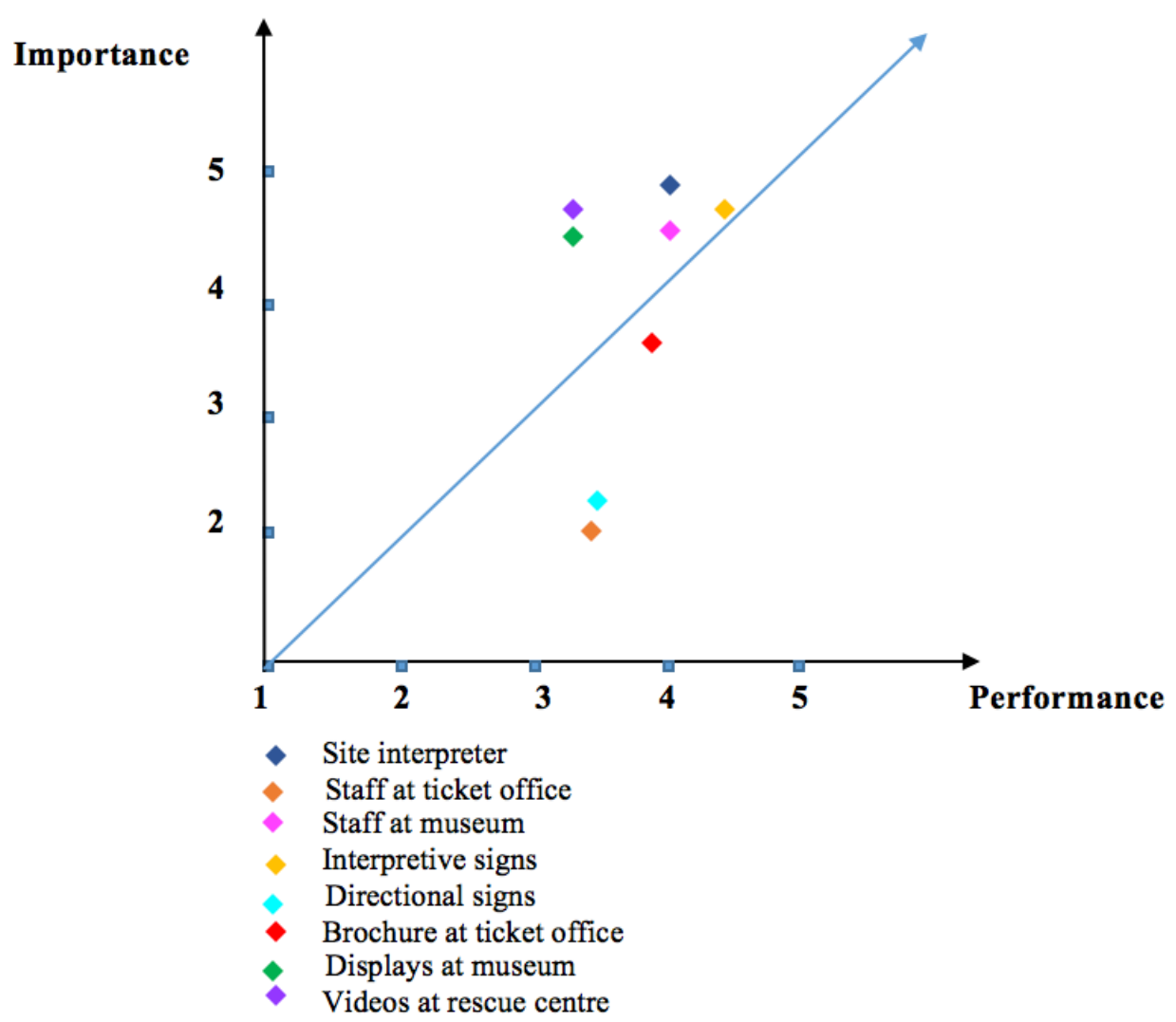

Figure 5.2. Importance-performance grid of services for environmental interpretation with iso-rating line

\subsection{Visitor satisfaction with roles of site interpreters in Cat Tien National Park}

The previous section analysed visitor satisfaction with each service for environmental interpretation. This section will explore visitor satisfaction with roles of site interpreters via their importance and performance ratings. Site interpreters were considered as the most essential and effective service for 
environmental interpretation by some tourism scholars (see Chapter 2) as well as by the interviewees. Thus, 12 statements representing for 12 roles of site interpreters were used to ask visitors to identify the strengths and weaknesses of site interpreters in Cat Tien National Park for future training and development. A paired samples t-test was applied to investigate the significant difference between importance and performance means. Finally, an importance-performance grid was used to illustrate the relationship between importance and performance means of roles of site interpreters in Cat Tien National Park.

\subsubsection{The importance of roles of site interpreters in Cat Tien National Park to visitor satisfaction}

Table 5.4 shows the top six roles of site interpreters $(7,1,12,8,2$ and 11) with high importance means (equal to or above 4.6). These were "introduce ecological and cultural points of interest", (4.94), "set a pace for the trip that was comfortable for you" (4.72), "increase your knowledge and understanding of the natural environment of the national park" (4.70), "disseminate correct information and translation" (4.66), "discuss dangers that may exist in the tour" (4.63) and "help you to develop a keener awareness and appreciation of the national park" (4.60). The findings indicated that visitors cared most about the communicative roles of site interpreters, the comfortable pace of the trip, safety issues and the knowledge achieved. They were followed by a positive group environment and a well organisation. Two roles of a motivator of responsible behaviour were also perceived as important. Four roles $(4,6,10$ and 9) had the importance means in the middle. The importance means of these roles were quite high (above 3.6). 
Table 5.4. The importance means of roles of site interpreters

\begin{tabular}{|l|c|c|}
\hline \multicolumn{1}{|c|}{ Roles } & $\begin{array}{c}\text { Importance } \\
\text { mean }\end{array}$ & SD \\
\hline $\begin{array}{l}\text { 7. Mediatory-Communicative: Introduce ecological and } \\
\text { cultural points of interest }\end{array}$ & 4.94 (\#1) & 0.24 \\
\hline $\begin{array}{l}\text { 1. Leadership-Instrumental: Set a pace for the trip that } \\
\text { was comfortable for you }\end{array}$ & $4.72(\# 2)$ & 0.51 \\
\hline $\begin{array}{l}\text { 12. Resource Management-Environmental } \\
\text { Interpreter: Increase your knowledge and understanding } \\
\text { of the natural environment of the national park }\end{array}$ & 4.70 (\#3) & 0.47 \\
\hline $\begin{array}{l}\text { 8. Mediatory-Communicative: Disseminate correct } \\
\text { information and translation }\end{array}$ & 4.66 (\#4) & 0.53 \\
\hline $\begin{array}{l}\text { 2. Leadership-Instrumental: Discuss dangers that may } \\
\text { exist in the tour }\end{array}$ & $4.63(\# 5)$ & 0.53 \\
\hline $\begin{array}{l}\text { 11. Resource Management-Environmental } \\
\text { Interpreter: Help you to develop a keener awareness and } \\
\text { appreciation of the national park }\end{array}$ & $4.60(\# 6)$ & 0.55 \\
\hline $\begin{array}{l}\text { 4. Leadership-Social: Promote a social and happy group } \\
\text { environment }\end{array}$ & $4.11(\# 7)$ & 0.58 \\
\hline $\begin{array}{l}\text { 6. Mediatory-Interactional: Keep the group organized } \\
\text { and on schedule }\end{array}$ & 4.09 (\#8) & 0.65 \\
\hline $\begin{array}{l}\text { 10. Resource Management-Motivator of Responsible } \\
\text { Behaviour: Highlight the importance of not taking } \\
\text { anything from national park }\end{array}$ & 3.64 (\#9) & 0.98 \\
\hline $\begin{array}{l}\text { 9. Resource Management-Motivator of Responsible } \\
\text { Behaviour: Discuss code of ethics with the group }\end{array}$ & $3.61(\# 10)$ & 0.97 \\
\hline $\begin{array}{l}\text { 5. Mediatory-Interactional: Reduce conflicts with other } \\
\text { groups at sites, etc. }\end{array}$ & $3.14(\# 11)$ & 0.66 \\
\hline $\begin{array}{l}\text { 3. Leadership-Social: Handle tension or conflict quickly } \\
\text { and effectively }\end{array}$ & $3.12(\# 12)$ & 0.79 \\
\hline
\end{tabular}

$S D=$ Standard deviation $;=237$ in all cases

The bottom two roles of site interpreters with low importance means were role 5 and 3 . The importance mean of role 5, "reduce conflict with other groups at sites" was 3.14 and the importance mean of role 3, "handle tension or conflict quickly and effectively" was 3.12. All of the standard deviations were less than 1.0. This means that there was a consistency in visitor assessment about the importance of twelve roles of site interpreters. 
5.3.2 The performance of roles of site interpreters in Cat Tien National Park to visitor satisfaction

Table 5.5 describes the top four roles of site interpreters $(7,1,6$ and 12) in Cat Tien National Park with the best performances (above 4.10). Those were "introduce ecological and cultural points of interest" (4.36), "set a pace for the trip that was comfortable for you" (4.28), "keep the group organized and on schedule" (4.23) and "increase your knowledge and understanding of the natural environment of the national park" (4.10). The performance of these roles was quite high and relevant to their corresponding importance analysed in section 5.3.1. Role 5, 3, 8 and 11 of site interpreters had performance means in the middle of the performance list. The performance means of these roles were quite high (above 3.7). Role 5 and role 3 had their performance higher than their importance maybe because the research was conducted in the low season of the national park, which meant there were not so many visitors going to each site at the same time. 
Table 5.5. The performance means of roles of site interpreters

\begin{tabular}{|c|c|c|}
\hline Roles & $\begin{array}{c}\text { Performance } \\
\text { mean }\end{array}$ & SD \\
\hline $\begin{array}{l}\text { 7. Mediatory-Communicative: Introduce ecological } \\
\text { and cultural points of interest }\end{array}$ & $4.36(\# 1)$ & 0.50 \\
\hline $\begin{array}{l}\text { 1. Leadership-Instrumental: Set a pace for the trip that } \\
\text { was comfortable for you }\end{array}$ & $4.28(\# 2)$ & 0.48 \\
\hline $\begin{array}{l}\text { 6. Mediatory-Interactional: Keep the group organized } \\
\text { and on schedule }\end{array}$ & $4.23(\# 3)$ & 0.49 \\
\hline $\begin{array}{l}\text { 12. Resource Management-Environmental } \\
\text { Interpreter: Increase your knowledge and } \\
\text { understanding of the natural environment of the national } \\
\text { park }\end{array}$ & $4.10(\# 4)$ & 0.36 \\
\hline $\begin{array}{l}\text { 5. Mediatory-Interactional: Reduce conflict with other } \\
\text { groups at sites, etc. }\end{array}$ & $3.95(\# 5)$ & 0.46 \\
\hline $\begin{array}{l}\text { 3. Leadership-Social: Handle tension or conflict } \\
\text { quickly and effectively }\end{array}$ & 3.89 (\#6) & 0.49 \\
\hline $\begin{array}{l}\text { 8. Mediatory-Communicative: Disseminate correct } \\
\text { information and translation }\end{array}$ & $3.88(\# 7)$ & 0.42 \\
\hline $\begin{array}{l}\text { 11. Resource Management-Environmental } \\
\text { Interpreter: Help you to develop a keener awareness } \\
\text { and appreciation of the national park }\end{array}$ & $3.76(\# 8)$ & 0.43 \\
\hline $\begin{array}{l}\text { 4. Leadership-Social: Promote a social and happy } \\
\text { group environment }\end{array}$ & 3.42 (\#9) & 0.72 \\
\hline $\begin{array}{l}\text { 2. Leadership-Instrumental: Discuss dangers that may } \\
\text { exist in the tour }\end{array}$ & $3.32(\# 10)$ & 0.92 \\
\hline $\begin{array}{l}\text { 9. Resource Management-Motivator of Responsible } \\
\text { Behaviour: Discuss code of ethics with the group }\end{array}$ & $2.00(\# 11)$ & 0.80 \\
\hline $\begin{array}{l}\text { 10. Resource Management-Motivator of Responsible } \\
\text { Behaviour: Highlight the importance of not taking } \\
\text { anything from national park }\end{array}$ & $1.96(\# 12)$ & 0.82 \\
\hline
\end{tabular}

$S D=$ Standard deviation; $n=237$ in all cases

The bottom four roles of site interpreters (4, 2, 9 and 10) had the lowest performance means (below 3.5). As can be seen clearly from Table 5.5, the two worst performing roles of site interpreters in Cat Tien National Park were "discuss code of ethics with the group" (2.00) and "highlight the importance of not taking anything from national park" (1.96). These two roles also had low importance ratings as analysed in section 5.3.1. All of the standard deviations were less than 1.0. This means that there was a consistency in visitor evaluation of the performance of 12 roles of site interpreters in Cat Tien National Park. 


\subsubsection{Differences between the importance and performance means of roles of site interpreters in Cat Tien National Park}

In this section, the importance and performance means of roles of site interpreters were tested in pairs (paired samples t-test) to examine whether there was a significant difference between the importance and performance means or not. The p-values (two-tailed) and t-values of the 12 roles of site interpreters are presented in Table 5.6.

The paired $t$-test showed that all of the importance means were statistically different from their corresponding performance means. This means that the importance ratings of visitors for 12 roles of site interpreters did not significantly influence their performance ratings. Regarding the leadership roles, the importance means of two roles of instrumental function ("1. Set a pace for the trip that was comfortable for you"; "2. Discuss dangers that may exist in the tour") were significantly higher than their performance means $(t(212)=-11.441, \mathrm{p}<0.05 ; t(210)=-19.243, \mathrm{p}<0.05)$. The importance mean of role 4 of Social function ("Promote a social and happy group environment") was also higher than its performance $(t(212)=-10.884, \mathrm{p}<0.05)$. Meanwhile, the importance mean of role 3 of Social function ("Handle tension or conflict quickly and effectively") was significantly lower than its performance $(t(199)=11.786, \mathrm{p}<0.05)$.

In terms of mediatory roles, the importance means of two roles of Interactional function (" 5 . Reduce conflict with other groups at sites"; "6. Keep the group organized and on schedule") were all lower than their corresponding performances $(t(201)=14.999, \mathrm{p}<0.05 ; t(212)=3.058, \mathrm{p}<0.05)$. However, the importance means of two roles of Communicative function ("7. Introduce ecological and cultural points of interest"; "8. Disseminate correct information and translation") were significantly higher than their performances $(t(212)=-16.559, \mathrm{p}<0.05 ; t(212)=-17.024, \mathrm{p}<0.05)$

With resource management roles, the importance means of two roles of Motivator function ("9. Discuss code of ethics with the group"; "10. Highlight the importance of not taking anything from national park") and two roles of Environmental interpreter function ("11. Help you to develop a keener awareness and appreciation of the national park"; "12. Increase your knowledge and understanding of the natural environment of the national park") were significantly higher than their corresponding performance means $(t(211)=-19.185, \mathrm{p}<0.05 ; t(209)=-20.485, \mathrm{p}<0.05 ; t(212)=$ 17.633, $\mathrm{p}<0.05 ; t(212)=-15.364, \mathrm{p}<0.05)$.

The above results indicated that future trainings for site interpreters should focus on roles 1, 2, 4, 7, $8,9,10,11$ and 12 , as these roles had the performance ratings lower than their importance rating. 
Table 5.6. Paired samples t-test for the importance and performance means of roles of site interpreters

\begin{tabular}{|l|c|c|c|c|c|}
\hline \multicolumn{1}{|c|}{ Roles } & $\begin{array}{c}\text { Importance } \\
\text { mean }\end{array}$ & $\begin{array}{c}\text { Performance } \\
\text { mean }\end{array}$ & $\begin{array}{c}\text { Gap } \\
\text { (P-I) }\end{array}$ & t & $\begin{array}{c}\text { Sig. } \\
\text { (2-tailed) }\end{array}$ \\
\hline $\begin{array}{l}\text { 1. Set a pace for the trip that was comfortable for } \\
\text { you }\end{array}$ & 4.72 & 4.28 & -0.44 & -11.441 & $\mathrm{p}<0.0005$ \\
\hline 2. Discuss dangers that may exist in the tour & 4.63 & 3.32 & -1.31 & -19.243 & $\mathrm{p}<0.0005$ \\
\hline $\begin{array}{l}\text { 3. Handle tension or conflict quickly and } \\
\text { effectively }\end{array}$ & 3.12 & 3.89 & 0.77 & 11.786 & $\mathrm{p}<0.0005$ \\
\hline 4. Promote a social and happy group environment & 4.11 & 3.42 & -0.69 & -10.884 & $\mathrm{p}<0.0005$ \\
\hline 5. Reduce conflict with other groups at sites, etc. & 3.14 & 3.95 & 0.81 & 14.999 & $\mathrm{p}<0.0005$ \\
\hline $\begin{array}{l}\text { 6. Keep the group organized and on schedule } \\
\text { 7. Introduce ecological and cultural points of } \\
\text { interest }\end{array}$ & 4.09 & 4.23 & 0.14 & 3.058 & 0.003 \\
\hline $\begin{array}{l}\text { 8. Disseminate correct information and translation } \\
\text { 9. Discuss code of ethics with the group }\end{array}$ & 4.66 & 3.36 & -0.58 & -16.559 & $\mathrm{p}<0.0005$ \\
\hline $\begin{array}{l}\text { 10. Highlight the importance of not taking anything } \\
\text { from national park }\end{array}$ & 3.64 & 1.96 & -1.68 & -20.485 & $\mathrm{p}<0.0005$ \\
\hline $\begin{array}{l}\text { 11. Help you to develop a keener awareness and } \\
\text { appreciation of the national park }\end{array}$ & 4.60 & 3.76 & -0.84 & -17.633 & $\mathrm{p}<0.0005$ \\
\hline $\begin{array}{l}\text { 12. Increase your knowledge and understanding of } \\
\text { the natural environment of the national park }\end{array}$ & 4.70 & 4.10 & -0.60 & -15.364 & $\mathrm{p}<0.0005$ \\
\hline
\end{tabular}

$t=(t$-values); Sig (2-tailed $)=p$-value; degree of freedom is 237 in all cases .

\subsubsection{The importance-performance grid of roles of site interpreters in Cat Tien National Park}

The importance-performance grid was also used to present the link between the importance and performance means of roles of site interpreters in Cat Tien National Park. This grid shows the strengths and weaknesses of site interpreters in Cat Tien National Park. As can be seen in Figure 5.3 , the red intersection lines placed on the middle means of two scales created the importance performance grid with four quadrants. With these intersection lines, 10 roles of site interpreters (1, $2,3,4,5,6,7,8,11$ and 12) were plotted into the "Keep up the good work" quadrant. Only two roles of a motivator of responsible behaviour (9-discusses code of ethics with the group and 10highlights the importance of not taking anything from national park) were put in the "Concentrate here" quadrant. These two roles had quite high importance means but very low performance means. This means that these two roles need to improve their performances in the future to meet visitor satisfaction.

Meanwhile, the blue intersection lines drawn by the grand means of these services $(4.16 ; 3.60)$ gave more specific management messages. Five roles (1, 7, 8, 11 and 12) fell within "Keep up the good work" quadrant. Three roles (3, 5 and 6) were in the "Possibly Overkill" quadrant. Role 2 (discusses dangers that may exist in the tour) was distributed into the "Concentrate here" quadrant. This means 
that site interpreters in Cat Tien National Park need to perform this role better in the future to meet visitor satisfaction. Role 4, 9 and 10 was in the "Low priority" quadrant, which means that this role should not receive high attention from the managers. However, the comparisons between the importance and performance means of these roles (Table 5.6) show that four roles $(2,4,9$ and 10) had low performance in comparison with their high importance.

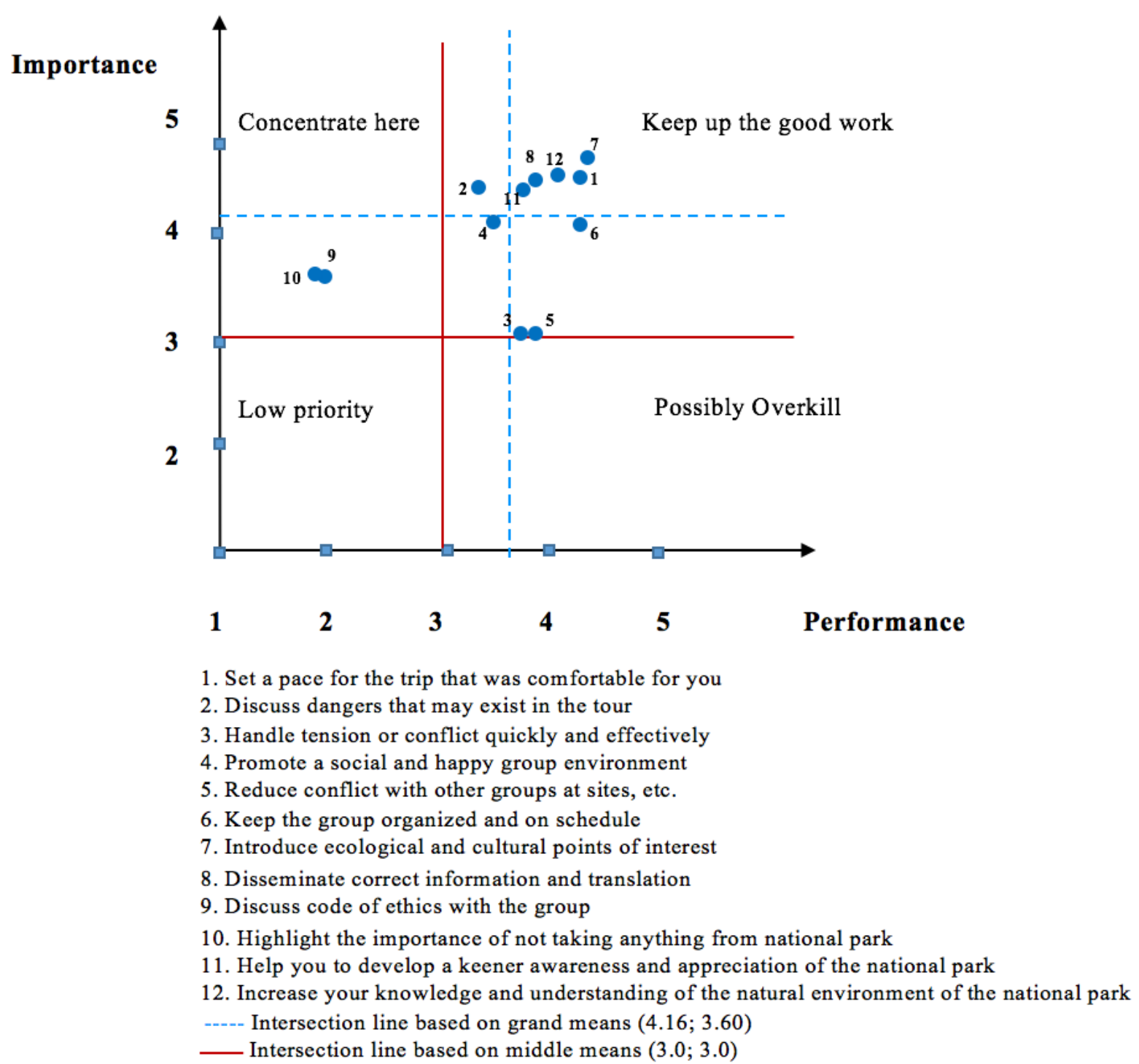

Figure 5.3. Importance-performance grid of roles of site interpreters

The iso-rating was also combined with the importance-performance grid. Figure 5.4 shows that the importance ratings of nine roles of site interpreters $(1,2,4,7,8,9,10,11$ and 12) were higher than their performance ratings according to visitor evaluations. Hence, managers of Cat Tien National Park should concentrate on enhancing the performances of these nine roles of site interpreters in the future. On the contrary, the performances of three roles $(3,5$ and 6$)$ were higher than their importance ratings. Hence, the performances of these roles should be retained in the future.

In terms of the relative distance, there were big gaps from the positions of eight roles $(10,9,2,11$, 8, 4, 12 and 7, respectively) to the iso-rating line. This means that site interpreters need to be trained more to perform these roles better to meet visitor satisfaction in the future. The author suggests that 
the priority list should be 2, 4, 9, 10,11,8,12 and 7 because two roles ( 2 and 4) were the only two roles having low performance in comparison with their high importance.

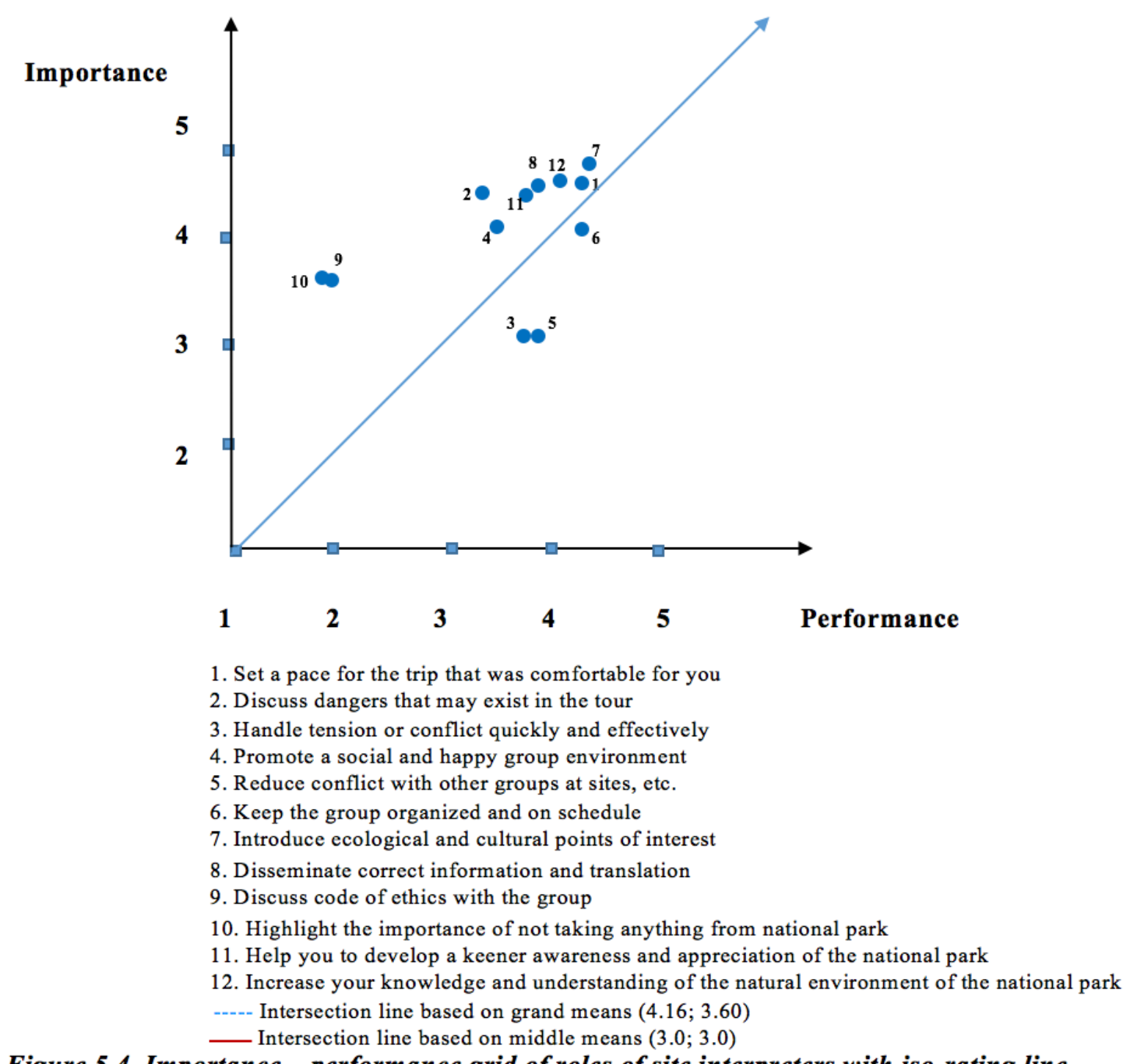

Figure 5.4. Importance - performance grid of roles of site interpreters with iso-rating line

\subsection{Overall satisfactions}

This section will present overall visitor satisfactions with the services for environmental interpretation and their visit to Cat Tien National Park as well as their intentions to recommend the national park. Next, the relationships between performance ratings of services for environmental interpretation and overall satisfactions and recommendation intention will be examined. The relationship between overall satisfaction with interpretive services and overall satisfaction with their visit will also be explored.

\subsubsection{Overall satisfactions and recommendation intention}

Table 5.7 describes the overall satisfaction of visitors with services for environmental interpretation. In general, the respondents were quite satisfied with services for environmental interpretation with a high mean score (3.87). The standard deviation was quite small (0.40). This means that there was a consistency in visitor evaluation about overall satisfaction with services for environmental 
interpretation. Specifically, most of the respondents were satisfied at level 4 with $83.5 \%$. $2.1 \%$ of the respondents felt extremely satisfied with services for environmental interpretation. 13.9\% was the proportion of respondents with satisfaction level 3 . The remaining rate $(0.4 \%)$ was for those with satisfaction level 2.

Table 5.7. Overall satisfaction with services for environmental interpretation

\begin{tabular}{|l|c|c||l|c|}
\hline Level of satisfaction & $\begin{array}{c}\text { Number of } \\
\text { respondents }\end{array}$ & $\begin{array}{c}\text { Percentage } \\
\text { (\%) }\end{array}$ & Measure & Value \\
\hline Not satisfied at all & 0 & 0 & Mean & 3.87 \\
Satisfaction level 2 & 1 & 0.4 & Median & 4 \\
Satisfaction level 3 & 33 & 13.9 & Mode & 4 \\
Satisfaction level 4 & 198 & 83.5 & SD & 0.40 \\
Extremely satisfied & 5 & 2.1 & & \\
Total & 237 & 100 & & \\
\hline
\end{tabular}

$S D=$ Standard deviation; $n=237$ in all cases

Table 5.8 shows overall satisfaction of visitors with their visit to Cat Tien National Park. Visitors seemed to be satisfied with their experience in Cat Tien National Park, with a high mean score (3.92). The small standard deviation (0.35) showed that there was a high consensus among respondents in their evaluation. $91.1 \%$ of the respondents were satisfied with their trip at level 4 . $0.8 \%$ of the respondents were extremely satisfied with the trip. However, $6.8 \%$ of them expressed their satisfaction at level 3. The remainder (1.3\%) was satisfied at level 2.

Table 5.8. Overall satisfaction with the visit to Cat Tien National Park

\begin{tabular}{|l|c|c||l|c|}
\hline Level of satisfaction & Number of respondents & $\begin{array}{c}\text { Percentage } \\
\text { (\%) }\end{array}$ & Measure & Value \\
\hline Not satisfied at all & 0 & 0 & Mean & 3.92 \\
Satisfaction level 2 & 3 & 1.3 & Median & 4 \\
Satisfaction level 3 & 16 & 6.8 & Mode & 4 \\
Satisfaction level 4 & 216 & 91.1 & SD & 0.35 \\
Extremely satisfied & 2 & 0.8 & & \\
Total & 237 & 100 & & \\
\hline
\end{tabular}

$S D=$ Standard deviation $;=237$ in all cases

When answering the likelihood of recommending Cat Tien National Park to others, the respondents expressed a high possibility of recommendation (97.5\%). 64.6\% of the respondents answered "yes", $32.9 \%$ of them chose "maybe", leaving $2.5 \%$ for those who has no opinion (Figure 5.5 ). 


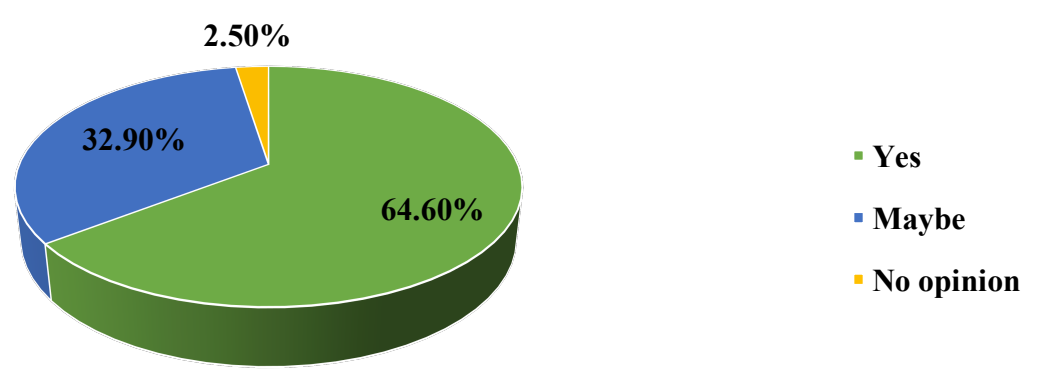

Figure 5.5. Recommendation intention

\subsubsection{Correlations}

Table 5.9 shows the results from Pearson's correlation test for the performance means of eight services for environmental interpretation in Cat Tien National Park and post-visit behaviour ratings. This test was used to examine whether the performances of these services influence overall visitor satisfactions with environmental interpretation, their trip and their future recommendations or not. Regarding the relationship between performance ratings for eight interpretive services and overall satisfaction with interpretive services, the results show that there were significant correlations between performance ratings for seven services (site interpreters, staff at the ticket office, staff at the museum, interpretive signs, directional signs, brochure and displays at the museum) and overall satisfaction with interpretive services (all $p$-values less than 0.00625; Bonferroni correction applied). This means that the performance of these seven services positively influenced overall visitor satisfaction with interpretive services in Cat Tien National Park. The highest significant positive relationship was found between the performance rating for brochures and overall satisfaction with interpretive services $(\mathrm{r}=0.373)$.

Table 5.9. Pearson's correlation test for the performance of 8 interpretive services
and post visit behaviours
\begin{tabular}{|l|c|c|c|c|c|c|}
\hline \multirow{3}{*}{$\begin{array}{c}\text { Performance of services for } \\
\text { environmental interpretation }\end{array}$} & $\begin{array}{c}\text { Overall } \\
\text { satisfaction with } \\
\text { these services }\end{array}$ & $\begin{array}{c}\text { Overall } \\
\text { satisfaction with } \\
\text { the visit }\end{array}$ & $\begin{array}{c}\text { Recommendation } \\
\text { intention }\end{array}$ \\
\cline { 2 - 8 } & $\mathbf{r}$ & Sig. & $\mathbf{r}$ & Sig. & r & Sig. \\
\hline Site interpreter/ local tour guide & 0.234 & $\mathrm{p}<0.0005$ & 0.148 & 0.015 & 0.004 & 0.475 \\
\hline Staff at ticket office & 0.298 & $\mathrm{p}<0.0005$ & 0.188 & 0.002 & -0.132 & 0.024 \\
\hline Staff at museum & 0.256 & $\mathrm{p}<0.0005$ & 0.000 & 0.500 & -0.061 & 0.198 \\
\hline Interpretive signs about the site & 0.363 & $\mathrm{p}<0.0005$ & 0.223 & $\mathrm{p}<0.0005$ & 0.047 & 0.238 \\
\hline Directional signs & 0.211 & 0.001 & 0.117 & 0.037 & 0.055 & 0.204 \\
\hline Brochure at ticket office & 0.373 & $\mathrm{p}<0.0005$ & 0.208 & 0.001 & -0.013 & 0.423 \\
\hline Displays at museum & 0.193 & 0.003 & 0.093 & 0.094 & 0.078 & 0.137 \\
\hline Videos at rescue centre & 0.081 & 0.131 & 0.032 & 0.330 & -0.089 & 0.110 \\
\hline
\end{tabular}

$r=$ correlation coefficient $;$ Sig (1-tailed $)=p$-value 
In terms of the relationship between performance ratings for eight interpretive services and overall satisfaction with their visit, the results show that there were small correlations between the performance ratings for three services (staff at the ticket office, interpretive signs and brochures) and overall visitor satisfaction with the trip. This means that the performance of these three services positively influenced overall visitor satisfaction with their trip to Cat Tien National Park. No correlation was found in the relationship between the performance ratings for eight interpretive services and recommendation intention (Table 5.9). These findings were consistent with the findings of Crilley et al. (2012).

The results from Pearson's correlation test also show that there is a significant positive relationship between visitor satisfaction with interpretive services and visitor satisfaction with their visit (as $p$ value $<0.0005)$. Overall visitor satisfaction with interpretive services positively influenced overall visitor satisfaction with their visit.

\subsection{Conclusion}

To sum up, this chapter presented visitor satisfaction with environmental interpretation in Cat Tien National Park through analysing the importance and performance ratings for eight services and twelve roles of site interpreters. The results indicate that site interpreters, interpretive signs about the site, videos at the rescue centre, staff at the museum and displays at the museum were the five most important services for environmental interpretation while directional signs and staff at the ticket office had very low importance in visitors' perceptions. Regarding their performance, four services (interpretive signs, site interpreters, staff at the museum and brochures) performed well according to these visitors, corresponding to their high importance. Directional signs and staff at the ticket office had low performance, corresponding to their low importance. However, videos at the rescue centre and displays at the museum had very low performance in comparison with their high importance. These two services should receive high attention from managers of the national park to improve the performance as soon as possible. Moreover, the results from a paired t-test suggest that alongside with videos at the rescue centre and displays at the museum, the performance of site interpreters, staff at the museum and interpretive signs also need to be improved in the future, as their performances were lower than their corresponding importance. This finding is also in line with the finding from the importance-performance grid. The iso rating line suggests the priority should be given to videos at the rescue centre, displays at the museum, site interpreters and staff at the museum, as these services having the greatest gaps to the the line.

Regarding the importance of twelve roles of site interpreters, six roles $(7,1,12,8,2$ and 11) were perceived as high important. This means visitors cared most about the communicative roles of site interpreters, the comfortable pace of the trip, safety issues and the knowledge achieved. They were followed by a positive group environment and a well group organisation (role 4 and 6). Two roles 
of a motivator of responsible behaviour (role 9 and 10) were also perceived as important. The two roles having low importance means were role 5, "reduce conflict with other groups at sites" and role 3, "handle tension or conflict quickly and effectively". In terms of their performance, four roles of site interpreters $(7,1,6$ and 12) had the best performances in visitors' perceptions, corresponding to their high importance. These roles are related to communicative role, the comfortable pace of the trip, the well group organisation and the great dissemination of knowledge. The performance of role 5 and role 3 were quite high in comparison with their low importance. The performance of role 2 and role 4 were quite low in comparison with their high importance. The performance of role 9 and role 10 were very low but their importance was quite high. Hence, four roles of site interpreters (2, 4,9 and 10) need to be improved in the future to meet visitor satisfaction. This finding is in line with the finding from the importance-performance grid, in which role 2, role 9 and role 10 were in the "Concentrate here" quadrant. Moreover, the results from a paired t-test suggest that along with role 2, 4, 9 and 10, five other roles $(1,7,8,11$ and 12) also need to be improved, as these roles had the performance lower than their importance. The iso rating line suggests the priority should be given to role $10,9,2,11,8,4,12$ and 7 , as theses roles had the greatest gaps to the line.

In addition, the findings show that apart from videos at the rescue centre, the performance of seven other services positively influenced overall visitor satisfaction with interpretive services in Cat Tien National Park. Also, the performance of three services (staff at the ticket office, interpretive signs and brochures) had a slight influence on overall visitor satisfaction with the trip to Cat Tien National Park. The next chapter will analyse the similarities and differences in visitor satisfaction between different groups of visitors (motivation-based segments and market-based segments). 


\section{CHAPTER 6}

\section{VISITOR SATISFACTION WITH SERVICES FOR ENVIRONMENTAL INTERPRETATION ACCORDING TO MOTIVATION AND MARKET SEGMENTS}

\subsection{Introduction}

The previous chapter presented visitor use and satisfaction with services for environmental interpretation for the whole sample. This chapter follows on from findings from previous chapters to analyse visitor satisfaction according to visitor segments. This chapter tries to answer the last research aim: to analyse the similarities and differences in visitor satisfaction with services for environmental interpretation among different motivation segments and market segments. Firstly, similarities and differences among motivation segments in visitor satisfaction with services for environmental interpretation will be presented. It is followed by similarities and differences between market segments in visitor satisfaction with these services.

\subsection{Visitor satisfaction with services for environmental interpretation according to motivation segments}

This section presents the similarities and differences in visitor satisfaction among motivation segments. Firstly, motivations to visit Cat Tien National Park will be analysed. This is followed by the segmentation process that involves factor analysis and cluster analysis. Motivation factors derived from factor analysis are used in cluster analysis to generate clusters of visitors. Next, comparisons are implemented including clusters' profiles, importance and performance ratings for services across clusters, and importance and performance ratings for roles of site interpreters across clusters. Then, the importance-performance grids of services for environmental interpretation and roles of site interpreters will be drawn for each cluster, to identify the differences in visitor satisfaction among clusters.

\subsubsection{Visitor motivation to visit Cat Tien National Park}

Respondents were asked to rate the importance level of each motivational variable for visiting Cat Tien National Park according to a 5-point Likert scale. Level 1 indicated the motivational variable was "not important at all" and level 5 indicated it was "extremely important". Table 6.1 describes a comparison of motivational variables according to means. As these motivational variables will be analysed later by factor analysis, this section will only discuss the most and the least important motivations. The motivations were organized into three different categories identifying different groups of motivations: Mean>4.00, 3.91 $>$ Mean $>3.68$ and Mean=3.17.

As can be seen from Table 6.1, the four most important motivations were "To relax and rest" (4.44), "To enjoy scenic beauty" (4.43), "To view reptiles" (4.43) and "To view mammals" (4.42). These high means along with low standard deviations show the consistency among visitor evaluations, 
emphasizing the importance of these four motivations. Similarly, "To take photographs" and "To learn more about ecosystems" were also important motivations to visit Cat Tien National Park of these respondents with high mean scores of 4.19 and 4.05 respectively. The standard deviations were less than 1.0 showing the high consensus among visitors in assessing the importance of these motivations.

The second most important group of motivations (with mean range from 3.68 to 3.91) included "To learn about reptiles", "To learn about mammals”, "To learn about history of Cat Tien National Park", "For a totally new and different experience", "To travel with friends and family" and "To escape from the daily life routine". These motivational variables served for learning and novelty seeking purposes. All of the standard deviations were less than 1.0 indicating that visitor evaluation of these motivations was consistent.

The least important motivation according to these respondents was "To meet people with similar interests and hobbies" (3.17). The standard deviation was less than 1.0 showing the high consensus among these respondents in assessing the importance of this motivation.

Table 6.1. Comparison of motivational variables

\begin{tabular}{|l|c|c|}
\hline \multicolumn{1}{|c|}{ Motivation statements } & Mean & SD \\
\hline M9-To relax and rest & 4.44 & 0.65 \\
\hline M1-To enjoy scenic beauty & 4.43 & 0.64 \\
\hline M5-To view reptiles & 4.43 & 0.66 \\
\hline M3-To view mammals & 4.42 & 0.68 \\
\hline M13- To take photographs & 4.19 & 0.59 \\
\hline M2-To learn more about ecosystems & 4.05 & 0.67 \\
\hline M6-To learn about reptiles & 3.91 & 0.78 \\
\hline M4-To learn about mammals & 3.90 & 0.79 \\
\hline M7-To learn about history of Cat Tien National Park & 3.89 & 0.73 \\
\hline M8-For a totally new and different experience & 3.84 & 0.85 \\
\hline M12-To travel with friends and family & 3.84 & 0.95 \\
\hline M10-To escape from the daily life routine & 3.68 & 0.93 \\
\hline M11-To meet people with similar interests and hobbies & 3.17 & 0.96 \\
\hline SD= Standard deviation; $n=237$ & &
\end{tabular}

This comparison showed that visitors came to Cat Tien National Park mostly for relaxing, learning and novelty-seeking reasons. In order to identify the dimensions driving these motivational variables, factor analysis was undertaken to reduce the original data into a small set of factors based on the correlation among variables.

\subsubsection{Factor analysis}

Before conducting factor analysis, the data set was assessed in terms of its suitability. The sample size, inter-correlations among variables, KMO measure and Bartlett's test were examined. The data set was proved to be suitable for conducting factor analysis (see Chapter 3, Methodology). Principal 
Component Analysis with Varimax orthogonal rotation was chosen in this study to extract factors. Firstly, it is essential to identify the number of factors. One rule of thumb to decide the number of factors is the eigenvalue-greater-than-one (Blaikie, 2003). The eigenvalue presents the proportion of variance that each factor occupied in the total variance (Hair et al., 2010). Factor analysis revealed two factors that had eigenvalues greater than one (3.388 and 2.662 respectively) and explained $33.9 \%$ and $26.6 \%$ of the total variance, respectively. Visual inspection of the scree plot also indicated that two factors should be retained. The two-factor solution explained $60.5 \%$ of the total variance. According to Blaikie (2003) and Field (2013), the importance of a variable to a factor can be measured by the factor loadings. The proportion of variance that a variable occupied in the total variance is presented by communalities (Hair et al., 2010). Factor loadings and communalities of the rotated solution are presented in Table 6.2. As can be seen in the Table 6.2, both factors 1 and 2 were loaded on "To view reptiles". To identify the variable "To view reptiles" belonging to which factor, its factor loading was squared. As indicated by Field (2013), by squaring the loading, the amount of variance caused by a variable in a factor can be measured. It was recommended to use a factor loading greater than 0.4 which explains $16 \%$ of the variance (Stevens, 2002, cited in Field, 2013, p. 682). The factor loading for the variable "To view reptiles" in factor 1 was $0.718>0.4$ which explains $51.6 \%$ of the variance. Therefore, this variable belongs to factor 1 .

The next step was testing the reliability of the factors created. Cronbach's alpha coefficients of factor 1 and factor 2 were 0.834 and 0.728 respectively. This means that the variables within each factor were internally consistent. The mean of factor 1 was 3.89 (Standard deviation $=0.59)$. The mean of factor 2 was 3.99 (Standard deviation $=0.56)$. 
Table 6.2. Factor analysis for visitor motivations to visit Cat Tien National Park

\begin{tabular}{|c|c|c|c|}
\hline \multicolumn{3}{|l|}{ Factor loadings } & \multirow[b]{2}{*}{ Communalities } \\
\hline Motivational variables & $\begin{array}{c}\text { Factor } 1 \\
\text { Learning }\end{array}$ & $\begin{array}{c}\text { Factor } 2 \\
\text { Experience }\end{array}$ & \\
\hline M6 - To learn about reptiles & 0.938 & & 0.910 \\
\hline M7 - To learn about the history of Cat Tien National Park & 0.922 & & 0.867 \\
\hline M2 - To learn more about ecosystems & 0.879 & & 0.783 \\
\hline M5 - To view reptiles & 0.718 & 0.339 & 0.631 \\
\hline M11 - To meet people with similar interest and hobbies & 0.471 & & 0.240 \\
\hline M9 - To relax and rest & & 0.802 & 0.679 \\
\hline M13 - To take photographs & & 0.744 & 0.562 \\
\hline M10 - To escape from the daily life routine & & 0.702 & 0.541 \\
\hline M12 - To travel with friends and family & & 0.659 & 0.439 \\
\hline M8 - For a totally new and different experience & & 0.594 & 0.400 \\
\hline Eigenvalues & 3.388 & 2.662 & \\
\hline Variance explained (\%) & 33.9 & 26.6 & \\
\hline Cumulative variance explained (\%) & 33.9 & 60.5 & \\
\hline Scale mean & 3.89 & 3.99 & \\
\hline Standard deviation & 0.59 & 0.56 & \\
\hline Cronbach's alpha & 0.834 & 0.728 & \\
\hline
\end{tabular}

After the factors were identified, they were interpreted in the next step. Two factors were labelled "Learning" and "Experience" according to the common features of the motivational variables included in each factor.

The first factor, "Learning", consists of five motivational variables, which are "To learn about reptiles", "To learn about the history of Cat Tien National Park", "To learn more about ecosystems", "To view reptiles" and "To meet people with similar interest and hobbies". Table 6.2 shows that motivational variables constructing the "Learning" factor had the highest factor loadings in comparison with the other factor, which reflects a strong correlation with the factor. Moreover, the variables included in this factor had high correlations with each other as reflected by the Cronbach's alpha coefficient $=0.834$. With an eigenvalue of 3.388 , this factor constituted the highest amount of variance explained (33.9\%).

The second factor, "Experience", also includes five motivational variables, which are "To relax and rest", "To take photographs", "To escape from the daily life routine", "To travel with friends and family" and "For a totally new and different experience". The reliability coefficient for this factor was relatively high with 0.728 , which indicates a strong correlation between variables under this factor. With an eigenvalue of 2.662 , this factor explained $26.6 \%$ of the total variance. 
To conclude, the two main motivations for visiting Cat Tien National Park resulted from factor analysis were labelled "Learning" and "Experience". However, these motivations may play different roles for each visitor, which may influence visitors in rating the importance and performance of services for environmental interpretation. Hence, visitors were classified based on these motivations to understand how they are different in their demographic features, trip-related characteristics and their satisfaction levels with services for environmental interpretation.

\subsubsection{Cluster identification - Cluster analysis}

As mentioned in Chapter Three, this study used the K-means clustering method, in which the number of clusters had to be identified at the first stage. K-means was first run for 1 to 10 clusters in $\mathrm{R}$ to determine the optimal number of clusters by applying the elbow approach (Frochot and Morrison, 2000). The scatter plot from $R$ indicated that having four clusters is optimal (Figure 6.1). Increasing the number of clusters will not improve the within-cluster Sum of Squares by much.

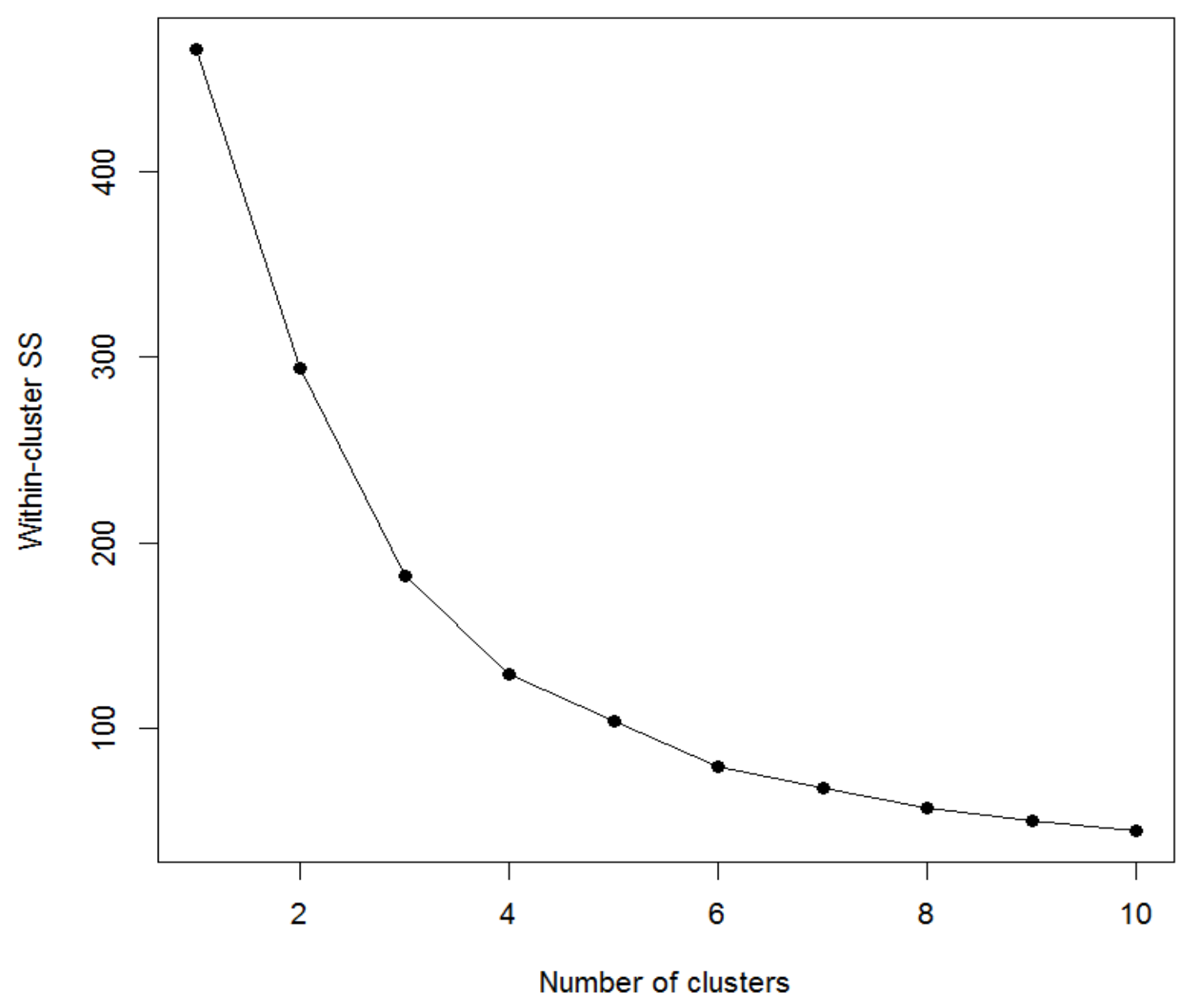

Figure 6.1. Elbow for K-means clustering in $R$ 
K-means clustering was then run in SPSS with a four cluster solution. Table 6.3 shows that cluster memberships were reasonably distributed in the four cluster solution: 70 cases in cluster 1; 56 cases in cluster 2; 56 cases in cluster 3 and 52 cases in cluster 4 . The final cluster centres (i.e. means on the variables used to cluster) were compared using ANOVA and the results confirmed that the difference among four clusters were statistically significant, which indicates a large distance among clusters.

Table 6.3 illustrates the one-way ANOVA results of motivation factors across clusters. The results of a post hoc test $(\mathrm{p}<0.0005 ; \mathrm{p}<0.0005 ; \mathrm{p}<0.0005$; $\mathrm{p}<0.0005)$ indicate that significant differences were found among means of four clusters for the factor "Learning", with respect to learning motivations. Likewise, the results of a post hoc test $(p<0.0005 ; p<0.0005 ; p<0.0005 ; p=0.001)$ show that there were significant differences among means of four clusters for the factor "Experience".

Table 6.3. Mean comparison of motivation factors by clusters

\begin{tabular}{|c|c|c|c|c|c|c|}
\hline \multirow[b]{2}{*}{ Factors } & \multicolumn{4}{|c|}{ Clusters } & \multirow[b]{2}{*}{ F ratio } & \multirow[b]{2}{*}{ Sig. } \\
\hline & $\begin{array}{c}\text { Cluster 1 } \\
\text { Area } \\
\text { enthusiasts } \\
n=70\end{array}$ & $\begin{array}{c}\text { Cluster } 2 \\
\text { Passive } \\
\text { visitors } \\
n=56\end{array}$ & $\begin{array}{c}\text { Cluster 3 } \\
\text { Active } \\
\text { Learners } \\
n=56\end{array}$ & $\begin{array}{c}\text { Cluster } 4 \\
\text { Novelty } \\
\text { seekers } \\
\text { n=52 }\end{array}$ & & \\
\hline Learning & 4.15 & 3.41 & 4.56 & 3.36 & 173.481 & $p<0.0005$ \\
\hline M6 - To learn about reptiles & 4.10 & 3.45 & 4.86 & 3.15 & & \\
\hline $\begin{array}{l}\text { M7 - To learn about the history of } \\
\text { Cat Tien National Park }\end{array}$ & 4.10 & 3.45 & 4.73 & 3.21 & & \\
\hline $\begin{array}{l}\text { M2 - To learn more about } \\
\text { ecosystems }\end{array}$ & 4.20 & 3.63 & 4.77 & 3.54 & & \\
\hline M5 - To view reptiles & 4.86 & 3.80 & 4.86 & 4.15 & & \\
\hline $\begin{array}{l}\text { M11 - To meet people with similar } \\
\text { interest and hobbies }\end{array}$ & 3.50 & 2.75 & 3.59 & 2.75 & & \\
\hline Experience & 4.51 & 3.40 & 3.69 & 4.29 & 148.309 & $\mathrm{p}<0.0005$ \\
\hline M9 - To relax and rest & 4.89 & 3.95 & 4.04 & 4.83 & & \\
\hline M13 - To take photographs & 4.50 & 3.86 & 3.89 & 4.44 & & \\
\hline $\begin{array}{l}\text { M10 - To escape from the daily life } \\
\text { routine }\end{array}$ & 4.39 & 2.75 & 3.46 & 3.96 & & \\
\hline $\begin{array}{l}\text { M12 - To travel with friends and } \\
\text { family }\end{array}$ & 4.30 & 3.25 & 3.46 & 4.27 & & \\
\hline $\begin{array}{l}\text { M8 - For a totally new and different } \\
\text { experience }\end{array}$ & 4.46 & 3.18 & 3.61 & 3.94 & & \\
\hline
\end{tabular}

To interpret the cluster profile, clusters were labelled according to the importance of motivation factors to each cluster. It should be accepted that it is hard to create a label that represents all features of a cluster. Short labels were used to reflect the distinct features of the cluster only. Cluster 1 had relatively high means for both factors "Learning" and "Experience”. Therefore, this cluster was named "Area enthusiasts". Cluster 2 had low means for both factors; thus, it was labelled "Passive visitors". Cluster 3 had the highest mean for "Learning" factor but had a relatively low mean for the "Experience" factor in comparison with the means of the three other clusters; therefore, it was labelled "Active Learners". The last cluster had a high mean for the "Experience" factor but had the lowest mean for the "Learning" factor; hence, it was called "Novelty seekers". 
"Area enthusiasts" is the largest cluster with 70 visitors representing nearly one third of the total sample (29.9\%). "Passive visitors" and "Active Learners" clusters each accounted for $23.9 \%$ of the sample. The remaining $22.2 \%$ of respondents are in the "Novelty seekers" cluster.

Regarding the similarity of the clusters, Table 6.4 shows that the Euclidean distance between "Active learners" and "Novelty seekers" was the furthest (1.339) while the distance between "Area enthusiasts" and "Novelty seekers" was the closest (0.819). Moreover, "Active learners" seems to be furthest from the three other clusters.

Table 6.4. Distances between final clusters centres

\begin{tabular}{|l|c|c|c|c|}
\hline \multicolumn{1}{|c|}{ Clusters } & $\begin{array}{c}\text { Area } \\
\text { enthusiasts }\end{array}$ & $\begin{array}{c}\text { Passive } \\
\text { visitors }\end{array}$ & $\begin{array}{c}\text { Active } \\
\text { learners }\end{array}$ & $\begin{array}{c}\text { Novelty } \\
\text { seekers }\end{array}$ \\
\hline Area enthusiasts & & 1.332 & 0.910 & 0.819 \\
Passive visitors & 1.332 & & 1.184 & 0.894 \\
Active learners & 0.910 & 1.184 & & 1.339 \\
Novelty seekers & 0.819 & 0.894 & 1.339 & \\
\hline
\end{tabular}

To sum up, it appears that a large number of visitors to Cat Tien National Park were classified as "Area enthusiasts", who gave high ratings for both "Learning" and "Experience" factors. A significant number of visitors with low ratings on both factors were classified as "Passive visitors". "Active Learners" were those who rated highly for "Learning” factor. "Novelty seekers" shared more similarities with "Area enthusiasts" than "Passive visitors" and "Active learners". These were the visitors who looked for new and relaxing experience.

\subsubsection{Clusters' demographic characteristics}

The previous section showed that there are four groups of visitors to Cat Tien National Park. These groups of visitors differed from each other according to their motivations for visiting Cat Tien National Park. This section will provide some background information of these groups of visitors in terms of their demographic features.

Table 6.5 shows that these four clusters shared some differences and similarities in demographic features. There were significant differences among clusters regarding nationality, gender and educational level (all $\mathrm{p}<0.05$ ). In contrast, no statistically significant difference was found in age group across clusters. 
Table 6.5. Summary of Chi square test for clusters' social demographic profiles

\begin{tabular}{|l|c|c|c|}
\hline \multicolumn{1}{|c|}{ Profile attributes } & $\chi^{2}$ & df & Sig. \\
\hline Nationality & 47.179 & 3 & $\mathrm{p}<0.0005$ \\
\hline Gender & 10.091 & 3 & 0.018 \\
\hline Educational level & 21.952 & 9 & 0.009 \\
\hline Age group & 10.742 & 6 & 0.097 \\
\hline
\end{tabular}

Sig (2-tailed $)=p$-value $; d f=$ degree of freedom

As displayed in Table 6.6, the four clusters of visitors were significantly different from each other in terms of nationality $\left(\chi^{2}(3)=47.179, p=0.000\right)$. In general, domestic visitors were dominant in the total sample, particularly with "Novelty seekers" (98.1\%) and “Area enthusiasts" (88.6\%). Approximately half of the total "Active learners" were domestic visitors. Domestic visitors also accounted for one half of the total "Passive visitors". With a favourable location (approximately 150km from Ho Chi Minh City), Cat Tien National Park has been a popular destination for domestic visitors who want to go for a short holiday. "Passive visitors" and "Active learners" were the two clusters having large proportions of international visitors, with $50 \%$ and $41.1 \%$ respectively.

Visitors also showed significant difference in terms of gender $\left(\chi^{2}(3)=10.091, p=0.018\right)$. "Area enthusiasts" and "Novelty seekers" were the two clusters including more females than males with $64.3 \%$ and 59.6\%, respectively. However, "Passive visitors" witnessed a gender balance between males and females. "Active learners" was the only cluster having a majority of males with $62.5 \%$.

In addition, visitors across clusters differed in educational level $\left(\chi^{2}(9)=21.952, p=0.009\right)$. University graduates were dominant across the four clusters in the same pattern as the total sample. The difference was found in the "Passive visitors" cluster. This cluster had the highest rate of those holding postgraduate degrees ( $23.2 \%$ of the total cluster) in comparison with the three other clusters, "Area enthusiasts" (5.7\%), "Active learners" (8.9\%) and "Novelty seekers" (3.8\%). As a result, "Passive visitors" was also the cluster with those having the highest educational level. 
Table 6.6. Social demographic profiles by clusters

\begin{tabular}{|c|c|c|c|c|c|c|c|c|c|c|}
\hline \multirow[t]{2}{*}{ Groups } & \multicolumn{2}{|c|}{$\begin{array}{c}\text { Area } \\
\text { enthusiasts } \\
\mathbf{n}=\mathbf{7 0} \\
\end{array}$} & \multicolumn{2}{|c|}{$\begin{array}{c}\text { Passive } \\
\text { visitors } \\
n=56\end{array}$} & \multicolumn{2}{|c|}{$\begin{array}{c}\text { Active } \\
\text { learners } \\
\mathbf{n}=\mathbf{5 6} \\
\end{array}$} & \multicolumn{2}{|c|}{$\begin{array}{c}\text { Novelty } \\
\text { seekers } \\
\mathbf{n}=\mathbf{5 2} \\
\end{array}$} & \multicolumn{2}{|c|}{$\begin{array}{r}\text { Total } \\
\mathbf{n}=\mathbf{2 3 4}\end{array}$} \\
\hline & $\mathbf{n}$ & $\%$ & $\mathbf{n}$ & $\%$ & $\mathbf{n}$ & $\%$ & $\mathbf{n}$ & $\%$ & $\mathbf{n}$ & $\%$ \\
\hline \multicolumn{11}{|l|}{ Nationality } \\
\hline International visitors & 8 & 11.4 & 28 & 50.0 & 23 & 41.1 & 1 & 1.9 & 60 & 25.6 \\
\hline Domestic visitors & 62 & 88.6 & 28 & 50.0 & 33 & 58.9 & 51 & 98.1 & 174 & 74.4 \\
\hline \multicolumn{11}{|l|}{ Gender } \\
\hline Female & 45 & 64.3 & 28 & 50.0 & 21 & 37.5 & 31 & 59.6 & 125 & 53.4 \\
\hline Male & 25 & 35.7 & 28 & 50.0 & 35 & 62.5 & 21 & 40.4 & 109 & 46.6 \\
\hline \multicolumn{11}{|l|}{ Educational level } \\
\hline $\begin{array}{l}\text { Secondary education } \\
\text { and vocational school }\end{array}$ & 15 & 21.4 & 8 & 14.3 & 12 & 21.4 & 11 & 21.2 & 46 & 19.7 \\
\hline University Graduate & 51 & 72.9 & 35 & 62.5 & 39 & 69.6 & 39 & 75.0 & 164 & 70.1 \\
\hline Postgraduate & & 5.7 & 13 & 23.2 & 5 & 8.9 & 2 & 3.8 & 24 & 10.3 \\
\hline \multicolumn{11}{|l|}{ Age } \\
\hline $15-34$ & 36 & 51.4 & 20 & 35.7 & 21 & 37.5 & 24 & 46.2 & 101 & 43.2 \\
\hline $35-44$ & 9 & 12.9 & 20 & 35.7 & 18 & 32.1 & 14 & 26.9 & 61 & 26.1 \\
\hline 45 and over & 25 & 35.7 & 16 & 28.6 & 17 & 30.4 & 14 & 26.9 & 72 & 30.8 \\
\hline
\end{tabular}

Conversely, there were no significant differences in terms of their age across clusters as shown in Table 6.6. Visitors aged from 15 to 34 were dominant in all four clusters. It is worth noticing that "Area enthusiasts" had a higher proportion of those aged 45 and over (35.7\% of the total cluster) in comparison to other clusters. "Area enthusiasts" also had a lower percentage of those aged 35-44. However, these differences were not statistically significant.

To sum up, most of the visitors to Cat Tien National Park were in the young age group (15-34). However, there were significant differences across clusters in other characteristics. "Area enthusiasts" tended to be domestic visitors who are females, who may hold Bachelor degrees. "Passive visitors" were domestic or international visitors with a high educational level. These people tend to be university graduates or postgraduates. "Active learners" were domestic visitors and they tend to be males. These people are also university graduates. "Novelty seekers" are domestic visitors who are females with a Bachelor's degree.

The clusters' demographic profile has been described. The next section will present the trip related characteristics across clusters to better understand their travel patterns.

\subsubsection{Clusters' trip related characteristics}

Table 6.7 summarizes the results of the Chi-square test for trip-related characteristics across clusters. It showed that these clusters were significantly different in terms of length of stay and the number 
of times they had visited national parks in the last three years but were not significantly different regarding their mode of travel and number of times visited Cat Tien National Park. Most of the visitors were free independent travellers with (65\%). Most of them had not yet been to Cat Tien National Park before (90.2\%) (see Table 6.8).

Table 6.7. Summary of Chi square test for clusters' trip related characteristics

\begin{tabular}{|l|c|c|c|}
\hline \multicolumn{1}{|c|}{ Trip related attributes } & $\chi^{2}$ & df & Sig. \\
\hline Length of stay & 10.215 & 3 & 0.019 \\
\hline Times visited national parks & 13.261 & 3 & 0.004 \\
\hline Mode of travel & 5.959 & 3 & 0.114 \\
\hline Times visited Cat Tien National Park & 5.837 & 3 & 0.120 \\
\hline
\end{tabular}

Sig (2-tailed) $=p$-value; $d f=$ degree of freedom

Table 6.8 shows that there was a significant difference in visitor length of stay across clusters $\left(\chi^{2}(3)=10.215, p=0.019\right)$. Overall, the majority of visitors tended to stay for two days and one night. This pattern remains the same for "Area enthusiasts", "Passive visitors" and "Active learners" with the percentages of $67.1 \%, 73.2 \%$ and $76.8 \%$ respectively. A significant difference was found in the "Novelty seekers" cluster. This cluster had a high percentage of those who intended to stay for only a day, with $50 \%$ of the total cluster.

Also, a statistically significant difference was found in the number of times clusters had visited national parks in the last three years $\left(\chi^{2}(3)=13.261, p=0.004\right)$. Generally, there was a relatively balance between visitors who had not been to national parks in the last three years and those who had visited one or more times. However, most of the "Novelty seekers" and "Area enthusiasts" had not visited national parks in the last three years with $71.2 \%$ and $58.6 \%$ respectively. Conversely, the majority of "Passive visitors" and "Active learners" had visited national parks more than once in the last three years, with $57.1 \%$ and $58.9 \%$ respectively. 
Table 6.8. Trip related characteristics by clusters

\begin{tabular}{|c|c|c|c|c|c|c|c|c|c|c|}
\hline \multirow[t]{2}{*}{ Groups } & \multicolumn{2}{|c|}{$\begin{array}{c}\text { Area } \\
\text { enthusiasts } \\
\mathbf{n}=\mathbf{7 0} \\
\end{array}$} & \multicolumn{2}{|c|}{$\begin{array}{c}\begin{array}{c}\text { Passive } \\
\text { visitors } \\
\mathrm{n}=56\end{array} \\
\end{array}$} & \multicolumn{2}{|c|}{$\begin{array}{c}\text { Active } \\
\text { learners } \\
n=56 \\
\end{array}$} & \multicolumn{2}{|c|}{$\begin{array}{c}\text { Novelty } \\
\text { seekers } \\
\mathbf{n}=52 \\
\end{array}$} & \multicolumn{2}{|c|}{$\begin{array}{r}\text { Total } \\
\mathbf{n}=\mathbf{2 3 4}\end{array}$} \\
\hline & $\mathbf{n}$ & $\%$ & $\mathbf{n}$ & $\%$ & $\mathbf{n}$ & $\%$ & $\mathbf{n}$ & $\%$ & $\mathbf{n}$ & $\%$ \\
\hline Length of stay & & & & & & & & & & \\
\hline For 1 day & 23 & 32.9 & 15 & 26.8 & 13 & 23.2 & 26 & 50 & 77 & 32.9 \\
\hline 2 days and 1 night & 47 & 67.1 & 41 & 73.2 & 43 & 76.8 & 26 & 50 & 157 & 67.1 \\
\hline Times visited national park & & & & & & & & & & \\
\hline 0 times & 41 & 58.6 & 24 & 42.9 & 23 & 41.1 & 37 & 71.2 & 125 & 53.4 \\
\hline One or more times & 29 & 41.4 & 32 & 57.1 & 33 & 58.9 & 15 & 28.8 & 109 & 46.6 \\
\hline Mode of travel & & & & & & & & & & \\
\hline Free independent travellers & 53 & 75.7 & 33 & 58.9 & 32 & 57.1 & 34 & 65.4 & 152 & 65.0 \\
\hline Packaged tour & 17 & 24.3 & 23 & 41.1 & 24 & 42.9 & 18 & 34.6 & 82 & 35.0 \\
\hline $\begin{array}{l}\text { Times visited Cat Tier } \\
\text { National Park }\end{array}$ & & & & & & & & & & \\
\hline 0 times & 59 & 84.3 & 52 & 92.9 & 54 & 96.4 & 46 & 88.5 & 211 & 90.2 \\
\hline Once & 11 & 15.7 & 4 & 7.1 & 2 & 3.6 & 6 & 11.5 & 23 & 9.8 \\
\hline
\end{tabular}

In brief, the visitors to Cat Tien National Park tended to be similar to each other in their mode of travel (arranging their own travel). Moreover, these visitors had not been to Cat Tien National Park before. However, these four clusters were significantly different regarding the length of stay and number of times visited national parks. Specifically, "Area enthusiasts” tend to stay for two days and one night, and have not visited national parks in the last three years. "Passive visitors" and "Active learners" also tended to spend two days and one night in Cat Tien National Park, but the majority of them had visited national parks in the last three years. "Novelty seekers" appear to be those who have not visited national parks in the last three years and half of them only wanted to stay for one day in the national park.

\subsubsection{Visitor satisfaction with services for environmental interpretation according to motivation segments}

The previous sections helped to identify visitor clusters according to their motivations for visiting Cat Tien National Park. These sections also described the demographic profiles and trip-related characteristics of each cluster. This section will point out the similarities and differences in visitor evaluations of the importance and performance of services for environmental interpretation in Cat Tien National Park across four clusters. Ranking order, ANOVA and post-hoc tests will be used to support the analysis. Lastly, an importance-performance grid will be drawn for each cluster, to find 
out the differences in visitor satisfaction with services for environmental interpretation across clusters.

\subsubsection{The importance of services for environmental interpretation by clusters}

Table 6.9 shows that the evaluations of the importance of site interpreters, interpretive signs, videos at the rescue centre, staff at the museum and displays at the museum remained high, while the evaluations of the importance of staff at the ticket office and directional signs were very low across clusters. Regarding ranking order, site interpreters were still the most important service for environmental interpretation across the four clusters. Staff at the ticket office and directional signs were still the least important services according to the four clusters. Site interpreters, interpretive signs, videos at the rescue centre and staff at the museum were the four most important services according to "Area enthusiasts", "Passive visitors" and "Novelty seekers". Meanwhile, site interpreters, videos at the rescue centre, staff at the museum and displays at the museum were the four most important services according to "Active learners".

Table 6.9. The importance of services for environmental interpretation by clusters

\begin{tabular}{|c|c|c|c|c|c|c|c|c|c|c|}
\hline $\begin{array}{c}\text { Importance of } \\
\text { services } \\
\text { for environmental } \\
\text { interpretation }\end{array}$ & $\begin{array}{c}\text { Overall } \\
\text { sample } \\
\mathbf{n}=\mathbf{2 3 7}\end{array}$ & RO & $\begin{array}{c}\text { Area } \\
\text { enthusiasts } \\
\mathbf{n}=\mathbf{7 0}\end{array}$ & RO & $\begin{array}{c}\begin{array}{c}\text { Passive } \\
\text { visitors } \\
\mathrm{n}=56\end{array}\end{array}$ & RO & $\begin{array}{c}\text { Active } \\
\text { learners } \\
\mathrm{n}=56\end{array}$ & RO & $\begin{array}{c}\begin{array}{c}\text { Novelty } \\
\text { seekers } \\
\mathbf{n}=52\end{array}\end{array}$ & RO \\
\hline Site interpreter & 4.82 & 1 & 4.86 & 1 & 4.67 & 1 & 4.93 & 1 & 4.90 & 1 \\
\hline Interpretive signs & 4.67 & 2 & 4.79 & 2 & 4.45 & 2 & 4.70 & 5 & 4.77 & 2 \\
\hline Videos at rescue centre & 4.64 & 3 & 4.73 & 3 & 4.42 & 3 & 4.78 & 2 & 4.66 & 4 \\
\hline Staff at museum & 4.58 & 4 & 4.56 & 4 & 4.34 & 4 & 4.76 & 3 & 4.67 & 3 \\
\hline Displays at museum & 4.44 & 5 & 4.32 & 5 & 4.26 & 5 & 4.72 & 4 & 4.49 & 5 \\
\hline Brochure & 3.51 & 6 & 3.69 & 6 & 2.98 & 6 & 3.71 & 6 & 3.62 & 6 \\
\hline Directional signs & 2.18 & 7 & 2.04 & 8 & 2.16 & 7 & 2.25 & 7 & 2.29 & 7 \\
\hline Staff at ticket office & 2.03 & 8 & 2.10 & 7 & 1.87 & 8 & 2.07 & 8 & 2.08 & 8 \\
\hline
\end{tabular}

$R O=$ Ranking order

Table 6.10 shows the results from ANOVA testing for the importance means of eight services for environmental interpretation in Cat Tien National Park. Statistically significant differences were found in the importance ratings for site interpreters, interpretive signs about the site, brochures at the ticket office, displays at the museum and videos at the rescue centre (all $p$-values less than 0.00625, as determined by applying the Bonferroni correction to adjust for multiple comparisons). However, there was no significant difference in the importance ratings for staff at the ticket office, staff at the museum, and directional signs across clusters.

Table 6.10 shows that there was a significant difference in the importance ratings for site interpreters across clusters $(p=0.001)$. The result from a post hoc test $(p=0.006)$ indicates that the significant 
difference was found between "Passive visitors" and "Active learners". The importance of site interpreters rated by "Passive visitors" (4.67) was lower than by "Active learners" (4.93) (see Table $6.9)$.

The result from ANOVA shows that a significant difference was found in the importance ratings for interpretive signs $(p=0.001)$. The result from a post hoc test $(p=0.005)$ indicates that the importance rating from "Passive visitors" (4.45) was significantly lower than from "Area enthusiasts" (4.79) (see Table 6.9).

In addition, there was a significant difference in the importance assessments of videos at the rescue centre across clusters $(p=0.002)$. The result from a post hoc test $(p=0.001)$ indicates that importance of videos at rescue centre assessed by "Passive visitors" (4.42) was significantly lower than by “Active learners" (4.78) (see Table 6.9).

A significant difference was also found in the importance means for displays at the museum across clusters $(p=0.002)$. The results from a post hoc test $(p=0.003 ; p=0.003)$ show that importance mean for displays at museum from "Active learners" (4.72) was significantly higher than from "Area enthusiasts" (4.32) and "Passive visitors" (4.26) (see Table 6.9).

Interestingly, there was a significant difference in the importance ratings for brochure at the ticket office across four clusters $(p<0.0005)$. The results from a post hoc test $(p<0.0005 ; p<0.0005$; $p<0.0005)$ show that importance mean of brochure assessed by "Passive visitors" (2.98) was significantly lower than by 3 other clusters "Area enthusiasts" (3.69), "Active learners" (3.71) and "Novelty seekers" (3.62) (see Table 6.9). Passive visitors, being those who do not come to Cat Tien National Park for learning purposes, may rely on site interpreters when exploring the national park. Brochures for information about on-site activities may be not necessary.

Table 6.10. ANOVA testing for the importance ratings of services across clusters

\begin{tabular}{|l|c|}
\hline \multicolumn{1}{|c|}{$\begin{array}{c}\text { Importance of services } \\
\text { for environmental } \\
\text { interpretation }\end{array}$} & $\begin{array}{c}\text { Sig. } \\
\text { (ANOVA) }\end{array}$ \\
\hline Site interpreter/ local tour guide & 0.001 \\
\hline Interpretive signs about the site & 0.001 \\
\hline Videos at rescue centre & 0.002 \\
\hline Displays at museum & 0.002 \\
\hline Brochure at ticket office & $\mathrm{p}<0.0005$ \\
\hline Staff at ticket office & 0.273 \\
\hline Staff at museum & 0.007 \\
\hline Directional signs & 0.264 \\
\hline
\end{tabular}

Sig (2-tailed) $=p$-value 
In brief, there was a high consensus in visitor evaluation of the importance of staff at the ticket office, directional signs and staff at the museum. Nonetheless, there were some significant differences across clusters in importance assessments for other services. The importance means for site interpreters, displays at the museum and videos at the rescue centre rated by "Passive visitors" were significantly lower than by "Active learners", although the mean scores were high. Also, the importance rating for interpretive signs from "Passive visitors" was significantly lower than from "Area Enthusiasts" although all mean scores were high. Especially, the importance mean of brochures rated by "Passive visitors" was significantly lower than by 3 other clusters. The importance of displays at the museum assessed by "Active learners" (4.72) was higher than by “Area enthusiasts" (4.32).

\subsubsection{The performance of services for environmental interpretation by clusters}

Table 6.11 describes the performance means of services for environmental interpretation across clusters. Interpretive signs, site interpreters, staff at the museum and brochures were the top four services with high performance while directional signs, staff at the ticket office, displays at the museum and videos at the rescue centre were still at the bottom of the ranking order in all four clusters.

Table 6.11. The performance of services for environmental interpretation by clusters

\begin{tabular}{|c|c|c|c|c|c|c|c|c|c|c|}
\hline $\begin{array}{c}\text { Performance of } \\
\text { services } \\
\text { for environmental } \\
\text { interpretation }\end{array}$ & $\begin{array}{c}\text { Overall } \\
\text { sample } \\
\mathbf{n}=\mathbf{2 3 7}\end{array}$ & RO & $\begin{array}{c}\text { Area } \\
\text { enthusiasts } \\
n=70\end{array}$ & RO & $\begin{array}{c}\begin{array}{c}\text { Passive } \\
\text { visitors } \\
\mathrm{n}=56\end{array}\end{array}$ & RO & $\begin{array}{c}\text { Active } \\
\text { learners } \\
n=56\end{array}$ & RO & $\begin{array}{c}\text { Novelty } \\
\text { seekers } \\
\mathbf{n}=\mathbf{5 2}\end{array}$ & RO \\
\hline Interpretive signs & 4.45 & 1 & 4.66 & 1 & 4.25 & 1 & 4.27 & 1 & 4.65 & 1 \\
\hline Site interpreter & 4.03 & 2 & 4.05 & 3 & 4.00 & 2 & 3.96 & 3 & 4.13 & 2 \\
\hline Staff at museum & 4.00 & 3 & 4.08 & 2 & 3.85 & 4 & 4.00 & 2 & 4.05 & 3 \\
\hline Brochure at ticket office & 3.94 & 4 & 4.00 & 4 & 3.91 & 3 & 3.91 & 4 & 3.90 & 4 \\
\hline Directional signs & 3.42 & 5 & 3.39 & 6 & 3.63 & 5 & 3.32 & 6 & 3.38 & 5 \\
\hline Staff at ticket office & 3.34 & 6 & 3.49 & 5 & 3.22 & 8 & 3.27 & 8 & 3.37 & 6 \\
\hline Displays at museum & 3.28 & 7 & 3.32 & 7 & 3.26 & 7 & 3.28 & 7 & 3.23 & 7 \\
\hline Videos at rescue centre & 3.26 & 8 & 3.14 & 8 & 3.36 & 6 & 3.37 & 5 & 3.09 & 8 \\
\hline
\end{tabular}

$$
R O=\text { Ranking } \text { order }
$$

Table 6.12 shows the results from ANOVA testing for the performance means of eight services for environmental interpretation in Cat Tien National Park. The results show that a statistically significant difference was found in the performance rating for interpretive signs across clusters $(p<0.00625$, Bonferroni correction applied). However, there was no significant difference in the performance ratings for site interpreters, staff at the museum, brochures, directional signs, staff at the ticket office, displays at the museum and videos at the rescue centre across clusters. 
Table 6.12 shows that four clusters differed significantly in the performance ratings for interpretive signs $(p<0.0005)$. The results from a post hoc test indicate that the performance ratings for interpretive signs from “Area enthusiasts" $(p<0.0005 ; p=0.001)$ and "Novelty seekers" $(p=0.002$; $p=0.003$ ) were significantly higher than from "Passive visitors" and "Active learners" although the performance means were all high and ranked the $1^{\text {st }}$ in four clusters (see Table 6.11).

Table 6.12. ANOVA testing for the performance ratings of services across clusters

\begin{tabular}{|l|c|}
\hline \multicolumn{1}{|c|}{$\begin{array}{c}\text { Performance of services } \\
\text { for environmental } \\
\text { interpretation }\end{array}$} & $\begin{array}{c}\text { Sig. } \\
\text { (ANOVA) }\end{array}$ \\
\hline Interpretive signs about the site & $\mathrm{p}<0.0005$ \\
\hline Site interpreter/ local tour guide & 0.118 \\
\hline Staff at museum & 0.087 \\
\hline Brochure at ticket office & 0.536 \\
\hline Directional signs & 0.010 \\
\hline Staff at ticket office & 0.016 \\
\hline Displays at museum & 0.932 \\
\hline Videos at rescue centre & 0.017 \\
\hline
\end{tabular}

Sig (2-tailed $)=p$-value

In brief, there was a high consensus among four groups of visitors in assessing the performance of seven services: site interpreters, staff at the museum, brochures at the ticket office, directional signs, staff at the ticket office, displays at the museum and videos at the rescue centre. Still, a statistically significant difference was found in the performance rating for interpretive signs, where "Area enthusiasts" and "Novelty seekers" assessed higher than "Passive visitors" and "Active learners".

\subsubsection{The importance-performance grid of services for environmental interpretation for each cluster}

Figures 6.2, 6.3, 6.4 and 6.5 illustrate the importance-performance grids for the four clusters "Area enthusiasts", "Passive visitors", “Active learners" and "Novelty seekers". The intersection line was drawn according to the new grand means of each cluster ("Area enthusiasts", (3.89; 3.77); "Passive visitors", (3.70; 3.69); "Active learners", (3.99; 3.67) and "Novelty seekers", (3.94; 3.73)). The results indicate that there was no great difference found in the positions of these services in the importance-performance grids across clusters. Site interpreters, interpretive signs and staff at the museum were still in the "Keep up the good work" quadrant. Displays at the museum and videos at the rescue centre were in the "Concentrate here" quadrant. The "Low priority" quadrant contains staff at the ticket office and directional signs. However, in the grid for "Passive visitors", directional signs seem to move a bit nearer to the "Possibly overkill" quadrant (Figure 6.3). This means that the performance of directional signs assessed by "Passive visitors" was higher than by the three other clusters. Brochures were still in the "Possibly overkill" quadrant. However, the position of 
brochures in the grid of "Passive visitors" was lower than in three other grids of "Area enthusiasts", "Active learners" and "Novelty seekers" (Figure 6.3). Brochures were not perceived as important by "Passive visitors".

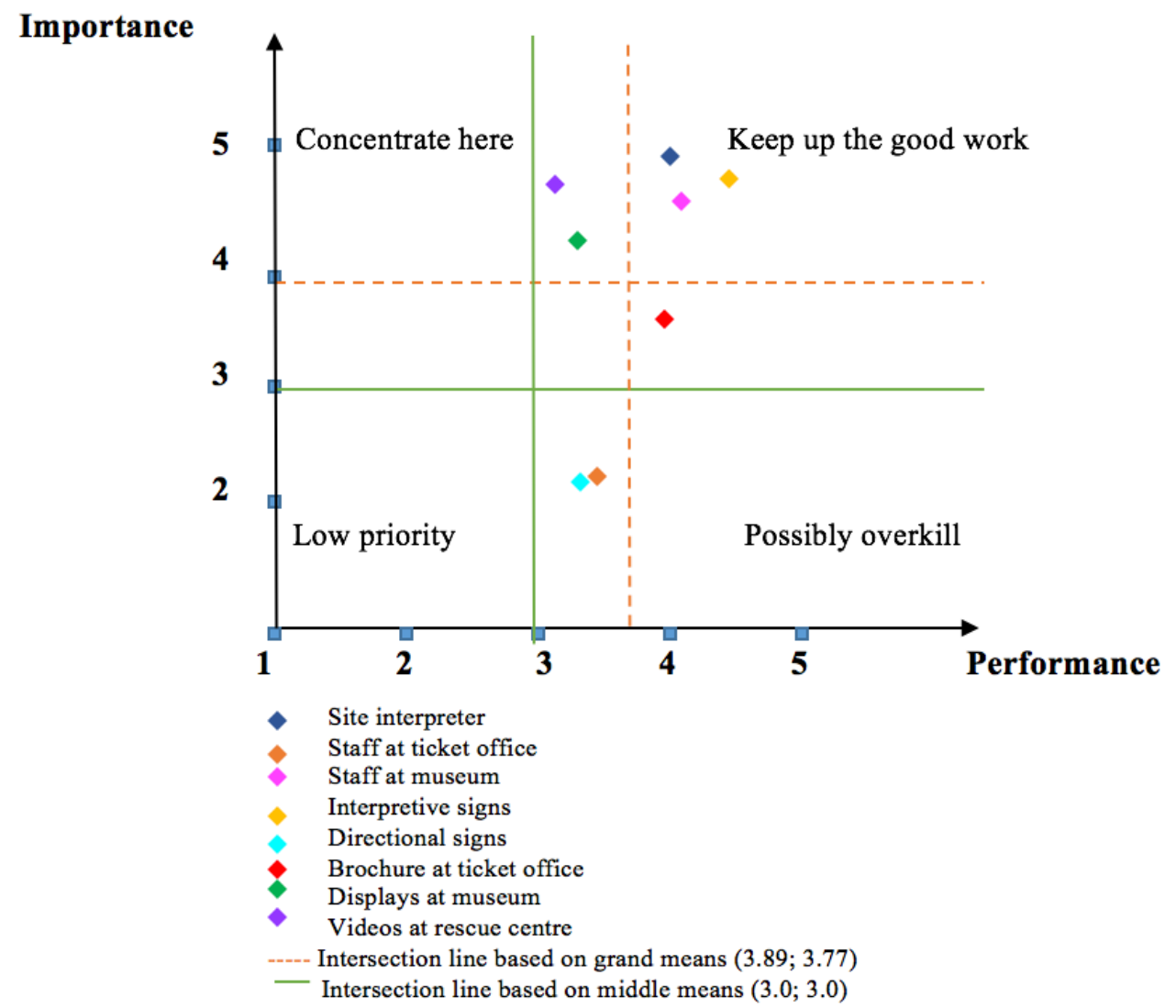

Figure 6.2. The grid of services for Area enthusiasts

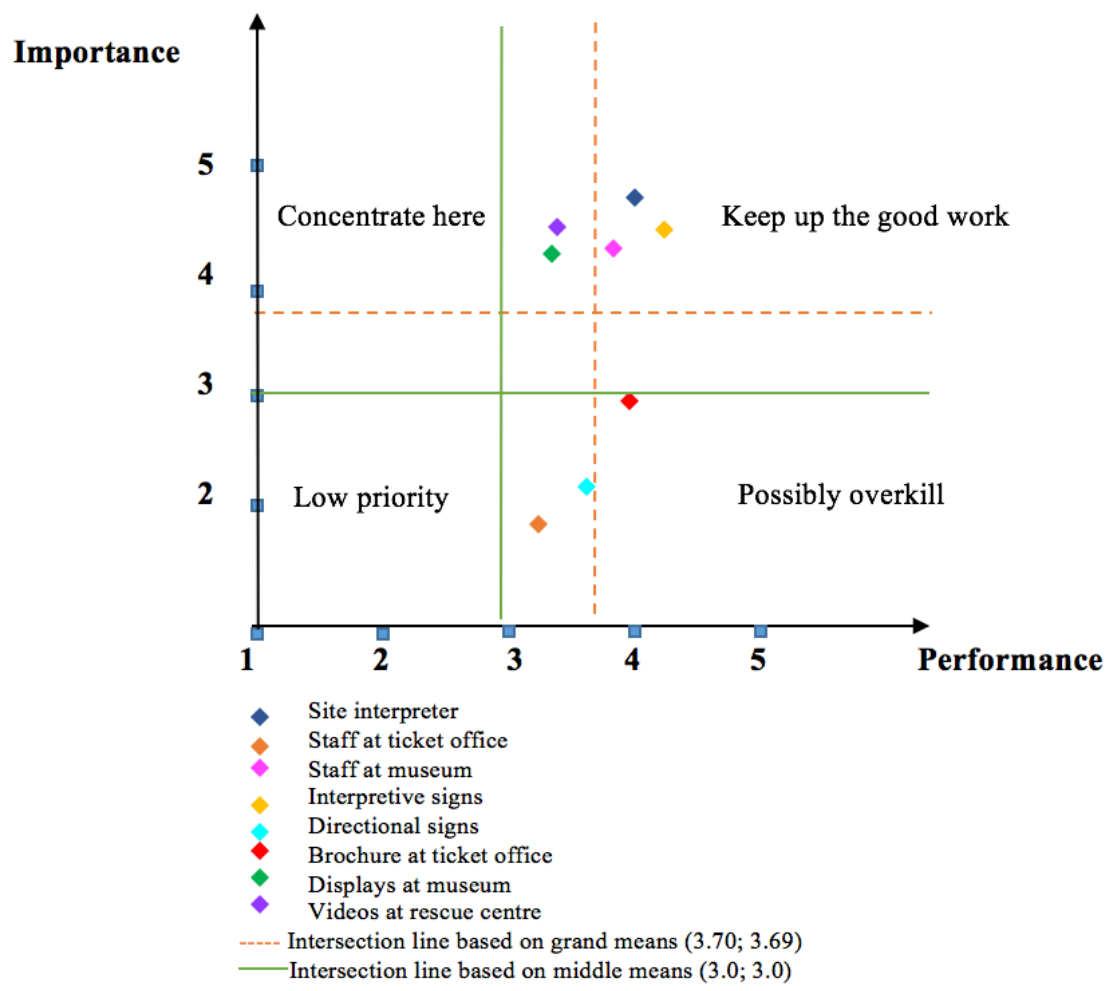

Figure 6.3. The grid of services for Passive visitors 


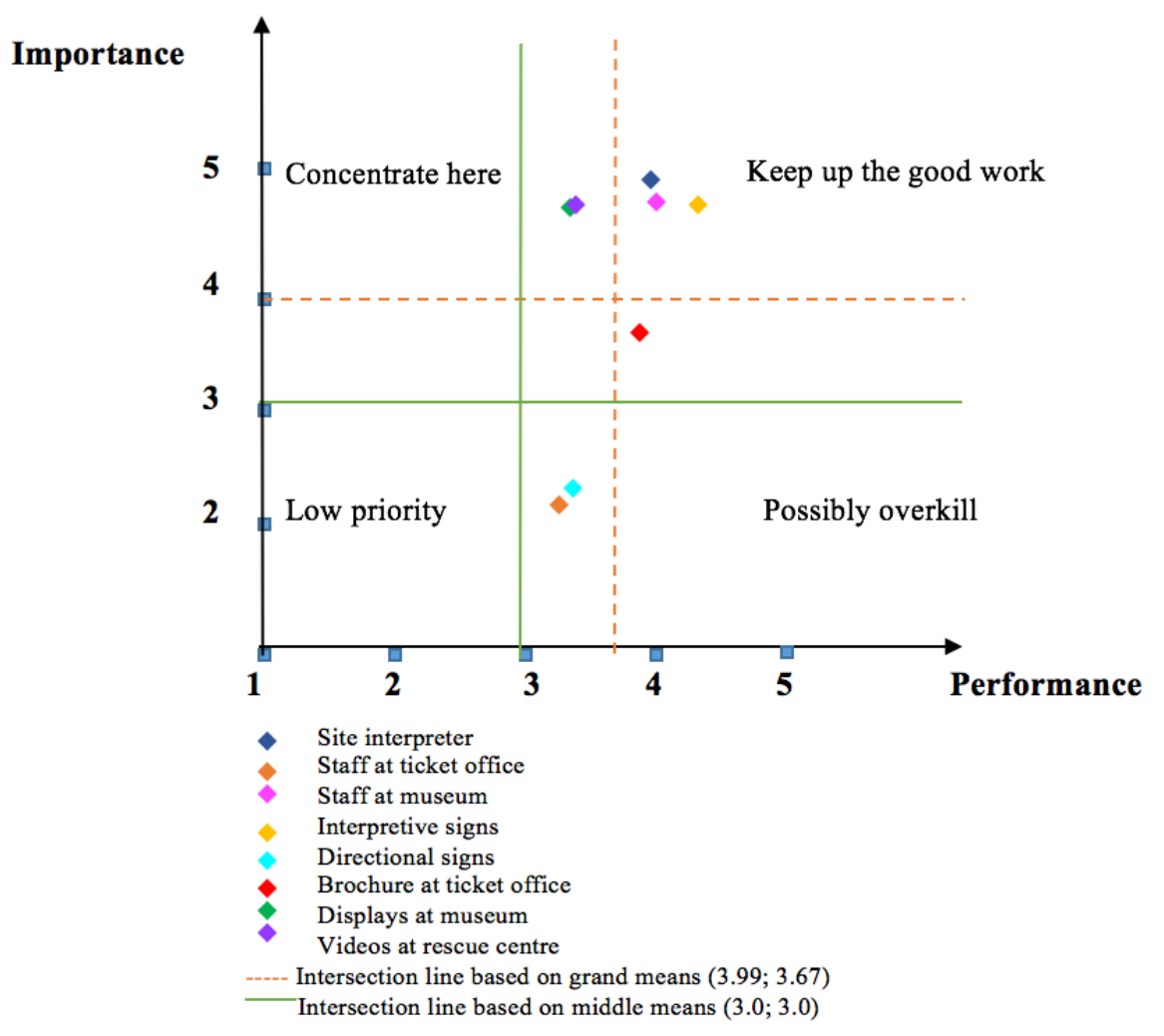

Figure 6.4. The grid of services for Active learners

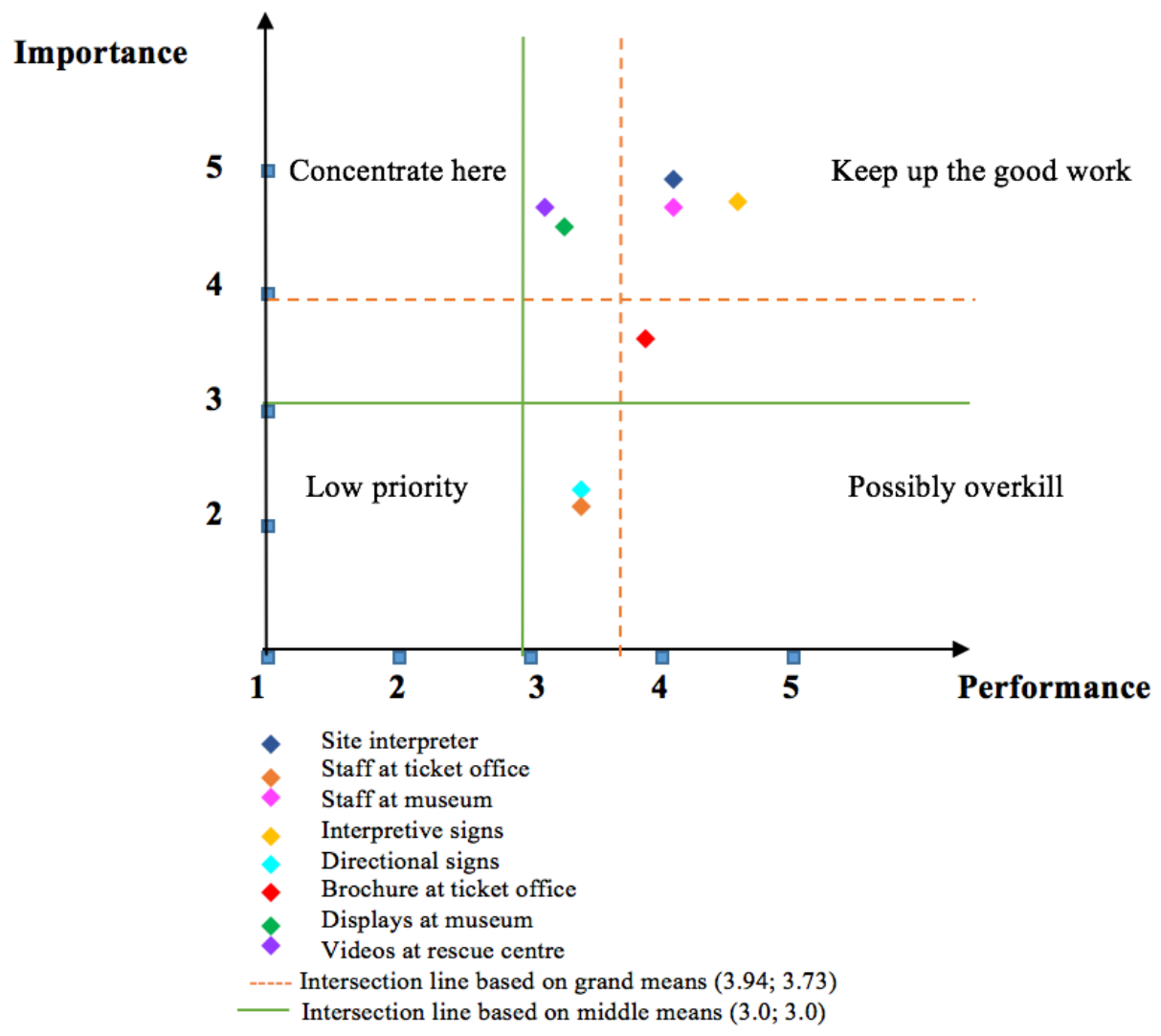

Figure 6.5. The grid of services for Novelty seekers 


\subsubsection{Visitor satisfaction with roles of site interpreters according to motivation segments}

This section will point out the similarities and differences in visitor evaluations of the importance and performance of 12 roles of site interpreters in Cat Tien National Park across four clusters. Ranking order and ANOVA will also be used in this section. The differences among motivation clusters will be explored thanks to importance-performance grids drawn for each cluster.

\subsubsection{The importance of roles of site interpreters by clusters}

Table 6.13 shows the importance means of roles of site interpreters across the four clusters. The results from Table 6.13 indicate that the importance means of role 1 , role 2 , role 4 , role 6 , role 7 , role 8, role 11 and role 12 remained high across the four clusters. Role 9 and role 10 were of high importance according to "Passive visitors" and "Active learners", but were not important according to "Area enthusiasts" and "Novelty seekers". Role 3 and role 5 were not important according to all four groups of visitors. Regarding ranking order, role 7, role 8, role 1 and role 12 were still the top four roles with high importance according to "Passive visitors" and "Active learners" while role 1, role 2, role 7 and role 12 were the four most important roles according to the "Area enthusiasts" and "Novelty seekers" clusters. In contrast, role 9, role 10, role 3 and role 5 were still the least important roles for "Area enthusiasts", "Passive visitors" and "Novelty seekers" while role 3, role 4 , role 5 and role 6 were the bottom four roles with low importance according to "Active learners". 
Table 6.13. The importance of roles of site interpreters by clusters

\begin{tabular}{|c|c|c|c|c|c|c|c|c|c|c|}
\hline $\begin{array}{l}\text { Importance of roles } \\
\text { of site interpreters }\end{array}$ & $\begin{array}{c}\text { Overall } \\
\text { sample } \\
\mathbf{n}=\mathbf{2 3 7}\end{array}$ & RO & $\begin{array}{c}\text { Area } \\
\text { enthusiasts } \\
\mathrm{n}=\mathbf{7 0}\end{array}$ & RO & $\begin{array}{c}\begin{array}{c}\text { Passive } \\
\text { visitors } \\
n=56\end{array}\end{array}$ & RO & $\begin{array}{c}\text { Active } \\
\text { learners } \\
\mathrm{n}=56\end{array}$ & RO & $\begin{array}{c}\text { Novelty } \\
\text { seekers } \\
\mathbf{n}=\mathbf{5 2}\end{array}$ & RO \\
\hline $\begin{array}{l}\text { 7. Introduce ecological } \\
\text { and cultural points of } \\
\text { interest }\end{array}$ & 4.94 & 1 & 4.97 & 1 & 4.88 & 1 & 4.96 & 1 & 4.95 & 1 \\
\hline $\begin{array}{l}\text { 1. Set a pace for the trip } \\
\text { that was comfortable for } \\
\text { you }\end{array}$ & 4.72 & 2 & 4.90 & 2 & 4.47 & 4 & 4.70 & 3 & 4.85 & 2 \\
\hline $\begin{array}{l}12 . \quad \text { Increase your } \\
\text { knowledge and } \\
\text { understanding of the } \\
\text { natural environment of } \\
\text { the national park }\end{array}$ & 4.70 & 3 & 4.83 & 3 & 4.57 & 3 & 4.68 & 4 & 4.70 & 4 \\
\hline $\begin{array}{l}\text { 8. Disseminate correct } \\
\text { information } \\
\text { translation }\end{array}$ & 4.66 & 4 & 4.70 & 6 & 4.61 & 2 & 4.77 & 2 & 4.53 & 6 \\
\hline $\begin{array}{l}\text { 2. Discuss dangers that } \\
\text { may exist in the tour }\end{array}$ & 4.63 & 5 & 4.81 & 4 & 4.41 & 5 & 4.52 & 6 & 4.80 & 3 \\
\hline $\begin{array}{l}\text { 11. Help you to develop } \\
\text { a keener awareness and } \\
\text { appreciation of the } \\
\text { national park }\end{array}$ & 4.60 & 6 & 4.78 & 5 & 4.35 & 6 & 4.59 & 5 & 4.68 & 5 \\
\hline $\begin{array}{l}\text { 4. Promote a social and } \\
\text { happy group } \\
\text { environment }\end{array}$ & 4.11 & 7 & 4.08 & 8 & 4.00 & 8 & 4.11 & 8 & 4.30 & 7 \\
\hline \begin{tabular}{|lcr}
$6 . \quad$ Keep the group \\
organized \\
schedule
\end{tabular} and $\begin{array}{r}\text { on } \\
\end{array}$ & 4.09 & 8 & 4.25 & 7 & 4.04 & 7 & 3.86 & 9 & 4.25 & 8 \\
\hline $\begin{array}{l}10 . \text { Highlight the } \\
\text { importance of not taking } \\
\text { anything from national } \\
\text { park }\end{array}$ & 3.64 & 9 & 3.25 & 11 & 3.92 & 9 & 4.23 & 7 & 3.00 & 11 \\
\hline $\begin{array}{l}\text { 9. Discuss code of ethics } \\
\text { with the group }\end{array}$ & 3.61 & 10 & 3.24 & 12 & 3.86 & 10 & 4.23 & 7 & 3.00 & 11 \\
\hline $\begin{array}{l}\text { 5. Reduce conflict with } \\
\text { other groups at sites, etc. }\end{array}$ & 3.14 & 11 & 3.30 & 10 & 3.20 & 11 & 2.98 & 10 & 3.05 & 10 \\
\hline $\begin{array}{l}\text { 3. Handle tension or } \\
\text { conflict quickly and } \\
\text { effectively }\end{array}$ & 3.12 & 12 & 3.38 & 9 & 3.02 & 12 & 2.82 & 11 & 3.25 & 9 \\
\hline
\end{tabular}

$R O=$ Ranking order

Table 6.14 shows the results from ANOVA testing for the importance means of 12 roles of site interpreters in Cat Tien National Park. The results show that statistically significant differences were found in the importance ratings for role 1 , role 2 , role 3 , role 6 , role 9 , role 10 and role 11 ( $p$-values less than 0.00417, as Bonferroni applied). However, there was no significant difference in the importance ratings for role 4 , role 5 , role 7 , role 8 and role 12 across clusters.

As can be seen from Table 6.14, there was a significant difference found in the importance ratings for role 1 and role 2 (Leadership-Instrumental) across four clusters ( $p<0.0005$ for both roles). The results from a post hoc test $(p<0.0005 ; p=0.001)$ show that the importance mean of role 1 rated by "Passive visitors" (4.47) was significantly lower than by "Area enthusiasts" (4.90) and "Novelty seekers" (4.85). Similarly, the results from a post hoc test $(p=0.001 ; p=0.002)$ show that the importance mean of role 2 rated by "Passive visitors" (4.41) was significantly lower than by "Area enthusiasts" (4.81) and "Novelty seekers" (4.80) (see Table 6.13). 
Moreover, there was a significant difference in importance rating for role 11 of Resource Management-Environmental interpreter function across clusters $(p<0.0005)$. The result from a post hoc test $(p<0.0005)$ shows that importance mean of role 11 evaluated by "Passive visitors" (4.35) was significantly lower than by “Area enthusiasts” (4.78) (see Table 6.13).

A significant difference was also found in the importance ratings for role 6 of MediatoryInteractional function across clusters $(p=0.003)$. The importance rating for role 6 from "Active learners" (3.86) was lower than from "Area enthusiasts" (4.25) and "Novelty seekers" (4.25) (see Table 6.13).

Also, there were significant differences found in the importance ratings for role 9 and role 10 of Resource Management-Motivator of Responsible Behaviour function ( $p<0.0005$ for both roles). The results from a post hoc test indicate that importance ratings for role 9 from "Area enthusiasts" $(p=0.001 ; p<0.0005)$ and "Novelty seekers" $(p<0.0005 ; p<0.0005)$ were significantly lower than from "Passive visitors" and "Active learners". Likewise, the results from a post hoc test indicate that importance ratings for role 10 from "Area enthusiasts" $(p<0.0005 ; p<0.0005)$ and "Novelty seekers" ( $p<0.0005 ; p<0.0005)$ were significantly lower than from "Passive visitors" and "Active learners" (see Table 6.13).

Another significant difference was found in importance ratings for role 3 of Leadership-Social function $(p=0.001)$. The result from a post hoc test $(p<0.0005)$ shows that importance rating of role 3 "Handle tension or conflict quickly and effectively" from "Active learners" (2.82) was significantly lower than “Area enthusiasts" (3.38) (see Table 6.13).

Table 6.14. ANOVA testing for the importance ratings of roles across clusters

\begin{tabular}{|l|c|}
\multicolumn{1}{|c|}{ Importance of roles of site interpreters } & \multicolumn{1}{|c|}{$\begin{array}{c}\text { Sig. } \\
\text { (ANOVA) }\end{array}$} \\
\hline 1. Set a pace for the trip that was comfortable for you & $\mathrm{p}<0.0005$ \\
\hline 2. Discuss dangers that may exist in the tour & $\mathrm{p}<0.0005$ \\
\hline $\begin{array}{l}\text { 11. Help you to develop a keener awareness and appreciation } \\
\text { of the national park }\end{array}$ & $\mathrm{p}<0.0005$ \\
\hline 6. Keep the group organized and on schedule & 0.003 \\
\hline $\begin{array}{l}\text { 10. Highlight the importance of not taking anything from } \\
\text { national park }\end{array}$ & $\mathrm{p}<0.0005$ \\
\hline 9. Discuss code of ethics with the group & $\mathrm{p}<0.0005$ \\
\hline 3. Handle tension or conflict quickly and effectively & 0.001 \\
\hline 7. Introduce ecological and cultural points of interest & 0.194 \\
\hline $\begin{array}{l}\text { 12. Increase your knowledge and understanding of the natural } \\
\text { environment of the national park }\end{array}$ & 0.034 \\
\hline 8. Disseminate correct information and translation & 0.126 \\
\hline 4. Promote a social and happy group environment & 0.098 \\
\hline 5. Reduce conflict with other groups at sites, etc. & 0.041 \\
\hline
\end{tabular}

Sig (2-tailed $)=p$-value 
In brief, there was a high consensus among the four groups of visitors in evaluating the importance of role 4 , role 7 , role 8 , role 12 and role 5 . Nevertheless, there were some significant differences found across clusters in the importance ratings for role 1 , role 2 , role 11 , role 6 , role 9 , role 10 and role 3. The importance means for role 1 and role 2 assessed by "Passive visitors" were significantly lower than by "Area enthusiasts" and "Novelty seekers". Moreover, the importance ratings from "Passive visitors" for role 11 was significantly lower than from the "Area enthusiasts". However, "Passive visitors" evaluated the importance of role 9 and 10 higher than "Area enthusiasts" and "Novelty seekers". Regarding "Active learners", the importance means in this group for role 9 and role 10 were significantly higher than in the "Area enthusiasts" and "Novelty seekers" clusters. In addition, "Active learners" assessed the importance of role 3 lower than "Area enthusiasts". "Active learners" also assessed the importance of role 6 lower than "Area enthusiasts" and "Novelty seekers".

\subsubsection{The performance of roles of site interpreters by clusters}

Table 6.15 presents the performance means of the 12 roles of site interpreters across clusters. The performance means of role 1,3, 5, 6, 7, 8, 11 and 12 remained high across clusters while role 9 and 10 had poor performance according to these clusters. As shown in Table 6.15, role 1, role 6, role 7 and role 12 remained the top four roles with high performance while role 2 , role 4 , role 9 and role 10 were still at the bottom of the ranking order in all four clusters. 
Table 6.15. The performance of roles of site interpreters by clusters

\begin{tabular}{|c|c|c|c|c|c|c|c|c|c|c|}
\hline $\begin{array}{c}\text { Performance of roles of } \\
\text { site interpreters }\end{array}$ & $\begin{array}{c}\text { Overall } \\
\text { sample } \\
\mathbf{n}=\mathbf{2 3 7}\end{array}$ & RO & $\begin{array}{c}\text { Area } \\
\text { enthusiasts } \\
n=70\end{array}$ & RO & $\begin{array}{c}\text { Passive } \\
\text { visitors } \\
\mathrm{n}=\mathbf{5 6}\end{array}$ & RO & $\begin{array}{c}\text { Active } \\
\text { learners } \\
\mathbf{n}=\mathbf{5 6}\end{array}$ & RO & $\begin{array}{c}\text { Novelty } \\
\text { seekers } \\
\mathbf{n}=\mathbf{5 2}\end{array}$ & RO \\
\hline $\begin{array}{l}\text { 7. Introduce ecological } \\
\text { and cultural points of } \\
\text { interest }\end{array}$ & 4.36 & 1 & 4.54 & 1 & 4.18 & 1 & 4.23 & 1 & 4.48 & 1 \\
\hline $\begin{array}{l}\text { 1. Set a pace for the trip } \\
\text { that was comfortable for } \\
\text { you }\end{array}$ & 4.28 & 2 & 4.46 & 2 & 4.12 & 4 & 4.20 & 2 & 4.35 & 2 \\
\hline $\begin{array}{lcr}6 . \quad \text { Keep } & \text { the group } \\
\text { organized } & \text { and } \\
\text { schedule } & & \text { on }\end{array}$ & 4.23 & 3 & 4.40 & 3 & 4.16 & 2 & 4.05 & 3 & 4.35 & 2 \\
\hline $\begin{array}{l}12 \text { Increase your } \\
\text { knowledge } \\
\text { understanding of the } \\
\text { natural environment of } \\
\text { the national park }\end{array}$ & 4.10 & 4 & 4.11 & 4 & 4.14 & 3 & 4.00 & 4 & 4.15 & 3 \\
\hline $\begin{array}{l}\text { 5. Reduce conflict with } \\
\text { other groups at sites, etc. }\end{array}$ & 3.95 & 5 & 4.08 & 5 & 3.75 & 7 & 3.91 & 5 & 4.00 & 4 \\
\hline $\begin{array}{l}\text { 3. Handle tension or } \\
\text { conflict quickly and } \\
\text { effectively }\end{array}$ & 3.89 & 6 & 4.03 & 6 & 3.70 & 8 & 3.87 & 6 & 3.90 & 5 \\
\hline $\begin{array}{lr}8 . \quad \text { Disseminate } & \text { correct } \\
\text { information } & \text { and } \\
\text { translation } & \end{array}$ & 3.88 & 7 & 3.97 & 7 & 3.84 & 5 & 3.84 & 7 & 3.83 & 6 \\
\hline $\begin{array}{l}\text { 11. Help you to develop a } \\
\text { keener awareness and } \\
\text { appreciation of the } \\
\text { national park }\end{array}$ & 3.76 & 8 & 3.68 & 8 & 3.82 & 6 & 3.80 & 8 & 3.73 & 7 \\
\hline $\begin{array}{l}\text { 4. Promote a social and } \\
\text { happy group environment }\end{array}$ & 3.42 & 9 & 3.43 & 10 & 3.61 & 9 & 3.20 & 9 & 3.43 & 9 \\
\hline $\begin{array}{l}\text { 2. Discuss dangers that } \\
\text { may exist in the tour }\end{array}$ & 3.32 & 10 & 3.44 & 9 & 3.37 & 10 & 2.98 & 10 & 3.53 & 8 \\
\hline $\begin{array}{l}\text { 9. Discuss code of ethics } \\
\text { with the group }\end{array}$ & 2.00 & 11 & 1.84 & 11 & 2.18 & 11 & 1.79 & 11 & 2.15 & 10 \\
\hline $\begin{array}{l}10 . \quad \text { Highlight the } \\
\text { importance of not taking } \\
\text { anything from national } \\
\text { park }\end{array}$ & 1.96 & 12 & 1.77 & 12 & 2.18 & 11 & 1.75 & 12 & 2.10 & 11 \\
\hline
\end{tabular}

\section{$R O=$ Ranking order}

Table 6.16 presents the results from ANOVA testing for the performance means of 12 roles of site interpreters in Cat Tien National Park. Statistically significant differences were found in the performance ratings for role 1 , role 5 , role 6 and role 7 across clusters (all $p$-values less than $0.05 / 12=0.00417$; Bonferroni correction applied). However, there was no significant difference found in the performance ratings for role $2,3,4,8,9,10,11$ and role 12 across clusters.

As can be seen from Table 6.16, there was a significant difference in the performance ratings for role 7 of Mediatory-Communicative function across clusters $(p<0.0005)$. The results from a post hoc test ( $p=0.001 ; p=0.004)$ indicate that performance rating for role 7 from "Area enthusiasts" (4.54) was significantly higher than from "Passive visitors" (4.18) and "Active learners" (4.23).

A significant difference was also found in the performance ratings for role 1 of LeadershipInstrumental function of site interpreters $(p<0.0005)$. The result from a post hoc test show that 
performance rating for role 1 from "Area enthusiasts" (4.46) was significantly higher than from "Passive visitors" (4.12).

Also, there was a significant difference found in the performance rating for role 6 of MediatoryInteractional function $(p<0.0005)$. The result from a post hoc test $(p=0.001)$ shows that the performance mean in the group of "Area enthusiasts" (4.40) was significantly higher than in the group of “Active learners” (4.05).

Similarly, a significant difference was also found in the performance means of role 5 of MediatoryInteraction function ( $p=0.002)$. The performance rating from "Area enthusiasts" (4.08) was higher than from "Passive visitors" (3.75).

Table 6.16. ANOVA testing for the performance ratings of roles across clusters
\begin{tabular}{|l|c|}
\hline \multicolumn{1}{|c|}{ Performance of roles of site interpreters } & $\begin{array}{c}\text { Sig. } \\
\text { (ANOVA) }\end{array}$ \\
\hline 7. Introduce ecological and cultural points of interest & $\mathrm{p}<0.0005$ \\
\hline 1. Set a pace for the trip that was comfortable for you & $\mathrm{p}<0.0005$ \\
\hline 6. Keep the group organized and on schedule & $\mathrm{p}<0.0005$ \\
\hline 5. Reduce conflict with other groups at sites, etc. & 0.002 \\
\hline $\begin{array}{l}\text { 12. Increase your knowledge and understanding of the natural } \\
\text { environment of the national park }\end{array}$ & 0.117 \\
\hline 3. Handle tension or conflict quickly and effectively & 0.008 \\
\hline 8. Disseminate correct information and translation & 0.224 \\
\hline $\begin{array}{l}\text { 11. Help you to develop a keener awareness and appreciation } \\
\text { of the national park }\end{array}$ & 0.263 \\
\hline 4. Promote a social and happy group environment & 0.029 \\
\hline 2. Discuss dangers that may exist in the tour & 0.013 \\
\hline 9. Discuss code of ethics with the group & 0.011 \\
\hline $\begin{array}{l}\text { 10. Highlight the importance of not taking anything from } \\
\text { national park }\end{array}$ & 0.006 \\
\hline Sig (2-tailed) = p-value & \\
\hline
\end{tabular}

In short, there was a consistency in the performance ratings for role 2, 3, 4, 8, 9, 10, 11 and 12 across the four clusters. Some significant differences were found in the performance ratings for role 1, 5, 6 and 7. The performance means of role 1,5 and 7 assessed by "Passive visitors" were significantly lower than by "Area enthusiasts". "Active learners" also assessed the performance of role 6 and 7 lower than "Area enthusiasts".

\subsubsection{The importance-performance grid of roles of site interpreters for each cluster}

Figures 6.6, 6.7, 6.8 and 6.9 present the importance-performance grids of 12 roles of site interpreters for the four clusters "Area enthusiasts", "Passive visitors", "Active learners" and "Novelty seekers". The blue intersection line was drawn according to the new grand means of each cluster 
("Area enthusiasts", (4.21; 3.65); "Passive visitors", (4.11; 3.59); "Active learners", (4.20; 3.47) and "Novelty seekers", $(4.11 ; 3.67))$. The results from these grids show that there were some differences in the positions of these roles across clusters.

In the grid for "Area enthusiasts" (Figure 6.6), role 6 was in the "Keep up the good work" quadrant instead of being in the "Possibly Overkill" as presented in the grid for the whole sample (see Chapter 5). This means that according to "Area enthusiasts", role 6 was more important than according to the whole sample. According to "Passive visitors", role 4 was in the "Possibly overkill" instead of being in the "Low priority" (Figure 6.7). This means that "Passive visitors" assessed the performance of role 4 higher than the whole sample. Meanwhile, in the grid of "Novelty seekers" (Figure 6.9), role 4 was in the "Concentrate here" instead of being in the "Low priority". This means that site interpreters need to perform role 4 better in the future together with role 2 . Moreover, role 6 was in the "Keep up the good work" instead of "Possibly overkill". This means that the importance of role 6 according to "Novelty seekers" was higher than according to the whole sample. "Active learners" assigned role 9 and 10 in the "Concentrate here" quadrant instead of "Low priority" (Figure 6.8). This means that role 9 and role 10 of site interpreters need to be improved in the future together with role 2 . Hence, to satisfy all of the users, managers should train site interpreters to enhance the performance of role 2,4 , role 9 and role 10 in the future.



Figure 6.6. The grid of roles for Area enthusiasts 


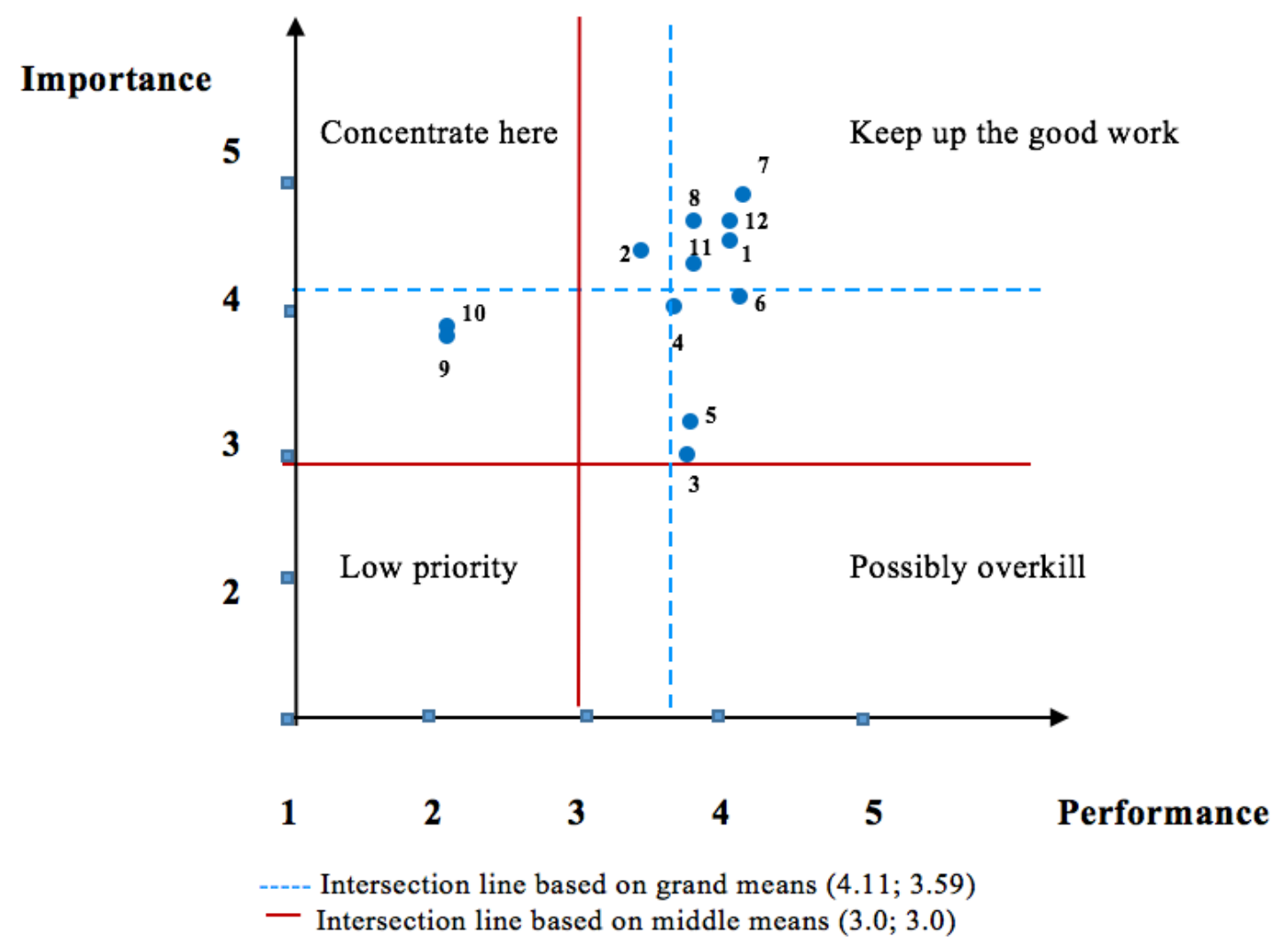

Figure 6.7. The grid of roles for Passive visitors

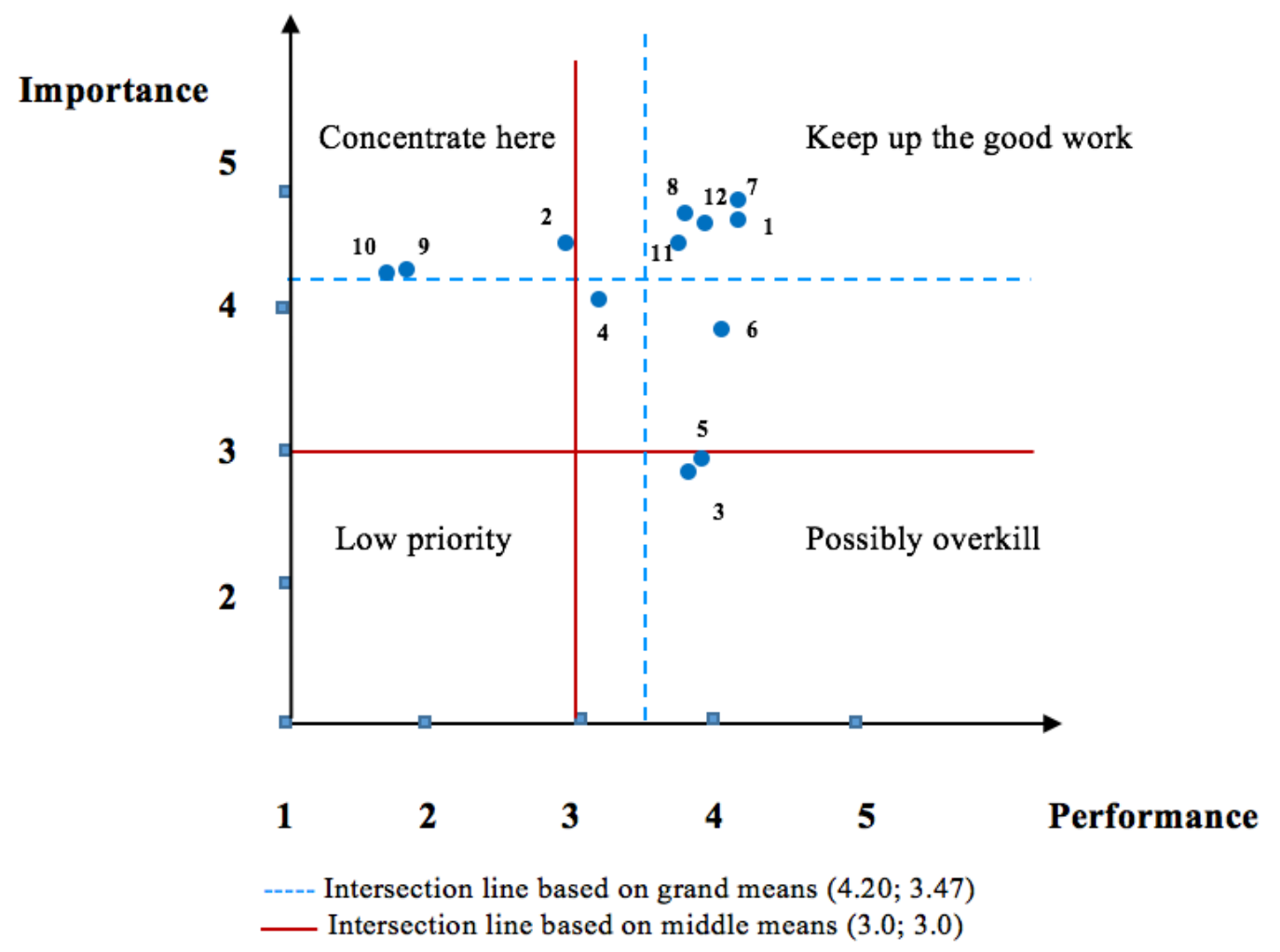

Figure 6.8. The grid of roles for Active learners 


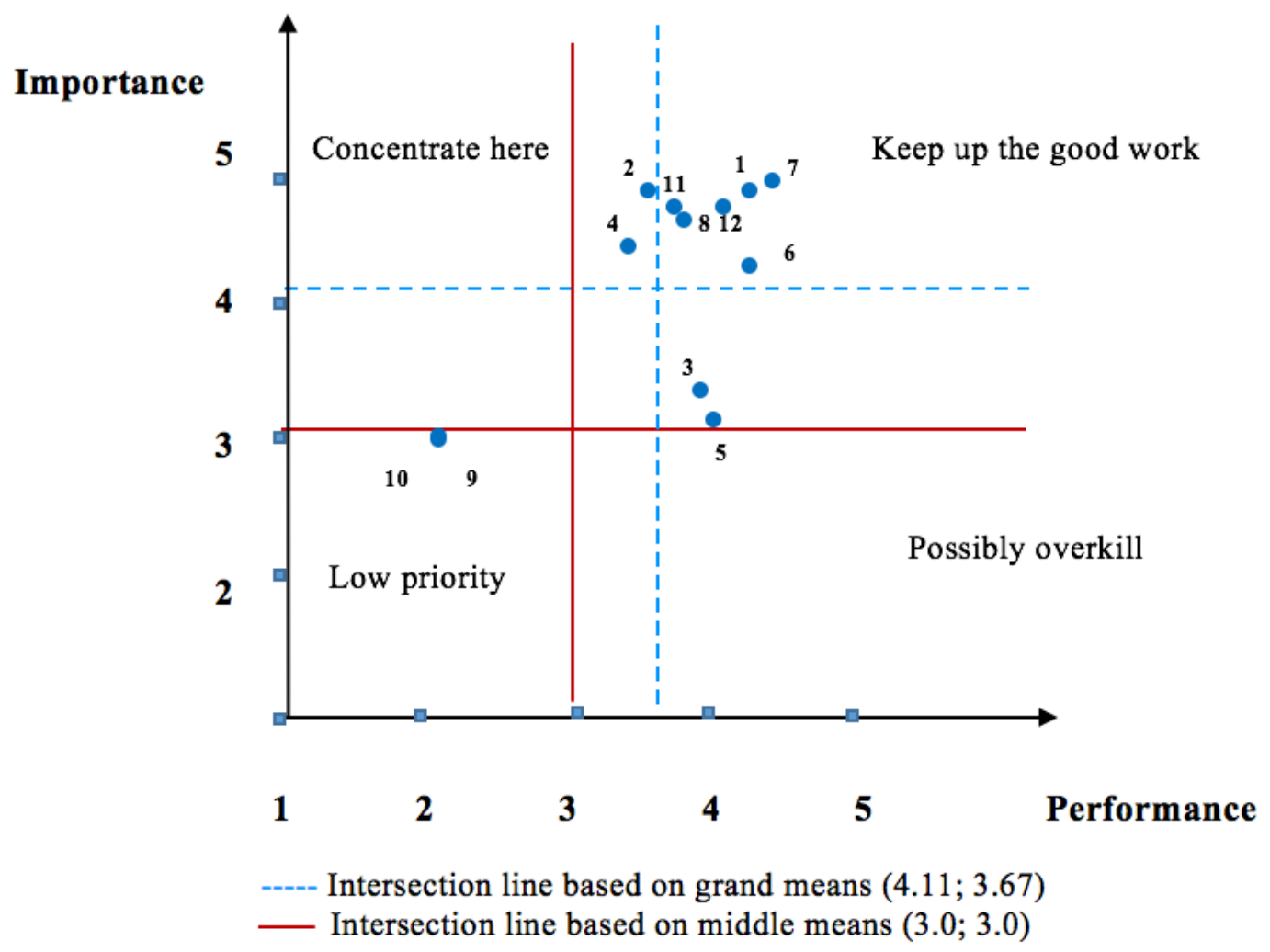

Figure 6.9. The grid of roles for Novelty seekers

\subsection{Visitor satisfaction with services for environmental interpretation according to market segments}

Section 6.2 analysed the similarities and differences among motivation-based clusters in visitor satisfaction with services for environmental interpretation. This section shows the similarities and differences between two markets (domestic and international visitors) in visitor satisfaction with services for environmental interpretation in Cat Tien National Park. In this section, the similarities and differences among market segments will be analysed regarding importance and performance ratings of services for environmental interpretation and roles of site interpreters. Importance and performance grids will also be drawn for each market segments.

\subsubsection{Visitor satisfaction with services for environmental interpretation according to market segments}

This section points out the similarities and differences in visitor evaluations of the importance and performance of services for environmental interpretation in Cat Tien National Park according to two market segments. Independent t-tests will be used to find out significant differences between two segments in their evaluations. Next, an importance-performance grid will be drawn for each segment to find out the differences in visitor satisfaction with these services between the two market segments. 


\subsubsection{The importance of services for environmental interpretation by nationalities}

Table 6.17 shows that the evaluations of the importance of site interpreters, interpretive signs, videos at the rescue centre, staff at the museum and displays at the museum remained high while the evaluations of the importance of staff at the ticket office and directional signs were very low between market segments. Regarding ranking order, site interpreters were still the most important service for environmental interpretation between two segments. Brochures, staff at the ticket office and directional signs were still the least important services according to two segments. Site interpreters, interpretive signs, videos at the rescue centre and staff at the museum were still the four most important services according to domestic visitors. Meanwhile, site interpreters, displays at the museum, staff at the museum and videos at the rescue centre were the four most important services according to international visitors.

Table 6.17. The importance of services for environmental interpretation by nationalities

\begin{tabular}{|l|c|c|c|c|c|c|}
\hline $\begin{array}{c}\text { Importance of services } \\
\text { for environmental } \\
\text { interpretation }\end{array}$ & $\begin{array}{c}\text { Overall } \\
\text { sample } \\
\mathbf{n = 2 3 7}\end{array}$ & $\mathbf{R O}$ & $\begin{array}{c}\text { Domestic } \\
\text { visitors } \\
\mathbf{n = 1 7 6}\end{array}$ & $\mathbf{R O}$ & $\begin{array}{c}\text { International } \\
\text { visitors } \\
\mathbf{n = 6 1}\end{array}$ & $\mathbf{R O}$ \\
\hline Site interpreter & 4.82 & 1 & 4.84 & 1 & 4.79 & 1 \\
\hline Interpretive signs & 4.67 & 2 & 4.81 & 2 & 4.28 & 5 \\
\hline Videos at rescue centre & 4.64 & 3 & 4.70 & 3 & 4.51 & 4 \\
\hline Staff at museum & 4.58 & 4 & 4.58 & 4 & 4.57 & 3 \\
\hline Displays at museum & 4.44 & 5 & 4.38 & 5 & 4.60 & 2 \\
\hline Brochure & 3.51 & 6 & 3.65 & 6 & 3.12 & 6 \\
\hline Directional signs & 2.18 & 7 & 2.11 & 7 & 2.38 & 7 \\
\hline Staff at ticket office & 2.03 & 8 & 2.03 & 8 & 2.00 & 8 \\
\hline
\end{tabular}

Table 6.18 shows the results from an independent t-test for eight services. The results indicate that significant differences were found in the importance ratings for interpretive signs and brochures at the ticket office between market segments $(p<0.0005$ for both services). The importance of interpretive signs assessed by domestic visitors (4.81) was higher than by international visitors (4.28). Likewise, the importance of brochures assessed by domestic visitors (3.65) was higher than by international visitors (3.12). Brochures seem to have low importance towards environmental interpretation in the perception of international visitors (see Table 6.17). In contrast, after adjusting for multiple comparisons, no significant difference was found in the importance ratings for site interpreters, videos at the rescue centre, staff at the museum, displays at the museum, directional signs, and staff at the ticket office (Table 6.18). 
Table 6.18. Independent t-test for the importance ratings of services across nationalities

\begin{tabular}{|l|c|}
\hline \multicolumn{1}{|c|}{$\begin{array}{c}\text { Importance of services } \\
\text { for environmental } \\
\text { interpretation }\end{array}$} & Sig. \\
\hline Interpretive signs about the site & $\mathrm{p}<0.0005$ \\
\hline Brochure at ticket office & $\mathrm{p}<0.0005$ \\
\hline Site interpreter/ local tour guide & 0.385 \\
\hline Videos at rescue centre & 0.021 \\
\hline Staff at museum & 0.891 \\
\hline Displays at museum & 0.044 \\
\hline Directional signs & 0.018 \\
\hline Staff at ticket office & 0.747 \\
\hline
\end{tabular}

Sig (2-tailed $)=p$-value

In brief, visitor evaluations about the importance of site interpreters, videos at the rescue centre, staff and displays at the museum, directional signs and staff at the ticket office were consistent between the two market segments. Some significant differences were found in the importance ratings for interpretive signs and brochures at the ticket office, where domestic visitors rated these higher than international visitors. Brochures were not perceived as an important service for environmental interpretation by international visitors.

\subsubsection{The performance of services for environmental interpretation by nationalities}

Table 6.19 describes the performance means of services for environmental interpretation between the two market segments. As can be seen from Table 6.19, interpretive signs, site interpreters, staff at the museum and brochures were the top four services with high performance while staff at the ticket office and displays at the museum were still at the bottom of the ranking order for the two market segments. 
Table 6.19. The performance of services for environmental interpretation by nationalities

\begin{tabular}{|l|c|c|c|c|c|c|}
\hline $\begin{array}{c}\text { Performance of services } \\
\text { for environmental } \\
\text { interpretation }\end{array}$ & $\begin{array}{c}\text { Overall } \\
\text { sample } \\
\mathbf{n = 2 3 7}\end{array}$ & $\mathbf{R O}$ & $\begin{array}{c}\text { Domestic } \\
\text { visitors } \\
\mathbf{n = 1 7 6}\end{array}$ & $\mathbf{R O}$ & $\begin{array}{c}\text { International } \\
\text { visitors } \\
\mathbf{n = 6 1}\end{array}$ & $\mathbf{R O}$ \\
\hline Interpretive signs & 4.45 & 1 & 4.60 & 1 & 4.03 & 1 \\
\hline Site interpreter & 4.03 & 2 & 4.06 & 2 & 3.95 & 2 \\
\hline Staff at museum & 4.00 & 3 & 4.04 & 3 & 3.89 & 3 \\
\hline Brochure at ticket office & 3.94 & 4 & 3.96 & 4 & 3.87 & 4 \\
\hline Directional signs & 3.42 & 5 & 3.36 & 5 & 3.61 & 5 \\
\hline Staff at ticket office & 3.34 & 6 & 3.35 & 6 & 3.32 & 6 \\
\hline Displays at museum & 3.28 & 7 & 3.30 & 7 & 3.23 & 7 \\
\hline Videos at rescue centre & 3.26 & 8 & 3.11 & 8 & 3.61 & 5 \\
\hline$R O=$ Ranking order & & & & & &
\end{tabular}

Table 6.20 shows the results from an independent t-test for the performance ratings of services between the two market segments. Some significant differences were found in the performance ratings for interpretive signs, directional signs and videos at the rescue centre $(p<0.0005 ; p=0.001$; $\mathrm{p}<0.0005$ respectively). The performance mean for interpretive signs from domestic visitors (4.60) was higher than from international visitors (4.03). This may be because most interpretive signs were in Vietnamese and had clear explanations, so domestic visitors were more satisfied with the performance of interpretive signs. However, the performance means for directional signs and videos at the rescue centre from domestic visitors (3.36 and 3.11 respectively) were significantly lower than from international visitors (3.61 and 3.61 respectively). Directional signs and videos at the rescue centre did not perform well in the perception of domestic visitors (see Table 6.19). Conversely, no significant difference was found in performance ratings for site interpreters, staff at the museum, brochures at the ticket office, staff at the ticket office and displays at the museum (Table 6.20). 


\begin{tabular}{|l|c|}
\hline \multicolumn{1}{|c|}{$\begin{array}{c}\text { Performance of services } \\
\text { for environmental } \\
\text { interpretation }\end{array}$} & Sig. \\
\hline Interpretive signs about the site & $\mathrm{p}<0.0005$ \\
\hline Directional signs & 0.001 \\
\hline Videos at rescue centre & $\mathrm{p}<0.0005$ \\
\hline Site interpreter/ local tour guide & 0.033 \\
\hline Staff at museum & 0.049 \\
\hline Brochure at ticket office & 0.153 \\
\hline Staff at ticket office & 0.707 \\
\hline Displays at museum & 0.544 \\
\hline Sig (2-tailed) $=p$-value &
\end{tabular}

In brief, there was a high consensus in visitor evaluation about the performance of site interpreters, staff at the museum, brochures at the ticket office, staff at the ticket office and displays at the museum. Some significant differences were found in performance ratings for interpretive signs, directional signs and videos at the rescue centre. The performance mean for interpretive signs from domestic visitors was higher than from international visitors. However, the performance means for directional signs and videos at the rescue centre from domestic visitors were significantly lower than from international visitors. Directional signs and videos at the rescue centre had quite low performance in the perception of domestic visitors.

\subsubsection{The importance-performance grid of services for environmental interpretation for each market segment}

Figures 6.10 and 6.11 illustrate the importance-performance grids for domestic and international visitors. The intersection line was drawn according to new grand means of each segment (Domestic visitors, $(3.89 ; 3.72)$ and international visitors, $(3.78 ; 3.69))$. The results indicate that there was no great difference found in the positions of these services in the importance-performance grids for both market segments. Site interpreters, interpretive signs and staff at the museum were still in the "Keep up the good work" quadrant. Displays at the museum and videos at the rescue centre were in the "Concentrate here" quadrant. However, in the grid for international visitors, the position of videos at the rescue centre seems to move nearer to the "Keep up the good work" quadrant (Figure 6.11). Videos at the rescue centre were in English, so international visitors may have been more satisfied than domestic visitors. The "Low priority" quadrant contains staff at the ticket office and directional signs. Directional signs seem to move a bit nearer to the "Possibly overkill" quadrant in the grid for international visitors (Figure 6.11). International visitors were more satisfied with the performance of directional signs than domestic visitors. Brochures were still in the "Possibly 
overkill" quadrant. However, the position of brochures in the grid of international visitors was lower than in the grid of domestic visitors (Figure 6.11). Brochures were not perceived as important by international visitors.

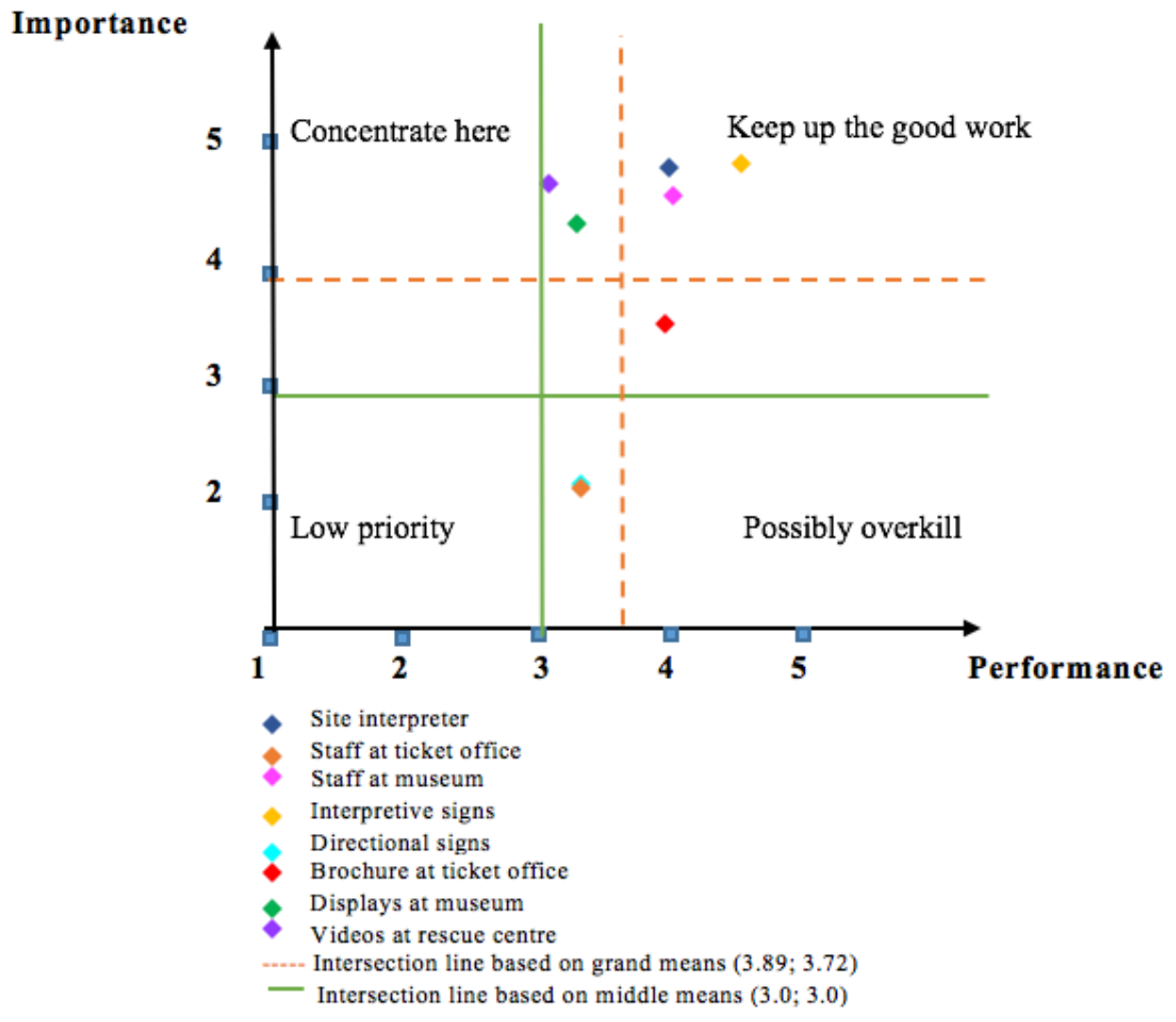

Figure 6.10. The grid of services for domestic visitors

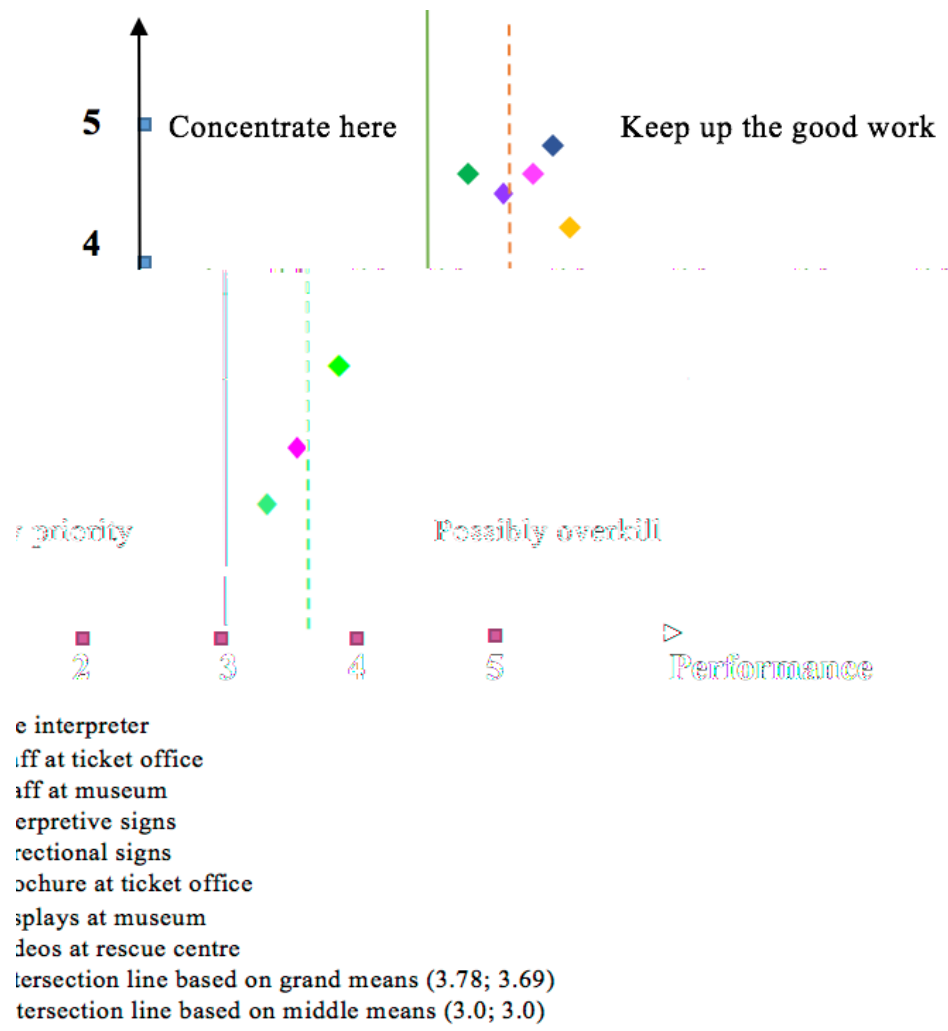

6.11. The grid of services for international visitors

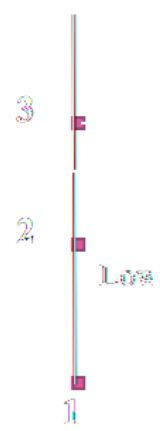

Sit

- Sta

St:

Int

- Dis

- Bri

$\mathrm{Dis}$
$\mathrm{Vi}$

In 1
In

Figure 


\subsubsection{Visitor satisfaction with roles of site interpreters according to market segments}

The previous section presented visitor satisfaction with services for environmental interpretation according to the two market segments. This section analyses visitor satisfaction with twelve roles of site interpreters with importance and performance ratings of each market segment. Independent ttests will be used to support the analysis. An importance-performance grid for each segment will also be provided at the end of this section.

\subsubsection{The importance of roles of site interpreters by nationalities}

Table 6.21 shows the importance means of roles of site interpreters according to the two market segments. The results from Table 6.21 indicate that the importance means of role 1, role 2, role 4, role 6 , role 7 , role 8 , role 11 and role 12 remained high in both segments. Role 3 and role 5 were not important according to both segments. Regarding ranking order, role 7, role 8 and role 12 were still the top three roles with high importance according to domestic visitors while role 7 , role 8 and role 12 were the top three important roles according to international visitors.

Table 6.21. The importance of roles of site interpreters by nationalities

\begin{tabular}{|c|c|c|c|c|c|c|}
\hline $\begin{array}{l}\text { Importance of roles of site } \\
\text { interpreters }\end{array}$ & $\begin{array}{c}\text { Overall } \\
\text { sample } \\
\mathbf{n}=\mathbf{2 3 7}\end{array}$ & RO & $\begin{array}{c}\text { Domestic } \\
\text { visitors } \\
\mathrm{n}=176\end{array}$ & RO & $\begin{array}{c}\text { International } \\
\text { visitors } \\
\mathbf{n}=\mathbf{6 1}\end{array}$ & RO \\
\hline $\begin{array}{l}\text { 7. Introduce ecological and cultural } \\
\text { points of interest }\end{array}$ & 4.94 & 1 & 4.93 & 1 & 4.95 & 1 \\
\hline $\begin{array}{l}\text { 1. Set a pace for the trip that was } \\
\text { comfortable for you }\end{array}$ & 4.72 & 2 & 4.88 & 2 & 4.34 & 4 \\
\hline $\begin{array}{l}\text { 12. Increase your knowledge and } \\
\text { understanding of the natural } \\
\text { environment of the national park }\end{array}$ & 4.70 & 3 & 4.82 & 3 & 4.41 & 3 \\
\hline $\begin{array}{l}\text { 8. Disseminate correct information } \\
\text { and translation }\end{array}$ & 4.66 & 4 & 4.59 & 6 & 4.84 & 2 \\
\hline $\begin{array}{l}\text { 2. Discuss dangers that may exist in } \\
\text { the tour }\end{array}$ & 4.63 & 5 & 4.79 & 4 & 4.25 & 5 \\
\hline $\begin{array}{l}\text { 11. Help you to develop a keener } \\
\text { awareness and appreciation of the } \\
\text { national park }\end{array}$ & 4.60 & 6 & 4.75 & 5 & 4.21 & 6 \\
\hline $\begin{array}{l}\text { 4. Promote a social and happy group } \\
\text { environment }\end{array}$ & 4.11 & 7 & 4.16 & 8 & 3.98 & 8 \\
\hline $\begin{array}{l}\text { 6. Keep the group organized and on } \\
\text { schedule }\end{array}$ & 4.09 & 8 & 4.25 & 7 & 3.70 & 9 \\
\hline $\begin{array}{l}\text { 10. Highlight the importance of not } \\
\text { taking anything from national park }\end{array}$ & 3.64 & 9 & 3.49 & 9 & 4.02 & 7 \\
\hline $\begin{array}{l}\text { 9. Discuss code of ethics with the } \\
\text { group }\end{array}$ & 3.61 & 10 & 3.45 & 10 & 3.98 & 8 \\
\hline $\begin{array}{l}\text { 5. Reduce conflict with other groups } \\
\text { at sites, etc. }\end{array}$ & 3.14 & 11 & 3.19 & 11 & 3.03 & 10 \\
\hline $\begin{array}{l}\text { 3. Handle tension or conflict } \\
\text { quickly and effectively }\end{array}$ & 3.12 & 12 & 3.18 & 12 & 2.97 & 11 \\
\hline
\end{tabular}

$R O=$ Ranking order 
Table 6.22 shows the results from an Independent t-test for importance ratings of roles of site interpreters between the two segments. Some significant differences were found in the importance ratings for role $1,2,6,8,9,10,11$ and $12(p<0.0005 ; p<0.0005 ; p<0.0005 ; p=0.002 ; p<0.0005$; $\mathrm{p}<0.0005 ; \mathrm{p}<0.0005$ and $\mathrm{p}<0.0005$, respectively). The importance ratings for role $1,2,6,11$ and 12 assessed by domestic visitors $(4.88,4.79,4.25,4.75$ and 4.82 respectively) were significantly higher than by international visitors $(4.34,4.25,3.70,4.21$ and 4.41 respectively). The importance of role 8 evaluated by domestic visitors (4.59) was lower than by international visitors (4.84) although both means were high. Role 9 and role 10 were of high importance according to international visitors but were not important according to domestic visitors (see Table 6.21). Conversely, no significant difference was found in importance ratings for role 3, 4, 5 and 7 (Table 6.22).

\section{Table 6.22. Independent t-test for the importance ratings of roles across nationalities}

\begin{tabular}{|l|c|}
\hline \multicolumn{1}{|c|}{ Importance of roles of site interpreters } & Sig. \\
\hline $\begin{array}{l}\text { 1. Set a pace for the trip that was comfortable for you } \\
\text { environment of the national park }\end{array}$ & $\mathrm{p}<0.0005$ \\
\hline 8. Disseminate correct information and translation & $\mathrm{p}<0.0005$ \\
\hline 2. Discuss dangers that may exist in the tour & 0.002 \\
\hline $\begin{array}{l}\text { 11. Help you to develop a keener awareness and appreciation } \\
\text { of the national park }\end{array}$ & $\mathrm{p}<0.0005$ \\
\hline 6. Keep the group organized and on schedule & $\mathrm{p}<0.0005$ \\
\hline $\begin{array}{l}\text { 10. Highlight the importance of not taking anything from } \\
\text { national park }\end{array}$ & $\mathrm{p}<0.0005$ \\
\hline 9. Discuss code of ethics with the group & $\mathrm{p}<0.0005$ \\
\hline 7. Introduce ecological and cultural points of interest & 0.649 \\
\hline 4. Promote a social and happy group environment & 0.046 \\
\hline 5. Reduce conflict with other groups at sites, etc. & 0.126 \\
\hline 3. Handle tension or conflict quickly and effectively & 0.078 \\
\hline
\end{tabular}

Sig $(2$-tailed $)=p$-value

In brief, there was a high consensus between two market segments in evaluating the importance of role 3, 4, 5 and 7. Some significant differences were found in the importance assessments for role $1,2,6,8,9,10,11$ and 12 . The importance ratings for role 1, 2, 6, 11 and 12 assessed by domestic visitors were significantly higher than by international visitors. The importance of role 8,9 and 10 as evaluated by domestic visitors was lower than by international visitors. Role 9 and role 10 were important according to international visitors but were not important according to domestic visitors.

\subsubsection{The performance of roles of site interpreters by nationalities}

Table 6.23 presents the performance means of 12 roles of site interpreters between the two market segments. The performance means of role 1, 3, 5, 6, 7, 8, 11 and 12 remained high between the two 
market segments while role 9 and 10 had poor performance according to these clusters. As shown in Table 6.15 , role 1 , role 6 , role 7 and role 12 remained the top four roles with high performance while role 2 , role 4 , role 9 and role 10 were still at the bottom of the ranking order of the two segments.

Table 6.23. The performance of roles of site interpreters by nationalities

\begin{tabular}{|c|c|c|c|c|c|c|}
\hline $\begin{array}{l}\text { Performance of roles of site } \\
\text { interpreters }\end{array}$ & $\begin{array}{c}\text { Overall } \\
\text { sample } \\
\mathbf{n}=\mathbf{2 3 7}\end{array}$ & RO & $\begin{array}{c}\text { Domestic } \\
\text { visitors } \\
n=176\end{array}$ & RO & $\begin{array}{c}\text { International } \\
\text { visitors } \\
n=61\end{array}$ & RO \\
\hline $\begin{array}{l}\text { 7. Introduce ecological and } \\
\text { cultural points of interest }\end{array}$ & 4.36 & 1 & 4.46 & 1 & 4.10 & 1 \\
\hline $\begin{array}{l}\text { 1. Set a pace for the trip that was } \\
\text { comfortable for you }\end{array}$ & 4.28 & 2 & 4.36 & 2 & 4.08 & 2 \\
\hline $\begin{array}{l}\text { 6. Keep the group organized and } \\
\text { on schedule }\end{array}$ & 4.23 & 3 & 4.32 & 3 & 4.03 & 3 \\
\hline $\begin{array}{l}\text { 12. Increase your knowledge and } \\
\text { understanding of the natural } \\
\text { environment of the national park }\end{array}$ & 4.10 & 4 & 4.13 & 4 & 4.02 & 4 \\
\hline $\begin{array}{l}\text { 5. Reduce conflict with other } \\
\text { groups at sites, etc. }\end{array}$ & 3.95 & 5 & 3.97 & 5 & 3.87 & 5 \\
\hline $\begin{array}{l}\text { 3. Handle tension or conflict } \\
\text { quickly and effectively }\end{array}$ & 3.89 & 6 & 3.90 & 6 & 3.85 & 6 \\
\hline $\begin{array}{l}8 . \quad \text { Disseminate correct } \\
\text { information and translation }\end{array}$ & 3.88 & 7 & 3.89 & 7 & 3.87 & 5 \\
\hline $\begin{array}{l}\text { 11. Help you to develop a keener } \\
\text { awareness and appreciation of the } \\
\text { national park }\end{array}$ & 3.76 & 8 & 3.72 & 8 & 3.84 & 7 \\
\hline $\begin{array}{l}\text { 4. Promote a social and happy } \\
\text { group environment }\end{array}$ & 3.42 & 9 & 3.43 & 9 & 3.38 & 8 \\
\hline $\begin{array}{l}\text { 2. Discuss dangers that may exist } \\
\text { in the tour }\end{array}$ & 3.32 & 10 & 3.42 & 10 & 3.08 & 9 \\
\hline $\begin{array}{l}\text { 9. Discuss code of ethics with the } \\
\text { group }\end{array}$ & 2.00 & 11 & 2.02 & 11 & 1.93 & 10 \\
\hline $\begin{array}{l}\text { 10. Highlight the importance of } \\
\text { not taking anything from national } \\
\text { park }\end{array}$ & 1.96 & 12 & 1.97 & 12 & 1.92 & 11 \\
\hline
\end{tabular}

Table 6.24 presents the results from an independent t-test for performance ratings of roles of site interpreters between two segments. The results indicate that some significant differences were found in the performance ratings for role 1 , role 6 and role 7 ( $p<0.0005$ for three roles). The performance of role 1,6 and 7 assessed by domestic visitors (4.36, 4.32 and 4.46) was higher than by international visitors $(4.08,4.03$ and 4.10) (see Table 6.23). In contrast, no significant difference was found in the performance ratings for role $2,3,4,5,8,9,10,11$ and 12 between the two segments (Table 6.24). 
Table 6.24. Independent t-test for the performance ratings of roles across nationalities

\begin{tabular}{|l|c|}
\hline \multicolumn{1}{|c|}{ Performance of roles of site interpreters } & Sig. \\
\hline 7. Introduce ecological and cultural points of interest & $\mathrm{p}<0.0005$ \\
\hline 1. Set a pace for the trip that was comfortable for you & $\mathrm{p}<0.0005$ \\
\hline 6. Keep the group organized and on schedule & $\mathrm{p}<0.0005$ \\
\hline $\begin{array}{l}\text { 12. Increase your knowledge and understanding of the natural } \\
\text { environment of the national park }\end{array}$ & 0.033 \\
\hline 5. Reduce conflict with other groups at sites, etc. & 0.169 \\
\hline 3. Handle tension or conflict quickly and effectively & 0.529 \\
\hline 8. Disseminate correct information and translation & 0.765 \\
\hline $\begin{array}{l}\text { 11. Help you to develop a keener awareness and appreciation } \\
\text { of the national park }\end{array}$ & 0.085 \\
\hline 4. Promote a social and happy group environment & 0.601 \\
\hline 2. Discuss dangers that may exist in the tour & 0.015 \\
\hline 9. Discuss code of ethics with the group & 0.483 \\
\hline $\begin{array}{l}\text { 10. Highlight the importance of not taking anything from } \\
\text { national park }\end{array}$ & 0.660 \\
\hline
\end{tabular}

Sig $(2$-tailed $)=p$-value

In short, there was a consistency in visitor assessment for the performance of role 2, 3, 4, 5, 8, 9, 10, 11 and 12 between the two segments. Some significant differences were found in the performance ratings for role 1, role 6 and role 7 . The performance of these roles assessed by domestic visitors were higher than by international visitors.

\subsubsection{The importance-performance grid of roles of site interpreters for each market segment}

Figures 6.12 and 6.13 present the importance-performance grids of twelve roles of site interpreters for two market segments (domestic and international visitors). The blue intersection line was drawn according to the new grand means of domestic visitors $(4.21 ; 3.63)$ and international visitors (4.06; 3.50). The results from these grids show that there were some differences in the positions of these roles between two market segments.

In the grid of domestic visitors (Figure 6.12), role 6 was in the "Keep up the good work" quadrant instead of being in the "Possibly Overkill" quadrant as in the grid for the whole sample (see Chapter 5). This means that role 6 received higher importance ratings from domestic visitors than from international visitors. In the grid of international visitors (Figure 6.13), role 2 seems to move nearer to the "Low priority" quadrant. This means that the importance of role 2 assessed by international visitors was lower than by domestic visitors. Domestic visitors may not have much experience in 
national parks, so they may need some information about the dangers that they may encounter in the tour.

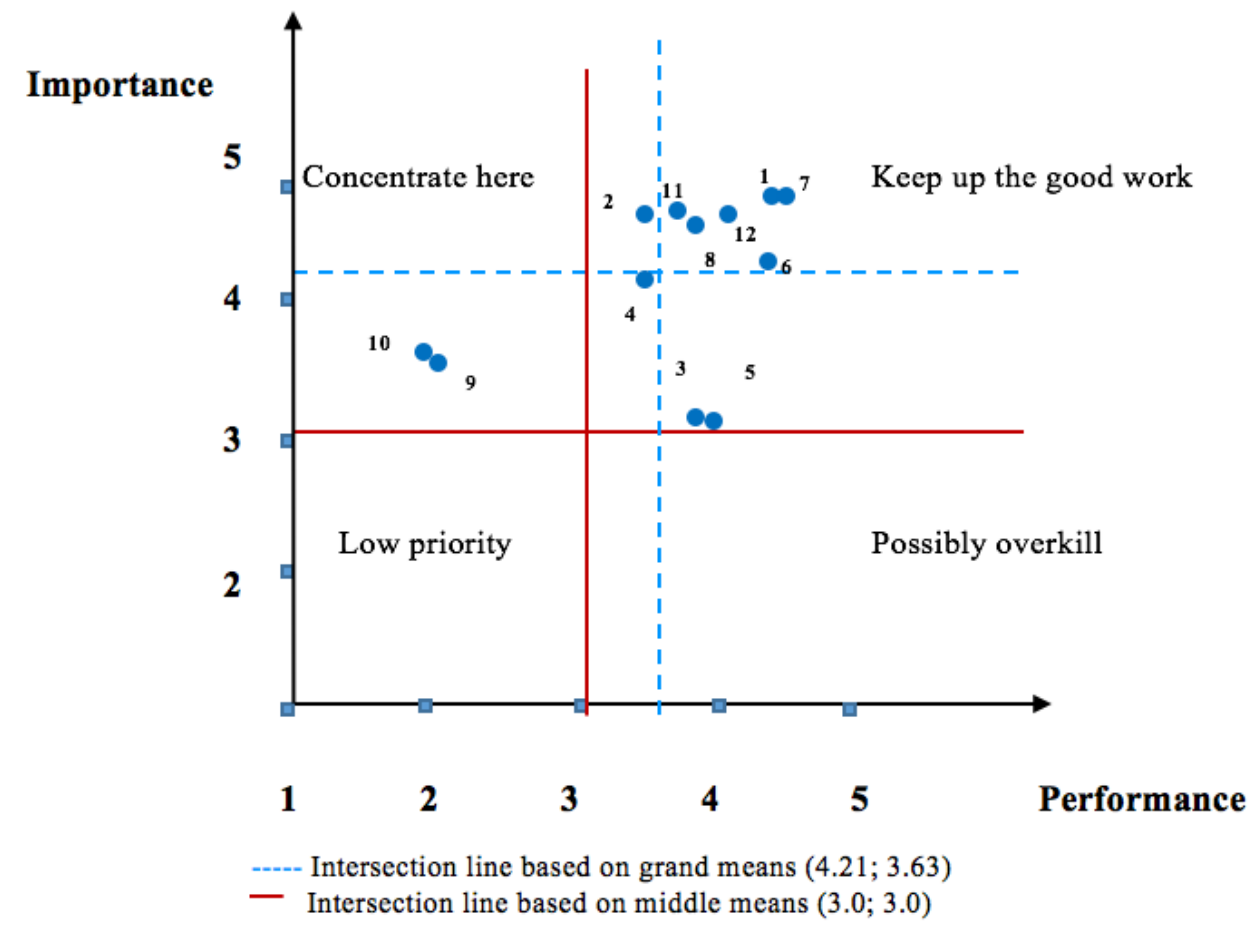

Figure 6.12. The grid of roles for domestic visitors

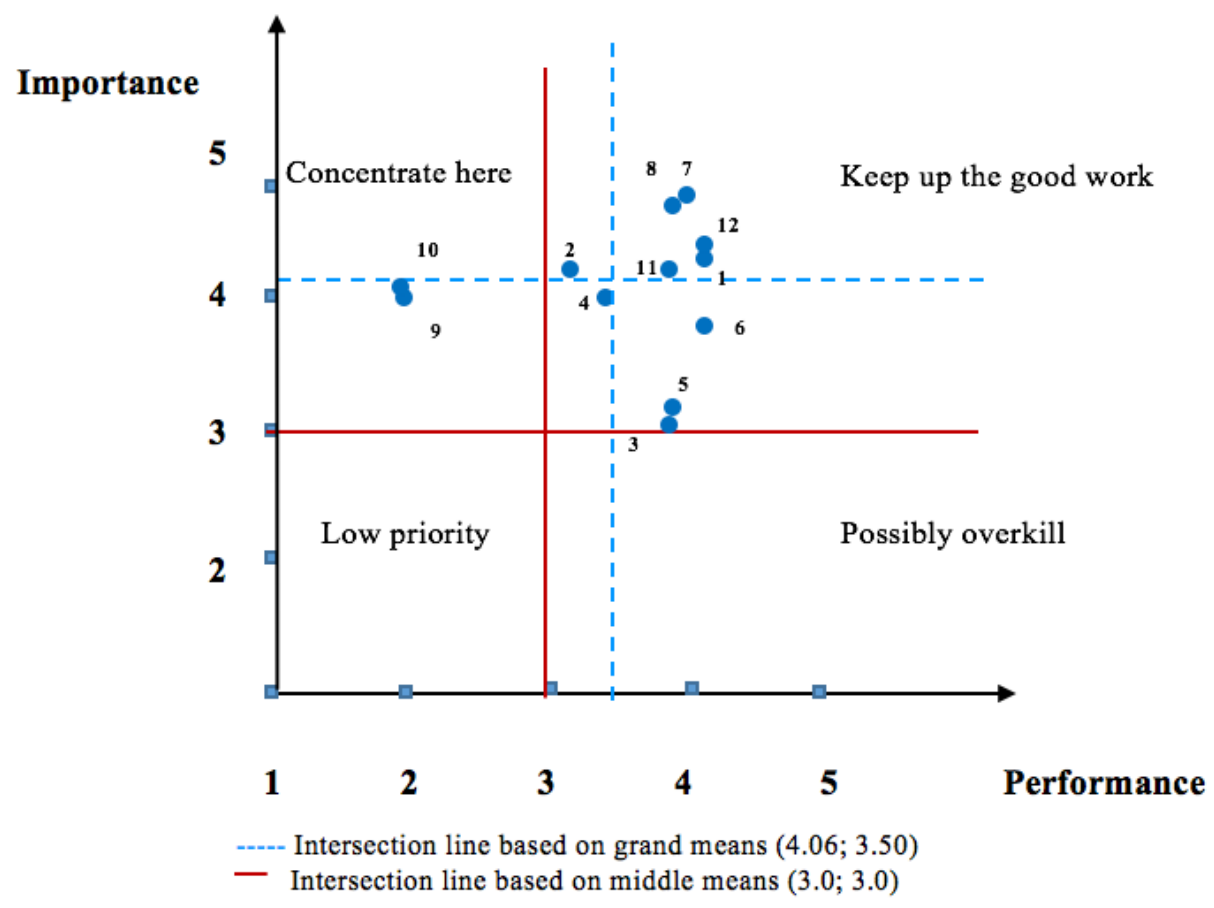

Figure 6.13. The grid of roles for international visitors

\subsection{Conclusion}

This chapter presented the similarities and differences in visitor satisfaction with services for environmental interpretation according to motivation-based segments. The segmentation process 
involved factor analysis and cluster analysis. The factor analysis conducted on 13 motivational variables generated two factors (Learning and Experience), which served as two dimensions for the cluster analysis. Four clusters (Area enthusiasts, Passive visitors, Active learners and Novelty seekers) were formed from the cluster analysis. These four clusters were different from each other regarding their demographic and trip-related characteristics. The similarities and differences in visitor satisfaction between the four motivation segments were analysed with importance and performance ratings for eight services and twelve roles of site interpreters.

The evaluations of the importance of site interpreters, interpretive signs, videos at the rescue centre, staff at the museum and displays at the museum remained high, while the evaluations of the importance of staff at the ticket office and directional signs were very low across clusters. Some significant differences were found in the importance ratings for site interpreters, interpretive signs about the site, brochures at the ticket office, displays at the museum and videos at the rescue centre. Noticeably, brochures were not an important service for environmental interpretation according to "Passive visitors" while brochures were quite important to "Area enthusiasts", "Active learners" and "Novelty seekers". This finding is in line with the finding from the importance-performance grids for each cluster. Regarding the performance of these services, interpretive signs, site interpreters, staff at the museum and brochures were still the top four services with high performance in all four clusters, corresponding to their importance. Videos at the rescue centre and displays at the museum still had the worst performance in all four clusters in comparison with their high importance. Directional signs and staff at the ticket office had low performance in all four clusters, corresponding to their low importance. A significant difference was found in the performance ratings for interpretive signs, where "Area enthusiasts" and "Novelty seekers" were assessed higher than "Passive visitors" and "Active learners".

Regarding the importance of twelve roles of site interpreters, the importance means of eight roles $(1,2,4,6,7,8,11$ and 12$)$ remain high across the four clusters. Role 3 and role 5 were not important according to all four groups of visitors. The importance ratings for role 9 and role 10 from "Passive visitors" and "Active learners" were significantly higher than from "Area enthusiasts" and "Novelty seekers". Role 9 and role 10 were important according to "Passive visitors" and "Active learners", but were not important according to "Area enthusiasts" and "Novelty seekers". The performance means of eight roles $(1,3,5,6,7,8,11$ and 12) remained high across clusters while role 9 and 10 had poor performance according to these clusters. Role 1 , role 6 , role 7 and role 12 remained the top four roles with high performance in all four clusters, corresponding to their high importance. The performance of role 8 and role 11 were quite high in all four clusters, corresponding to their high importance. Role 3 and role 5 of site interpreters performed quite well according to four clusters in comparison with their low importance. The performance ratings for role 2 and role 4 were quite low in all four clusters in comparison with their high importance. These roles need to improve 
their performance in the future to meet visitor satisfaction. Moreover, according to two clusters ("Passive visitors" and "Active learners"), the performance of role 9 and role 10 also need to be improved, as these two roles had high importance to these two clusters but their performance ratings were very low. These findings are also in line with the findings from the importance-performance grids for the four clusters.

This chapter also presented the similarities and differences in visitor satisfaction with services for environmental interpretation according to two market segments (domestic and international visitors). The importance means of site interpreters, interpretive signs, videos at the rescue centre, staff at the museum and displays at the museum were high in both segments, while the importance means of staff at the ticket office and directional signs were very low. Significant differences were found in the importance ratings for interpretive signs and brochures. The importance of interpretive signs and brochures to domestic visitors were higher than to international visitors. Especially, brochures were not perceived as important by international visitors. This finding is in line with the finding from the grids for both segments. Regarding the performance of these services, interpretive signs, site interpreters and staff at the museum were the top services with the best performance, corresponding to their importance. The performance of directional signs was quite high according to international visitors in comparison with their low importance. The performance of brochures was quite high in comparison with low importance according to international visitors. The performance of videos at the rescue centre was low according to domestic visitors, in comparison with their high importance. The performance of displays at the museum was low, in comparison with their high importance in both segments. Hence, the performance of displays at the museum needs to be improved in the future to meet visitor satisfaction from both segments. Also, the performance of videos at the rescue centre needs to be improved to meet visitor satisfaction from domestic visitors. Regarding the importance of twelve roles of site interpreters, it is highlighted that role 9 and role 10 were important according to international visitors but not important to domestic visitors. The performance of role 9 and 10 were very low in comparison with their high importance according to international visitors. Role 9 and role 10 need to be improved in the future to satisfy international visitors. The next chapter, Discussions, Implications and Conclusions discusses the findings of this research. 


\section{CHAPTER 7}

\section{DISCUSSIONS, IMPLICATIONS AND CONCLUSIONS}

\subsection{Introduction}

Little research has been done on environmental interpretation in national parks. In particular, no research has investigated visitor satisfaction with all services for environmental interpretation in national parks using Importance-Performance Analysis. Moreover, environmental interpretation in national parks and protected areas is still a new research area in Vietnam. By gaining an understanding of the importance and performance of each service for environmental interpretation in a national park, managers can develop these services effectively. In addition, the incorporation of market-based and motivation-based segmentation into Importance-Performance Analysis can provide information for designing these services to satisfy multiple groups of users. Hence, this study has investigated visitor satisfaction with services for environmental interpretation in Cat Tien National Park. Table 7.1 provides a summary of the study with the research aims and results to examine how well these aims were achieved. Using Importance-Performance Analysis and visitor segmentation, four research aims were addressed.

1 To identify current interpretive services in Cat Tien National Park.

5. To explore the use of services for environmental interpretation in Cat Tien National Park.

6. To investigate visitor satisfaction with services for environmental interpretation in Cat Tien National Park using Importance-Performance Analysis.

7. To analyze the similarities and differences in visitor satisfaction with services for environmental interpretation according to motivation segments and market segments.

This chapter discusses key research findings in relation to the literature, and is structured into five sections. Section 7.2 discusses findings relating to services for environmental interpretation in Cat Tien National Park and visitor use of these services, addressing the first two research aims. Sections 7.3 analyses the main findings for visitor satisfaction with eight services for environmental interpretation and twelve roles of site interpreters using Importance-Performance Analysis. Section 7.4 discusses main findings from visitor segmentations. Issues from Importance-Performance Analysis and visitor segmentation are then demonstrated in section 7.5 and 7.6. Implications for tourism practitioners as well as implications for future research will be given in section 7.7 and 7.8. Section 7.9 presents the contribution of this study to academic literature. Some limitations will also be acknowledged in section 7.10. Section 7.11 summarizes the main findings and the significance of this research. 
1. To identify current services environmental interpretation in Cat Tien National Park

2. To explore the use of services for

environmental interpretation in Cat Tien National Park

3. To investigate visitor satisfaction services with environmental interpretation in Cat Tien National Park using ImportancePerformance Analysis.

\section{To analyze the} differences in visitor satisfaction with services environmental interpretation according motivation segments and market segments.

\section{Eight services for environmental interpretation:}

- Site interpreters, staff at the ticket office, staff at the museum, interpretive signs, directional signs, brochures, displays at the museum and videos at the rescue centre.

- Interpretive signs, directional signs, brochures at the ticket office and staff at the ticket office were the most common services.

- Videos at the rescue centre, staff and displays at the museum were the least common.

\section{The importance of services for environmental interpretation:}

- Site interpreters, interpretive signs, videos at the rescue centre, staff at the museum and displays at the museum were the five most important services.

- Directional signs and staff at the ticket office had very low importance.

The performance of services for environmental interpretation:

- Interpretive signs, site interpreters, staff at the museum and brochures performed well.

- Directional signs and staff at the ticket office had low performance.

$\rightarrow$ Videos at the rescue centre and displays at the museum had very low performance in comparison with their high importance.

The importance of roles of site interpreters:

- Ten roles $(7,1,12,8,2,11,4,6,9$ and 10) were high important.

- Role 5 and role 3 had low importance means.

The performance of roles of site interpreters:

- Eight roles (7, 1, 6, 12, 5, 3, 8 and 11) had high performances.

$\rightarrow$ The performance of four roles $(2,4,9$ and 10$)$ were quite low in comparison with their high importance.

\section{The importance of services for environmental interpretation:}

$\rightarrow$ Brochures were not an important service to "Passive visitors".

$\rightarrow$ Brochures were not important to international visitors.

The performance of services for environmental interpretation:

$\rightarrow$ The performance of interpretive signs according to "Area enthusiasts" and "Novelty seekers" were higher than according to "Passive visitors" and "Active learners".

$\rightarrow$ The performance of interpretive signs according to domestic visitors were higher than international visitors.

$\rightarrow$ The performance of directional signs was quite high according to international visitors.

$\rightarrow$ The performance of videos at the rescue centre were low according to domestic visitors.

The importance of roles of site interpreters:

$\rightarrow$ Two roles (9 and 10) were important to "Passive visitors" and "Active learners", but were not to "Area enthusiasts" and "Novelty seekers".

$\rightarrow$ Role 9 and 10 were important to international visitors but not important to domestic visitors.

The performance of roles of site interpreters:

$\rightarrow$ According to "Passive visitors" and "Active learners", two roles (9 and 10) did not perform well but had high importance.

$\rightarrow$ Two roles ( 9 and 10$)$ had very low performance but had high importance according to international visitors. 


\subsection{Services for environmental interpretation and visitor use of services for environmental interpretation in Cat Tien National Park}

This section discusses the findings in relation to the first two research aims (Table 7.1). Regarding the current services for environmental interpretation, the results from examining secondary data, conducting interviews, a site visit and a pilot test found eight services for environmental interpretation: site interpreters, staff at the ticket office, staff at the museum, interpretive signs, directional signs, brochures, displays at the museum and videos at the rescue centre. These services were identified as personal (staff at the ticket office, site interpreters and staff at the museum) and non-personal services (interpretive signs, directional signs, brochures, displays at the museum and videos at the rescue centre). This classification was adopted from studies of Munro et al. (2008), Skanavis and Giannoulis (2010) and Tsang et al. (2011). Munro et al. (2008) defined interpersonal (personal) interpretation as the two-way communication between staff and visitors. Personal services include not only site interpreters (tour guides) but also other staff members in natural areas.

Regarding the second aim, interpretive signs, directional signs, brochures at the ticket office, staff at the ticket office were the most common services used by questionnaire respondents. Site interpreters were also used quite frequently by visitors who came to Cat Tien National Park (Table 4.8). This finding is different from the finding of Tsang et al. (2011), in that many visitors did not know about guided tours in the park. Cat Tien National Park always recommends visitors to use site interpreters when they explore the park to prevent them from getting lost and to protect them from dangerous animals which may appear during the trip. Videos at the rescue centre and staff and displays at the museum were the least common used services. This finding is different from the finding of Tsang et al. (2011) in Hong Kong Wetland Park, in which experiential facilities and exhibits were used commonly by visitors. This difference may be because displays at the museum in Cat Tien National Park were not as attractive as in Hong Kong Wetland Park. The museum was quite old, small and hidden because of surrounding buildings. Moreover, displays at the museum were only specimens with name labels. There was no explanation or audio media for visitors to learn more about the specimens. In addition, domestic visitors often do not like to listen to educational content of interpretation. To enhance the use of these services, the range of services for environmental interpretation should be introduced to visitors with their importance when visitors arrive to the national park. Also, enhancing the attractiveness of these services could improve their use by visitors to the national park.

\subsection{Visitor satisfaction with services for environmental interpretation in Cat Tien National}

\section{Park}

This section discusses the findings in relation to the third research aim, which is to investigate visitor satisfaction with services for environmental interpretation using Importance-Performance Analysis 
(Table 7.1). The importance of these services for environmental interpretation and visitor satisfaction with these services are discussed.

Regarding the importance of services for environmental interpretation, five services (site interpreters, interpretive signs about the site, videos at the rescue centre, staff at the museum and displays at the museum) were identified as the most important services (Table 5.1). This reflects the finding of Wei-ching (2015), suggesting the importance of site interpreters. The finding of Weiching (2015) indicated that interpretation by tour guides was perceived as necessary by most of the visitors in Taijiang National Park of Taiwan. The finding of the high importance of site interpreters is also relevant to Vietnamese culture, as Vietnamese people generally like to use guides to explore national parks.

The finding of the importance of interpretive signs, videos at the rescue centre and displays at the museum are in line with the findings of Carr (2004), in which visitors who came to Aoraki/Mount Cook, New Zealand preferred using audio-visual shows, displays at the visitor centre and interpretive signs. Museums and interpretive signs were also the most desired services according to visitors in Ocala National Forest in Florida, USA (Stein et al., 2003). These medium can contain rich information about environment and deliver information to visitors in an attractive way (with images and sounds).

Brochures were quite important to the visitors of Cat Tien National Park. According to Carr (2004), brochures can be a good service as they are cheap, so visitors can take them away. Brochures contain brief information about activities in the national park with images and a map. However, directional signs and staff at the ticket office had very low importance, as they may have little potential for environmental interpretation according to visitors (Table 5.1). The findings of Xu et al. (2013) also showed that visitors in China did not often read signs.

Visitor satisfaction with a service can be referred to as the performance of that service (i.e. high visitor satisfaction with a service indicates a high performance of that service). Regarding visitor satisfaction with services for environmental interpretation, visitors were satisfied with the performance of site interpreters and staff at the museum, interpretive signs, and brochures (Table 5.2). Most of the site interpreters in Cat Tien National Park are local people who have deep knowledge about the site. Also, the staff at the museum are knowledgeable people who had gained qualifications in Forestry. This finding is in line with those of Munro et al. (2008), who pointed out that interpersonal interpretation (or personal interpretation) was often described as a more effective tool than non-personal interpretation. Xu et al. (2013) also showed that guided tours using stories, art and poetry were more effective in China. Tsang et al. (2011) also found that visitors were most satisfied with the performance of guided interpretive tours. The high satisfaction with interpretive signs and brochures in Cat Tien National Park is also in line with the finding of Tsang et al. (2011). 
By contrast, visitors were not satisfied with directional signs and staff at the ticket office (Table 5.2). Some visitors commented that some safety signs were faded, unclear and needed to be replaced. Moreover, they expressed that the national park should display safety signs in places with dangerous animals (e.g. snakes). This finding is consistent with the findings of Xu et al. (2013) and Tsang et al. (2011). The finding of Xu et al. (2013) showed that self-guided interpretation with directional signs and information centres was ineffective in China. Visitors often got lost because of the imprecise nature of directional signs or safety signs.

Also, the performance of videos at the rescue centre and displays at the museum did not satisfy visitors (Table 5.2). Regarding videos at the rescue centre, some visitors commented that the quality and content of the videos was quite poor, and that the volume of the videos was not loud enough. In addition, some international visitors expressed their disappointment that there was no video in the Bear Rescue Centre. This finding is not consistent with the finding of Komatsu and Liu (2007), which demonstrated the effectiveness of educational videos in changing visitors' attitudes and behaviours towards environmental issues. In terms of displays at the museum, many visitors said that the exhibits and displays at the museum were not attractive. They suggested that visual interpretation (e.g. images and videos, etc.) could be more effective. The finding for displays at the rescue centre is in line with the finding of Xu et al. (2013), in which self-guided interpretation with a geological museum was ineffective in China.

The relationship between the importance and performance of services for environmental interpretation was illustrated with mean comparisons, a paired samples t-test, the importanceperformance grid and iso rating line. The comparison of importance and satisfaction ratings for eight services showed that videos at the rescue centre and displays at the museum had very low performance in comparison with their high importance (Table 5.3). The importance-performance grid also showed that the national park should concentrate on improving the performance of these two services to meet visitor satisfaction (Figure 5.1). Interpretive signs, site interpreters and staff at the museum were the three most important and satisfying services. Visitors are often very satisfied with the performance of services which are very important to them. Hence, the performance of these three services needs to be maintained to retain visitor satisfaction with services for environmental interpretation in Cat Tien National Park. Brochures were considered as 'possible overkill' in the importance-performance grid as their performance was rated higher than their importance. Staff at the ticket office and directional signs should receive low attention from the managers of Cat Tien National Park as these services had low importance and low performance. The results of the paired samples $t$ test show that alongside videos at the rescue centre and displays at the museum, the performance of site interpreters, staff at the museum and interpretive signs also need to be improved in the future, as their performances were lower than their corresponding importance (Table 5.3). The iso rating line also creates the same results and further gives the priority list for future investment 
(videos at the rescue centre, displays at the museum, site interpreters and staff at the museum, respectively) (Figure 5.2).

In short, many services did not perform well in visitors' perceptions (e.g. videos at the rescue centre, displays at the museum, etc.). An unclear guideline for environmental interpretation in the national park and a lack of visitor input may lead to unsuitably designed interpretive services ( $\mathrm{Xu}$ et al., 2013). Moreover, some services such as videos at the rescue centre, directional signs and interpretive signs, etc. were designed by experts from external organisations who had little knowledge about the national park; hence, the design of these services may have been not suitable for the park.

Because of the high importance of site interpreters, visitor satisfaction with twelve roles of site interpreters was analysed separately with importance and satisfaction ratings. Regarding the importance of twelve roles of site interpreters, the communicative, instrumental and environmental roles of an interpreter were perceived as highly important (Table 5.4). Providing a comfortable pace for the trip and informing visitors of dangers to ensure their safety were important roles of a tour guide. Disseminating correct information about the site to increase knowledge about the local environment was a vital role of a site interpreter. This was followed by the social role for a positive group environment and the interactional role for a well-organised group. Two roles of a motivator of responsible behaviour were also quite important in visitors' perceptions. According to the visitors, site interpreters should discuss a code of ethics in the national park and highlight the importance of not taking anything from the national park.

The interactional role for on-site conflicts and the social role for group conflicts were the least important roles of site interpreters according to visitors in Cat Tien National Park. This finding is different from the finding of Randall and Rollins (2009), in which these two roles were important to visitors who came to Pacific Rim National Park, Canada. This may be explained by the research having been conducted during the low season, where not many visitors arrived to the national park at the same time.

Regarding the satisfaction ratings of twelve roles of site interpreters in Cat Tien National Park, the communicative roles, the instrumental role for the comfortable pace of the trip, the interactional roles, the roles of an environmental interpreter and the social role for group conflicts performed well in visitors' perceptions (Table 5.5). However, the performance of the social role for a positive group environment and the instrumental role for the safety of visitors did not satisfy visitors. Some visitors expressed that the guide was not enthusiastic because they did not receive a monetary tip. Tipping is perceived as a way to enhance the performance of site interpreters; however, it can cause visitor dissatisfaction with site interpreters and the trip. Moreover, as their English may be poor, it is hard for guides to explain the information in-depth to international visitors and make some jokes. Regarding the dangers that may exist in the tour, visitors expressed that they were not informed in 
advance by the tour guides. The performance of site interpreters as a motivator of responsible behaviour also did not satisfy visitors. Some visitors expressed that tour guides should inform visitors of a code of ethics in the national parks.

The relationship between the importance and performance of roles of site interpreters was illustrated with mean comparisons, paired samples $t$ test, the importance-performance grid and iso rating line as the importance-performance grid is not complicated enough to give correct management suggestions (e.g. in the case of the importance-performance grid for roles of site interpreters-Figure 5.3). The comparison of the importance and performance ratings for twelve roles of site interpreters suggested that the social role for a positive group environment and the instrumental role for safety information need to improve the performance in the future to meet visitor satisfaction (Table 5.6). The results from a paired samples t-test (Table 5.6) and iso rating line (Figure 5.4) show that alongside the two roles above, the instrumental role for a comfortable pace of the trip, the communicative roles, the roles of a motivator of responsible behaviour and an environmental interpreter also need to be improved. These findings were different from the findings of Randall and Rollins (2009), in which only two roles of a motivator of responsible behaviour had a performance rating lower than their importance. This means that the performance of site interpreters in Western countries like Canada tends to be higher than in Eastern countries like Vietnam.

In short, site interpreters should inform visitors of the dangers that they may encounter in the tour, as well as the code of ethics of the national park. This information may increase visitor satisfaction with site interpreters and overall visitor satisfaction with the trip. As suggested by Skanavis and Giannoulis (2010), proper training about environmental education for tour guides are necessary to enhance the performance of their roles of a motivator of responsible behaviours with regard to their environmental knowledge and interpretation skills. Moreover, the level of spoken English is also an important issue to site interpreters in Cat Tien National Park. There are four site interpreters in Cat Tien National Park, all of whom are locals. However, only two of them can communicate in English and their English is poor. Future training for communication skills and English classes are really essential for their future performance, as expressed by the staff members of Centre of Environmental Education and Services. In addition, a regular assessment of service quality for site interpreters is needed to provide visitors with consistent service quality. Raising the enthusiasm and responsibility of site interpreters is the most important task for the managers of Cat Tien National Park.

\subsection{Similarities and differences in visitor satisfaction with services for environmental interpretation according to motivation-based and market-based segments}

The fourth aim of this thesis was achieved via using visitor segmentations (motivation-based and market-based segmentations) (Table 7.1). Some important results from the findings in Chapter 6 are discussed in this section. 
Brochures were quite important to the visitors of Cat Tien National Park. However, the results from market-based segmentations indicated that brochures were not perceived as an important service by international visitors. According to international visitors, brochures may have little potential for environmental interpretation. Hence, future development for brochures should focus more on domestic visitors.

Regarding the performance of videos in the rescue centre, the results from market-based segmentation indicated that the performance of videos was low according to domestic visitors, but was quite high according to international visitors. This low performance rating may be because the videos were only available in English, which is not suitable for domestic visitors and non-Englishspeaking international visitors. Videos at the rescue centre need to be improved the performance in the future to ensure domestic visitor satisfaction.

The results from motivation-based segmentations show that two roles of a motivator of responsible behaviour were important to "Passive visitors" and "Active learners", but were not important to "Area enthusiasts" and "Novelty seekers". These two roles were also important to international visitors, but were not important to domestic visitors. International visitors seem to care more about environmental issues than Vietnamese and be more active in learning, as they may have more experience in national parks and other protected areas. Domestic visitors seem to be not interested in listening to rules or code of ethics because relaxing and experience may have been their main motivations to Cat Tien National Park. However, according to the interviewees, domestic visitors seem to be more likely to leave litter in national parks. The performance of these two roles were low, in comparison of their high importance, according to "Passive visitors", "Active learners" and international visitors. Thus, the performance of these two roles also need to be improved in the future to meet the satisfaction of "Passive visitors" and "Active learners", as well as international visitors.

\subsection{Importance-Performance Analysis and its implications}

This study adopted Importance-Performance Analysis as an approach to measure visitor satisfaction, because this approach can demonstrate visitor perceptions of the importance of these services for environmental interpretation in Cat Tien National Park and provide useful management implications for future development of these services. This study attempted to solve the common problems identified by Oh (2001) (Section 2.7). Firstly, the criterion concept of importance has not been defined clearly in the Importance-Performance Analysis literature. Moreover, Oh (2001) indicated that there has been a misunderstanding of two concepts (importance and expectation). In this research, visitors were asked to rate the importance and performance of interpretive services with respect to their satisfaction, to assess the importance and performance related statements consistently. In this regard, the importance is different from a predictive expectation about future performance or an ideal expectation about the best performance of the service. Secondly, because 
this research used all services for environmental interpretation in Cat Tien National Park instead of selected services, higher ratings for a set of importance attributes do not exist. Thirdly, according to Oh (2001), importance ratings of visitors can influence their performance ratings. Hence, to minimize the causal relationship between them, the questions for the importance of services were separated with the questions for their performance by using pre-visit and post-visit questionnaires. Fourthly, the study used a scale from 1 (not at all important) to 5 (extremely important) instead of a scale from 1 (very unimportant) to 5 (very important). Fifthly, Oh (2001) indicated that using actual means (grand means) versus scale means (midpoints of the scale) in drawing the importanceperformance grid can create different results. In this study, grand means were used to create the importance-performance grid as grand means can create more meaningful implications. Scale means were also used to confirm the results. When the results from both grids were different, mean comparisons, paired samples $\mathrm{t}$ test and iso rating line were used to give correct management suggestions.

The importance-performance grid drawn for eight services for environmental interpretation provided some useful suggestions for future development. However, the strategic suggestions given from the importance-performance grid for twelve roles of site interpreters were not accurate (Section 5.3.4). As a result, crosshairs drawn by grand means also did not give more accurate results than scale means (midpoints of the scale) for the study. This has been mentioned by Oh (2001). He indicated that Importance-Performance Analysis may not be detailed enough to give accurate strategic suggestions. Some questionable positions need to be considered carefully via other methods. When using the results from the importance-performance grid without using other comparisons (mean comparisons, paired sample t test, etc.), some important results can be missed. Using other comparisons such as the ones used in this study can help confirm and supplement the results from the importance-performance grid.

The above findings also demonstrate that using visitor segmentation for Importance-Performance Analysis is very useful in providing a clearer overview of visitor satisfaction. Randall and Rollins (2009) suggested that visitor segmentation is needed to identify the most wanted roles according to each segment when importance ratings are inconsistent. The next sections discuss the use of marketbased and motivation-based segmentation.

\subsection{Visitor segmentation}

Better designs for services can be achieved through understanding visitors' perceptions of the importance and performance of services, and can be maximized through understanding of visitor segments (Hendricks et al., 2004). An investment can only be considered as effective when it satisfies all groups of users. Stein et al. (2003) indicated that visitors who come to natural areas are different in their motivations and that they require different services and facilities to attain these 
motivations. They pointed out that designing services and facilities according to different types of people with different motivations can support the sustainable development of natural areas.

In terms of methods used to create motivation-based clusters, a literature review by Frochot and Morrison (2000) showed that there have been many different techniques used, depending on the availability of statistical packages and common techniques used by researchers. The most common is to use a combination of both factor analysis and cluster analysis. This strategy helps to reduce benefit variables into a smaller number of underlying dimensions and then group visitors into a number of clusters according to these dimensions (Frochot and Morrison, 2000). Some other methods involve using only factor analysis (e.g. Crilley et al., 2012) or cluster analysis (e.g. Williams and Dossa, 2003). Frochot and Morrison (2000) indicated that the combination of factor and cluster analysis seems be more effective as it can facilitate the interpretation of clusters. In this study, the motivational-based segmentation process involved factor and cluster analysis. The factor analysis conducted on 13 motivational variables generated two factors (Learning and Experience), which served as two dimensions for cluster analysis. Four clusters (Area enthusiasts, Passive visitors, Active learners and Novelty seekers) were formed from the cluster analysis.

The results from the importance-performance grids for visitor segments show that significant differences were found mostly in importance ratings but few differences were found in performance ratings (Tarrant, Bright, Smith and Cordell, 1999). The current study also used statistical tests to identify significant differences between the importance ratings (performance ratings) across clusters, as learnt from the study of Hendricks et al. (2004). Moreover, Hendricks et al. (2004) suggested that because there were differences between visitor segments, managers should carefully consider these differences in designing services or making future investments. For example, in this study, videos at the rescue centre fell in the "Concentrate here" quadrant. Analysing visitor segments identified that the performance of videos at the rescue centre was low according to domestic visitors but was quite high according to international visitors. This means that the managers of Cat Tien National Park need to create videos which are more suitable to domestic visitors, perhaps by providing Vietnamese subtitles or translators rather than trying to satisfy both visitor segments at once. As a result, the interpretation of the data and the grid becomes more clear and specific and the investment becomes more effective. Hendricks et al. (2004) contended that it is vital to recognize and make changes to meet the need of different visitor segments if the differences are significant.

\subsection{Implications and recommendations for tourism practitioners}

Previous research demonstrates that Importance-Performance Analysis is a useful tool in providing information for more accurate management decisions. It provides information about problem areas which need more attention, strength areas, 'possible overkill' and low priority areas. The incorporation of market-based and motivation-based segmentations into the Importance- 
Performance Analysis also provide more specific information for effective investment in the future. This study has pointed out some implications which need to be applied to develop a more relevant environmental interpretation system in Cat Tien National Park.

\subsubsection{Implications and recommendations for Vietnam's national tourism organisations}

Although environmental interpretation has been demonstrated as an effective tool for environmental education in Western countries in the 1970s (Xu et al., 2013), it has been a relatively new research area in the context of Vietnamese tourism. No appropriate guidance from Central Government has been elaborated to develop suitable interpretation in the national parks. Some of the national parks have received the financial and technical assistance from international organisations to develop services for environmental interpretation. However, Central Government and Vietnam National Administration of Tourism should play an important role in guiding the development of interpretation systems in national parks and other protected areas. A lack of guidance can be the rationale for the irrelevance and ineffectiveness of some services for environmental interpretation in Cat Tien National Park. Moreover, Central Government and Vietnam National Administration of Tourism should provide site interpreters (tour guides) with regular training about environmental education to enhance the performance of two roles of a motivator of responsible behaviour as suggested by Skanavis and Giannoulis (2010). Also, a code of ethics for visitors needs to be elaborated to apply for all national parks of Vietnam.

\subsubsection{Implications and recommendations for the management of Cat Tien National Park and other national parks of Vietnam}

Cat Tien National Park has received technical and financial supports from outside organisations. However, the support can only last for a short period and it is important for the national park to take their responsibility for strengthening their own interpretation system. Several management decisions need to be considered by the managers of the national park.

Firstly, the national park should provide visitors with an introduction and rationale for using the museum and watching videos at the rescue centre at the entry or via other channels as suggested by Komatsu and Liu (2007), to enhance visitor use of these services. Enhancing the attractiveness of services can improve visitor use of and satisfaction with these services. Visual interpretation (e.g. images and videos, etc.) should also be used in the museum. Tubb (2003) emphasized the importance of audio media for interpretation in protected areas. According to Tsang et al. (2011), the audio media is quite convenient to visitors as they can use it anytime and repeat it. Moreover, Hwang et al. (2005) suggested that services should be developed as an "ecological observation area" (p.154). Tsang et al. (2011) also recommended that activities such as tree-planting should be implemented together with the interpretation by tour guides. 
Regarding videos at the rescue centre, translators should be provided at the site to convey the information for visitors. Vietnamese subtitles could be another option. Moreover, the sound quality of the videos should be improved. Also, the content of the videos needs to be adjusted to effectively convey environmental messages to visitors. According to Tsang et al. (2011), video content should include information about the possible influence of humans on the ecosystems and environment. Also, videos should be provided in both rescue centres. Regarding directional signs, faded safety signs need to be replaced.

Site interpreters in Cat Tien National Park are non-formal environmental interpreters, so they need to be trained about distinctive features of interpretation contexts such as the audience, time limitations, etc. and the way to optimize their non-formal education experience (Skanavis and Giannoulis, 2010). In addition, they should be trained about environmental education. Lessons in English language and communication skills should be arranged regularly for site interpreters to meet the satisfaction of international visitors.

Moreover, the national park should provide a 'to-do list' for site interpreters, including discussing dangers that may exist in the tour and introducing the code of ethics for visitors. Regular assessments of the performance of site interpreters should also be implemented. According to Tsang et al. (2011), a recording card with multiple choice questions can be a useful tool to measure visitor satisfaction with site interpreters. Last but not least, raising a sense of enthusiasm and responsibility for site interpreters is an important task for the managers of Cat Tien National Park.

\subsection{Implications for future research}

Importance-Performance Analysis has been used widely in measuring visitor satisfaction. This study is the first to measure visitor satisfaction with environmental interpretation in a national park using Importance-Performance Analysis and visitor segmentation. This study demonstrates that using Importance-Performance Analysis with visitor segmentation can provide better information for the strategic management of services. Although the research methodology has been carefully designed, some following areas still need more attention in future research:

Firstly, it is suggested that further research on visitor satisfaction should be conducted again in other seasons and every two or three years. According to Farnum and Hall (2007), seasonal bias can affect the results of visitor satisfaction. Frochot and Morrison (2000) also suggested that the studies with benefit segmentation should be applied in different seasons, every two or three years, because benefit segments may not be the same over time due to internal and external factors.

Secondly, there is a need to conduct further research using in-depth interviews or focus groups with both domestic and international visitors to know more about their different wants and needs about services for environmental interpretation. Especially, some problem areas such as displays at the 
museum, videos at the rescue centre need to be explored in-depth to provide better services in the future. Moreover, participant observation can also be used in the future to find out specific problems of each service for better investment.

Thirdly, this research only attempted to find out visitors' perceptions of the importance and performance of current services. Research on visitor demand of other services should also be conducted to consolidate the environmental interpretation systems in Cat Tien National Park. This kind of research can adopt quantitative, qualitative or mixed methods.

Fourthly, this research only used market-based and motivation-based segmentations. Future research can adopt other criterion for visitor segmentation. According to Farnum and Hall (2007), market segmentation or visitor segmentation according to visitors' other characteristics (e.g. day visits or overnight stays) can create more meaningful importance-performance grids. Randall and Rollins (2009) also suggested that visitor segmentation according to length of stay should be implemented to yield more meaningful results. Western visitors seem to visit a national park several times. Hence, loyalty levels to a national park can be a criterion for visitor segmentation.

Fifthly, in terms of the analytical approach, this research compared visitor satisfaction according to motivation-based segments and market-based segments respectively, due to the small number of international visitors. Another approach could be to first classify visitors into market-based segments, then create motivation-based sub-segments for each market-based segment. This approach of Williams and Dossa (2003) seems to be more useful to make comparisons between market segments as well as between their motivation-based sub-segments. Future research should collect data from a larger sample to adopt this approach.

Finally, this research pointed out that management implications resulting from ImportancePerformance Analysis are not always accurate. Future research should adopt different methods or statistical tests (e.g. mean comparison, paired samples t-tests and iso rating line, etc.) to confirm and supplement the results.

\subsection{Research contributions}

By achieving the research aims, this study contributed to the tourism literature and practically to Vietnamese tourism. Firstly, this study is the first one in the literature examining visitor satisfaction with all service for environmental interpretation in a national park using Importance-Performance Analysis. Secondly, in this study, motivation-based and market-based segmentations were incorporated into Importance-Performance Analysis. These segmentations have provided some helpful information for future designs of interpretive services. Thirdly, this study contributed to the literature on visitor satisfaction using Importance-Performance Analysis when collecting data about the importance and performance of services separately through pre-visit and post-visit questionnaires. These questionnaires were distributed to the same participants by using playing cards 
as a tracking tool. Lastly, environmental interpretation is a new research area in the context of Vietnam tourism. This study contributed to the development of interpretive services in the national parks of Vietnam in general and in Cat Tien National Park in particular.

\subsection{Research limitations}

Although the research was designed carefully by using a mixed method, there were still some limitations (section 3.10). The sample may not be representative due to the use of convenience sampling. Further research with a larger sample should be conducted in other seasons every two to three years to confirm the results as suggested by Frochot and Morrison (2000). Moreover, this study used quantitative methods to collect information about the importance and performance levels of services for environmental interpretation from a significant response; hence, it lacks in-depth information. Further research should conduct qualitative interviews with visitors in Cat Tien National Park to get more information about their needs and get more suggestions from them.

\subsection{Conclusion}

This study measured visitor satisfaction with services for environmental interpretation in Cat Tien National Park using Importance-Performance Analysis and visitor segmentation (market-based and motivation-based segmentation). The Importance-Performance Analysis and visitor segmentation were useful tools for providing park management with implications from this research.

This thesis indicated that site interpreters were the most important service for environmental interpretation in Cat Tien National Park towards visitor satisfaction. Site interpreters, interpretive signs and staff at the museum are very important and very satisfying services for environmental interpretation in Cat Tien National Park. Displays at the museum and videos at the rescue centre need to be redesigned to meet visitor satisfaction. With regard to twelve roles of site interpreters, the role for a comfortable pace of the trip, the role for a good group organisation, the communicative roles and the roles of an environmental interpreter are important and satisfying roles according to visitors in Cat Tien National Park. The performance of the instrumental role for visitor safety, the social role for a positive group environment and the roles for a motivator of responsible behaviour need to be enhanced to meet visitor satisfaction.

Environmental interpretation is a very important tool to any national park. However, this research area has not received significant attention from the managers of national parks in Vietnam. Proper design of services for environmental interpretation can help to increase the number of visitors, better manage on-site visitors and minimize visitor impacts on the national park. This study suggested some management solutions for Vietnam's national tourism organisations and Cat Tien National Park to address problem areas of the current environmental interpretation systems in Cat Tien National Park. 


\section{REFERENCES}

Adina Cosma, S. (2012). Measurement Tourism Performance of Urban Destinations. Journal Of Travel \& Tourism Research, 50-60.

Akama, J. S., \& Kieti, D. M. (2003). Measuring tourist satisfaction with Kenya's wildlife safari: a case study of Tsavo West National Park. Tourism Management, 24(1), 73

Archer, D., \& Wearing, S. (2002). Interpretation and marketing as management tools in national parks: Insights from Australia. Journal Of Leisure Property, 2(1), 29.

Balnaves, M., \& Caputi, P. (2001). Introduction to quantitative research methods: An investigative approach. London, UK: SAGE.

Beh, A., \& Bruyere, B. L. (2007). Segmentation by visitor motivation in three Kenyan national reserves. Tourism Management, 28(6), 1464-1471. doi:10.1016/j.tourman.2007.01.010

Blaikie, N. (2003). Analyzing Quantitative Data From Description to Explanation. London, UK: SAGE.

Bruyere, B. L., Rodriguez, D. A. \& Vaske, J. J. (2002). Enhancing Importance-Performance Analysis Through Segmentation. Journal of Travel \& Tourism Marketing, 12(1), 81.

Caber, M., Albayrak, T. \& Matzler, K. (2012). Classification of the destination attributes in the content of competitiveness (by revised importance-performance analysis). Journal of Vacation Marketing, 18(1), 43-56.

Carr, A. (2004). Mountain Places, Cultural Spaces: The Interpretation of Culturally Significant Landscapes. Journal Of Sustainable Tourism, 12(5), 432-459.

Catibog-Sinha, C., \& Wen, J. (2008). Sustainable Tourism Planning and Management Model for Protected Natural Areas: Xishuangbanna Biosphere Reserve, South China. Asia Pacific Journal Of Tourism Research, 13(2), 145-162. doi:10.1080/10941660802048431

Creswell, J. W. (2014). Research design: qualitative, quantitative, and mixed methods approaches $\left(4^{\text {th }}\right.$ ed.). California: SAGE.

Crilley, G., Weber, D., \& Taplin, R. (2012). Predicting Visitor Satisfaction in Parks: Comparing the Value of Personal Benefit Attainment and Service Levels in Kakadu National Park, Australia. Visitor Studies, 15(2), 217-237. doi:10.1080/10645578.2012.715038

Curtin, S. (2010). The self-presentation and self development of serious wildlife tourists. International Journal of Tourism Research, 12, 17-33. doi: 10.1002/jtr.734 
Daniels, M. L., \& Marion, J. L. (2005). Communicating Leave No Trace Ethics and Practices: Efficacy of Two-Day Trainer Courses. Journal Of Park \& Recreation Administration, 23(4), $1-19$.

De Nisco, A., Riviezzo, A., \& Napolitano, M. R. (2015). An Importance-performance analysis of tourist satisfaction at destination level: evidence from Campania (Italy). European Journal of Tourism Research, 10.

Denscombe, M. (2007). The good research guide: For small-scale social research projects (3rd ed.). Maidenhead, England: Open University Press.

Driver, B. L. (1983). Master list of items for Recreation Experience Preference scales and domains. Unpublished document. USDA Forest Service, Fort Collins, CO: Rocky Mountain Forest and Range Experiment Station.

Dwyer L., Cvelbar, L. K., Edwards, D. \& Mihalic, T. (2012). Fashioning a destination future: the case of Slovenia. Tourism Management, 13, 305-316.

Eagles, P. F. J. \& McCool, S. F. (2002). Tourism in National Parks and Protected Areas. London, United Kingdom: CABI Publishing.

Everitt, B. S. (2002). The Cambridge dictionary of statistics (2nd ed.). Cambridge, UK: Cambridge University Press.

Farnum, J. O., \& Hall, T. E. (2007). Exploring the Utility of Importance Performance Analysis Using Confidence Interval and Market Segmentation Strategies. Journal Of Park \& Recreation Administration, 25(2), 64-83.

Fernandez, G., \& Ramos, A. G. (2015). Sustainability in tourism through environmental education applied to itineraries. Revista De Turism - Studii Si Cercetari In Turism, (19), 8-14.

Field, A. (2009). Discovering statistics using SPSS (and sex and drugs and rock ' $n$ ' roll) (3rd ed.). London, UK: SAGE.

Field, A. (2013). Discovering statistics using IBM SPSS statistics: And sex and drugs and rock ' $n$ ' roll (4th ed.). Los Angeles: SAGE.

Finn, M., Elliot-White, M., \& Walton, M. (2000). Tourism and leisure research methods: Data collection, analysis, and interpretation. Harlow, England: Longman.

Frochot, I., \& Morrison, A. M. (2000). Benefit Segmentation: A Review Of Its Applications To Travel And Tourism Research. Journal Of Travel \& Tourism Marketing, 9(4), 21.

Hair, J. F., Black, W. C., Babin, B. J. \& Anderson, R. E. (2010). Multivariate data analysis (2nd ed.). Upper Saddle River, NJ: Prentice Hall. 
Henderson, K. A. (2011). Post-Positivism and the Pragmatics of Leisure Research. Leisure Sciences, 33(4), 341-346. Doi: http://dx.doi.org/10.1080/01490400.2011.583166

Hendricks, W. W., Schneider, I. E., \& Budruk, M. (2004). Extending Importance-Performance Analysis with Benefit-Based Segmentation. Journal Of Park \& Recreation Administration, 22(1), 53-74.

Hoang, H., Le, V. L., Nguyen, B. T., Nguyen, D. K. \& Vu, V. D. (2001) (Eds.). National Parks of Vietnam. Hanoi, Vietnam: Agricultural Publishing House.

Hothorn, T., \& Everitt, B. S. (2009). A Handbook of Statistical Analyses Using $R$ (2 ${ }^{\text {nd }}$ ed.). Boca Raton, FL: Chapman \& Hall.

Hwang, S., Lee, C. \& Chen, H. (2005). The relationship among tourists' involvement, place attachment and interpretation satisfaction in Taiwan's national parks. Tourism Management., $26(2), 143-156$.

Jin, H., Uysal, M., \& Williams, J. A. (2003). Satisfaction with Cultural/Heritage Sites: Virginia Historic Triangle. Current Issues \& Development in Hospitality \& Tourism Satisfaction, 177194. Haworth Press, Inc. doi:10.1300/J162v04n03_12

Jurdana, D. S., \& Frleta, D. S. (2012). Sustainable rural tourism development - tourists' satisfaction with Istria as a rural holiday destination. Tourism \& Hospitality Industry, 51-59.

Komatsu, M., \& Liu, J. C. (2007). Cross-cultural Comparison Between Japanese and Western Visitors for the Effectiveness of the Hanauma Bay Education Programme. Tourism Recreation Research, 32(3), 3-12.

Kuo, C. M. (2009). The managerial implications of an analysis of tourist profiles and international hotel employee service attitude. International Journal of Hospitality Management, 28(3), 302.

Kuo, I-L. (2002). The effectiveness of environmental interpretation at resource-Sensitive tourism destinations. International Journal Of Tourism Research, 4(2), 87-101. doi:10.1002/jtr.362

Kuo, N. T., Chang, K. C., Cheng, Y. S., \& Lin, J. C. (2016). Effects of Tour Guide Interpretation and Tourist Satisfaction on Destination Loyalty in Taiwan's Kinmen Battlefield Tourism: Perceived Playfulness and Perceived Flow as Moderators. Journal of Travel \& Tourism Marketing, 33, 103.

Lee, G. \& Lee, C. K. (2009). Cross-cultural comparison of the image of Guam perceived by Korean and Japanese leisure travelers: Importance-performance analysis. Tourism Management, 30(6), 922-931. 
Li, J., W. J. \& Carr, N. (2004). Visitor satisfaction: An analysis of Mainland Chinese Tourists on the Australian Gold Coast. International Journal of Hospitality and Tourism Administration, $5(3), 31-48$.

Lipscombe, N., \& Thwaites, R. (2003). Contemporary challenges for ecotourism in Vietnam. Tourism Review International, 7(1), 23-35.

Lonely Planet (n.d.). Introducing Cat Tien National Park. http://www.lonelyplanet.com/vietnam/around-ho-chi-minh-city/cat-tien-nationalpark/introduction

Manly, B. (1994). Multivariate statistical methods: A primer (2nd ed.). London: Chapman and Hall. Martilla, J. A., \& James, J. C. (1977). Importance-performance analysis. The Journal of Marketing, 41(1), 77-79.

Martín, H. S., Collado, J., \& del Bosque, I. R. (2009). New Approach to Tourist Service Satisfaction with Alternative Comparison Standards. Journal Of Travel \& Tourism Research, 9(1), 1-16.

McDowall, S. \& Ma, E. (2010). An Analysis of Tourists' Evaluation of Bangkok's Performance, Their Satisfaction, and Destination Loyalty: Comparing International Versus Domestic Thai Tourists. Journal of Quality Assurance in Hospitality \& Tourism, 11, 260-282. doi: 10.1080/1528008X.2010.50418

Mehmetoglu, M. \& Normann, Ø. (2013). The link between travel motives and activities in naturebased tourism. Tourism Review, 68(2), 3 - 13. doi: http://dx.doi.org/10.1108/TR-02-20130004

Moscardo, G. (2014). Interpretation and tourism: holy grail or emperor's robes? International Journal of Culture, Tourism and Hospitality Research, 8(4), 462-476. doi: 10.1108/IJCTHR08-2014-0071

Moscardo, G. (2003). Interpretation and Sustainable Tourism: Functions, examples and principles. Journal Of Tourism Studies, 14(1), 112-123.

Munro, J. K., Morrison-Saunders, A. \& Hughes, M. (2008). Environmental Interpretation Evaluation in Natural Areas. Journal of Ecotourism, 7(1), 1-14. doi: 10.2167/joe137.0

Muso, G., Hall, C. M., \& Higham, J. S. (2004). Tourism Sustainability and Health Impacts in High Altitude Adventure, Cultural and Ecotourism Destinations: A Case Study of Nepal's Sagarmatha National Park. Journal Of Sustainable Tourism, 12(4), 306-331.

Naidoo, P., Ramseook-Munhurrun, P. \& Ladsawut, J. (2010). Tourist satisfaction with Mauritius as a holiday destination. Global Journal of business research, 4(2), 113-123. 
Nielsen, N. C. \& Liburd, J. J. (2008). Geographical information and landscape history in tourism communication in the age of Web 2.0. The case of the Salt River Bay National Park in St Croix of the U.S. Virgin islands. Journal of Travel \& Tourism Marketing, 25(3/4), 282.

Oh, H. (2001). Revisiting importance-performance analysis. Tourism Management, 22(6), 617-627.

Okata, Y., Inui, Y., Lankford, S. V., \& Scholl, K. (2007). Applying Importance-Performance Analysis for Japanese Senior Travellers to Hawaii. Tourism Review International, 11(1), 5765.

Pan, S. \& Ryan, C. (2007). Mountain Areas and Visitor Usage - Motivations and Determinants of Satisfaction: The Case of Pirongia Forest Park, New Zealand. Journal of Sustainable Tourism, 15(3), 288-308. doi: 10.2167/jost662.0

Pearce, D. G. (2012). Frameworks for Tourism Research. Retrieved from http://www.eblib.com

Perrett, J. J. \& Mundfrom, D. J. (2010). Bonferroni Procedure. In Salkind, N. J. (Eds.) Encyclopedia of Research Design. (pp. 98-101). Thousand Oaks: SAGE. Doi: http://dx.doi.org/10.4135/9781412961288

Phillips, A. (2004). The history of the international system of protected area management categories. $\begin{array}{llll}\text { Parks, } & \text { 14(3), } & \text { 4-14. } & \text { Retrieved }\end{array}$ https://cmsdata.iucn.org/downloads/14_3lowres.pdf\#page $=25$

Pizam, A. \& Milman, A. (1993). Predicting satisfaction among first time visitors to a destination by using the expectancy disconfirmation theory. International Journal of Hospitality Management, 12(2), 197-209. doi:10.1016/0278-4319(93)90010-7.

Plano Clark, V. L. \& Creswell, J. W. (2008). The mixed methods reader. Thousand Oaks, Calif.: SAGE.

Polet, G., \& Ling, S. (2004). Protecting mammal diversity: opportunities and constraints for pragmatic conservation management in Cat Tien National Park, Vietnam. Oryx, 38(02), 186196.

Powell, R. B., \& Ham, S. H. (2008). Can Ecotourism Interpretation Really Lead to Pro-Conservation Knowledge, Attitudes and Behaviour? Evidence from the Galapagos Islands. Journal Of Sustainable Tourism, 16(4), 467-489.

Randall, C., \& Rollins, R. B. (2009). Visitor perceptions of the role of tour guides in natural areas. Journal Of Sustainable Tourism, 17(3), 357-374. doi:10.1080/09669580802159727

Rood, A. S., \& Dziadkowiec, J. (2010). Why Use Importance Performance Analysis in Mystery Shopping? A USA-Poland Comparative Answer. Journal Of Quality Assurance In Hospitality \& Tourism, 11(1), 1-16. doi:10.1080/15280080903520592 
Rugendyke, B., \& Nguyen. T. S. (2005). Conservation costs: Nature-based tourism as development at Cuc Phuong National Park, Vietnam. Asia Pacific Viewpoint, 46(2), 185-200. Doi: 10.1111/j.1467-8373.2005.00265.x

Saldaña, J. (2013). The coding manual for qualitative researchers (2nd ed.). Los Angeles: SAGE.

Skanavis, C., \& Giannoulis, C. (2010). Improving quality of ecotourism through advancing education \& training of Greek eco tour guides: The role of training in environmental interpretation. Tourismos, 5(2), 49-68.

Skanavis, C., \& Sakellari, M. (2011). International tourism, domestic tourism, and environmental change: environmental education can find the balance. Tourismos, 6(1), 233-249

Slabbert, E. \& Du Plessis, L. (2011). The influence of demographic factors on travel behavior of visitors to nature based products in South Africa. Tourism \& Management Studies, 211181121. Retrieved from http://web.b.ebscohost.com.helicon.vuw.ac.nz/ehost/pdfviewer/

Slabbert, E., \& Laurens, M. (2011). Motivation-based clustering: an empirical study of visitors to Kruger National Park in South Africa. Tourism \& Management Studies, 21122-1126.

Sowman, P. \& Pearce, D. (2000). Chapter 14: Tourism, national parks and visitor management. In R.W., Butler \& S. W. Boyd (Eds), Tourism and National Parks. Issues and Implications (pp. 224-243). UK: John Wiley \& Sons, Ltd.

Stein, T. V., Denny, C. B., \& Pennisi, L. A. (2003). Using Visitors' Motivations to Provide Learning Opportunities at Water-based Recreation Areas. Journal Of Sustainable Tourism, 11(5), 404425.

Stolton, S., Nguyen, T. D. \& Dudley, N. (2004). Categorising protected areas in Vietnam. Parks, 14(3), 23-27. Retrieved from https://cmsdata.iucn.org/downloads/14_3lowres.pdf\#page=25

Tan, E. \& Law, R. (2016). MLearning as a softer visitor management approach for sustainable tourism. Journal of Sustainable Tourism, 24(1), 132.

Tarrant, M. A., Bright, A. D., Smith, E., \& Cordell, H. K. (1999). Motivations, attitudes, preferences, and satisfactions among outdoor recreationists. In H. K. Cordell, C. Betz, J. M. Bowker (Eds.). Outdoor recreation in American life: a national assessment of demand and supply trends. Champaign, IL: Sagamore Publishing. Retrieved from https://www.srs.fs.usda.gov/pubs/20813.

Teddlie, C. \& Tashakkori, A. (2009). Foundations of mixed methods research: Integrating quantitative and qualitative approaches in the social and behavioral sciences. Los Angeles: SAGE. 
Tonge, J., Moore, S. A., \& Taplin, R. (2011). Visitor satisfaction analysis as a tool for park managers: a review and case study. Annals Of Leisure Research, 14(4), 289-303. doi:10.1080/11745398.2011.639339

Tsang, N. F., Cheung, C., \& Yeung, S. (2011). A Critical Investigation of the Use and Effectiveness of Interpretive Services. Asia Pacific Journal Of Tourism Research, 16(2), 123-137. doi:10.1080/10941665.2011.556336

Tubb, K. N. (2003). An Evaluation of the Effectiveness of Interpretation within Dartmoor National Park in Reaching the Goals of Sustainable Tourism Development. Journal Of Sustainable Tourism, 11(6), 476-498.

UNESCO (n.d.). Cat Tien National Park. Retrieved from http://whc.unesco.org/en/tentativelists/5070/

Vaske, J. J., Kiriakos, R., Cottrell, S. P. \& Khuong, M. N. (2009). Importance-Performance and Segmentation: An Application at a Biosphere Reserve in Vietnam. Journal of Travel \& Tourism Marketing, 26(1), 30.

Veal, A. J. (2006). Research methods for leisure and tourism: A practical guide (3rd ed.). Harlow, England: FT Prentice Hall.

Vietnam National Administration of Tourism (2015). Retrieved from www.vietnamtourism.gov.vn. [01/04/2016]

Wade, D. J., \& Eagles, P. F. J. (2003). The use of importance-performance analysis and market segmentation for tourism management in parks and protected areas: An application to Tanzania's National Parks. Journal of Ecotourism, 2(3), 196-212.

Wearing, S. L. \& Whenman, A. E. (2009). Tourism as an interpretive and mediating influence: A review of the authority of guidebooks in protected areas. Tourism Analysis., 14(5), 701.

Wei-Ching, W. (2015). Visitor perception, interpretation needs and satisfaction of ecotourism: The case of Taijiang National Park, Taiwan. Enlightening Tourism, 23(2), 180-200

White, D. D., Aquino, J. F., Budruk, M., \& Golub, A. (2011). Visitors' Experiences of Traditional and Alternative Transportation in Yosemite National Park. Journal Of Park \& Recreation Administration, 29(1), 38-57.

Williams, P. W. \& Dossa, K. B. (2003). Non-Resident Wine Tourist Markets: Implications for British Colxuumbia's Emerging Wine Tourism Industry. Journal of Travel \& Tourism Marketing, 14(3/4). 
Xu, H., Cui, Q., Ballantyne, R., \& Packer, J. (2013). Effective environmental interpretation at Chinese natural attractions: the need for an aesthetic approach. Journal Of Sustainable Tourism, 21(1), 117-133. doi:10.1080/09669582.2012.681787

Zikmund, W. G., Babin, B. J., Carr, J. C. \& Griffin, M. (2013). Business research methods (9th ed.). Mason, OH: South-Western, CENGAGE Learning. 


\section{APPENDICES}

\section{Appendix 1: Information handout for the interviewee}

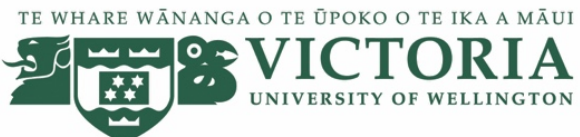

\section{VISITOR SATISFACTION WITH SERVICES FOR ENVIRONMENTAL INTERPRETATION IN CAT TIEN NATIONAL PARK, VIETNAM}

\section{INFORMATION HANDOUT FOR THE INTERVIEWEE}

Dear Sir/Madam! Thank you for your interest in this project. Please read this information before deciding whether or not to take part.

My name is Thi Thuy Linh Phan and I am a Masters student in Tourism Management at Victoria University of Wellington, New Zealand. I am conducting a project for my Masters thesis.

The project aims to examine visitor satisfaction with each interpretive service of Cat Tien National Park. Your participation in this survey is extremely important to develop a deep understanding of the current interpretive services in this national park.

- I will interview you in a public place, such as a café.

- I will ask you questions about current interpretive services of Cat Tien National Park.

- The interview will take from 30 to 60 minutes and be audio recorded.

- You can withdraw from the study up to one week after the interview. In that case, the information you provided will be destroyed.

- The interview transcripts, summaries and any recordings will be kept securely and destroyed 3 years after the research ends.

- You will not be named in the final report but your organisation will be named.

- The findings of this project may be used for conference presentations, and academic reports and publications.

You do not have to accept this invitation if you don't want to. If you do decide to participate, you have the right to:

- choose not to answer any question.

- $\quad$ ask for the recorder to be turned off at any time during the interview.

- $\quad$ withdraw from the study up to one week after your interview.

- $\quad$ ask any question about the study at any time.

- receive a copy of your interview recording.

- read over and comment on a written transcript of your interview.

- agree on another name for me to use rather than your real name.

- be able to read any report of this research by emailing the researcher to request a copy.

If you have any questions or would like to receive further information about the project, please contact:

Investigator:

Thi Thuy Linh Phan

Masters student of Tourism Management

Email: ThiThuyLinh.Phan@,vuw.ac.nz
Supervisor:

Dr. Christian Schott

Victoria University of Wellington

Phone: 044635719

Email: $\underline{\text { Christian.Schott@vuw.ac.nz }}$

\section{Human Ethics Committee information}

If you have any concerns about the ethical conduct of the research you may contact the Victoria University HEC Convener: Associate Professor Susan Corbett. Email susan.corbett@vuw.ac.nz or telephone $+64-4-4635480$. 
Appendix 2: Interview agenda

TE WHARE WĀNANGA O TE ŪPOKO O TE IKA A MĀUI SOF

UNIVERSITY OF WELLINGTON

\title{
VISITOR SATISFACTION WITH SERVICES FOR ENVIRONMENTAL INTERPRETATION IN CAT TIEN NATIONAL PARK, VIETNAM
}

\author{
RESEARCHER \\ Thi Thuy Linh Phan
}

1. Contact the interviewee to ask for an interview by sending an email. The information sheet will also be sent to him.

2. After receiving his/her acceptance, the consent form will be sent to him via email. Ask the suitable date for him to conduct the interview.

3. At the interview, ask if the interviewee has received and read the research information sheet and research consent form. If not, then provide documents and allow time for him to read them.

4. Ask if the interviewee understands everything and if there is any doubt. Answer any question raised by the interviewee.

5. Ensure that personal information will not be disclosed in the research outputs, but identification of interviewee' organisation may be revealed in the thesis and publication.

6. Ask if the interview can be recorded.

7. Ask the interviewee to sign the consent form and return a copy to him. 


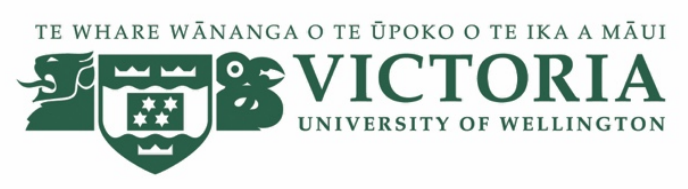

\section{INTERVIEW AGENDA}

1. STAFF'S PROFILE

1.1 What position do you hold in Cat Tien National Park?

How long have you been working here and in this position?

1.2 Could you please tell me a little bit about your background?

2. ENVIRONMENTAL EDUCATION RELATED WORK

Could you please tell me about your work?

2.1 What are your main responsibilities?

What are the three top priorities?

2.2 What are the main challenges for environmental education management?

3. INTERPRETATION

3.1 How would you explain what interpretation is?

In your view, what is the main purpose of interpretation?

In your view, how important is interpretation in conveying meaningful visitor experiences?

3.2 Who within your division handles with interpretation issues?

Are there other staff responsible for interpretation issues?

How interpretation issues fit your responsibilities?

4. INTERPRETIVE SERVICES

4.1 What is the current interpretive services that Cat Tien National Park is providing for tourists?

4.2 What are the reasons for adoption of each interpretive service?

What are the benefits for adoption of each interpretive service?

What are the barriers for adoption of each interpretive service?

4.3 What is the educational message delivered via each interpretive service?

4.4 Who invested in building up these interpretive services?

4.5 In your view, which interpretive service is the most important?

4.6 In your view, which interpretive service is the most effective?

4.7 Has your organisation done anything to measure the quality/effectiveness of these services?

How does your organisation make sure the quality of each interpretive service?

Has your organisation received any feedback for interpretive services?

How satisfied do you think tourists are with the performance of interpretive services?

Is there any survey conducted to evaluate that?

What are the barriers for your organisation in monitoring the interpretive services?

4.8 Has your organisation had any training for personnel about environmental interpretation?

If so, please give some information about type, length, the date and the trainers.

Has the training improved the performance of personnel?

Do you feel more training in interpretation is needed?

4.9 Does your organisation have any future intention in monitoring/ upgrading interpretive services or adding new interpretive services? 


\section{VISITOR SATISFACTION WITH SERVICES FOR ENVIRONMENTAL INTERPRETATION IN CAT TIEN NATIONAL PARK, VIETNAM}

\section{INFORMATION HANDOUT FOR VISITORS}

\section{Dear Sir/Madam!}

My name is Thi Thuy Linh Phan and I am a Masters student in Tourism Management at Victoria University of Wellington, New Zealand. I am conducting this survey for my Masters thesis.

This project aims to examine visitor satisfaction with interpretive services of Cat Tien National Park. Your participation in this survey contributes to the future developments of this national park.

The Human ethics approval has been sought from Pipitea Ethics Committee of Victoria University of Wellington and has been granted.

- It takes approximately 4-6 minutes to complete the pre visit questionnaire.

- It takes approximately 5-7 minutes to complete the post visit questionnaire.

- Your participation in this survey is voluntary and you are free to withdraw at any stage, in this case, your incomplete questionnaire will be destroyed.

- Your answers will be treated as anonymous and destroyed 3 years after the completion of the project.

- The results may be used for a future conference report or a publication and shared with the local tourism industry.

- Your participation in this survey will be considered as your agreement with the conditions outlined above.

If you have any questions or would like to receive further information about the project, please contact either:

\section{Investigator:}

Thi Thuy Linh Phan

Masters student of Tourism Management

Email: ThiThuyLinh.Phan@vuw.ac.nz

\section{Human Ethics Committee information}

If you have any concerns about the ethical conduct of the research you may contact the Victoria University HEC Convener: Associate Professor Susan Corbett. Email susan.corbett@vuw.ac.nz or telephone +64-4-463 5480 .

\author{
Supervisor: \\ Dr. Christian Schott \\ Victoria University of Wellington \\ New Zealand \\ Phone: 044635719 \\ Email: $\underline{\text { Christian.Schott@,vuw.ac.nz }}$
}




\section{Appendix 4: Self administered questionnaires for survey participants}

Interviewer:

Date:

Site:
Time:

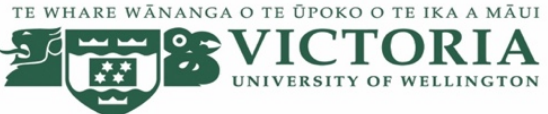

\section{VISITOR SATISFACTION WITH SERVICES FOR ENVIRONMENTAL INTERPRETATION IN CAT TIEN NATIONAL PARK}

Notes: Please tick $(\checkmark)$ the appropriate answer or fill in the information reflecting your viewpoints!

\section{PART 1: TRIP CHARACTERISTICS OF VISITORS}

1. What is your mode of travel?

2. How long do you intend to stay in Cat Tien National Park?
For 1day
2 days and 1 night
3 days and 2 nights
3 days (please specify)...
Don't know yet

3. What kind of accommodation do you intend to use during your visit to Cat Tien National Park?

(You can choose more than 1 option)
Hotel
Backpacker hostel
Camps
Guesthouse
Homestay
$\square$ Home of friend/family member
Other (please specify).

4. In your opinion, please indicate the level of importance of these motivations for your current visit to Cat Tien National Park.

(Please tick $(\checkmark)$ into the box that reflects your opinion according to 5 point Likert scale from 1-not important at all to 5extremely important)

\begin{tabular}{|c|c|c|c|c|c|c|}
\hline \multirow[t]{2}{*}{ MOTIVATIONS } & \multicolumn{5}{|c|}{ IMPORTANCE LEVELS } & \multirow{2}{*}{$\begin{array}{l}\text { DO NOT } \\
\text { KNOW/ NO } \\
\text { OPINION }\end{array}$} \\
\hline & $\begin{array}{c}\text { NOT } \\
\text { IMPORTANT } \\
\text { AT ALL } \\
\end{array}$ & & & & $\begin{array}{l}\text { EXTREMELY } \\
\text { IMPORTANT }\end{array}$ & \\
\hline To enjoy scenic beauty & 1 & 2 & 3 & 4 & 5 & N/A \\
\hline To learn more about ecosystems & 1 & 2 & 3 & 4 & 5 & N/A \\
\hline To view mammals & 1 & 2 & 3 & 4 & 5 & $\mathrm{~N} / \mathrm{A}$ \\
\hline To learn about mammals & 1 & 2 & 3 & 4 & 5 & $\mathrm{~N} / \mathrm{A}$ \\
\hline To view reptile & 1 & 2 & 3 & 4 & 5 & N/A \\
\hline To learn about reptiles & 1 & 2 & 3 & 4 & 5 & N/A \\
\hline To learn the history of Cat Tien National Park & 1 & 2 & 3 & 4 & 5 & N/A \\
\hline For a totally new and different experience & 1 & 2 & 3 & 4 & 5 & N/A \\
\hline To relax and rest & 1 & 2 & 3 & 4 & 5 & $\mathrm{~N} / \mathrm{A}$ \\
\hline To escape from the daily life routine & 1 & 2 & 3 & 4 & 5 & N/A \\
\hline To meet people with similar interests and hobbies & 1 & 2 & 3 & 4 & 5 & $\mathrm{~N} / \mathrm{A}$ \\
\hline To travel with friends and my family & 1 & 2 & 3 & 4 & 5 & N/A \\
\hline
\end{tabular}




\begin{tabular}{|l|c|c|c|c|c|c|}
\hline To take photographs & 1 & 2 & 3 & 4 & 5 & N/A \\
\hline Others (please specify) $\ldots \ldots \ldots \ldots \ldots \ldots \ldots \ldots \ldots$ & 1 & 2 & 3 & 4 & 5 & N/A \\
\hline
\end{tabular}

Notes: Environmental visitor interpretation is the interpretation to deliver environmental messages to visitors. Environmental interpretive services are services for environmental interpretation.

\section{PART 2: THE IMPORTANCE LEVELS OF ENVIRONMENTAL INTERPRETIVE SERVICES}

1. Please indicate the level of importance of these services towards your satisfaction with environmental interpretation.

(Please tick $(\checkmark)$ into the box that reflects your opinion according to 5 point Likert scale from 1-not important at all to 5extremely important)

\begin{tabular}{|c|c|c|c|c|c|c|}
\hline \multirow{2}{*}{$\begin{array}{c}\text { SERVICES FOR } \\
\text { ENVIRONMENTAL } \\
\text { INTERPRETATION }\end{array}$} & \multicolumn{5}{|c|}{ IMPORTANCE LEVELS } & \multirow{2}{*}{$\begin{array}{c}\text { DO NOT } \\
\text { KNOW/ } \\
\text { NO } \\
\text { OPINION }\end{array}$} \\
\hline & $\begin{array}{c}\text { NOT } \\
\text { IMPORTANT } \\
\text { AT ALL }\end{array}$ & & & & $\begin{array}{l}\text { EXTREMELY } \\
\text { IMPORTANT }\end{array}$ & \\
\hline \multicolumn{7}{|l|}{ PERSONAL SERVICES } \\
\hline Site interpreter/ local tour guide & 1 & 2 & 3 & 4 & 5 & $\mathrm{~N} / \mathrm{A}$ \\
\hline Staff at ticket office & 1 & 2 & 3 & 4 & 5 & N/A \\
\hline Staff at museum & 1 & 2 & 3 & 4 & 5 & $\mathrm{~N} / \mathrm{A}$ \\
\hline \multicolumn{7}{|l|}{ NON PERSONAL SERVICES } \\
\hline Interpretive signs about the site & 1 & 2 & 3 & 4 & 5 & N/A \\
\hline Directional signs & 1 & 2 & 3 & 4 & 5 & $\mathrm{~N} / \mathrm{A}$ \\
\hline Brochure at ticket office & 1 & 2 & 3 & 4 & 5 & N/A \\
\hline Displays at museum & 1 & 2 & 3 & 4 & 5 & $\mathrm{~N} / \mathrm{A}$ \\
\hline Videos at rescue center & 1 & 2 & 3 & 4 & 5 & $\mathrm{~N} / \mathrm{A}$ \\
\hline
\end{tabular}


2. Please indicate the level of importance of these roles of site interpreter/local tour guide in national parks towards your satisfaction.

(Please tick $(\checkmark)$ into the box that reflects your opinion according to 5 point Likert scale from 1-not important at all to 5-extremely important)

\begin{tabular}{|c|c|c|c|c|c|c|}
\hline \multirow[t]{2}{*}{ ROLES } & \multicolumn{5}{|c|}{ IMPORTANCE LEVELS } & \multirow{2}{*}{$\begin{array}{c}\text { DO NOT } \\
\text { KNOW/ } \\
\text { NO } \\
\text { OPINION }\end{array}$} \\
\hline & $\begin{array}{c}\text { NOT } \\
\text { IMPORTANT } \\
\text { AT ALL }\end{array}$ & & & & $\begin{array}{l}\text { EXTREMELY } \\
\text { IMPORTANT }\end{array}$ & \\
\hline \multicolumn{7}{|l|}{ Leadership: Instrumental } \\
\hline Sets a pace for the trip that was comfortable for you & 1 & 2 & 3 & 4 & 5 & $\mathrm{~N} / \mathrm{A}$ \\
\hline Discusses dangers that may exist in the tour & 1 & 2 & 3 & 4 & 5 & $\mathrm{~N} / \mathrm{A}$ \\
\hline \multicolumn{7}{|l|}{ Leadership: Social } \\
\hline Handles tension or conflict quickly and effectively & 1 & 2 & 3 & 4 & 5 & $\mathrm{~N} / \mathrm{A}$ \\
\hline Promotes a social and happy group environment & 1 & 2 & 3 & 4 & 5 & N/A \\
\hline \multicolumn{7}{|l|}{ Mediatory: Interactional } \\
\hline Reduces conflict with other groups at sites, etc. & 1 & 2 & 3 & 4 & 5 & $\mathrm{~N} / \mathrm{A}$ \\
\hline Keeps the group organized and on schedule & 1 & 2 & 3 & 4 & 5 & $\mathrm{~N} / \mathrm{A}$ \\
\hline \multicolumn{7}{|l|}{ Mediatory: Communicative } \\
\hline Introduces ecological and cultural points of interest & 1 & 2 & 3 & 4 & 5 & $\mathrm{~N} / \mathrm{A}$ \\
\hline Disseminates correct information and translation & 1 & 2 & 3 & 4 & 5 & $\mathrm{~N} / \mathrm{A}$ \\
\hline \multicolumn{7}{|l|}{ Resource Management: Motivator of Responsible Behavior } \\
\hline Discusses code of ethics with the group & 1 & 2 & 3 & 4 & 5 & $\mathrm{~N} / \mathrm{A}$ \\
\hline $\begin{array}{l}\text { Highlights the importance of not taking anything from } \\
\text { national park }\end{array}$ & 1 & 2 & 3 & 4 & 5 & $\mathrm{~N} / \mathrm{A}$ \\
\hline \multicolumn{7}{|l|}{ Resource Management: Environmental Interpreter } \\
\hline $\begin{array}{l}\text { Helps you to develop a keener awareness and appreciation } \\
\text { of the national park }\end{array}$ & 1 & 2 & 3 & 4 & 5 & $\mathrm{~N} / \mathrm{A}$ \\
\hline $\begin{array}{l}\text { Increases your knowledge and understanding of the } \\
\text { natural environment of the national park }\end{array}$ & 1 & 2 & 3 & 4 & 5 & $\mathrm{~N} / \mathrm{A}$ \\
\hline
\end{tabular}

PART 3: PERSONAL INFORMATION (for statistical analysis purpose only)

1. What is your nationality?

\begin{tabular}{lllll}
$\square$ Vietnamese & $\square$ Chinese & $\square$ Korean & $\square$ Japanese & $\square$ American \\
$\square$ Taiwanese & $\square$ Malaysian & $\square$ Russian & $\square$ Australian & $\square$ Singaporean \\
\hline Cambodian & $\square$ Thai & $\square$ English & $\square$ French & $\square$ Other (please specify)
\end{tabular}

2. What is your gender?

Male

Female

Others (please specify)

3. Which age group are you in?
$\square 15-24$
25-34
35-44
45-54
口55-64
Over 64 
4. What is the highest level of formal education you have completed?

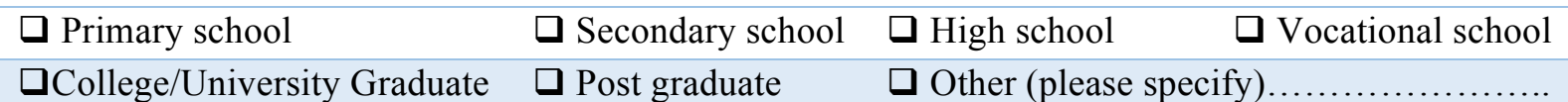

5. In the last 3 years, how many times have you visited national parks anywhere in the world?

$\square 0 \quad \square 1-3$ times $\square 4-6$ times $\square 7-10$ times $\square$ Over 10 times

6. In the last 3 years, how many times have you visited Cat Tien National Park?

$\square$ None $\square$ Once $\square$ Twice $\square 3$ times $\quad \square$ Over 3 times

Thank you so much for your kind help! Please keep the card with your number.

I will give you the post visit questionnaire to fill in after you finish your visit in Cat Tien National Park. 
Interviewer:

Date:

Time:

Site:

VISITOR SATISFACTION WITH SERVICES FOR ENVIRONMENTAL INTERPRETATION IN CAT TIEN NATIONAL PARK

Notes: Please tick $(\checkmark)$ the appropriate answer or fill in the information reflecting your viewpoints!

\section{PART 4: THE USE OF SERVICES FOR INTERPRETATION}

1. Have you used any interpretive services below during your visit in Cat Tien National Park?

(If your answer is ' $\mathrm{NO}$ ', please tick $(\checkmark)$ into the reason why you did not use it)

\begin{tabular}{|c|c|c|c|c|c|c|c|}
\hline $\begin{array}{l}\text { SERVICES FOR } \\
\text { INTERPRETATION }\end{array}$ & $\begin{array}{l}\text { YES, I } \\
\text { DID }\end{array}$ & $\begin{array}{l}\text { NO, I } \\
\text { DID } \\
\text { NOT }\end{array}$ & $\begin{array}{c}\text { NOT } \\
\text { ENOUGH } \\
\text { TIME }\end{array}$ & $\begin{array}{c}\text { NOT } \\
\text { AWARE OF } \\
\text { SERVICE }\end{array}$ & $\begin{array}{c}\text { NO } \\
\text { NEED } \\
\text { TO USE }\end{array}$ & $\begin{array}{c}\text { NOT } \\
\text { INTEREST } \\
\text {-ING }\end{array}$ & $\begin{array}{l}\text { OTHERS } \\
\text { (PLEASE } \\
\text { SPECIFY) }\end{array}$ \\
\hline \multicolumn{8}{|l|}{ PERSONAL SERVICES } \\
\hline Site interpreter/ local tour guide & $\mathrm{Y}$ & $\mathrm{N}$ & & & & & \\
\hline Staff at ticket office & $\mathrm{Y}$ & $\mathrm{N}$ & & & & & \\
\hline Staff at museum & $\mathrm{Y}$ & $\mathrm{N}$ & & & & & \\
\hline \multicolumn{8}{|l|}{ NON PERSONAL SERVICES } \\
\hline Interpretive signs about the site & $\mathrm{Y}$ & $\mathrm{N}$ & & & & & \\
\hline Directional signs & Y & $\mathrm{N}$ & & & & & \\
\hline Brochure at ticket office & $\mathrm{Y}$ & $\mathrm{N}$ & & & & & \\
\hline Displays at museum & $\mathrm{Y}$ & $\mathrm{N}$ & & & & & \\
\hline Videos at rescue center & $\mathrm{Y}$ & $\mathrm{N}$ & & & & & \\
\hline
\end{tabular}

\section{PART 5: THE PERFORMANCE LEVELS OF ENVIRONMENTAL INTERPRETIVE SERVICES}

1. Please indicate the level of performance of these services towards your satisfaction with environmental interpretation during your visit in Cat Tien National Park.

(Please tick $(\checkmark)$ into the box reflecting your opinion according to 5 point Likert scale from 1-poor to 5-excellent)

\begin{tabular}{|c|c|c|c|c|c|c|}
\hline \multirow{2}{*}{$\begin{array}{c}\text { SERVICES FOR } \\
\text { ENVIRONMENTAL } \\
\text { INTERPRETATION }\end{array}$} & \multicolumn{5}{|c|}{ PERFORMANCE LEVELS } & \multirow{2}{*}{$\begin{array}{l}\text { DO NOT } \\
\text { KNOW/ } \\
\text { NO } \\
\text { OPINION }\end{array}$} \\
\hline & POOR & & & & EXCELLENT & \\
\hline \multicolumn{7}{|l|}{ PERSONAL SERVICES } \\
\hline Site interpreter/ local tour guide & 1 & 2 & 3 & 4 & 5 & $\mathrm{~N} / \mathrm{A}$ \\
\hline Staff at ticket office & 1 & 2 & 3 & 4 & 5 & N/A \\
\hline Staff at museum & 1 & 2 & 3 & 4 & 5 & $\mathrm{~N} / \mathrm{A}$ \\
\hline \multicolumn{7}{|l|}{ NON PERSONAL SERVICES } \\
\hline Interpretive signs about the site & 1 & 2 & 3 & 4 & 5 & N/A \\
\hline Directional signs & 1 & 2 & 3 & 4 & 5 & $\mathrm{~N} / \mathrm{A}$ \\
\hline Brochure at ticket office & 1 & 2 & 3 & 4 & 5 & $\mathrm{~N} / \mathrm{A}$ \\
\hline Displays at museum & 1 & 2 & 3 & 4 & 5 & $\mathrm{~N} / \mathrm{A}$ \\
\hline Videos at rescue center & 1 & 2 & 3 & 4 & 5 & $\mathrm{~N} / \mathrm{A}$ \\
\hline
\end{tabular}


2. Please indicate the level of performance of these roles of site interpreter/ local tour guide during your visit in Cat Tien National Park towards your satisfaction.

(Please tick $(\checkmark)$ into the box reflecting your opinion according to 5 point Likert scale from 1-poor to 5-excellent)

\begin{tabular}{|c|c|c|c|c|c|c|}
\hline \multirow[t]{2}{*}{ ROLES } & \multicolumn{5}{|c|}{ PERFORMANCE LEVELS } & \multirow{2}{*}{$\begin{array}{c}\text { DO NOT } \\
\text { KNOW/ } \\
\text { NO } \\
\text { OPINION }\end{array}$} \\
\hline & $\overline{\mathrm{POOR}}$ & & & & EXCELLENT & \\
\hline \multicolumn{7}{|l|}{ Leadership: Instrumental } \\
\hline Set a pace for the trip that was comfortable for you & 1 & 2 & 3 & 4 & 5 & $\mathrm{~N} / \mathrm{A}$ \\
\hline Discussed dangers that may exist in the tour & 1 & 2 & 3 & 4 & 5 & $\mathrm{~N} / \mathrm{A}$ \\
\hline \multicolumn{7}{|l|}{ Leadership: Social } \\
\hline Tension or conflict was handled quickly and effectively & 1 & 2 & 3 & 4 & 5 & $\mathrm{~N} / \mathrm{A}$ \\
\hline Promoted a social and happy group environment & 1 & 2 & 3 & 4 & 5 & $\mathrm{~N} / \mathrm{A}$ \\
\hline \multicolumn{7}{|l|}{ Mediatory: Interactional } \\
\hline Reduced conflict with other groups at sites, etc. & 1 & 2 & 3 & 4 & 5 & $\mathrm{~N} / \mathrm{A}$ \\
\hline Kept the group organized and on schedule & 1 & 2 & 3 & 4 & 5 & N/A \\
\hline \multicolumn{7}{|l|}{ Mediatory: Communicative } \\
\hline Introduced ecological and cultural points of interest & 1 & 2 & 3 & 4 & 5 & $\mathrm{~N} / \mathrm{A}$ \\
\hline Disseminated correct information and translation & 1 & 2 & 3 & 4 & 5 & $\mathrm{~N} / \mathrm{A}$ \\
\hline \multicolumn{7}{|l|}{ Resource Management: Motivator of Responsible Behavior } \\
\hline Discussed code of ethics with the group & 1 & 2 & 3 & 4 & 5 & $\mathrm{~N} / \mathrm{A}$ \\
\hline $\begin{array}{l}\text { Highlighted the importance of not taking anything from } \\
\text { national park }\end{array}$ & 1 & 2 & 3 & 4 & 5 & $\mathrm{~N} / \mathrm{A}$ \\
\hline \multicolumn{7}{|l|}{ Resource Management: Environmental Interpreter } \\
\hline $\begin{array}{l}\text { Helped you to develop a keener awareness and } \\
\text { appreciation of Cat Tien National Park }\end{array}$ & 1 & 2 & 3 & 4 & 5 & $\mathrm{~N} / \mathrm{A}$ \\
\hline $\begin{array}{l}\text { Increased your knowledge and understanding of the } \\
\text { natural environment of Cat Tien National Park }\end{array}$ & 1 & 2 & 3 & 4 & 5 & $\mathrm{~N} / \mathrm{A}$ \\
\hline Comments: . & & & & & & \\
\hline
\end{tabular}




\section{PART 6: THE MESSAGES THAT YOU RECEIVED}

1. What is the message that you received from each service?

(Please tick $(\checkmark)$ into the answer reflecting the message that you received. You can choose more than 1 option)

\begin{tabular}{|c|c|c|c|c|c|c|}
\hline $\begin{array}{l}\text { SERVICES FOR } \\
\text { INTERPRETATION }\end{array}$ & $\begin{array}{c}\text { ENHANCED } \\
\text { YOUR } \\
\text { EXPERIENCE } \\
\text { IN GENERAL }\end{array}$ & \begin{tabular}{|l} 
DELIVERED \\
INFORMATION \\
ABOUT THE \\
SITE \\
(HISTORY, \\
ECOLOGICAL \\
VALUES...)
\end{tabular} & \begin{tabular}{|l} 
DELIVERED \\
SAFETY \\
INFORMATION
\end{tabular} & $\begin{array}{c}\text { DELIVERED } \\
\text { INFORMATION } \\
\text { ABOUT } \\
\text { POTENTIAL } \\
\text { IMPACTS OF } \\
\text { TOURISTS ON } \\
\text { ENVIRONMENT }\end{array}$ & \begin{tabular}{|c|} 
EDUCATED YOU \\
PROPER \\
BEHAVIORS \\
(DON'T LITTER, \\
DON'T TAKE \\
ANYTHING FROM \\
THE PARK)
\end{tabular} & $\begin{array}{c}\text { NO } \\
\text { MESSAGE }\end{array}$ \\
\hline \multicolumn{7}{|l|}{ PERSONAL SERVICES } \\
\hline \multicolumn{7}{|l|}{ Site interpreter } \\
\hline \multicolumn{7}{|l|}{ Staff at ticket office } \\
\hline \multirow{2}{*}{\multicolumn{7}{|c|}{\begin{tabular}{l|l} 
Staff at museum & \\
NON PERSONAL SERVICES
\end{tabular}}} \\
\hline & & & & & & \\
\hline \multicolumn{7}{|l|}{$\begin{array}{l}\text { Interpretive signs } \\
\text { about the site }\end{array}$} \\
\hline \multicolumn{7}{|l|}{ Directional signs } \\
\hline \multicolumn{7}{|l|}{ Brochure at ticket office } \\
\hline \multicolumn{7}{|l|}{ Displays at museum } \\
\hline Videos at rescue center & & & & & & \\
\hline
\end{tabular}

\section{PART 7: OVERALL SATISFACTION AND FUTURE BEHAVIOR}

1. Overall, how satisfied were you with environmental interpretive services and with your visit in Cat Tien National Park?

(Please tick $(\checkmark)$ into the box reflecting your opinion according to 5 point Likert scale from 1-not satisfied at all to 5-extremely satisfied)

\begin{tabular}{|c|c|c|c|c|c|c|}
\hline \multirow{2}{*}{$\begin{array}{c}\text { OVERALL SATISFACTION } \\
\text { WITH }\end{array}$} & \multicolumn{5}{|c|}{ SATISFACTION LEVELS } & \multirow{2}{*}{$\begin{array}{c}\text { DO NOT } \\
\text { KNOW/ } \\
\text { NO } \\
\text { OPINION }\end{array}$} \\
\hline & $\begin{array}{l}\text { NOT } \\
\text { SATISFIED } \\
\text { AT ALL }\end{array}$ & & & & $\begin{array}{l}\text { EXTREMELY } \\
\text { SATISFIED }\end{array}$ & \\
\hline $\begin{array}{l}\text { nvironmental interpretive services } \\
\text { Cat Tien National Park }\end{array}$ & 1 & 2 & 3 & 4 & 5 & \\
\hline our visit to Cat Tien National Park & 1 & 2 & 3 & 4 & 5 & \\
\hline
\end{tabular}

2. Would you recommend Cat Tien National Park to others?
$\square$ Yes
प Maybe
$\square$ No

3. Which topic of interpretation would you like to know more about and why?

4. Through which service should the topic be delivered and why?

5. In your opinion, which service for interpretation should be added and why?

\section{Thank you very much for your kind contribution and participation!}


Appendix 5: Information about questionnaire data collection

(06 August - 02 September, 2016)

\begin{tabular}{|c|c|c|c|c|c|c|}
\hline Date & Yes & No & $\begin{array}{l}\text { Response } \\
\text { rate }\end{array}$ & $\begin{array}{c}\text { Number of } \\
\text { usable pre visit } \\
\text { questionnaires }\end{array}$ & $\begin{array}{c}\text { Number of } \\
\text { usable post visit } \\
\text { questionnaires }\end{array}$ & $\begin{array}{l}\text { Response } \\
\text { rate }\end{array}$ \\
\hline 06-Aug & 14 & 17 & 45.16 & 14 & 11 & 78.57 \\
\hline 07-Aug & 25 & 13 & 65.79 & 25 & 23 & 92.00 \\
\hline 08-Aug & 7 & 2 & 77.78 & 7 & 6 & 85.71 \\
\hline 09-Aug & 4 & 5 & 44.44 & 3 & 3 & 100.00 \\
\hline \multicolumn{7}{|l|}{ 10-Aug* } \\
\hline 11-Aug & 8 & 7 & 53.33 & 5 & 4 & 80.00 \\
\hline 12-Aug & 9 & 11 & 45.00 & 9 & 7 & 77.78 \\
\hline 13-Aug & 17 & 21 & 44.74 & 17 & 12 & 70.59 \\
\hline 14-Aug & 22 & 28 & 44.00 & 22 & 17 & 77.27 \\
\hline 15-Aug & 8 & 3 & 72.73 & 8 & 5 & 62.50 \\
\hline 16-Aug & 9 & 12 & 42.86 & 9 & 8 & 88.89 \\
\hline \multicolumn{7}{|l|}{ 17-Aug* } \\
\hline 18-Aug & 6 & 5 & 54.55 & 6 & 5 & 83.33 \\
\hline 19-Aug & 13 & 9 & 59.09 & 11 & 7 & 63.64 \\
\hline 20-Aug & 15 & 22 & 40.54 & 18 & 15 & 83.33 \\
\hline 21-Aug & 23 & 25 & 47.92 & 23 & 20 & 86.96 \\
\hline 22-Aug & 8 & 7 & 53.33 & 6 & 6 & 100.00 \\
\hline 23-Aug & 7 & 8 & 46.67 & 5 & 3 & 60.00 \\
\hline \multicolumn{7}{|l|}{ 24-Aug* } \\
\hline 25-Aug & 7 & 12 & 36.84 & 7 & 6 & 85.71 \\
\hline 26-Aug & 9 & 7 & 56.25 & 9 & 7 & 77.78 \\
\hline 27-Aug & 21 & 16 & 56.76 & 21 & 18 & 85.71 \\
\hline 28-Aug & 19 & 24 & 44.19 & 19 & 16 & 84.21 \\
\hline 29-Aug & 10 & 13 & 43.48 & 7 & 4 & 57.14 \\
\hline 30-Aug & 5 & 6 & 45.45 & 3 & 1 & 33.33 \\
\hline 31-Aug & 12 & 15 & 44.44 & 12 & 7 & 58.33 \\
\hline 1-Sept & 13 & 17 & 43.33 & 13 & 12 & 92.31 \\
\hline 2-Sept & 25 & 30 & 45.45 & 25 & 14 & 56.00 \\
\hline Total & 316 & 335 & $48.54 \%$ & 304 & 237 & $77.96 \%$ \\
\hline
\end{tabular}

*: day off 
Appendix 6: Reasons for not using a specific service

\begin{tabular}{|c|c|c|c|c|c|c|c|c|c|c|}
\hline \multirow[t]{2}{*}{$\begin{array}{l}\text { Services for environmental } \\
\text { interpretation }\end{array}$} & \multicolumn{2}{|c|}{\begin{tabular}{|c|} 
Not enough \\
time \\
\end{tabular}} & \multicolumn{2}{|c|}{$\begin{array}{c}\text { Not aware of } \\
\text { service }\end{array}$} & \multicolumn{2}{|c|}{$\begin{array}{c}\text { No need to } \\
\text { use }\end{array}$} & \multicolumn{2}{|c|}{$\begin{array}{c}\text { Not } \\
\text { interesting }\end{array}$} & \multicolumn{2}{|c|}{ Others } \\
\hline & $\mathbf{n}$ & $\%$ & $\mathbf{n}$ & $\%$ & $\mathbf{n}$ & $\%$ & $\mathbf{n}$ & $\%$ & $\bar{n}$ & $\%$ \\
\hline \multicolumn{11}{|l|}{ Personal services } \\
\hline Staff at ticket office & 0 & 0 & 0 & 0 & 3 & 75 & 0 & 0 & 1 & 25 \\
\hline Site interpreter/ local tour guide & 1 & 4.3 & 1 & 4.3 & 21 & 91.3 & 0 & 0 & 0 & 0 \\
\hline Staff at museum & 24 & 68.6 & 1 & 2.9 & 14 & 40 & 4 & 11.4 & 1 & 2.9 \\
\hline \multicolumn{11}{|l|}{ Non personal services } \\
\hline Brochure at ticket office & 0 & 0 & 3 & 100 & 0 & 0 & 0 & 0 & 0 & 0 \\
\hline Displays at museum & 23 & 67.6 & 1 & 2.9 & 13 & 38.2 & 5 & 14.7 & 0 & 0 \\
\hline Videos at rescue centre & 43 & 97.7 & 1 & 2.3 & 1 & 2.3 & 0 & 0 & 0 & 0 \\
\hline
\end{tabular}

Appendix 7: Messages that visitors received from each service

\begin{tabular}{|c|c|c|c|c|c|c|c|c|c|c|c|c|}
\hline \multirow[t]{2}{*}{$\begin{array}{c}\text { Services for } \\
\text { environmental } \\
\text { interpretation }\end{array}$} & \multicolumn{2}{|c|}{$\begin{array}{c}\text { Enhanced } \\
\text { experience } \\
\text { in general }\end{array}$} & \multicolumn{2}{|c|}{$\begin{array}{l}\text { Delivered } \\
\text { information } \\
\text { about the } \\
\text { site (history, } \\
\text { ecological } \\
\text { values...) }\end{array}$} & \multicolumn{2}{|c|}{$\begin{array}{c}\text { Delivered } \\
\text { safety } \\
\text { information }\end{array}$} & \multicolumn{2}{|c|}{$\begin{array}{l}\text { Delivered } \\
\text { information } \\
\text { about } \\
\text { potential } \\
\text { impacts of } \\
\text { visitors on } \\
\text { environment }\end{array}$} & \multicolumn{2}{|c|}{$\begin{array}{c}\text { Educated } \\
\text { proper } \\
\text { behaviours (do } \\
\text { not litter, do } \\
\text { not take } \\
\text { anything from } \\
\text { the park) }\end{array}$} & \multicolumn{2}{|c|}{ No message } \\
\hline & $\mathrm{n}$ & $\%$ & $\mathrm{n}$ & $\%$ & $\mathrm{n}$ & $\%$ & $\mathrm{n}$ & $\%$ & $\mathrm{n}$ & $\%$ & $\mathbf{n}$ & $\%$ \\
\hline \multicolumn{13}{|l|}{ Personal services } \\
\hline Staff at ticket office & 225 & 96.6 & 189 & 81.5 & 120 & 51.5 & 0 & 0 & 0 & 0 & 8 & 3.4 \\
\hline $\begin{array}{l}\text { Site interpreter/local } \\
\text { tour guide }\end{array}$ & 210 & 98.1 & 212 & 99.1 & 196 & 91.6 & 165 & 77.1 & 52 & 24.3 & 1 & 0.5 \\
\hline Staff at museum & 198 & 98.5 & 189 & 94.0 & 6 & 3.0 & 147 & 73.5 & 10 & 5.0 & 1 & 0.5 \\
\hline \multicolumn{13}{|l|}{ Non personal services } \\
\hline $\begin{array}{l}\text { Interpretive signs } \\
\text { about the site }\end{array}$ & 232 & 97.9 & 235 & 99.2 & 2 & 0.8 & 5 & 2.1 & 205 & 86.5 & 0 & 0 \\
\hline Directional signs & 229 & 97.4 & 8 & 3.4 & 222 & 94.1 & 0 & 0 & 1 & 0.4 & 0 & 0 \\
\hline $\begin{array}{l}\text { Brochure at ticket } \\
\text { office }\end{array}$ & 226 & 96.6 & 225 & 96.2 & 1 & 0.4 & 2 & 0.9 & 0 & 0 & 0 & 0 \\
\hline Displays at museum & 195 & 97.0 & 187 & 93.0 & 0 & 0 & 0 & 0 & 0 & 0 & 0 & 0 \\
\hline Videos at rescue center & 185 & 95.4 & 167 & 86.1 & 6 & 3.1 & 183 & 94.3 & 8 & 4.1 & 0 & 0 \\
\hline
\end{tabular}

